\title{
THE DEVELOPMENT OF THE LEARNING EXCHANGE SCHOOL CLUSTERS IN NEW ZEALAND: AN ACTOR NETWORK THEORY AND COMPLEXITY THEORY ANALYSIS
}

\author{
By
}

Arif Ali

\begin{abstract}
A thesis
submitted to the Victoria University of Wellington in fulfilment of the requirements for the degree of Doctor of Philosophy in Information Systems
\end{abstract}

Victoria University of Wellington

2017 


\section{ABSTRACT}

Students and teachers from secondary schools located in remote areas are faced with barriers to educational access not seen in denser population areas. Students have the problem of accessing teachers of specialised subjects and the curriculum options their urban counterparts enjoy. In turn, their teachers have limited opportunities for professional learning and development. Some of the inhibiting factors include small numbers of students and staff, and schools' inability to offer a wide range of curricula, due to geographical challenges and other barriers. To overcome the barriers, some groups of schools in New Zealand initiated and self-organised a programme known as the Learning Exchange, which is an online collaborative, course-sharing programme. To participate in the programme, a number of the neighbouring schools form a regional virtual cluster and offer online classes to teach each other's students via video-conference and other ICT settings. Similarly, teachers form online groups to collaborate with and learn from other teachers. The basic strategy behind the programme is to maximise their existing educational resources and thus overcome the barriers.

Since the programme's inception in 2001-02, around 20 school clusters have been initiated; however as of 2016, only eight of the clusters have developed and become self-sustainable. Others struggled to continue their participation in the programme and have disappeared. Therefore, achieving selfsustainable development remains a challenge for the clusters. This research aimed to address the problem by having three main research questions: How was the Learning Exchange developed? How was the Learning Exchange utilised by some clusters in New Zealand? What were the facilitating and inhibiting factors in the development of self-sustainable school clusters?

This study adopted a qualitative research methodology within an interpretive research paradigm and a case research method. Four school clusters were selected based on a number of criteria. Each of the clusters served as the logical unit of analysis. In-depth interviews were used as the technique for data collection from individuals. Documents and other artefacts were also collected and analysed. Actor-Network Theory (ANT) was used as a theoretical lens for describing and explaining the four separate case findings. In particular, the four phases of Translation from ANT were adopted to describe the findings.

The four case findings, including the inhibiting and facilitating factors, were compared. As a result, a number of key features were concluded as the required conditions or principles for the development of self-sustaining clusters. To extend the research discussion, a complementary lens of Complexity Theory was utilised and some key principles of complex adaptive systems were used in assessing the research outcome and thus establishing further credibility of the ANT-based research findings. 
The findings from this research make practical contributions by facilitating a better understanding of the conditions required for the self-sustainability of the Learning Exchange clusters. The lessons drawn from this research are valuable for researchers and practitioners of virtual collaborations operating in a similar context. The main theoretical contribution is the combined use of the ANT and Complexity Theory lenses. The combined lenses facilitated the research to develop further insights with a deep level of conceptualisation and to improve the existing understanding regarding the Learning Exchange clusters' development and self-sustainability. 


\section{ACKNOWLEDGMENTS}

This is the most difficult part as you make sure to acknowledge the support of and thank each and every person during your PhD journey. I am the luckiest person as I received overwhelming support, encouragement, advice and love during each and every moment.

My immediate family members - my wife Batool, my two little princesses Sameen and Ayla - were always there to offer their support and sacrifices. They gave me the strength and reason to get to my goal. I owe them a lot of thanks. And then of course, I am lucky to have my mother, father, brothers and sisters as well as my friends, who have always full heartedly encouraged me with a combination of love, prayer and help during my hard times. Thank you all.

The supervisor's role during a PhD is like your GPS system in the middle of nowhere. The feeling that they are there to help you navigate gives you the hope and assures you that you are on the right track. I owe a bundle of thanks to both my supervisors Professor Pak Yoong and Dr Allan Sylvester for their availability, wonderful support and experiences. Without their guidance and motivation I would not have accomplished this goal.

I am greatly thankful to the School of Information Management (SIM) academic and administrative staff members for their valuable support. To name some, Dan Dorner, Usha Varatharaju, Jean Grant, Val Hooper, Benoit Albert, Janet Toland and all others have been amazing. Special thanks to all my PhD colleagues at SIM. You made this journey fun, enjoyable and lively. You all will be missed.

Finally, many thanks to all my research participants for their valuable and insightful contributions. In particular, I am very thankful to the Virtual Learning Network Community members and contributors for their help and input. 


\section{TABLE OF CONTENTS}

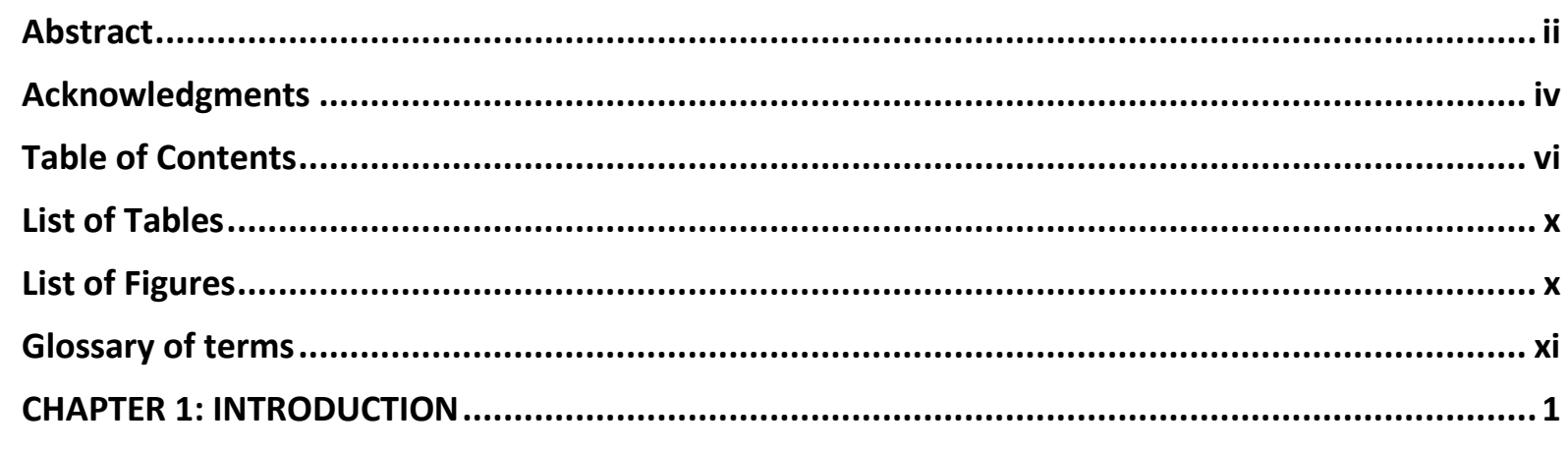

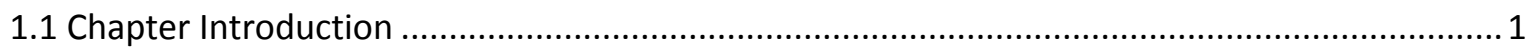

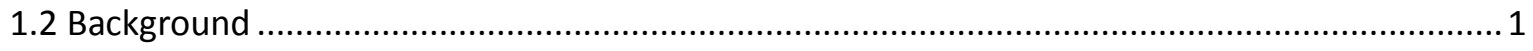

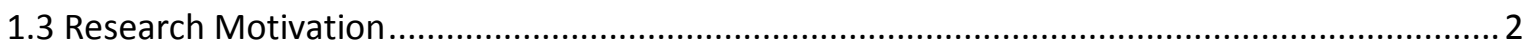

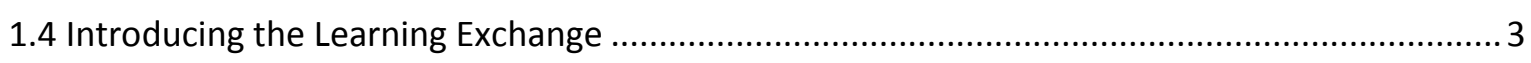

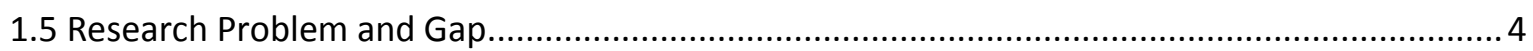

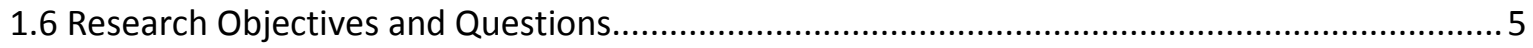

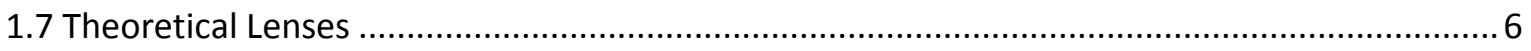

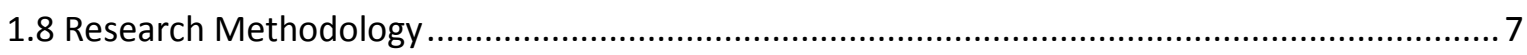

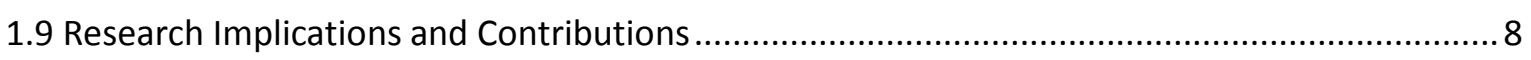

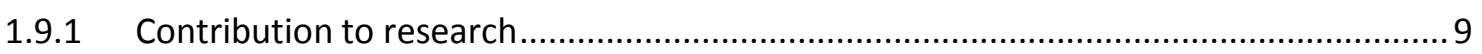

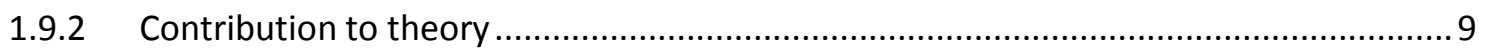

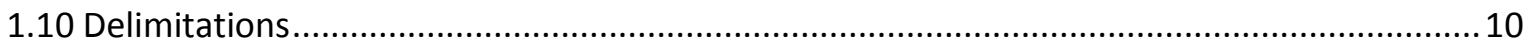

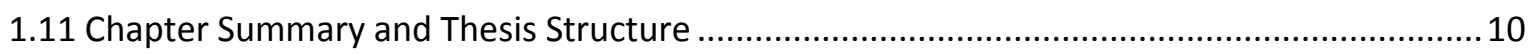

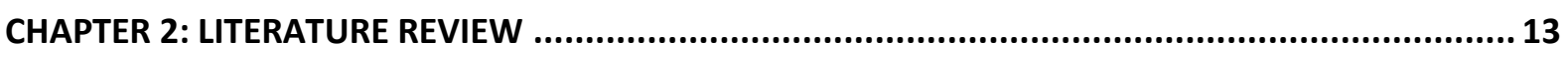

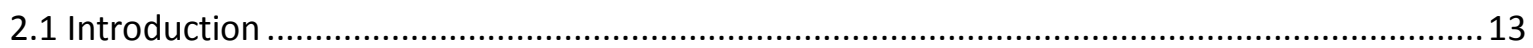

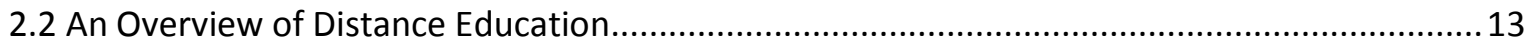

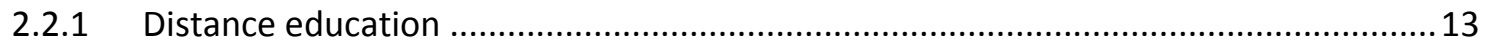

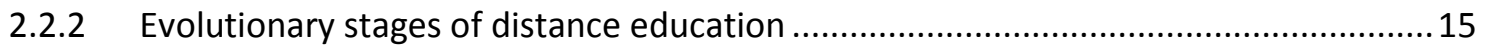

2.2.3 Subsequent generations of distance education and the New Zealand context ...........17

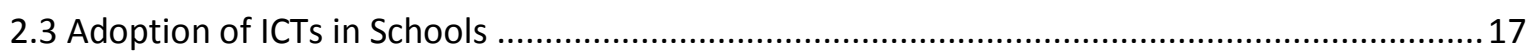

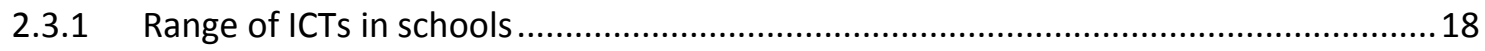

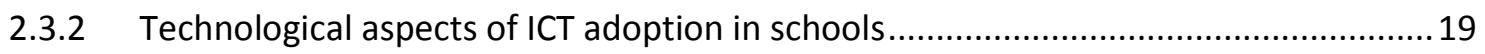

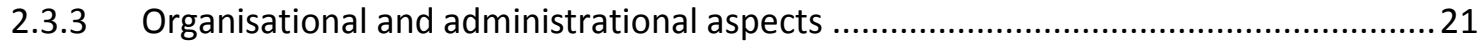

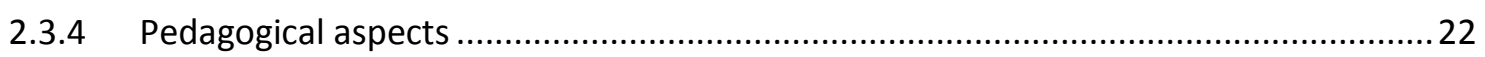

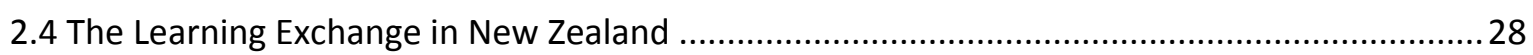

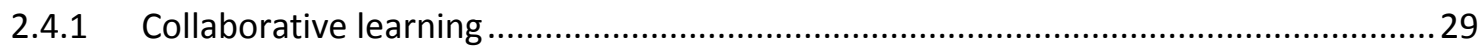

2.4.2 Cluster Theory and the New Zealand context ............................................................ 31

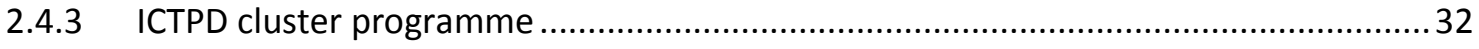




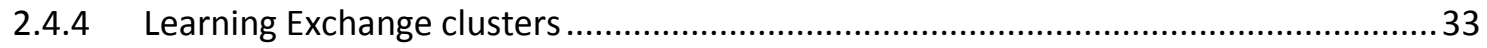

2.4.5 Development of the Learning Exchange programme ............................................... 35

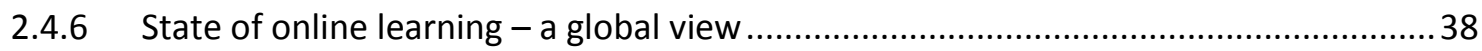

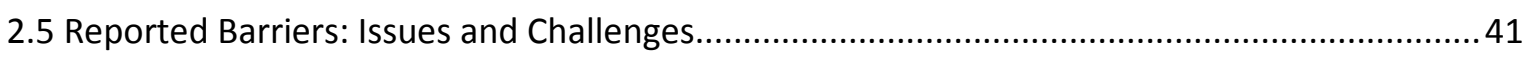

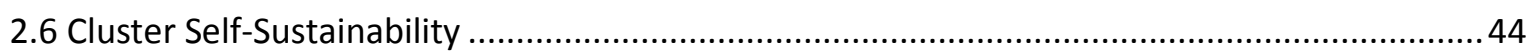

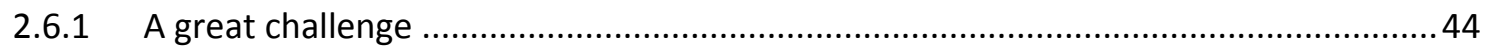

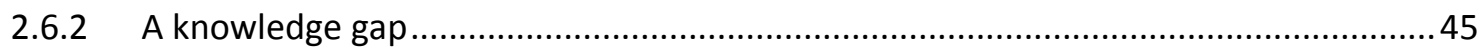

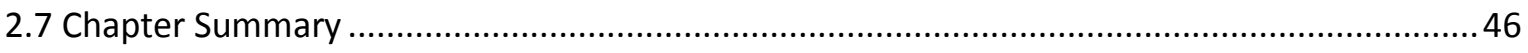

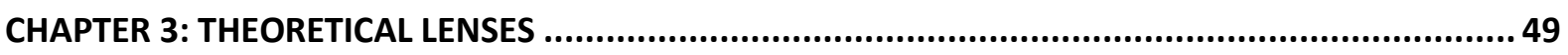

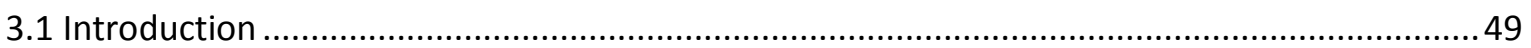

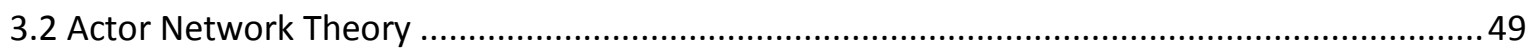

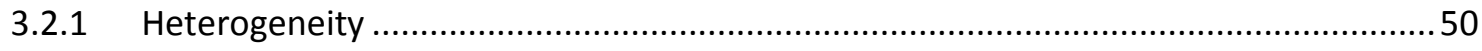

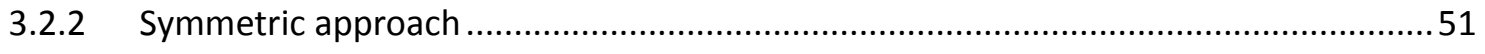

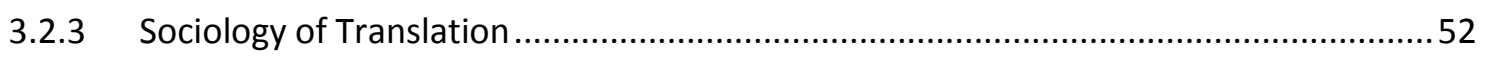

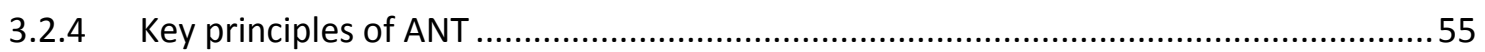

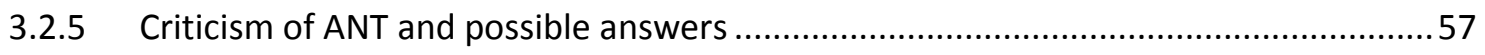

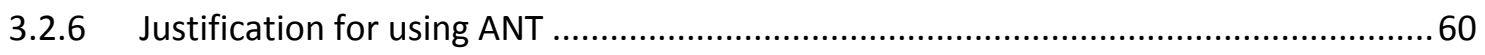

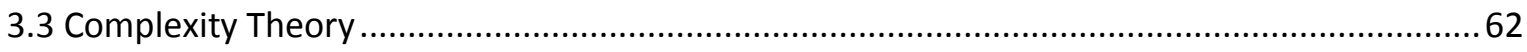

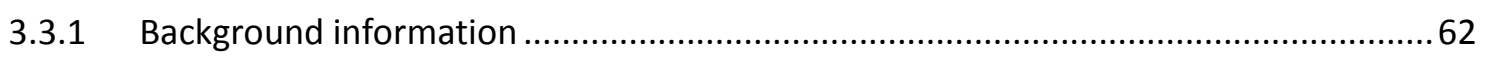

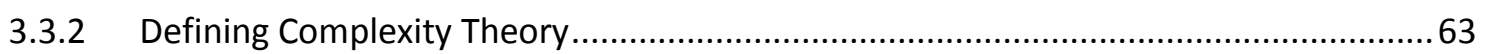

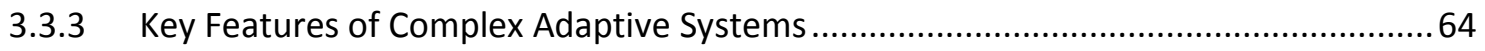

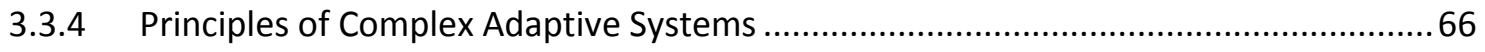

3.3.5 Use of Complexity Theory in Information Systems ..................................................... 70

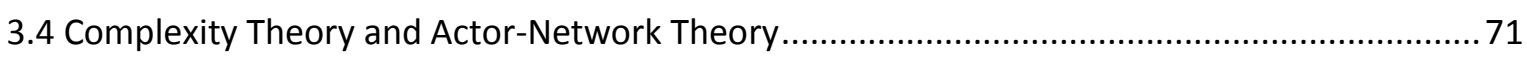

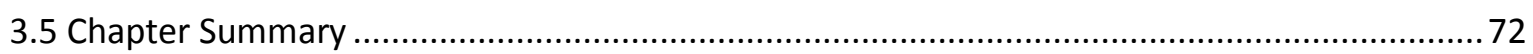

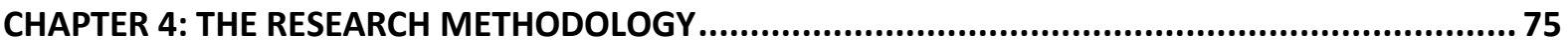

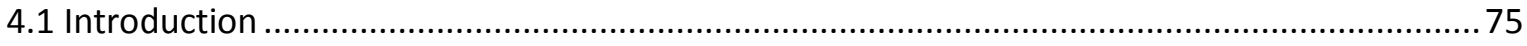

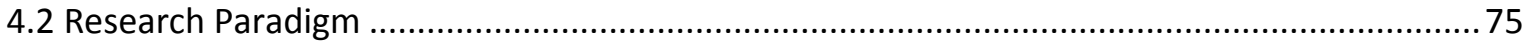

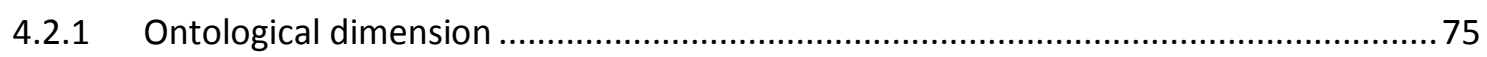

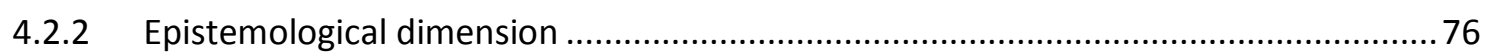

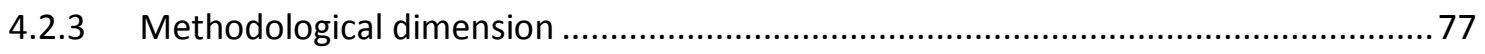

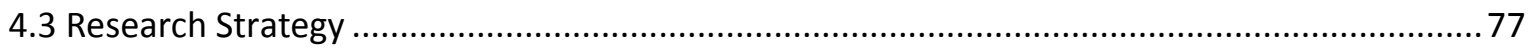

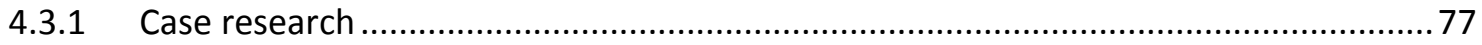

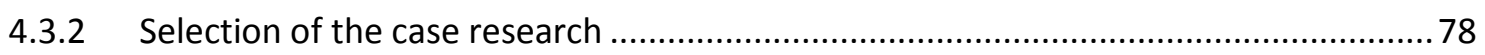

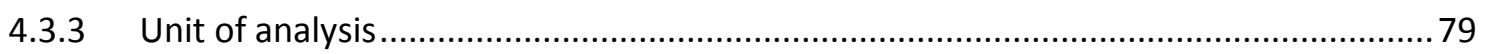

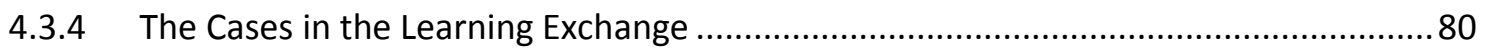

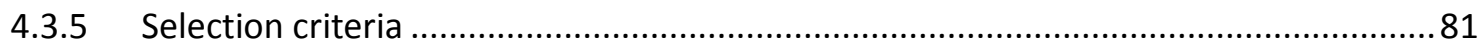

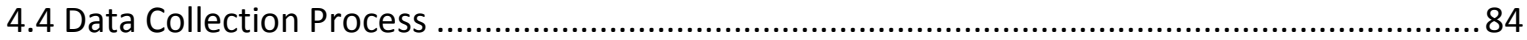




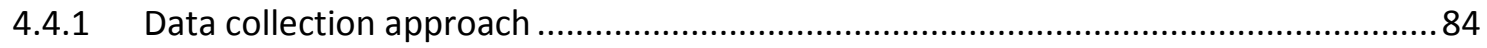

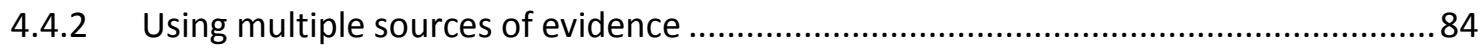

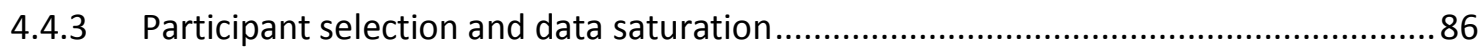

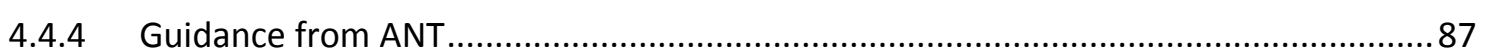

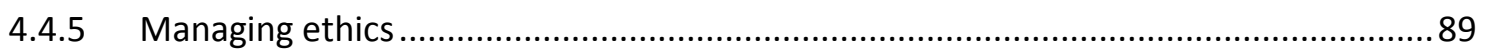

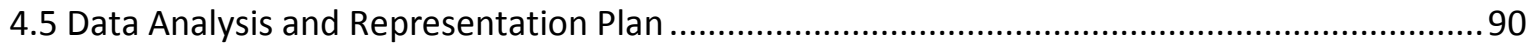

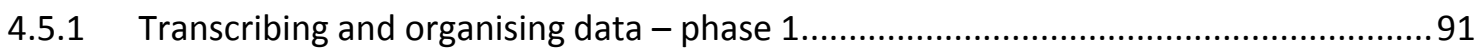

4.5.2 Segmenting, coding and reducing data - phase 2 ..................................................... 91

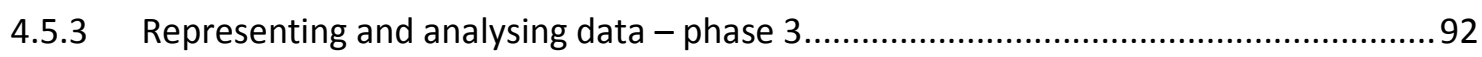

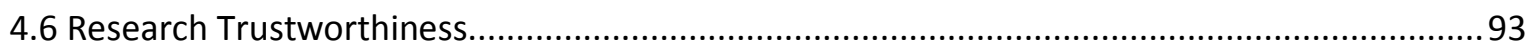

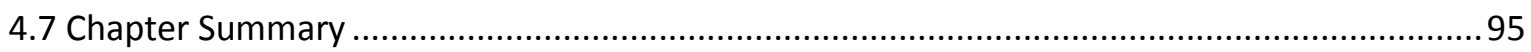

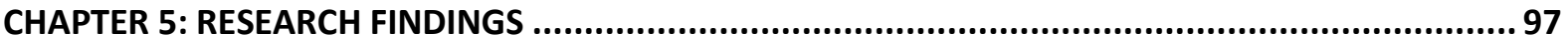

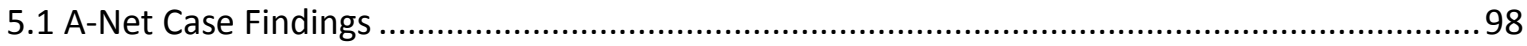

5.1.1 A-Net Problematisation - becoming indispensable..................................................99

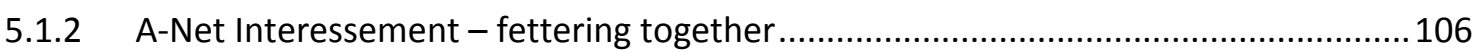

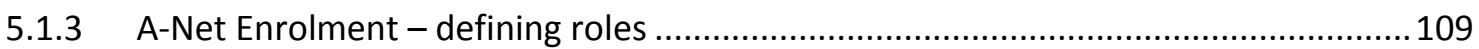

5.1.4 A-Net Mobilisation - supporting enrolled masses.................................................... 115

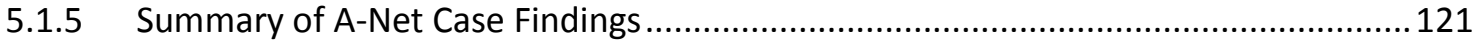

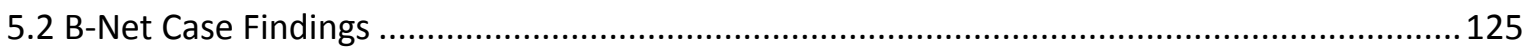

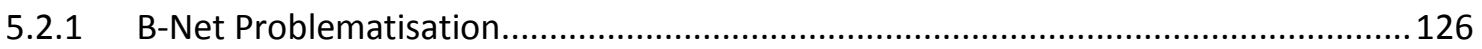

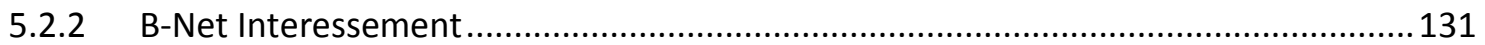

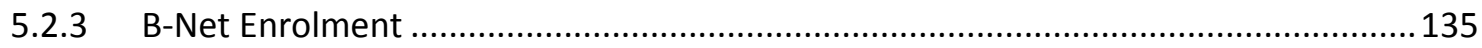

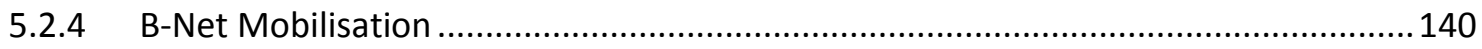

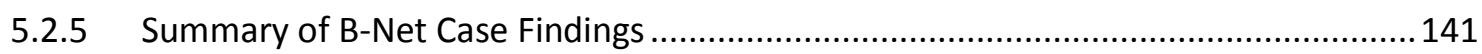

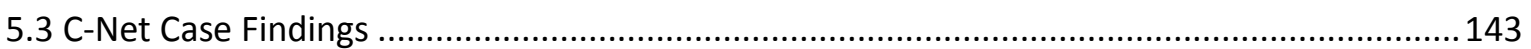

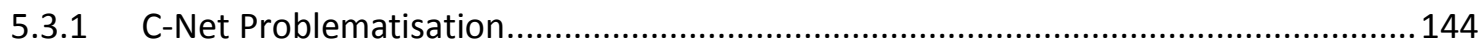

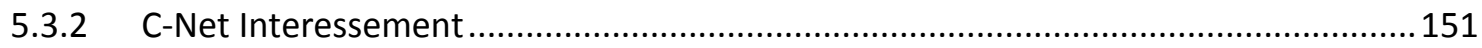

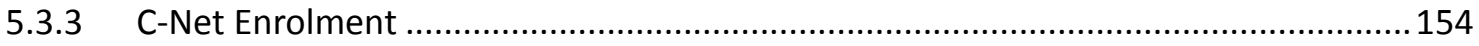

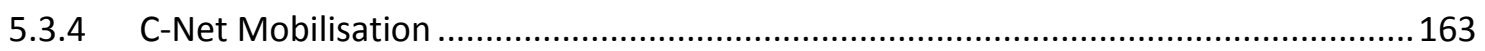

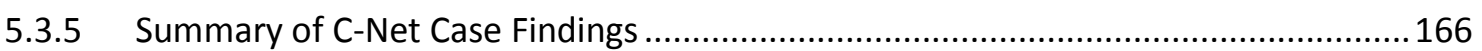

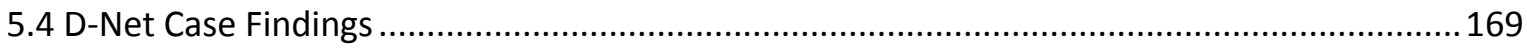

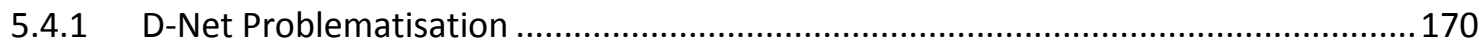

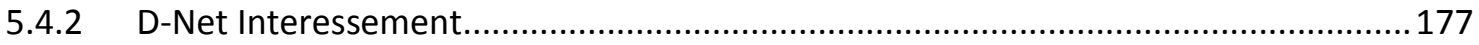

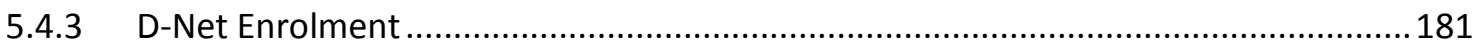

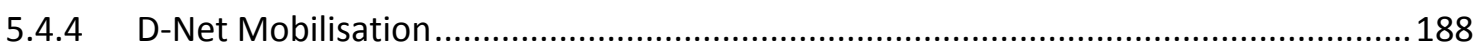

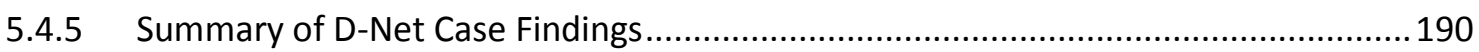

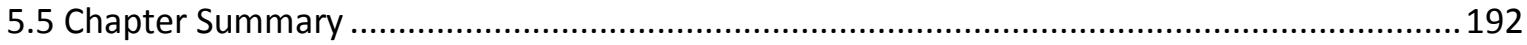




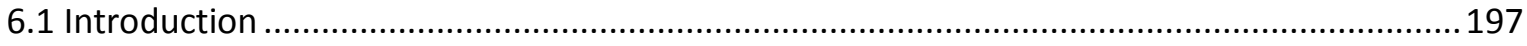

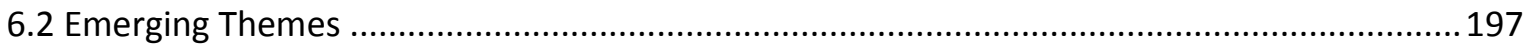

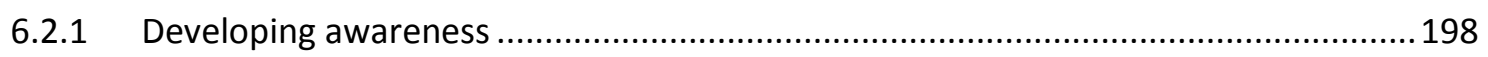

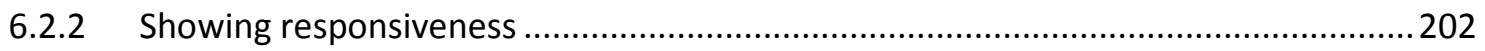

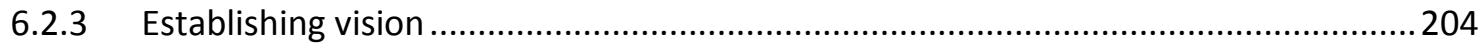

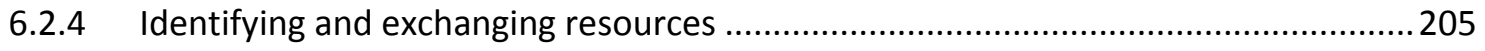

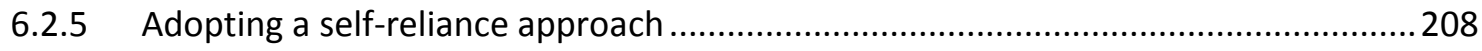

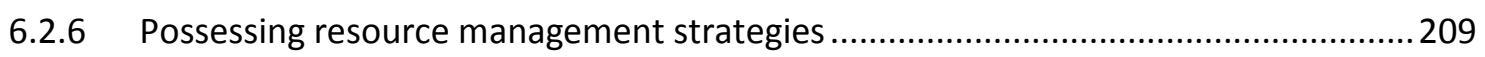

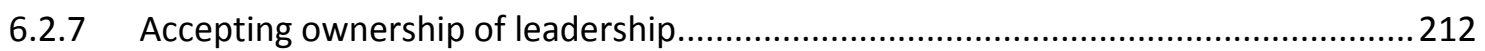

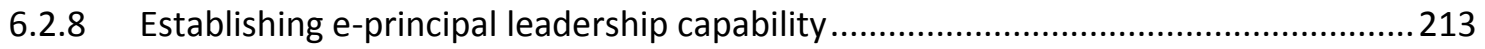

6.2.9 Reforming organisational structure/resources........................................................214

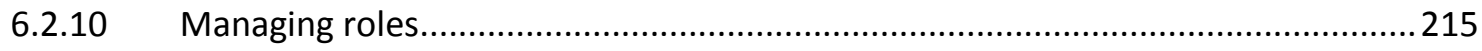

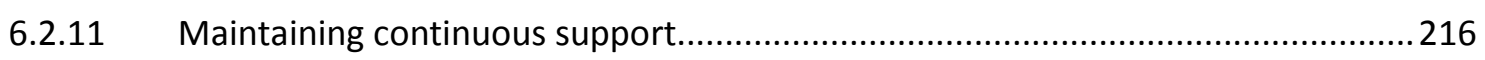

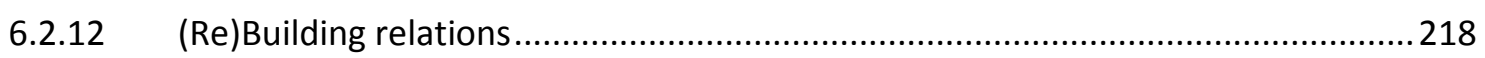

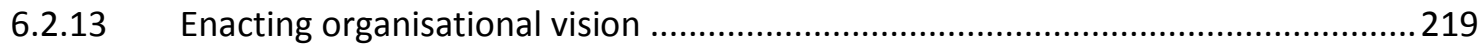

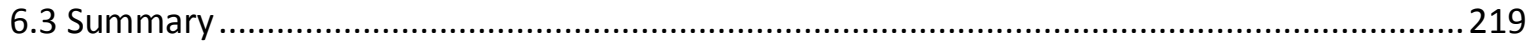

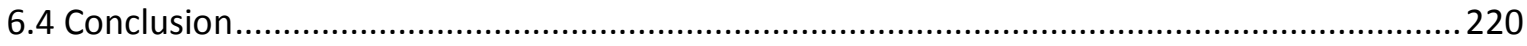

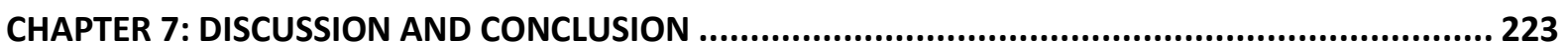

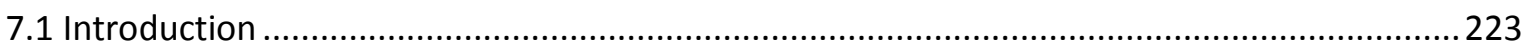

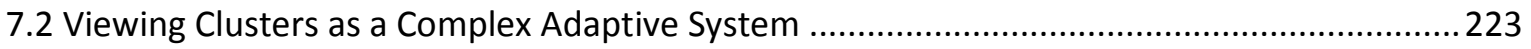

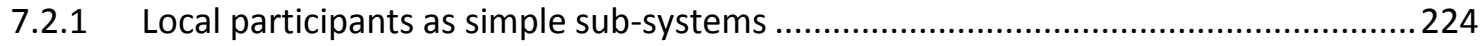

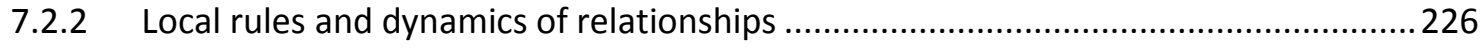

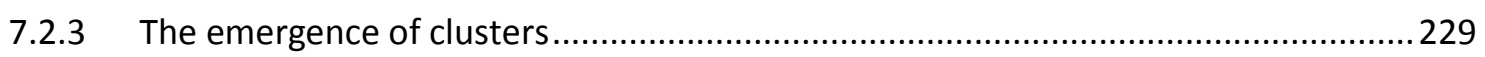

7.2.4 Self-sustaining clusters as Complex Adaptive Systems ...............................................2232

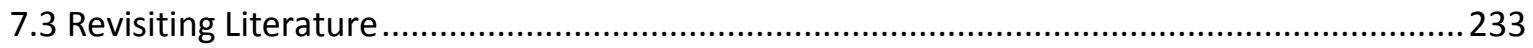

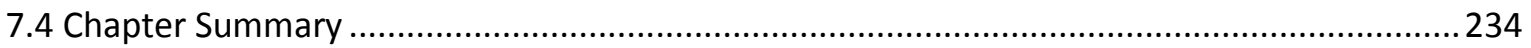

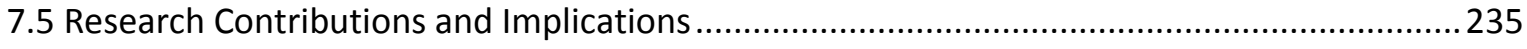

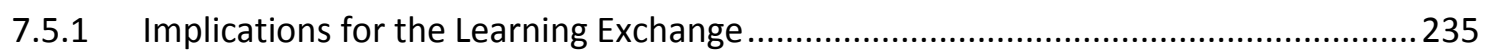

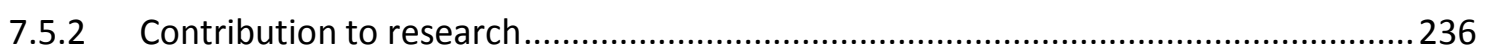

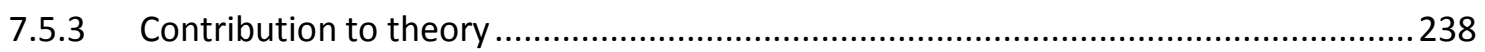

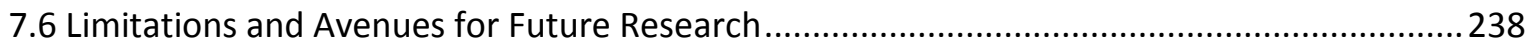

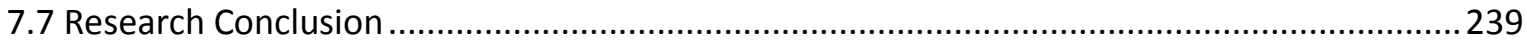

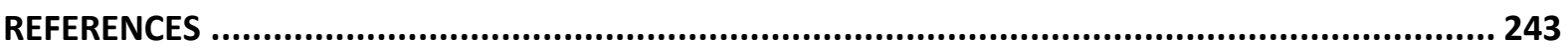

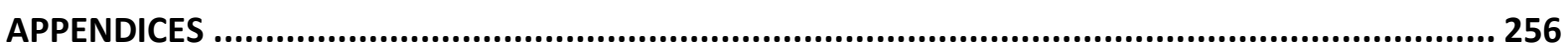




\section{LIST OF TABLES}

Table 2.1 New Zealand Ministry of Education's ICT Strategies and Components (Powell, 2011).......................28

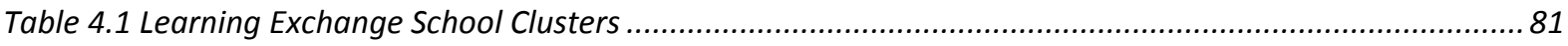

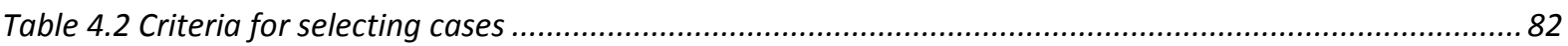

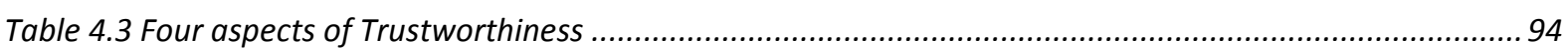

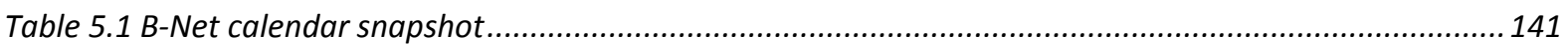

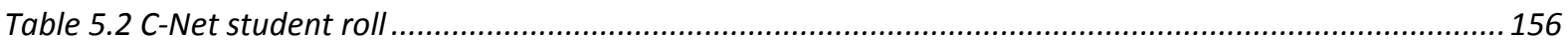

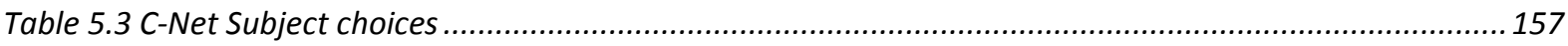

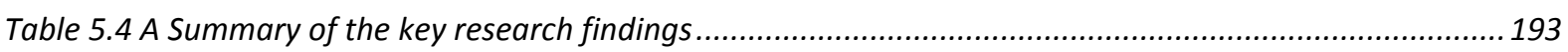

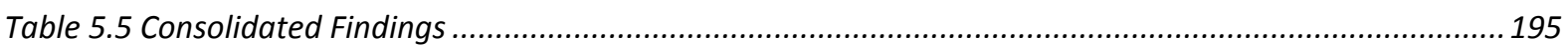

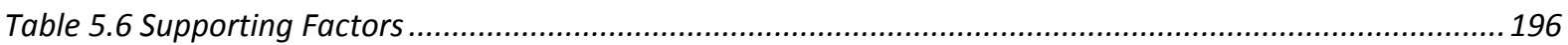

\section{LIST OF FIGURES}

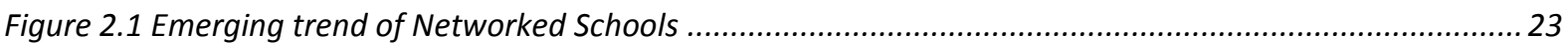

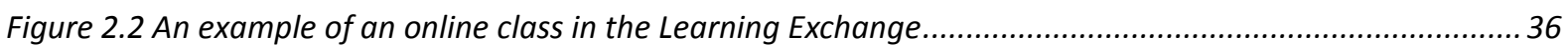

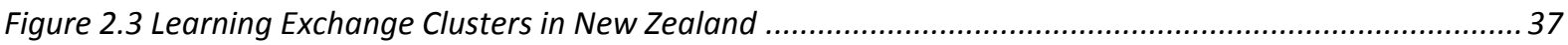

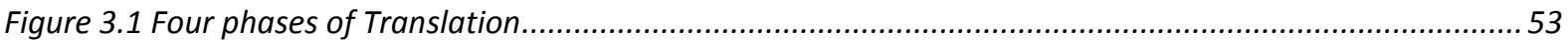

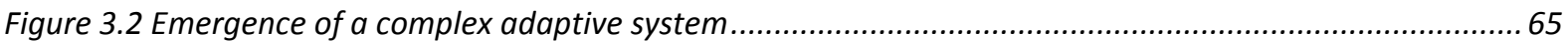

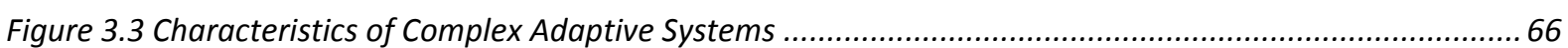

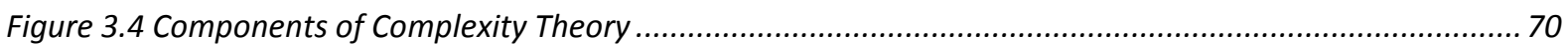

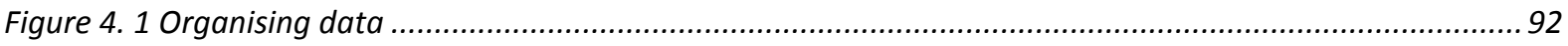

Figure 5.1 The Translation of Learning Exchange clusters in New Zealand ..............................................98

Figure 5.2 An illustration of Obligatory Passage Point for school clusters .................................................... 105

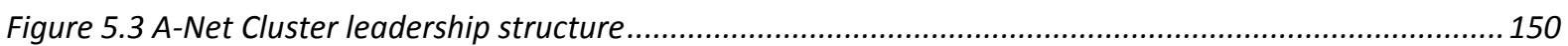

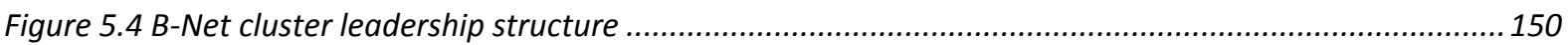

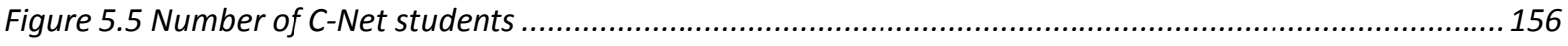

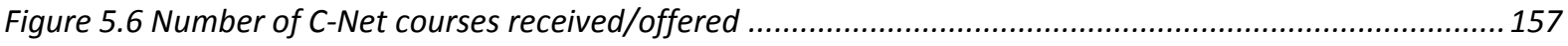

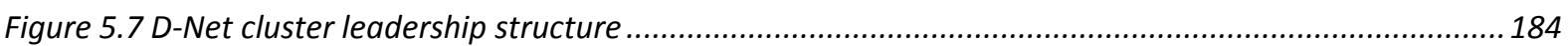

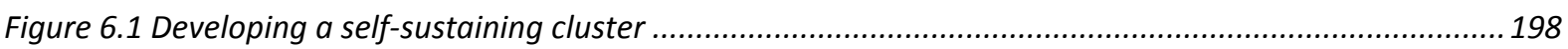

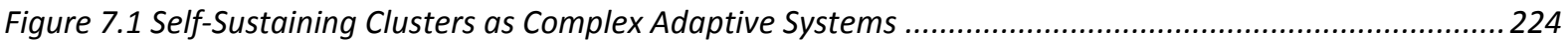

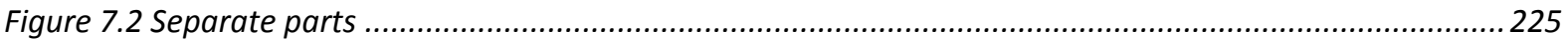

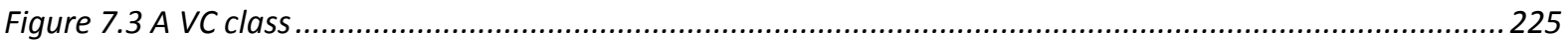

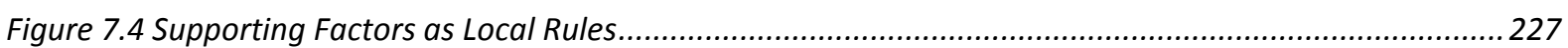

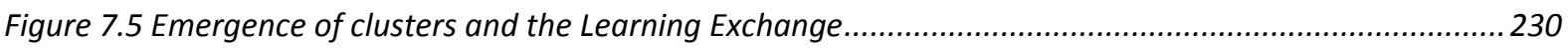

Figure 7.6 Co-evolution and the Emergence of self-sustainable clusters ...................................................231 


\section{GLOSSARY OF TERMS}

$\begin{array}{ll}\text { A-Net } & \text { Pseudonym used for the first cluster case study } \\ \text { ANT } & \text { Actor Network Theory } \\ \text { B-Net } & \text { Pseudonym used for the second cluster case study } \\ \text { CAS } & \text { Complex Adaptive Systems } \\ \text { CCS } & \text { Collaborative Consumption Services } \\ \text { CIF } & \text { Collaborative Innovative Fund } \\ \text { C-Net } & \text { Pseudonym used for the third cluster case study } \\ \text { CSDE } & \text { Computer-Supported Distance Education } \\ \text { D-Net } & \text { Pseudonym used for the fourth cluster case study } \\ \text { DPS } & \text { Digital Project for Schools (pseudonym) } \\ \text { ICT } & \text { Information and Communication Technology } \\ \text { ICTPD } & \text { Information and Communication Technology Professional Development } \\ \text { iNACOL } & \text { The International Association for K-12 Online Learning } \\ \text { IT } & \text { Information Technology } \\ \text { LEDA } & \text { Local Economic Development Advisory } \\ \text { MOE } & \text { Ministry of Education } \\ \text { OPP } & \text { Obligatory passage point } \\ \text { PBLP } & \text { Problem-Based Learning Programme } \\ \text { PD } & \text { Professional Development } \\ \text { TCS } & \text { The Correspondence School } \\ \text { VC } & \text { Video-conference } \\ \text { VLN } & \text { Virtual Learning Network } \\ \text { VLNC-NZ } & \text { Virtual Learning Network Community in New Zealand } \\ \end{array}$




\section{CHAPTER 1: INTRODUCTION}

\subsection{Chapter Introduction}

This chapter begins with the provision of background information leading to an explanation of the research motivation. The motivation section is followed by the introduction of the phenomenon of interest - The Learning Exchange - and the research problem. Then, the knowledge gap section describes some of the previous studies and justifies the existence of the gap that needed to be addressed. After that, the three research objectives and their subsequent questions are outlined. A brief description of the theories and research methodologies adopted in this study introduces how the research goal has been approached. Some of the major research implications and contributions are explained to specify the research significance. Finally, the chapter is summarised and the organisation of the upcoming chapters is outlined.

\subsection{Background}

Access to school education has been regarded as one of the basic human rights of every individual by the United Nations and other international organisations. Education For All and the Millennium Development Goals are only two of the large, global commitments for achieving the goal of 'universal education and literacy' (Johanson, 2010). However, due to a host of socio-demographic, socio-economic, political, and other disparities, a large portion of the global population still remains without access to basic education. The divide can also be in terms of the quality of access, the effectiveness of the education and the educational processes or the lack of access to expertise and other supporting resources. Therefore, regardless of the causes of disparities, the divide not only exists between developed and developing countries and economically stable and unstable regions but also within countries between various social classes, urban and rural populations, younger and senior citizens among other factors (Thatcher \& Ndabeni, 2010).

With the development of the Information and Communication Technologies (ICTs), prospects increased for the potential use of those technologies in schools to tackle the challenge of access and quality access to education and increase opportunities for schools on the wrong side of the digital divide (Voogt \& Knezek, 2008). Historically, different generations of distance education, such as The Correspondence School (TCS) and radio and TV broadcasts, have been used for supplementing school education and/or increasing the means of access to education. With the development of ICTs and increased use of digital devices and digital-based learning material, distance education also evolved - referred to as computer-supported distance education (CSDE). As a result of the ICT mediation, potential to reach a larger number of individual learners increased and distance 
education became lively and engaging (Anderson \& Simpson, 2012). On the other hand, governments and schools from around the world, particularly from developed countries like New Zealand, not only encouraged schools to use ICTs for complementing their regular classroom education but also facilitated the utilisation of the CSDE for enhancing teaching and learning performance (Ham, 2008). For example, students, particularly from rural schools, have been enrolled in CSDE programmes to not only overcome their geographical challenges but also benefit from alternate educational opportunities based on their individual needs and skills. Similarly, teachers located in rural regions have been encouraged to participate in virtual collaborative opportunities for their professional learning and development.

As a result of the amalgamation of ICTs, distance and school education, and the use of technologies for more affordable and equitable access to educational opportunities, the perception of school education has shifted (Anderson \& Simpson, 2012; Roblyer, 2008; Russell, 2004). The concept of school 'behind the walls' has changed and the face-to-face school education system has transformed. During the transformation, schools have evolved and emerged as virtual schools where all or some education is provided with the mediation of computers and the Internet (Clark, 2001). The boundaries between school face-to-face education and distance education have blurred and become indistinguishable. The Learning Exchange remains one of the initiatives that not only contains the attributes of the transformed school paradigm but also exists as a grass-roots level initiative aimed at increasing access to affordable and equitable opportunities for students and teachers located in rural schools of New Zealand.

\subsection{Research Motivation}

Based on the above, a number of factors motivated this study. Personal influence was the key factor for undertaking a study to extend my master's dissertation ${ }^{1}$ on online learning conducted in the UK to a PhD level. After a preliminary review of the literature, the Learning Exchange was identified as an online collaborative learning programme, self-directed and self-organised by local school communities for nearly two decades. Therefore, studying the development of the Learning Exchange became the subsequent motivation for this study.

From an Information Systems researcher's point of view, the programme attributes were compelling. Some examples of the major attributes include the use of the theory of clusters and ICTS for virtual collaborative learning and reciprocal exchange of educational resources between schools at a distance. Similarly, the rise of the Learning Exchange as a grass-roots level initiative led by local,

\footnotetext{
${ }^{1}$ The title of the dissertation was "Closing the digital gap in a developing country: A case of universities in Pakistan". The dissertation focused on identifying the factors that widened the divide.
} 
rural, small communities of schools with the bottom-up developmental approach were some of the other attributes that motivated this research project. These attributes not only suggested the Learning Exchange as the potential phenomenon of interest but also suggested the possible contributions of this research.

The preliminary investigation also found that some school clusters had sustained their development and continued utilising the programme while some had faced challenges in their cluster development and it had eventually disappeared. The variation in the utilisation of the programme not only served as the research problem but also became another key motivational factor. As a result, the research goal was set to study how the Learning Exchange has been developed and is being utilised by some school clusters for the provision of access to equitable educational opportunities for geographically dispersed learners and educators.

Finally, another motivational factor was the potential for application of the programme or some of its attributes in a school setting in a developing country. For example in Pakistan, access to specialist subject teachers or collaborative learning opportunities are not available to many of the large schools in urban areas with some basic ICT infrastructure. Therefore, while keeping the possible adoption/application of the programme in mind, learning about the attributes, such as a reciprocal exchange model, clustering strategy, the use of video-conference (VC) technology and others for distance education remained other key drivers for this study.

Before specifying research objectives and questions, the next section provides an introduction to the Learning Exchange and the research problem.

\subsection{Introducing the Learning Exchange}

The Learning Exchange is a cluster-based course-sharing programme using ICTs for connecting participants and forming a virtual collaborative learning environment (Roberts, 2009). The programme uses the cluster concept and reciprocal model for virtual sharing of courses between schools. As a result, the small, rural schools gain the benefit of economies of scale, maximising their existing educational benefits (Barbour, Davis, \& Wenmoth, 2011; Bolstad \& Lin, 2009; Ministry of Education, 2011; Zaka, 2013). Hence, the geographically isolated participants gain access to affordable and equitable educational opportunities in their own schools.

Based on the review of the literature, various generations of distance education initiatives along with a variety of technological settings have been used for addressing the educational needs of learners and educators located in rural areas. Earlier generations, such as The Correspondence School (TCS) programme and tele-broadcasting, adopted a mass broadcasting approach for reaching 
a high number of learners. However, with the mediation of telecommunication technologies and computers (and a shift in pedagogical thinking), the focus of educators in distance education shifted to improving the quality of the teaching and learning processes, student engagement and group or collaborative learning methods.

The review of the literature recognised the Learning Exchange as part of an emerging generation of distance education, in which ICTs are used for supporting virtual collaborative learning between participants mainly from small, rural schools. In addition, the programme was found to have used the cluster theory with 'collabetitive and co-opetitive' approaches, suggesting collaboration and cooperation between competitors (Crocombe, Enright, \& Porter, 1991; Molina \& Yoong, 2003; Wenmoth, 2010). The approaches were adopted not only for addressing the lack of access to wider curriculum choices and subject teachers for students, but also for facilitating the transformation of schools and embracing of emerging pedagogical approaches. Therefore, the Learning Exchange was a programme self-organised by regional school clusters, allowing schools to combine the emerging pedagogies from computer-mediated collaborative learning with the cluster theory.

The current Learning Exchange model began around 2001-02 as a grass-roots initiative by a group of schools from the Otago region of New Zealand (Barbour et al., 2011; Pratt \& Pullar, 2013; Roberts, 2009). Since then, the model has been adopted by a number of school clusters across New Zealand. Before the attempt from schools in Otago, a small group of schools from the nearby Canterbury region of New Zealand had also attempted to use ICTs as a solution to the same problem of accessing courses. However, the initiatives differed in terms of the tools as well as the financial model.

\subsection{Research Problem and Gap}

Since the inception of the programme, the model has been adopted by 20 school clusters in New Zealand. However, the problem is that some of the clusters have developed and become selfsustainable, whereas some school clusters were faced with challenges. The challenges inhibited them from becoming sustainable clusters and thus they disappeared.

Given the self-reliant and highly contextual nature of the programme, very little information was available. Some of the studies included Pratt and Pullar (2013), Barbour and Wenmoth (2013), Roberts (2009, 2013), Zaka (2013), Stevens (2011), Bolstad and Lin (2009), Pullar and Brennan (2008) and so on. However, the studies were limited and overlooked the problem. That was because they either only introduced and described the programme, outlined the history of the development of a specific cluster, focused on the students' experiences, studied the role of technology, or were the Ministry of Education (MOE) reports containing 'success stories' or reported teachers' experiences in 
the VC classes. Barbour et al. (2011) studied the Virtual Learning Network's (an alternate name used for the Learning Exchange) development, without specifically addressing the problem of disappearing clusters. Powell (2011) only briefly mentioned that some clusters have easily adjusted to the Learning Exchange while other clusters are struggling with the change; however, she does not explain or give any reasons for the problem.

Another possible reason could be that the issue of the disappearing clusters in the Learning Exchange has appeared in the last few years. Therefore, the identification of the facilitating and inhibiting factors remained a knowledge gap. As a result, an in-depth study was required to understand the development of the clusters and identify the factors contributing to the maturity of the Learning Exchange clusters.

Studies from overseas regarding similar initiatives were also reviewed to gain an international perspective. The survey by the International Association for K-12 Online Learning (iNACOL) was one of the major studies that reported a number of issues and challenges (Barbour et al., 2011). Some individual studies identified the ineffective use of technology, unfavourable organisational culture and the lack of managerial support as barriers to the adoption of computer-mediated online teaching and learning using ICTs (Anastasiades, Vitalaki, \& Gertzakis, 2008; Celikkan, Senuzun, Sari, \& Sahin, 2013; Smyth, 2005). Although the studies were very informative, they could not specifically address the research questions. That was because the studies did not address self-sustainability of self-organised clusters. Further, the unique nature of the Learning Exchange required a study specially designed to consider the programme's attributes and the context. Therefore, this study was designed to address the research problem and the knowledge gap.

\subsection{Research Objectives and Questions}

This study was designed with the key objectives of studying the development of some of the clusters and revealing the facilitating and inhibiting factors in the development of a self-sustaining Learning Exchange cluster. This research intended to address the following three key research objectives (RO): 
- RO1: To examine the development of the Learning Exchange programme in New Zealand

- RO2: To investigate the utilisation of the Learning Exchange programme in the school clusters in New Zealand

- RO3: To identify the facilitating and inhibiting factors for the development of self-sustainable Learning Exchange school clusters in New Zealand

The above research objectives were addressed by the following research questions (RQ):

- RQ1: How was the Learning Exchange programme developed in New Zealand?

- RQ2: How was the Learning Exchange programme utilised in the school clusters in New Zealand?

- RQ3: What were the factors that facilitated or inhibited the self-sustainable development of the Learning Exchange school clusters in New Zealand?

By answering the research questions, the study was expected to address the research problem and fill the knowledge gap. Hence, the study was to fulfil the research motivations.

\subsection{Theoretical Lenses}

The use of theories provides some researchers with the required lenses through which they can look at complicated problems and interpret research data (Reeves et al., 2008). This study used ActorNetwork Theory or ANT as a theoretical lens mainly for reporting the findings of the four cases. The Translation process from ANT was adopted to 'describe how' various actants from school clusters had grouped together and formed the network of the Learning Exchange cluster in New Zealand. In other words, ANT was not used as a method with its own ontology. Instead, ANT was used as a theoretical lens only in order to avoid any possible inconsistency or clash between ANT and the use of an interpretive paradigm in this study. Chapters 3 and 4 expand the approach used in this study.

To introduce the theory, ANT treats human societies as a network of heterogeneous elements or actants where all the actants, be they humans or nonhumans, participate in the transformation of the network (Law, 1992; Callon, 1986; Latour, 1986). In addition to their inclusion, network researchers and observers are advised to adopt a socio-technical approach. The approach means that all the actants should be treated equally, without any a priori distinction or superiority assumptions and with agnosticism or analytical impartiality (Callon, 1986). Therefore the theory not only suggests the existence of heterogeneity but also advises researchers to adopt a middle ground or socio-technical approach (Tatnall \& Gilding, 1999). 
In the Learning Exchange, users, organisations, technologies as well as schools and government policies are the major actants. They collectively (re)build the network of schools - the Learning Exchange. The use of ANT allowed me to follow those actants and observe how they interacted with each other and how those interactions were transforming their networks. In addition, as claimed by Hanseth et al. (2004), ANT helped to un-box (an ANT term which can be defined as 'expose') actants and their associations which had remained unnoticed and were taken for granted.

Most importantly, the ANT principle of Translation was utilised along with its four phases. The utilisation allowed the researcher, as suggested by Law (2009), to 'describe how' various actants in the clusters had come together and formed the Learning Exchange cluster. In particular, the continuous nature of the process of Translation facilitated describing the transformation of relations in terms of both constructing and dismantling of school clusters. Thereby, ANT allowed the research to address the research questions in the Findings Chapter.

In order to provide a comprehensive view or address some of the aspects that might not be possible with one theoretical lens, Complexity Theory was employed to complement the use of ANT. The use of Complexity Theory was restricted to the discussion and conceptualisation of the research findings in the Discussion Chapter only. The theory builds upon the outcome of the ANT-based research findings and explains the 'emergence' of the clusters and the Learning Exchange as a result of the coevolutionary processes of the system units. The theory also discusses the disappearance of some of the clusters as a 'decomposition' process due to the lack of interactions between system elements and some other factors. (The theoretical lens chapter explains the appropriateness of both the theories for this study.)

\subsection{Research Methodology}

This research has used a qualitative research methodology within an interpretive research paradigm and a case research method. Due to the insufficient body of knowledge regarding the Learning Exchange clusters, the adoption of the case study method allowed the researcher to include all aspects and get an in-depth view of each cluster. Regarding the data collection and data analysis processes, the individual cluster was the logical unit of analysis. The classification and selection of clusters were based on a number of criteria: the number of active member schools in a cluster; the number of courses offered by a cluster; the number of enrolled students in a cluster; the nature of a cluster (receiving or offering courses or both); and the operational level of a cluster. Based on those criteria, four clusters were selected for data gathering.

Multiple strategies were used for collecting data. In-depth interviews were used for data collection from individuals on a one-to-one basis. Direct observations were used to collect information 
regarding the elements or aspects of the clusters that was not collected during the interviews. Further, a number of documents were collected and used not only for further clarification and augmentation of the gathered data but also for making inferences. Further details have been provided in the Methods Chapter. In line with the socio-technical foundation of ANT, inputs were also gathered 'from and for' non-human elements. As consented to by participants, audio-recorded interviews were fully transcribed. Transcriptions were sent back to the participants to check accuracy. NVivo software was used for organising and reducing interview data into meaningful chunks represented by nodes. The nodes were further reduced into inhibiting factors or barriers. The four phases of Translation from ANT were used to outline the research findings. A summary of the initial findings was posted to the research participants for their review and confirmation. In most cases, they agreed with the findings and suggested some minor alterations.

\subsection{Research Implications and Contributions}

This study is significant as it has implications for school clusters and the wider school community and contributions to research and theory. The knowledge gained from this research provides insights for the growth and self-sustainable development of the Learning Exchange community. In particular, this study explains the development of the Learning Exchange and the self-sustainability of clusters by using two major theoretical lenses. As a result, the findings are expected to be more refined, providing a different angle for understanding the programme's development. Any decision based on the insights would be more effective, allowing the clusters to integrate into the main school systems. The possible implications of the Learning Exchange with such a different developmental approach make this research highly practical, for example, for the Information Communication Technology for Development (ICT4D) programmes. Often in ICT4D and community projects, 'development' and 'progress' are typically defined in terms of the capitalist economic worldview, involving the private sector interested in imposing its own exclusive commercial solutions without a great level of participation from the beneficiaries of the proposed project (Day, 2010; Jacques Steyn \& Johanson, 2010). However, the Learning Exchange was found to be a grass-roots level ICT-based project, encompassing social impact without replacing social needs with a 'cost benefit analysis' as described by Heeks (2012). These attributes of the Learning Exchange studied through the dual theoretical lenses enhanced the applicability of the phenomenon to other ventures with a virtual, collaborative, sharing-based model. Therefore, parts of the results of this research may be applied in a developing country - such as my home country Pakistan - in ICT4D projects for the provision of school education in rural areas. Therefore, the transferability of the Learning Exchange attributes will be highly valuable and carries potential contribution. 


\subsubsection{Contribution to research}

Sharing skills and knowledge through the use of ICT and virtual networking of the Learning Exchange participants provides a very relevant example of the 'Collaborative Consumption Services' (CCS) that underpin the emerging concept of a 'Sharing Economy'. The CCS or Sharing Economy is often described as an alternative model for efficient use of scarce resources such as products or services (Cohen \& Kietzmann, 2014; Roy, Cranefield \& Toland, 2015). This study contributes to the body of research by presenting the Learning Exchange as an innovative case of CCS and Sharing Economy research and making the case accessible for further scientific investigation.

In addition, the CCS and Sharing Economy are often linked to the scarcity of resources due to the population density in large cities. However, this study demonstrates that the CCS and Sharing Economy are similarly relevant to rural populations or thinly populated areas. Therefore, the study is considered to be making a contribution to that body of research.

Although the findings are highly contextual and relevant to New Zealand, the use of the Complexity Theory facilitated the generalisation and conceptualisation of the findings. The challenge of selfsustainability faced by the community-led, grass-roots level initiatives using various ICT settings is not specific to the New Zealand context only. The attributes highlight the programme features as well as the interplay between the Information Systems discipline, effective uses of ICTs and the wider society.

\subsubsection{Contribution to theory}

The first theoretical contribution is the presentation of school clusters as various layers of the Learning Exchange 'network'. Specifically, with the assistance of the ANT lens the research develops further insights and improves our exisitng understanding regarding the Learning Exchange clusters. The study treated the Learning Exchange as a network and the school clusters as its various layers. As a result of this exercise, our understanding of what the Learning Exchange is and how it has been developed has improved. Therefore, the ANT-based representation of the Learning Exchange having various layers remains a unique demonstration, and hence makes a theoretical contribution.

The second theoretical contribution is the combined use of ANT and Complexity Theory. By combining both, the research not only addresses the limitations and criticisms of both the theories, but also provides a holistic view of the cluster phenomenon. ANT is criticised for mainly being concerned with micro-management of a network. On the other hand, Complexity Theory is mainly concerned with the co-evolution of macro-structures and not the units of a system. Therefore, the dual lens presents the Learning Exchange as a 'complex socio-technical system'. 


\subsection{Delimitations}

This study includes evidence from some of the schools and Learning Exchange clusters. It would not have been possible to study and include evidence from each of those schools. Therefore, the study might have been weakened by not including each and every aspect of the schools, clusters and the Learning Exchange programme.

Similarly, more than 2,500 private, state and public-private partnership schools operate in New Zealand. Only around 200 of those schools have participated in the Learning Exchange. Therefore, the research is mainly about the schools in the Learning Exchange. However, the implications could be useful for the schools outside the Learning Exchange as well.

Regarding the use of ANT, the theory has been used in a limited manner in conjunction with other established research approaches in the Information Systems field. This limitation is discussed further in Chapters 3 and 4.

\subsection{Chapter Summary and Thesis Structure}

This chapter began with providing background information, which led to outlining the motivational factors, the personal influence and programme attributes and applicability, behind this study. The Learning Exchange was then introduced based on the previous studies. The introduction delineated the existence of a research problem. The research problem was reviewed within the existing studies and it was pointed out that those studies were limited. Based on the existence of the gap, the research objectives and subsequent research questions were outlined. The next section described ANT as a theoretical lens mainly for the reporting of the research findings. Complexity theory was introduced for use in the discussion of the findings and the emergence of the Learning Exchange. Then, the research methodology was outlined and the research design was briefly described. At the end, the research significance was demonstrated by the explanation of the research implications and theoretical contributions.

The thesis is organised as follows. The following chapter provides an overview of the literature and justifies this study. Chapter 3 describes ANT which has been used for the reporting of the findings and thus answering the research questions. The chapter also discusses the inclusion of the Complexity Theory used later in the discussion chapter. Chapter 4 discusses the research methodology and design. Chapter 5 reports the research findings based on the participants' accounts of the events through the lens of ANT. Chapter 6 provides a cross-sectional analysis of the four clusters and provides a holistic view of the phenomenon. Chapter 7 discusses the crosssectional analysis outcome through the lens of Complexity Theory and thus conceptualises the 
research outcome. At the end, the discussion chapter provides a conclusion of the study and the research significance and possible contributions. 


\section{CHAPTER 2: LITERATURE REVIEW}

\subsection{Introduction}

This chapter presents a review of the literature focusing on a number of key areas. The chapter starts with providing a historical overview of distance education leading to computer-mediated, online, learner-centred, collaborative distance learning. Section 2.3 discusses the adoption of ICTs in schools, covering the emergence and application of ICTs since the 1990s. The section ends with the discussion of the diffusion of ICTs in school departments and the role of ICTs in the transformation of educational processes into learner-centred pedagogies. Section 2.4 presents the Learning Exchange as an example of transformative pedagogical approaches. The section first covers 'co-opetitive' and 'collabetitive' as the founding concepts in the 'cluster theory', internationally and then in the New Zealand context. In particular, the section identifies a clear link from the literature between 'cluster theory' and the development of the Learning Exchange programme and the emergence of school clusters in New Zealand. The development of the Learning Exchange cluster programme is reviewed as a solution for computer-mediated distance education. Section 2.5 reports major issues and challenges identified by previous studies. Section 2.6 reviews those issues in relation to the development of sustainable Learning Exchange clusters and reports the knowledge gap. Finally, Section 2.7 recaps the chapter with a summary of the literature review.

\subsection{An Overview of Distance Education}

This section defines distance education and discusses its key attributes. That is followed by the discussion of various generations of distance education.

\subsubsection{Distance education}

For centuries, education has remained an important aspect of human lives and been defined by the particular time and demands of human societies (Russell, 2004). With the changing social, political and economic situations in the later part of the $19^{\text {th }}$ Century, one of the important needs was to "offer educational opportunities to ...women and working class people since neither group was well served by formal education institutions" (Anderson \& Simpson, 2012, p. 3). Distance education was seen as an opportunity for meeting the changing needs and thus TCS programme was developed in the late $19^{\text {th }}$ Century, in which educational materials were printed and posted back and forth (Sumner, 2000). Since then, distance education has evolved and its various generations have been developed to meet the educational needs of adults as well as younger learners. 
Many definitions of distance education exist in the literature, each highlighting different components of the education method. Moore and Kearsley (2011) define distance education as planned teaching and learning processes, occurring at different places and times and requiring communication through technologies as well as dedicated institutional organisation. Schlosser and Simonson (2009) have a similar definition, highlighting the method as institution-based, formal education in which interactive telecommunication systems are used to connect dispersed learners, resources, and educators. Both the above definitions are relatively clear and precise as they cover most of the key dimensions that exist in the previous as well as recent generations of distance education. The following paragraphs highlight those components and discuss their differences. Firstly, distance education is a formal and planned method of education provided by an educational organisation. This component separates distance education from any self-study type of initiative by an individual (adult) learner. This means learners are required to register with institutions that have set up departments for distance education courses and programmes. Simonson et al. (2009) support the component because the institutional basis differentiates distance education from individuals' self-study initiatives. Secondly, the method involves not only learning but also teaching processes. Therefore, labels such as e-learning and distance learning are inconsistent and partial representations of distance education (Moore \& Kearsley, 2011). Thirdly, the separation between learners and educators is another dimension in distance education (Schlosser \& Simonson, 2009). The separation is referred to in terms of both space and time. The separation in terms of space between learners and educators is obvious in distance education. A time separation is when participants access educational materials at their own convenience, known as asynchronous (not-atthe-same-time) learning.

Fourthly, various telecommunication technologies are utilised in the method to facilitate communication between participants and the development and exchange of educational resources. While reporting technology-based approaches, Moore and Kearsley (2011) describe three categories of technologies: recorded technologies such as print used in the TCS programme and Compact Discs (CD) used more recently; broadcasting technologies such as radio and television; and interactive technologies, such as two-way audio-conference, video-conference and computer systems. However, based on the communicative capability, Sumner (2000) discusses two categories of technologies in distance education: print and broadcasting technologies have one-way communication capability while audio- and video-conference have two-way communication capability. Based on these two types of categories, the adjective 'interactive' makes the above definition by Schlosser and Simonson (2009) limited because the definition highlights recent, twoway communication technologies only and does not cover the postal and broadcasting technologies. 
Finally, distance education participants need some form of medium for their communication. Moore and Kearsley (2011) argue for a clear distinction between media and technology as both are commonly and wrongly used as synonyms. According to the authors, media are used to represent messages in different ways, such as text, images (both still and moving), sounds and artefacts (for example instructional software and databases). On the other hand, technology - such as print, radio, television, computer or the Internet - is the physical vehicle carrying messages or the mediator used in distance education (Anderson \& Simpson, 2012).

\subsubsection{Evolutionary stages of distance education}

With a history of more than 150 years, distance education has passed through different stages or generations. Generally, researchers such as Taylor (2001), Garrison (1985) and Nipper (1989), have classified distance education on a technological basis, whereas other researchers such as Anderson and Dron (2011) draw distinctions based on the pedagogical characteristics and learning activities involved in the processes. This research follows the technological distinction due to its ease of use and relevance.

The Correspondence School programme is an example of the first generation of distance education, in which printed media and the postal system were used (Anderson \& Dron, 2011; Sumner, 2000). More recently, digital media and ICTs are being utilised for the design and exchange of learning resources, and the communication process between participants (Moore \& Kearsley, 2011). According to Lee (2009), TCS was formally recognised during the late $19^{\text {th }}$ Century as a remedy to the changing social and economic needs of the time. Some of the main reasons included the mass migration to cities, educational problems in rural areas, increased need for a technologically-skilled workforce, mass unemployment and limited opportunities and access to educational institutions (Reiach et al., 2012; Lee, 2009). In particular, sparsely populated countries, such as Canada and Australia, saw the TCS programme as a great opportunity for the development of national education systems and a solution to the industrial needs (Sumner, 2000). Therefore, by the end of the 19th Century, a number of North American and European universities started offering distance education (Moore \& Kearsley, 2011). However, due to the slowness of the postal system, the limitations of the one-way communication and the lack of interactivity, TCS was seen as limited and participants remained isolated from each other (Sumner, 2000; Thompson, 1990).

Tele-education is the second generation of distance education, in which broadcasting technologies are used (Anderson \& Simpson, 2012). Broadcasting technologies, such as radio in the 1920 s and television in the 1930s were used for educating learners at a distance; later telephone and film were introduced (Simonson et al., 2009; Anderson, 2009). The major aim of using the mass media was for 
the mass delivery of education - an industrial approach (Garrison, 1997). The approach was adopted to achieve two objectives: increase access to education and support high scalability or educating a large number of students at a lower cost than face-to-face education (Garrison, 1997). As a result, distance educators emphasised the mass delivery of the programmes rather than the quality and learning experiences, such as group interaction or social learning (Sumner, 2000).

A post-industrial phase started from the late 1960s with the introduction of the telephone or electronic transmission of resources in distance education. Audio-teleconferencing uses telecommunication systems to facilitate live, two-way voice communication between two or more places (Garrison, 1985). The innovation provided greater opportunities for learning - such as group learning, instant feedback and comments on course material - that did not exist previously. However, Sumner (2000) believes that the opportunities were not fully utilised, because distance educators mainly concentrated on student independence. Garrison (1985) also reports the underutilisation of the new opportunities because of the difficulty in scheduling a group for synchronous learning.

The third generation of distance education started around the late 1980s and early 1990s when computers were embedded with the telecommunication technologies (Anderson, 2009). The computer-mediated generation made it possible for the first time to teach face-to-face at a distance (Keegan, 1995). The revolution of telecommunication technologies with the embedding of computers helped the expansion of real-time, two-way, audio and video communication in distance education (Simonson et al., 2009). These capabilities of telecommunication technology combined with the power of computer systems started a new era of distance education and gave rise to the subsequent generation of distance education (Annand, 1999; D. Garrison, 1997). In addition, educators were more focused on learner-centred approaches. Therefore, from the pedagogical perspective, a number of factors contributed to the emergence of the new generation. According to Anderson and Dron (2011), some of the factors were: the growing need for greater learner presence, participation and control in the education process; the changing role of teachers from sole content creator to guide and group moderator; and the developing demand for different learning activities, such as discussion, creation and construction rather than just reading and watching. Despite different interpretations, Anderson and Simpson (2012) recognise the greater group interaction and social construction of knowledge as the central focus of the distance educators in the computermediated generation in the 1990s. 


\subsubsection{Subsequent generations of distance education and the New Zealand context}

More recently, the networking of computers with telecommunication technologies has fostered conversation and collaboration, allowing learners to connect and engage in discussions, and respond to the educational materials and feedback (Sumner, 2000). The possibility of connecting and clustering of distance education participants has not only helped learners to take control of and responsibility for their learning but also created a paradigm shift (Garrison, 1997). That is because distant learners became active processors of information (constructivist theory) rather than being passive recipients only (behaviourist theory) (Guri-Rosenblit, 2009; Jonassen et al., 1995). In short, none of these generations has been completely eliminated; rather the choices of technology and media increased (Anderson and Dron, 2011). For example, in New Zealand, which is a thinly populated country, TCS started around 100 years ago and still exists in 2016 . The correspondence programme first started in New Zealand in the early $20^{\text {th }}$ Century through the establishment of the International Correspondence Schools (Anderson \& Simpson, 2012; Bewley, 1996). This initiative was based overseas and was followed by the New Zealand Correspondence School (NZCS) programme in 1922 (Anderson \& Simpson, 2012; Bewley, 1996). After nearly a century and evolving through different generations, the programme remains "New Zealand's largest distance learning provider in the school sector with a roll of 16,000" students from years 1-13 (Roberts, 2009). However, the programme is criticised for not playing "a pivotal role in the development of online learning communities" (Roberts, 2009) and trailing in terms of innovation and learning effectiveness.

The Learning Exchange programme belongs to the subsequent generation of distance education in New Zealand. The ICT-mediated programme has a key focus on collaborative and connected learning through the formation of clusters of distance learners and educators. In other words, a clear connection exists between the Learning Exchange programme and the subsequent generations of distance education with learner-centred approaches. Before exploring the literature regarding the Learning Exchange and its underpinning concepts, the next section provides a review of literature on the adoption of ICTs in schools.

\subsection{Adoption of ICTs in Schools}

Schools in the developed countries have embraced ICTs for a number of obvious reasons, including the modernisation of technological infrastructure, organisational administration and management, and facilitating transformative pedagogies. As described by Voogt and Knezek (2008), the early focus of schools' adoption of ICTs was on 'learning to use IT' while later the focus was on 'using ICT to learn'. From that perspective, the initial phases of adoption were mainly about the emergence and 
application of ICTs in schools, whereas the infusion and transformation are more recent areas where leaders are focusing. "Notwithstanding certain tensions between the goals of governments and those of educators, ICTs are becoming more and more enmeshed in teaching and learning" (Pegrum, Oakley, \& Faulkner, 2013, p. 66). Before discussing the technological, organisational and pedagogical aspects, the following sub-section reviews the literature regarding the range of ICTs adopted and used in schools, particularly in the distance education and online learning context rather than a general school context.

\subsubsection{Range of ICTs in schools}

Voogt and Knezek (2008) define ICTs as all technologies used for communicating and processing information, including creation, storage and exchange of information. Since most of the recent technologies used for teaching and learning in schools are interactive and support collaborative learning, this study categorises ICTs differently, based on their synchronicity capabilities. Some technologies allow synchronous and some asynchronous teaching and learning processes. Some examples of technologies or technological settings supporting synchronous activities include: live two-way audio- and video-conference; digital telephoning using Voice over Internet Protocol (e.g., Skype); and scheduled, real-time, text chat using an online discussion forum or social networking sites such as Facebook (Murphy et al., 2011). According to Dennis, Fuller and Valacich (2008), technologies with synchronous capabilities are used for spontaneous, simultaneous and interactive communication and exchange of information between two or more sites.

Unlike the synchronous technologies, those with asynchronous capabilities have the anytime rather than the same-time feature. The anytime capability of the asynchronous systems means that both the learners and instructors or the recipients and deliverers of information are independent in choosing their own time (Carswell \& Venkatesh, 2002). Because of the flexibility, Moonen (2008) considers asynchronous systems as "complementary technologies" that can be used for searching the Internet for course content, using a graphic application or supporting the creation of a music track (Moonen, 2008, p. 1072).

According to a survey of distance education instructors by Branon and Essex (2001), the reasons for asynchronous communication include: encouraging in-depth, more thoughtful discussion; communicating with temporally diverse students; holding on-going discussions where archiving is required; and allowing all students to respond to a topic. Therefore, the capabilities of the asynchronous technologies make the category suitable for the conveyance process involving individuals to reflect on the meaning of the information (Dennis, Fuller \& Valacich, 2008). The flexibility of anytime and anyplace thus remains suitable for individuals to take time and understand 
the meaning of any content. Because of the 'anyplace and anytime' aspect and the separation between information deliverers and recipients, Kanuka and Conrad (2003) regard the asynchronous type as a 'distributed learning' process.

Branon and Essex (2001) compared and found some limitations regarding both the synchronous and asynchronous technologies and communication processes, and therefore suggested a combined use of both categories. Examples of the synchronous process's limitations included getting participants online at the same time, difficulty in moderating large-scale conversations, lack of reflection time for participants and some others. On the other hand, examples of the asynchronous process's limitations included lack of immediate feedback, students not checking in often enough, the length of time necessary for discussion to mature, and students feeling a sense of social disconnection (Branon \& Essex, 2001). Therefore, Dennis, Fuller and Valacich (2008) and Chen and Willits (1999) suggest a combined approach while using the tools not only for providing additional means but also producing effective results.

Because of viewing ICTs as complementary and supplementary technologies, they need to be embedded in the learning environment, including the teaching and learning process (Voogt \& Knezek, 2008). For the embedding purpose, demands have increased for the development of the educational technologies and applications that can support collaborative, connected and ubiquitous learning (Resta \& Laferrière, 2007). Ubiquitous learning is defined as the potential of educational technologies to make learning possible at any time and at any place (Voogt \& Knezek, 2008). As a result, a change is happening in the development of technology as well as the effective uses of it for improved educational outcomes.

\subsubsection{Technological aspects of ICT adoption in schools}

As reported by Campbell (2004), the application of ICTs in schools in New Zealand slowly started around the early 1980s when enthusiastic teachers began to use computers and explored the possibilities of using them in their classrooms. On the other hand, school administration staff were interested in using ICTs for the management of their organisational processes (Tilya, 2008). However, because of the limited access, their use remained limited to teachers and school administration staff only. Later, with the arrival of the Internet and wider computer use in the 1990s, accessibility and connectivity aspects of ICTs for wider use in schools became a focus for educators as well as governments. The networking of computers followed by the development of broadband Internet and more recently ultrafast broadband further highlighted the subject of ICT accessibility and connectivity for educational and management activities in schools around the world. 
Specifically, in the 1990s, governments from around the world were more concerned about achieving a specific target, such as the accessibility ratio of computers to students. As a result, infrastructure development or modernisation was the main investment focus. For example, most of the secondary schools in England had a better computer-to-student ratio of 1:3.7 in 2005 compared to 1:5.9 in 2002 (Condie \& Munro, 2007). Similarly, according to Condie and Munro (2007), computer-Internet connectivity in secondary schools in England had increased from $64 \%$ to $86 \%$. In New Zealand, the computer-to-student ratio was reported to be 1:6.3 in 2002 (Lai \& Pratt, 2004). According to Powell (2011), building ICT infrastructure and educators' capability were the two key components of the MOE's 1998 ICT strategy for schools in New Zealand (see table 2.2 in section 2.3.4). As another example, in 2004 , "over $90 \%$ of all U.S. schools had Internet connections in classrooms [...and] $77 \%$ of schools reported that at least half of their teachers used the Internet for instruction" (Roblyer, 2008, p. 695). Other ICT related targets included websites for schools and more recently, laptops-to-teachers ratios and the use of mobile handheld devices for learning (also referred to as m-learning) are the key focus (Pegrum et al., 2013).

Later, besides increasing the accessibility, the focus of governments included the reliability and effectiveness of the ICT infrastructure in schools. For that reason, access to "reliable, sustainable, efficient and appropriate ICT equipment, systems and services that meet [schools'] current and emerging needs became a key priority of the MOE and schools (Ministry of Education, 2003, p. 21). For the effective use and integration of ICTs into classrooms, increasing opportunities for professional development of school teachers became a major part of the New Zealand Government's strategy from 1998 until 2007 (Ham, 2008). The programme is known as the ICTPD or Information and Communication Technology Professional Development. (The programme is discussed later in this chapter).

More recently, efforts for the development of ICT infrastructure in schools are directed towards increasing the number of school-owned portable devices and improving wireless Internet connectivity. In addition, setting policies for using those devices as well as social networking sites such as Facebook and a personally owned device under BYOD (bring your own device) under the scheme of 'enabling e-learning' are some of the main areas scholars and school leaders are currently addressing (Hopkins, Sylvester, \& Tate, 2013). Similarly, a recent initiative by the MOE in New Zealand was to ensure that $95 \%$ of schools get access to ultrafast broadband by 2016 (Barbour \& Wenmoth, 2013). 


\subsubsection{Organisational and administrational aspects}

Although currently ICTs are mainly applied and viewed as mediators complementing teaching and learning processes, the application of ICTs for the organisation and administration purposes of schools should not be overlooked. According to Tilya (2008), the managerial use of ICTs was one of the main driving forces behind the adoption of technologies in schools. However, a literature review by Passey (2002) identified relatively little research that considered ICT with respect to school management and administration. A similar gap exists in the current literature. For example, according to ten Brummelhuis and Kuiper (2008, p. 98), "Four key elements determine the learning process: the teacher, the student as a learner, the learning content [in terms of what has to be learned] and the learning materials [including ICT infrastructure]". The authors did not consider the organisational and management aspect, such as ICTs for course design and administration of assessment processes. Instead, they regard the aspects as "the context or environment of the learning process". The rationale seems to be one of the possibilities behind the knowledge gap in the literature.

Notwithstanding, a school as an organisation - the context or environment - has administrative and management staff members who need to use ICTs for performing their responsibilities. Based on National Educational Technology Standards for Administrators (NETS- $\mathrm{A}^{2}$ ) in the USA, Thomas and Knezek (2008) report a number of standards for effective school leadership and administration for the comprehensive and appropriate use of technology in schools. Besides the development of digital age teaching and learning culture, school leaders are expected to adopt and apply ICTs for the development of visionary leadership, enhancement of productivity and professional practice, supporting management, operational improvement, assessment and evaluation, and understanding of social, legal and ethical issues (Thomas \& Knezek, 2008).

Specifically, ICTs are used for administrative functions in schools for various internal and external reasons (Strudler \& Hearrington, 2008). The internal purposes include coordinating school activities, performing individual responsibilities, exchanging information, internal communication and so on. Hoque et al. (2012) found administration of student assessments, preparation of student reports, accessing of information and communication as the main reasons behind the administrative use of ICTs in schools in the Maldives. On the other hand, external purposes include communication and coordination with key stakeholders as well as addressing the challenges of competition, cooperation and collaboration with their neighbouring schools.

\footnotetext{
2 NETS-A was published by the International Society for Technology in Education (ISTE), NETS Project. http://www.iste.org/standards/standards/standards-for-administrators
} 
In the context of this study, the organisational factors remain equally relevant as school leaders rely heavily upon the uses of ICTs for overcoming their geographical isolation via forming clusters or virtual collaborative groups of small rural schools.

\subsubsection{Pedagogical aspects}

Blended, virtual, collaborative, connected and ubiquitous learning are some of the pedagogical concepts driving the introduction and embedding of ICTs in laboratories and classrooms. As a result, the nature of education and the concept of learners and learning in school have been transformed in a paradigm shift. For example, 'ICT competence' has become a key part of the school curriculum and a general capability for students from developed countries (Pegrum et al., 2013). On the other hand, educational technologies are being designed to encompass the transformation of the teaching and learning process with more learner-centred approaches.

Some educationalists suggest a blended learning (also referred to as hybrid learning) approach in which face-to-face classroom learning is enhanced by supplementary online activities. According to Al-busaidi (2012), the adoption of ICT-based systems such as a Learning Management System is a great addition both for distance and face-to-face education. That is because on the one hand, the use of such systems supports distance education and on the other hand they supplement the traditional face-to-face education. In the blended or hybrid approach, integrated use of the face-toface instructional system with synchronous or asynchronous learning systems adds value to and augments the face-to-face education by improving the teaching and learning outcomes and making the education process more interactive. Further, the blended approach makes the teaching and learning resources accessible anytime and anywhere. In the context of schools in New Zealand, studies have found Moodle and KnowledgeNet are the two main learning management systems increasingly used for supporting students as well as the blended learning approach (Bolstad \& Lin, 2009; Stevens, 2011).

Scholars and learning style theorists have redefined learning as a process that can better take place in collaboration or groups rather than in isolation. According to the social learning theory, "knowledge is not abstract; instead, it is rooted in context and culture i.e. it is situated" (Nilsen \& Purao, 2005, p. 4). Subsequently, governments and educators are increasingly emphasising the development of students as well-informed and well-connected global citizens (Pegrum et al., 2013). Because of the redefinition, school leaders and practitioners are also emphasising the role of ICTs for increased connectivity between learners, educators and learning materials and thereby facilitating the development of a virtual, collaborative, group learning environment (Wenmoth, 2010). 
In the context of New Zealand, the concepts of 'Connected and Networked schools' suggested by Wenmoth (2010) can be seen as a very relevant and recent example, linking the adoption of ICTs in schools and the pedagogical aspects. Figure 2.1 adopted from Wenmoth (2010) illustrates the difference between Traditional, Connected and Networked Schools.

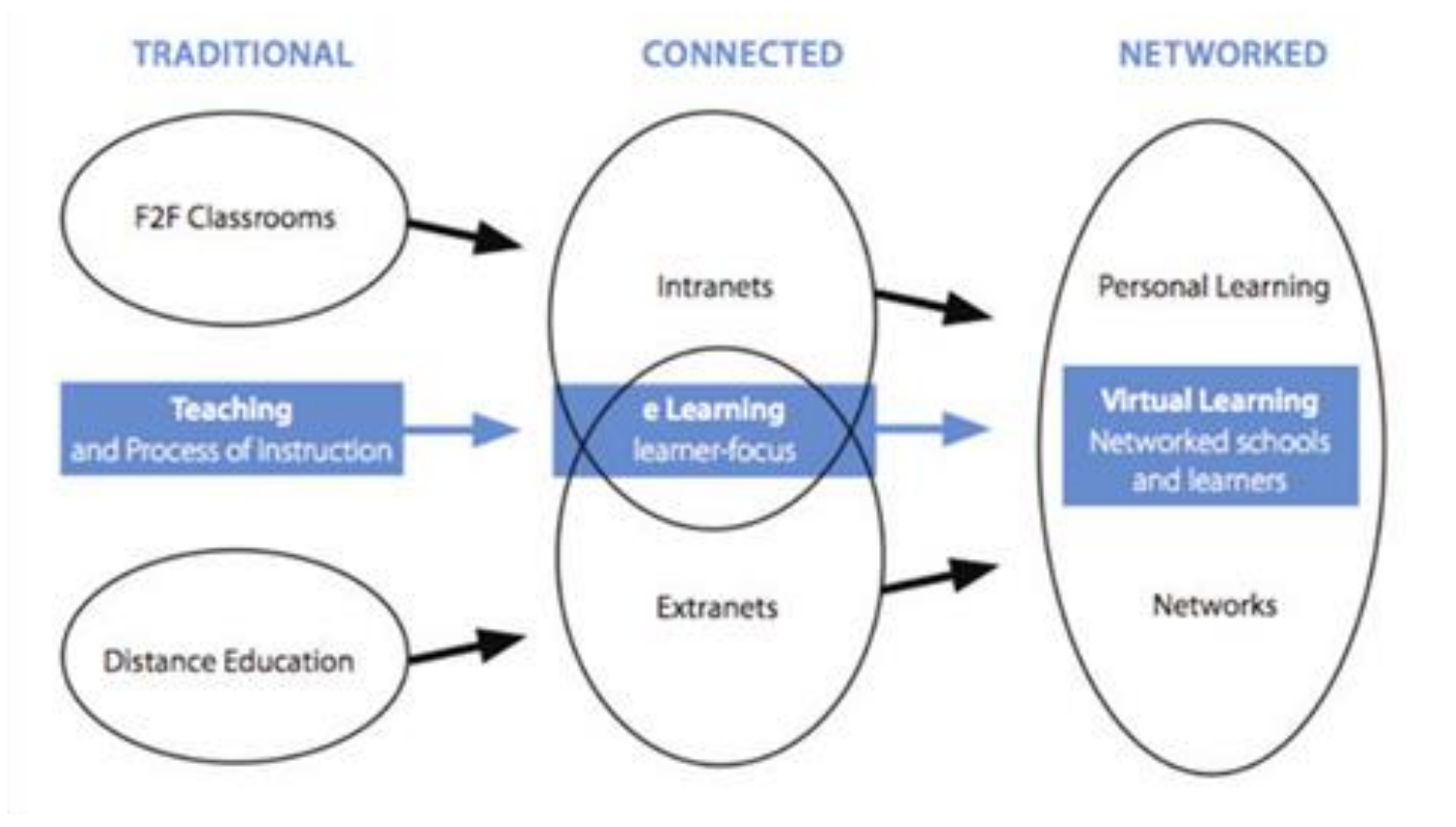

Figure 2.1 Emerging trend of Networked Schools

Barbour and Wenmoth (2013) define a connected school as one that combines physical and (virtual) distance schools. In a connected school students mostly attend classes in the physical premises of schools, however they may take one or more virtual courses as well. The Ministry of Education's (2011) guide book for the VLN community describes connected schools as being unlike traditional schools because the place of learning is not necessarily the same as the source of learning. As an example, a virtual meeting of students in a law class with a lawyer in his/her workplace from a different part of the country/world is a connected learning situation in which the place and the source of learning are different.

In this type of educational approach, the learner's perception about schools is also different. The idea of schools connected with the rest of the world from a learner's perspective is that the out-of-school world is richer than the school's world (Underwood et al., 2009). Similarly, from the angle of connected schools, the world can be a classroom so that the learning occurs in the real world context. In traditional schools' style of education, the boundaries between face-to-face and distance education are clear. However, the boundaries between face-to-face, distance education and the focus of teaching and learning start disappearing in the connected schools. That is because traditional face-to- 
face school education has some form of distance education through virtual means; the focus of education has changed to a learner-centred approach; and the boundaries between the three have some degree of overlap, albeit still distinguishable. That is because most of the students' time in a connected school's day still revolves around the traditional school system with students having very few experiences of real world learning.

In the networked school model the boundary between face-to-face and distance education converges and becomes seamless (Barbour \& Wenmoth, 2013). The source and place of learning remain different. In other words, schools and the virtual world are integrated as schools become places students visit to access learning from the outside world. Apart from the differing nature of the three schooling models, there are other aspects that distinguish these models: the uses of technology, the role of teachers, grouping of learners and learning resources. Table 2.1 adopted from Wenmoth (2010) provides a detailed comparison between the three schooling models and "illustrates more clearly where some of the differences lie, and teases out in more detail the areas of schooling that are likely to be challenged during the next decade or so" (p. 200).

Table 2.1 Comparison of the three schooling models

\begin{tabular}{|c|c|c|c|}
\hline & Traditional School & Connected School & Networked School \\
\hline $\begin{array}{l}\text { Nature of } \\
\text { school }\end{array}$ & $\begin{array}{l}\text { - Schools perceived as } \\
\text { physical sites of } \\
\text { learning } \\
\text { - Face-to-face } \\
\text { instruction regarded as } \\
\text { the 'norm', distance } \\
\text { education accepted as } \\
\text { 'second best' or what } \\
\text { you do if you cannot } \\
\text { attend face-to-face } \\
\text { classes } \\
\text { - Schools as } \\
\text { independent entities, } \\
\text { catering for all the } \\
\text { needs of their students }\end{array}$ & $\begin{array}{l}\text { - Schools remain as } \\
\text { physical sites of learning, } \\
\text { with emerging models of } \\
\text { connectivity between and } \\
\text { among school sites. } \\
\text { - 'E-enabled } \\
\text { opportunities for learning } \\
\text { embraced in traditional } \\
\text { settings } \\
\text { - Schools as collaborating } \\
\text { entities, negotiating areas } \\
\text { of collaboration; physical } \\
\text { sites of learning with } \\
\text { emerging models of } \\
\text { connectivity between and } \\
\text { among school sites }\end{array}$ & $\begin{array}{l}\text { - Networks of schools } \\
\text { and learners - accepted } \\
\text { models of differentiation } \\
\text { between places to learn } \\
\text { and sources of learning } \\
\text { and instruction } \\
\text { - Schools as nodes on a } \\
\text { network - integrally } \\
\text { connected as consumers } \\
\text { and contributors } \\
\text { - Ubiquitous presence - } \\
\text { complete integration of } \\
\text { physical/virtual nature of } \\
\text { school }\end{array}$ \\
\hline Governance & $\begin{array}{l}\text { - Centralised control } \\
\text { and governance } \\
\text { - Bureaucratic systems } \\
\text { and structures }\end{array}$ & $\begin{array}{l}\text { - Localised control and } \\
\text { governance } \\
\text { - Independent and } \\
\text { autonomous }\end{array}$ & $\begin{array}{l}\text { - Distributed control and } \\
\text { governance } \\
\text { - Interdependent and } \\
\text { collaborative }\end{array}$ \\
\hline
\end{tabular}




\begin{tabular}{|c|c|c|c|}
\hline Technology & $\begin{array}{l}\text { - Technology } \\
\text { appropriated by schools } \\
\text { in an additive manner; } \\
\text { schools/ teachers are in } \\
\text { charge of it } \\
\text { - Online environments } \\
\text { used for resource } \\
\text { location - the "online } \\
\text { encyclopaedia" }\end{array}$ & $\begin{array}{l}\text { - Technology } \\
\text { appropriated by schools } \\
\text { to create new learning } \\
\text { and teaching } \\
\text { opportunities; student } \\
\text { access and use a priority } \\
\text { - Online learning } \\
\text { environments } \\
\text { appropriated for use as: } \\
\text { o Intranets in schools, } \\
\text { providing student } \\
\text { access to resources and } \\
\text { support and as parent } \\
\text { portal } \\
\text { o Extranets, e.g. Learning } \\
\text { management systems } \\
\text { (LMS) for distance ed. } \\
\text { provision }\end{array}$ & $\begin{array}{l}\text { - Student appropriation } \\
\text { of technology - they } \\
\text { choose what, where, } \\
\text { when and how it is it } \\
\text { used } \\
\text { - Online environments } \\
\text { managed by learners } \\
\text { utilising existing and } \\
\text { emerging social } \\
\text { networking features }\end{array}$ \\
\hline $\begin{array}{l}\text { Role of } \\
\text { teacher }\end{array}$ & $\begin{array}{l}\text { - Teacher's primary role } \\
\text { as instructor } \\
\text { - Teachers as } \\
\text { generalists - including } \\
\text { subject matter expert, } \\
\text { pastoral care, } \\
\text { programme designers } \\
\text { and managers }\end{array}$ & $\begin{array}{l}\text { - Role of teacher } \\
\text { changing to facilitator, } \\
\text { guide, mentor etc. } \\
\text { - Emergence of specialist } \\
\text { teacher roles (subject } \\
\text { matter experts, 'e'- } \\
\text { principals etc.) }\end{array}$ & $\begin{array}{l}\text { - Role of teacher as } \\
\text { 'experienced' learner - } \\
\text { participant in the } \\
\text { learning process } \\
\text { - Teachers as specialists: } \\
\text { 'e'- teachers, 'm'- } \\
\text { teachers and 'c'-teachers }\end{array}$ \\
\hline $\begin{array}{l}\text { Organisation } \\
\text { of learner }\end{array}$ & $\begin{array}{l}\text { - Focus on teaching } \\
\text { classes of students in } \\
\text { age-based groupings }\end{array}$ & $\begin{array}{l}\text { - Focus on teaching } \\
\text { classes of students in age- } \\
\text { based groupings }\end{array}$ & $\begin{array}{l}\text { - Vertical groupings of } \\
\text { students, with focus on } \\
\text { interest/ability groups - } \\
\text { stage, not age }\end{array}$ \\
\hline Curriculum & $\begin{array}{l}\text { - Curriculum tends to } \\
\text { be factual, knowledge } \\
\text { based } \\
\text { - Organisation of } \\
\text { knowledge into } \\
\text { 'subjects', presented as } \\
\text { courses }\end{array}$ & $\begin{array}{l}\text { - Competency-based } \\
\text { curriculum, framework of } \\
\text { qualifications } \\
\text { - Subjects and courses } \\
\text { remain, with increased } \\
\text { use of themes and } \\
\text { integration. }\end{array}$ & $\begin{array}{l}\text { - Emergent and } \\
\text { 'negotiated' curriculum } \\
\text { - Many options and } \\
\text { choices, with granular } \\
\text { approach }\end{array}$ \\
\hline $\begin{array}{l}\text { Learning/ } \\
\text { instructional } \\
\text { design }\end{array}$ & $\begin{array}{l}\text { - Emphasis on teacher- } \\
\text { centred instruction, and } \\
\text { 'delivery' }\end{array}$ & $\begin{array}{l}\text { - Emphasis on } \\
\text { personalising learning, } \\
\text { and on understanding } \\
\text { acts of learning }\end{array}$ & $\begin{array}{l}\text { - Emphasis on student- } \\
\text { centred learning and } \\
\text { 'participation' } \\
\text { - Focus on 'mass } \\
\text { personalisation' to } \\
\text { address issues of scale } \\
\text { and sustainability }\end{array}$ \\
\hline
\end{tabular}




\begin{tabular}{|c|c|c|c|}
\hline $\begin{array}{l}\text { Resources of } \\
\text { learning }\end{array}$ & $\begin{array}{l}\text { - Copyrighted, 'owned' } \\
\text { - authoritative } \\
\text { - Expensive } \\
\text { - Require physical } \\
\text { storage } \\
\text { - Need to 'endure' as } \\
\text { physical artefacts }\end{array}$ & $\begin{array}{l}\text { - Increasing sharing of } \\
\text { resources based on issues } \\
\text { of cost and currency of } \\
\text { information } \\
\text { - Move to electronic } \\
\text { access and storage }\end{array}$ & $\begin{array}{l}\text { - Open education } \\
\text { resources } \\
\text { - Creative commons } \\
\text { licensing } \\
\text { - Available from the } \\
\text { 'cloud' } \\
\text { - Always current, } \\
\text { includes teacher created } \\
\text { and student created } \\
\text { resources }\end{array}$ \\
\hline $\begin{array}{l}\text { Learning } \\
\text { activity }\end{array}$ & $\begin{array}{l}\text { - Learning in artificial, } \\
\text { isolated contexts } \\
\text { - - Learning as a passive } \\
\text { activity - meeting } \\
\text { external expectations }\end{array}$ & $\begin{array}{l}\text { - Learning as an active } \\
\text { process - directed } \\
\text { by/with students }\end{array}$ & $\begin{array}{l}\text { - Learning in authentic } \\
\text { real world context }\end{array}$ \\
\hline $\begin{array}{l}\text { Assessment } \\
\text { of learning }\end{array}$ & $\begin{array}{l}\text { - Tests and external } \\
\text { assessments to meet } \\
\text { standards set by } \\
\text { examiners } \\
\text { - Paper-based, end of } \\
\text { year assessments } \\
\text { prevail }\end{array}$ & $\begin{array}{l}\text { - Mix of internal and } \\
\text { external assessments } \\
\text { - Standards-based } \\
\text { approaches, with rubrics } \\
\text { outlining levels of } \\
\text { achievement supported } \\
\text { by evidence }\end{array}$ & $\begin{array}{l}\text { - Students set learning } \\
\text { goals and participate in } \\
\text { development of rubrics } \\
\text { - Life-long portfolios of } \\
\text { evidence owned and } \\
\text { managed by learners }\end{array}$ \\
\hline
\end{tabular}

The appropriation of technology is another aspect that distinguishes the three models. In the traditional school's model, apart from the minimal use, technology is appropriated by the educators for learners to adopt. In a connected school, technology for learners is also appropriated by the educators; however, the use level remains higher. In the networked school's model, learners decide the appropriation and use of technologies, depending on their personal learning style. The comparison indicates that the networked schools involve a greater level of personalisation as compared to connected schools.

The role of teachers continuously evolves in the three school models. In a connected school, teachers facilitate students in their classrooms and assist students with learning materials. The facilitation provides students with some level of control over the class activities. The role of teacher considerably changes in the networked school model where teachers perform as experienced learners during educational processes and are referred to as e-teachers, $\mathrm{m}$-teachers and c-teachers (' $c$ ' means cloud, ' $\mathrm{m}$ ' means mobile and ' $\mathrm{e}$ ' means electronic).

Similarly, personalisation of learning in the networked school model is also evident from the organisation of learners and learning resources, activities and assessment. In the network school model, students are grouped based on their interests and abilities. Learning resources remain 'open' and always 'current' as the curriculum is continuously negotiated by teachers and students (Ministry 
of Education, 2011). These attributes reflect the depth of personalised learning proposed in the networked school model.

From the above literature review it can be concluded that approaches to school education have evolved and new approaches have emerged since the adoption of ICTs for school education. Broadband Internet has been used to support and connect physically isolated classrooms with the rest of the world. The move has not only supplemented the face-to-face classroom education but has also brought together distance and school education. Schools are better connected and able to exchange their learning resources with the outside world. As a result, school education has become a collaborative learning process. However, the transformation will require schools and policy makers to be more flexible and adaptive with their approaches. Their approach should reflect innovative uses of technologies and active participation of learners during the overall teaching and learning processes.

Only some of the above attributes exist in school practice. As described by Wenmoth (2010), some of the areas are yet to be tested. Similarly, level of shift or transformation of schools from a connected to networked model might not be very visible. Specifically, attempts to investigate the above emerging pedagogies with respect to the cluster classes in the Learning Exchange might also be premature. A study by Stevens (2011) found little evidence of innovative practice in networked schools. Attempts made by this study were unsuccessful in identifying substantial evidence from the literature examining the Learning Exchange programme with regard to the transformation of schools. Any such evidence could have assisted in suggesting the link between the VC-based classes and the networked school model.

Moreover, from a global perspective, the concept of connected and networked schools is a potential development in the virtual school trend that needs to be investigated. Therefore, as indicated by Garrison and Archer in 2007, this study is needed to find and interpret the new forms of educational practices that have emerged due to interactive communications technologies.

To conclude the section, a confluence of technological, organisational and pedagogical factors drove the adoption and continued use of ICTs in school education. The introduction and use of ICTs in school education followed a series of steps or phases. As suggested by Tilya (2008), the phases included an 'emerging phase' in which administrators and teachers explored the possibilities of using ICTs for school management and delivering the curriculum. In the 'applying' phase, ICTs were used for augmenting the tasks already carried out in school management and in the curriculum. The 'infusing' step involved the embedding of ICTs in laboratories, classrooms, and administrative offices. In the end, the 'transforming' phase involves the adoption of ICTs for learner-centred 
educational approaches. The Learning Exchange programme belongs to one of the transforming phase approaches. Table 2.2 adopted from Powell (2011) gives a snapshot of the key components of various MOE strategies with respect to the adoption and uses of ICTs in New Zealand schools. In particular, the table highlights a shift in focus over nearly 10 years, for example, from ICT infrastructure building in 1998 to the contribution of e-learning in 2006.

Table 2.2 New Zealand Ministry of Education's ICT Strategies and Components (Powell, 2011)

\begin{tabular}{|c|c|c|c|c|c|}
\hline $\begin{array}{l}\text { NZ MOE ICT } \\
\text { Strategies }\end{array}$ & Year & $\begin{array}{l}\text { Key } \\
\text { Component \#1 }\end{array}$ & $\begin{array}{l}\text { Key } \\
\text { Component \#2 }\end{array}$ & $\begin{array}{l}\text { Key } \\
\text { Component \#3 }\end{array}$ & $\begin{array}{l}\text { Key } \\
\text { Component } \\
\# 4\end{array}$ \\
\hline ICT Strategy & 1998 & $\begin{array}{l}\text { Develop the } \\
\text { use of ICT in } \\
\text { Schools }\end{array}$ & $\begin{array}{l}\text { Build } \\
\text { Infrastructure }\end{array}$ & $\begin{array}{l}\text { Build School } \\
\text { Capability }\end{array}$ & $\begin{array}{l}\text { Enable } \\
\text { educators to } \\
\text { gain skills and } \\
\text { insight into } \\
\text { potential of } \\
\text { ICT in } \\
\text { education }\end{array}$ \\
\hline $\begin{array}{l}\text { The Digital } \\
\text { Horizons } \\
\text { Learning } \\
\text { Through ICT }\end{array}$ & 2002 & $\begin{array}{l}\text { Improve } \\
\text { learning } \\
\text { experiences } \\
\text { and outcomes } \\
\text { for all students }\end{array}$ & $\begin{array}{l}\text { Support } \\
\text { educators in } \\
\text { integrating } \\
\text { ICT into } \\
\text { curriculum } \\
\text { and } \\
\text { management } \\
\text { practices }\end{array}$ & $\begin{array}{l}\text { Increase } \\
\text { efficiency and } \\
\text { effectiveness } \\
\text { of educational } \\
\text { management } \\
\text { and } \\
\text { administration }\end{array}$ & $\begin{array}{l}\text { Develop } \\
\text { partnerships } \\
\text { with } \\
\text { communities, } \\
\text { businesses } \\
\text { and other } \\
\text { stakeholders }\end{array}$ \\
\hline $\begin{array}{l}\text { ICT Strategic } \\
\text { Framework for } \\
\text { Education }\end{array}$ & 2006 & $\begin{array}{l}\text { Provide a } \\
\text { mechanism to } \\
\text { guide and co- } \\
\text { ordinate ICT } \\
\text { investment }\end{array}$ & $\begin{array}{l}\text { Provide a } \\
\text { strategy for } \\
\text { effective and } \\
\text { integrated use } \\
\text { of ICT across } \\
\text { all parts of the } \\
\text { education } \\
\text { sector }\end{array}$ & $\begin{array}{l}\text { Improve } \\
\text { learner } \\
\text { achievement } \\
\text { in an } \\
\text { innovative } \\
\text { education } \\
\text { sector, fully } \\
\text { connected and } \\
\text { supported by } \\
\text { the smart use } \\
\text { of ICT }\end{array}$ & \\
\hline $\begin{array}{l}\text { Enabling the } \\
21^{\text {st }} \text { Century } \\
\text { Learner: An e- } \\
\text { Learning } \\
\text { Action Plan for } \\
\text { Schools 2006- } \\
2010\end{array}$ & 2006 & $\begin{array}{l}\text { Describes the } \\
\text { goals for e- } \\
\text { learning in } \\
\text { schools and the } \\
\text { projects, tools, } \\
\text { and resources } \\
\text { that are being } \\
\text { developed to } \\
\text { address those } \\
\text { outcomes }\end{array}$ & $\begin{array}{l}\text { Demonstrates } \\
\text { how e- } \\
\text { learning can } \\
\text { contribute to } \\
\text { the Schooling } \\
\text { Strategy and } \\
\text { its priorities } \\
\text { for the next } \\
\text { five years }\end{array}$ & $\begin{array}{l}\text { To build an } \\
\text { education } \\
\text { system that } \\
\text { equips New } \\
\text { Zealanders } \\
\text { with } 21^{\text {st }} \\
\text { century skills, } \\
\text { through the } \\
\text { increased use } \\
\text { of e-learning } \\
\text { in schools }\end{array}$ & \\
\hline
\end{tabular}

\subsection{The Learning Exchange in New Zealand}

This section reviews the literature relevant to the cluster theory, the Learning Exchange programme in New Zealand and online learning around the world. In doing so, this section reviews some of the 
online educational approaches and concepts underpinning the initiation and transformation of the Learning Exchange.

\subsubsection{Collaborative learning}

In the above sections, a collaborative learning approach was identified as one of the key elements in computer-mediated distance education and the evolution of learning theories, in particular the social constructivist perspective. In addition to these relations, since the approach remains a founding concept in the initiation and development of the Learning Exchange programme and clusters, it needs to be discussed here.

From a general perspective, Dillenbourg $(1999$, p. 1) defines collaborative learning as "a situation in which two or more people learn or attempt to learn something together" (original emphasis). With the emphasis on the words 'situation', 'two or more', 'learn' and 'together', Dillenbourg (1999) emphasises that the words are interpreted differently by different scholars depending on the context and discipline. Therefore, a specific description of the approach remains highly contextual. For example, the words 'two or more' can refer to a pair, a group of 3-5 students or staff members, a class of 30 students or a community of teachers. Similarly, the word 'together' can refer to the faceto-face or computer-mediated synchronous or asynchronous grouping. Other scholars, such as Resta and Laferrière (2007) also agree with the complexity of the collaborative learning concept and note that "At the outset of this review, it must be acknowledged that collaborative learning is a complex concept and not a clearly defined one" (p. 66).

Therefore, a specific description of collaborative learning as one of the key underlying concepts in the Learning Exchange is similarly difficult and would be inconsistent if outlined here. That is due to a number of reasons:

1. The Learning Exchange participants are students, teachers, management staff members and schools.

2. They use a range of ICTs with both synchronous and asynchronous capabilities.

3. They form groups by themselves and are grouped by their cluster leaders both in online and face-to-face environments.

4. Their formal gatherings for solving or learning about a problem can be from a few minutes to one hour, once a week, for the whole school year.

5. The number of participants in their groups varies.

6. Actual learning can be from course material or based on discussions and sharing of experiences. 
7. Lastly, participants in the Learning Exchange can be students in a class or teachers in a professional development workshop.

Therefore, the explanation better describes collaborative learning in the Learning Exchange context rather than having a broad definition such as the one described in the second paragraph by Dillenbourg (1999).

Nonetheless, computer-supported collaborative learning (CSCL) or computer-mediated collaborative learning ( $\mathrm{CMCL}$ ) seems more relevant to the Learning Exchange, allowing identification of some commonalities and consensus. For example, according to Resta and Laferrière (2007), CSCL is a mode of collaborative learning that has a focus on "how technology can facilitate the sharing and creation of knowledge...through peer interaction and group learning processes" (p. 67). In addition, a CSCL process uses ICTs to "support asynchronous and synchronous communication between students oncampus as well as students who are geographically distributed...[in order to] provide an environment that supports collaboration between students to enhance their learning processes" (p. 67). These descriptions provide a better and more specific explanation of the collaborative learning that is happening in the Learning Exchange. Regarding the associated challenges, Stahl, Koschmann, and Suthers (2006) admit that combining two big ideas - computer support and collaborative learning for effective and enhanced learning remains a challenge. The authors, however, accept that CSCL is designed to address the challenge.

To move beyond the breadth of definitions and discuss common elements, collaborative learning is an educational approach that emphasises interaction in a social or group environment (Garrison, 1997). In other words, it is the pedagogical approach in which participants construct knowledge in groups through dialogue, negotiation, observation, experience and communication. Therefore, collaborative learning is an interactive process in which the emphasis is on the existence of various sources of information, including the curriculum rather than teachers or course material only. In addition, the approach involves well-defined, joint problem-solving tasks in which "learning is expected to occur as a side-effect of problem solving, measured by the elicitation of new knowledge or by the improvement of problem solving performance" (Dillenbourg, 1999, p. 4). Therein, collaborative learning does not cover activities such as sharing course assignments between students or a VC class 'led and not facilitated' by a teacher without any contribution from students. Those instances could be regarded as instant interaction or group teaching, but not collaborative learning. 


\subsubsection{Cluster Theory and the New Zealand context}

The formation of regional school clusters for computer-supported virtual collaborative learning remains one of the key strategies underpinning the initiation and development of the Learning Exchange. The concept of the cluster might be relatively new for schools or the education sector, but not for the international business community. According to Kuah (2002) and other scholars, the concept of clusters relates to Alfred Marshall's book in 1890, 'Principles of Economics', which refers to clusters as Industrial Districts. According to Marshall 1890 quoted in Bahlmann and Huysman (2008, p. 305), business clusters or industrial districts are "the concentration of large numbers of small businesses of a similar kind in the same locality". The availability of physical resources, labour, knowledge or suitable climate are the possible reasons for the adoption of such strategic groupings. More recent literature recognises Michael Porter's work, The Competitive Advantage of Nations (Porter, 1990), as the key source of changing ideas about the cluster. The new aspect he highlighted was 'competitiveness' (Bahlmann \& Huysman, 2008; Lazzeretti, Sedita, \& Caloffi, 2013).

Porter (2000, p. 15) defines clusters as "geographic concentrations of interconnected companies, specialized suppliers, service providers, firms in related industries, and associated institutions (e.g., universities, standards agencies, trade associations) in a particular field that compete but also cooperate". Cooperation between competitors for gaining competitive advantage was a key additional dimension. Kuah (2002) explains that the purpose of geographical gathering and cooperation of competing as well as related organisations is to enhance growth and increase profitability. Nalebuff and Brandenburger (1996) coin the word 'Co-opetition' for describing the coexistence of competition and cooperation in the cluster concept.

Initially, the new perspective on clusters received huge interest from government policymakers around the world for setting national and international economic policies (Bahlmann \& Huysman, 2008). However, the re-defined perspective has also gained general acceptance. For example, the theory of the cluster with the co-opetitive perspective has been applied to various fields, from economics to management and organisation studies, from sociology to economic geography and regional studies, from urban planning to innovation studies (Kuah, 2002; Lazzeretti et al., 2013). Bathelt, Malmberg and Maskell (2004) applied the concept of the cluster as a process for community learning and knowledge creation in local communities. Similarly, Molina and Yoong (2003) studied the interplay between business clusters and knowledge sharing in Wellington, New Zealand.

From the research context, Michael Porter and his colleagues were invited by the New Zealand Government in 1990 to lead a project with the aim of assessing competitive advantage and economic opportunities in the country. It is known as the "Upgrading New Zealand's Competitive 
Advantage Project" and also referred to as the "Porter Project" (Crocombe, Enright, \& Porter, 1991; Molina \& Yoong, 2003). As a result of the project, 20 New Zealand export industries were identified as possible sources of advantage (Crocombe et al., 1991). The education sector was identified as one of the emerging but overlooked industries that could become a source of competitive advantage for New Zealand (Crocombe et al., 1991). The whole education sector was recommended to restrategise and become capable of not only delivering the required skills for the other 19 industries, but also tapping into the international education market thus generating revenue by attracting foreign fee-paying students.

In relation to this study, the foreword by the Education Minister to the MOE's education policy in 1991 states, "Studies, like the Porter Project, questioned the relevance of our current curriculum with its excessive focus on social issues and poor preparation for the competitive world" (Minister of Education, 1991, p. 1). As another example of the link, Codd (2005) identified a reflection of the 'Porter Project' on clusters in New Zealand in the MOE's education strategy. While indicating the transformation of the educational sector during the 1990s, Codd (2005) claims that the goal of the New Zealand Government then was to promote education as an "export industry" that can deliver the skills required for competing in "an increasingly competitive international economy" (Codd, 2005 , p. 198). The elements of industry, competition and the international market clearly specify the direction in which the Government was aiming to transform the education sector, including schools. Therefore, both the ICTPD cluster programme and the Learning Exchange clusters in New Zealand can be viewed within the same context. As a part of government policy based upon Porter's recommendations, MOE announced the ICTPD cluster programme as a capability building initiative for teachers around the late 1990s. Around the same time, the Canterbury Area Schools' Association Technology or CASATech and later some school clusters adapted the cluster theory with the addition of a virtual aspect and the computer-mediated collaborative learning approach. The school clusters used the theory for addressing the issue of accessibility to wider curriculum choices at their schools. As a result of the school cluster initiative, a number of regional clusters mushroomed across New Zealand which thus contributed to the development of the Learning Exchange programme.

\subsubsection{ICTPD cluster programme}

In 1998, the New Zealand Ministry of Education (MOE) initiated a funding programme for enhancing teacher capability and encouraging uses and integration of ICTs in classrooms. The funding is known as the Information and Communication Technologies Professional Development or ICTPD Cluster Programme (Powell, 2011). The main objective of the programme was to enhance collaborative 
learning between groups of schools in order to improve teachers' and school management's performance for better student learning outcomes (Ham, 2008).

In his report to the MOE about 2002-04 ICTPD clusters, Ham (2008, p. 5) states that "The programmes are only available to groups of schools, which have committed to a 'clustered' model of professional development". Between 1999 and 2009 a total of 267 schools clusters benefited from the programme, comprising almost $75 \%$ of schools (Billowes \& Alexander, 2013). As a note, the clusters in the ICTPD programme included mainly geographical and partly virtual groups of schools. The following section discusses the difference between the ICTPD and the Learning Exchange school clusters.

The discussion about the Cluster theory in the section above highlighted the need for co-opetition through the formation of clusters. Wenmoth (2010) emphasised the adoption of strategies that can reduce competition between schools in the digital age and replace it with collabetition. Schools in New Zealand are related as well as competing organisations operating in a single sector. They are related since their key services are the provision of elementary education (Years 1-13). Similarly, schools, particularly secondary, in urban areas are in competition for better performance in order to have higher rankings in the region and attract an increased number of student enrolment applications. (In NZ, one of the funding criteria for schools is their number of students; the more students there are, the more funding the school receives). The formation of ICTPD clusters of schools in New Zealand indicates the presence of a vision containing co-opetition for better organisational performance and collabetition for enhanced learning opportunities.

\subsubsection{Learning Exchange clusters}

Clusters in the Learning Exchange are virtual groups of schools, mainly from rural regions of New Zealand, aimed at increasing educational opportunities for their students as well as teachers. The formation of virtual clusters enables member schools to exchange their available, albeit limited, resources and thus maximise their impact or benefits. In other words, the virtual collaboration is done to make the most of their socio-economic context. The cluster strategy has allowed member schools to not only maximise but also facilitate efficient utilisation of their educational resources and opportunities. From the Bathelt et al. (2004) point of view, such a collaboration of local communities not only results in better learning but also helps the creation of new knowledge.

Powell (2011), Alexander-Bennett (2016) and other scholars see a strong relation between the ICTPD cluster programme and the VC-based Learning Exchange clusters. Although the ICTPD cluster programme might be the main source of inspiration, clear differences also exist between both the programmes. First, the nature of collaboration in the Learning Exchange clusters is virtual only. 
Therefore, member schools and possible partners (e.g. local community groups, tertiary education providers, technical helpdesk and so on) participate in the programme from anywhere in New Zealand. On the other hand, the ICTPD clusters were physically proximate groups, mainly based within a geographical region and mostly collaborating during face-to-face interactions. Second, the main beneficiaries of the Learning Exchange clusters are students, accessing the subjects that are not available at their local schools. Secondary users of the Learning Exchange clusters are e-teachers and management staff members (e.g. e-dean and principals) taking part in professional development workshops.

The third difference is the duration of the collaboration. Clusters in the ICTPD programme could only receive the funding once and for the period of three years. Therefore, the contract for their collaboration was a limited time period. After the funding, collaboration depended upon their discretion. On the other hand, clusters in the Learning Exchange have no such limitations. The fourth key difference is the financial model. Most of the school clusters in the Learning Exchange have opted to follow a self-funding model rather than depending on external sources of funds. On the other hand, ICTPD clusters existed because of the availability of the funding from the MOE.

The next key difference is the developmental approach. Clusters in the ICTPD programme are the outcome of the Government initiative, for a certain period of time and dependent on the support from the Government. In contrast, the cluster model outlined by OtagoNet in the Learning Exchange defined clusters as self-initiated, self-directed, self-organised and independent groups of schools. Therefore, member schools should themselves be defining their priorities and setting strategies for achieving their objectives. The challenge for the model is achieving self-sustainable development. The challenge of achieving sustainable development thus makes a further distinction between both the cluster programmes. Hence, the cluster concept in the Learning Exchange might be an offshoot of the ICTPD cluster programme; however, both the clusters remain different from each other.

The roots of the school clusters can be traced to the Canterbury Area Schools' Association Technology or CASATech initiative that started around 1993-94. Before the possibility of using VC in New Zealand schools, a group of seven schools in CASATech started using telecommunication technologies in 1994 (Roberts, 2009). According to Campbell (2004), the CASATech aim was to teach classes over the telecommunication system and thus overcome their geographical barriers, as most of the schools were rural schools, facing geographical challenges and limited resources.

The CASATech telecommunication setting was known as audio-graphic and used two telephone lines in combination: one line for audio-conference and the second line for computer-based graphics using the internet or other specialised software (Ministry of Education, 2011; Moffatt, 1996). 
By 1996, other school networks had adopted the audio-graphic setting. Those networks included TosiTech (top of the South Island schools cluster), CentralTech (lower North Island schools), Ngata Memorial College, and Rangitikei College (Moffatt, 1996). "Funding from the Ministry of Education (MOE) Rural Schools Pool enabled these networks to grow" (Roberts, 2013, p. 146).

Later in 2000, Kaupapa Ara Whakawhiti Matauranga (KAWM) network was established as a cluster of Maori schools by the MOE. The KAWM network formally used VC for the first time in New Zealand schools to enhance learning opportunities for their students (Roberts, 2009).

"Although KAWM were pioneers in using video conferencing to provide online learning opportunities for their students, it was OtagoNet that provided the pedagogical model for many other NZ schools to follow" (Roberts, 2013, p. 147). Based on the previous experiences from KAWM and CASATech, the seven or eight schools from Otago with the support of their local Community Trust self-organised OtagoNet around 2002 (Barbour \& Wenmoth, 2013; Pratt \& Pullar, 2013). The current Learning Exchange programme is an extended model that was self-initiated by OtagoNet.

\subsubsection{Development of the Learning Exchange programme}

The Learning Exchange programme in New Zealand can be regarded as a grass-roots level selfinitiative by school clusters, which combines emerging pedagogies from computer-supported distance education and the co-opetition and collabetition concepts from cluster theory. According to Roberts (2009), the Learning Exchange programme uses video-conference and other ICTs for virtual exchange of educational resources between school clusters, mainly from rural regions of New Zealand. Specifically, to participate in the programme, interested schools first form virtual regional groups and then utilise a range of ICTs, including the VC for collaborative learning (Browning, 2005). According to Pratt and Pullar (2013), a synchronous VC setting was used as the primary mechanism to establish online classes between students and instructors from different locations. More recently, Google Hangout is being used as a group video application for online classes. With the use of VC and other tools with synchronous capability, classes are conducted in which participants interact with each other and take part in different collaborative learning activities. The 50 minutes long live VC classes, once a week for the whole school year, are supported with the use of applications with asynchronous capabilities, such as email, different Google applications, blogs and Moodle (a learning management system). The augmentation provides participants with the required support and time to absorb and reflect upon the lessons. Figure 2.2 illustrates an example of an online class in the Learning Exchange. Solid lines indicate the ICT-based communication and dotted lines indicate faceto-face interactions. 


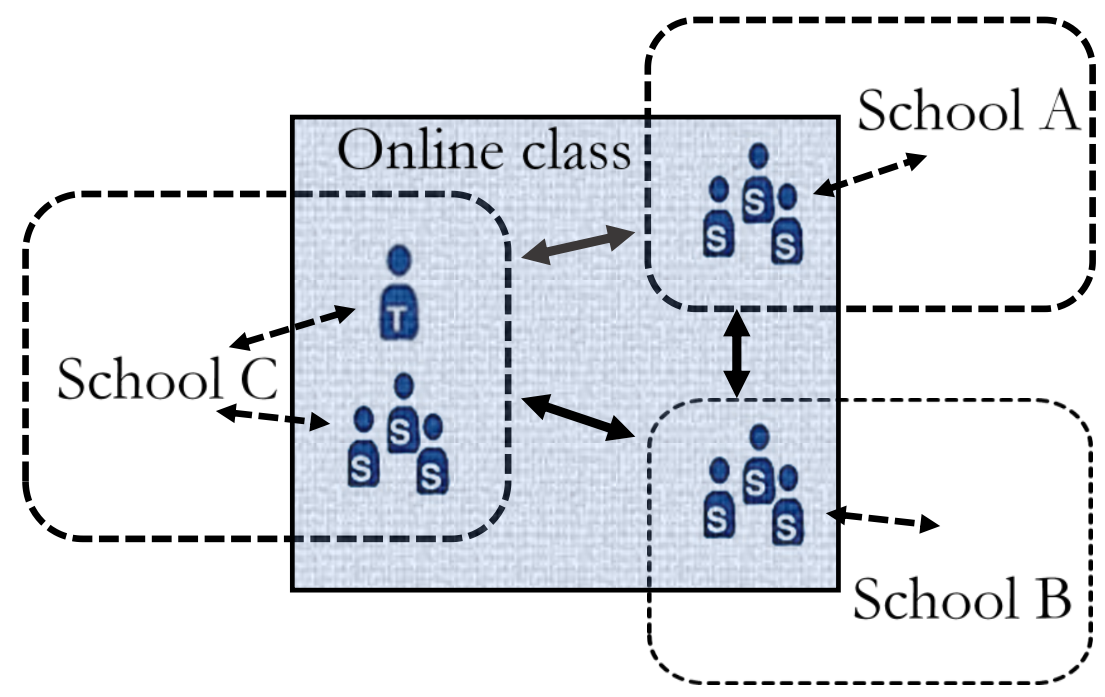

Figure 2.2 An example of an online class in the Learning Exchange

The programme basically enables educators to connect schools, teachers, learners and teaching and learning resources into a single network - a cluster. The connectivity then allows members to exchange teaching, learning and human resources. Hence, the strategy supports schools to maximise their existing, albeit limited, educational benefits and thus enhance their overall educational performance. According to Porter (1998), by being part of a cluster, members obtain additional important inputs and have greater access to information that can increase opportunities and organisational ability to innovate. Moreover, the intersection of cluster members merges skills and insights from various members, thus sparking new ideas, expanding avenues for new opportunities and strengthening clusters (Porter, 1998). These reasons clearly justify that clustering "allows each member to benefit as if it had greater scale or as if it had joined with others without sacrificing its flexibility" (Porter, 1998, p. 81).

Initially, according to Pullar and Brennan (2008, p. 5), the vision behind the school cluster (OtagoNet) was to "strengthen existing relationships and collaboration of these rural and geographically dispersed schools" and eventually benefit from the re-built associations. From Porter's (1998) perspective, such a strategy is to benefit from their socio-economic context for better organisational performance. The clustering enables schools to access each other's specialist teachers and learning resources, allowing schools to personalise learning based on the choice, need, ability and skill of their individual learners (Stevens, 2011).

It is more than a decade since the Learning Exchange programme was initiated. Since then, the programme has grown and its objectives have evolved from increasing accessibility to curriculum 
choices to supporting personalised learning and specialised projects. The following are some of the programme's main objectives that were listed in the Ministry of Education $(2011$, p.8):

- provide greater access to curriculum choices for students

- provide access to subject matter experts to enhance school-based learning

- participate in virtual field trips - engaging students in collaborative projects

- support gifted and talented students by enabling them to connect with others with similar skills and interests

- share (both access and contribute) a wide range of rich and current resources.

Since the inception of the first two clusters - CASATech in 1994 and OtagoNet in 2001-02 - around 20 virtual school clusters were formed in New Zealand (Compton, Davis, \& Mackey, 2009; Davis, Eickelmann, \& Zaka, 2013). According to Roberts (2009), the model was adopted mostly by rural school groups as it provides a means to overcome their geographical isolation. However, a number of urban and large schools have also adopted the model and formed urban clusters, such as HarbourNet in Auckland. Further, CASATech (renamed CantaTech) also adopted the OtagoNet model. The development indicates that despite the importance of globalisation and global competition, locality still matters (Lazzeretti et al., 2013; Porter, 1998). Figure 2.3, adopted from Powell (2011), shows some of the school clusters that participated in the programme.

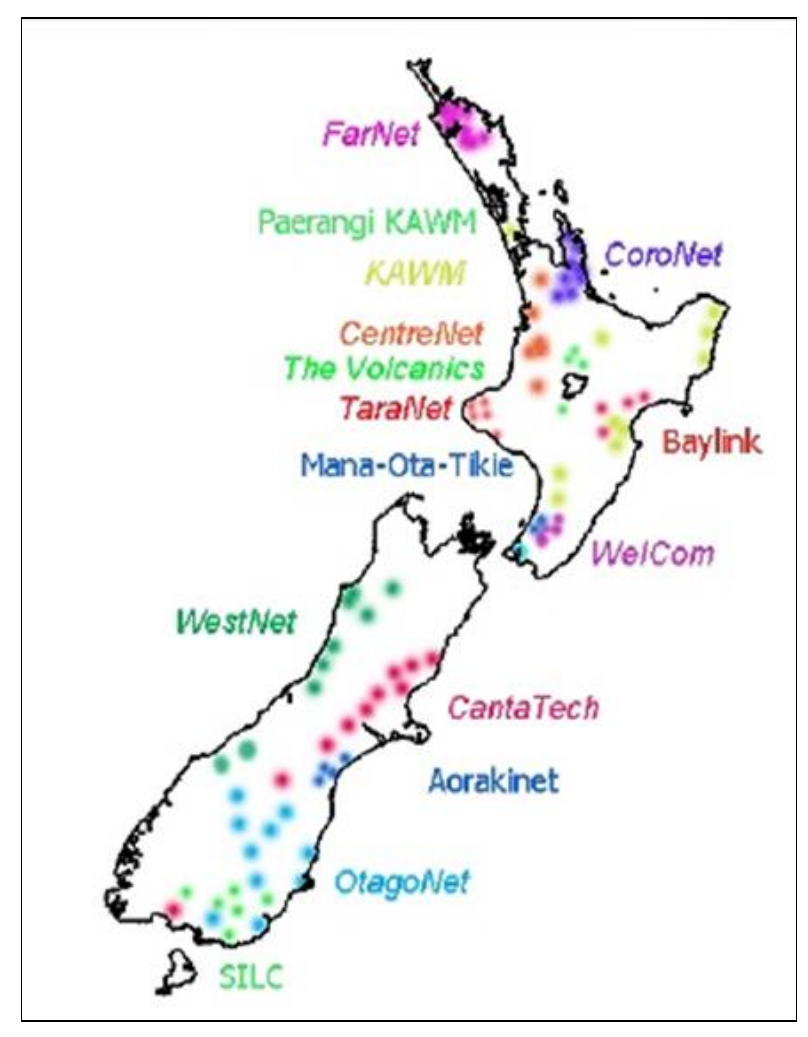

Figure 2.3 Learning Exchange Clusters in New Zealand 
However, some of those clusters have grown by becoming self-sustaining, whereas some have disappeared. The literature suggests some possibilities behind the disappearance of clusters; however, a knowledge gap exists regarding the supporting and inhibiting factors in the development of self-sustaining clusters. Section 2.6 addresses the gap in detail.

Before proceeding further, a clarification should be made here. The Learning Exchange programme is commonly known by the name of Virtual Learning Network or VLN, which is basically an online platform provided by the MOE for all New Zealand schools for accessing four services (Ministry of Education, 2016):

- The VLN Community - a forum for the community of schools using the cluster programme;

- The Learning Exchange - the interface allowing schools to organise VC classes and student enrolments (see appendix 2.7.1);

- VLN Groups - online groups of e-learning communities for teachers and schools; and,

- LCO Handbook - access to the Learning Communities Online (LCO) guidebook that provides schools with a framework for forming and developing Learning Exchange clusters.

Since the Learning Exchange programme is the main domain of this study, the study avoids using the term VLN for representing the Learning Exchange programme.

\subsubsection{State of online learning - a global view}

Internationally, primary and secondary (K-12) schools are increasingly participating in a variety of computer-mediated distance education activities. While some schools replace their traditional fulltime classes with purely virtual activities (virtual schools), some use a blended learning approach for supplementing or complementing their existing face-to-face classes (Pratt \& Pullar, 2013). The latter type of schools use computers and the Internet for the provision of some or all of the students' education (Russell, 2004). Roblyer (2008, p. 696) associates the beginning of the virtual school vision with the "more affordable and equitable access to high-quality educational opportunities for students who traditionally lack such opportunities: rural, underserved, and at-risk populations". Later on, factors such as technological changes, availability of high speed Internet, globalisation, perceptions of traditional schools, and the model of virtual and distance education in higher education, contributed to the growth of virtual schools (Anderson \& Simpson, 2012; Russell, 2004). Because of the variety of rationales and online learning programmes, identifying commonalities is a big challenge. Indeed, "Different types of online programs have different characteristics and attributes that define the ways that students learn" (Annua et al., 2009. p. 16). For example, some 
programmes have been established and are funded by governments whereas some are private initiatives. As a result, their developmental approaches and resourcing models differ.

In the United States, the Virtual High School (VHS) and Florida Virtual School (FLVS) were the first two virtual school programmes established by the Federal Government in 1997 (Barbour \& Reeves, 2009). Similarly, in Australia, national and state governments are responsible for funding online learning initiatives for secondary schools (Powell, 2011). For teacher training, "Universities are responsible for teacher education and have not made ICT a major focus" (Powell, 2011, p. 249). In New Zealand, the CASATech cluster in 1994 and OtagoNet cluster in 2002 were initiated by local groups of schools and the MOE provided some support. On the other hand, the New Zealand MOE established and funded the first e-learning cluster of schools, the KAWM project for Maori school students (Barbour \& Wenmoth, 2013). In addition, the Correspondence School programme is the largest online learning project for schools in New Zealand that is fully funded by the Government (Roberts, 2009).

Watson et al. (2014) report a number of both state owned and private groups of schools that offer online courses to secondary school students in the US. Regarding the variety of options, Watson et al. (2014) believe that "most districts, with the exception of some of the smallest ones, are using some form of digital learning, which may range from a fully online school, to supplemental online courses, to skills software used in math, English language arts (ELA), and other classes" (p. 10). Watson et al. (2014, p. 12) believe, "District size has considerable implications for digital learning, including the level at which decisions are made". For example, small districts (up to about 2,500 students) invested in and use video-conferencing as an important method for augmenting the small number of courses offered by the district's own schools. In addition, only a few of the smallest districts have full-time district level administrators for managing digital learning and providing technical support across the district (Watson et al., 2014).

In a literature review regarding the development and growth of virtual schools in North America, Barbour and Reeves (2009, p. 402) admit that their findings may not be extendable to other regions of the world. That review and findings only indicate the existence of a variety and distinctive nature of online school programmes.

Because of the diverse nature and the operational context of each of those cases, very few studies have attempted to identify common trends and challenges at an international level. Studies such as Barbour and Reeves (2009) are limited as the study covers the virtual school efforts in the US and Canada only. The International Association for K-12 Online Learning (iNACOL) is a major forum that has conducted a couple of surveys, reviewing the status of blended and online learning 
internationally (involving 50 countries). In their recent survey with inputs from 50 developed and developing countries from around the world, the survey identified five distinct trends:

"demographics, support from governments and schools, teacher training, the use of blended learning, and the use of online learning" (Barbour, Brown, Waters, \& Hoey, 2011, p. 10). They found that:

First, blended and online choices are mostly available to students in urban areas from developed countries. Second, growth in digital learning stems from shared authority between local schools and national governments. Third, specialized teacher training is not required but is encouraged and available. Fourth, blended learning is occurring with much greater frequency than online learning. Last, use of online learning is most prevalent by students with special circumstances. (Barbour et al., 2011, pp. 10-14)

With regard to the Learning Exchange, most of these trends do not clearly correspond with the programme or specify its focus. The survey also acknowledges that "there are major differences from country to country" (Barbour et al., 2011, p. 29). In Canada for example, "each of the thirteen provinces and territories have different types of regulation and different levels of activity when it comes to K-12 online learning" (Barbour et al., 2011, p. 116). Therefore, based on the review of literature in Section 2.4, it can be argued that the Learning Exchange involves mainly online, not blended, learning within existing schools. The Learning Exchange programme can be seen as a 'virtual class programme' rather than 'virtual school'. In other words, the programme is a replacement for the face-to-face classes, not because of virtual classes being better or more attractive than face-to-face classes. Rather, the adoption has been due to lack of access and unavailability of the courses at those small schools. In addition, although a number of urban schools and clusters have joined the Learning Exchange, the programme was initiated by small, rural schools and they are the majority of the current users. Also, the school clusters own and lead the Learning Exchange programme. Therefore, they set strategic directions and are responsible for providing the required resources. Because of the decentralised nature of schools in New Zealand, the MOE has only provided some technical facilities and decided to step back and let the local school community lead the programme. Similarly, the Learning Exchange clusters organise specialised training and workshops for their e-teachers or teachers with VC classes by themselves. These differences, therefore, indicate that the implications of the survey might be beneficial for the Learning Exchange leaders; however, they are very wide and not very relevant. 


\subsection{Reported Barriers: Issues and Challenges}

As discussed in the above sections, the emerging and applying phases of ICTs in schools are almost over in developed countries, whereas the infusing and transforming phases are on the rise, which require embedding of ICTs into existing practices and adoption of learner-centred approaches. However, a number of issues and challenges have inhibited the development of online learning programmes from across the world.

With an international perspective, the survey by iNACOL also reported a number of issues and challenges. Those barriers included: unclear understanding of online learning; the lack of equitable access to the Internet, technology, tools, and resources; lack of government funding or policies to promote online learning; lack of focus on teacher training; availability of the online learning to only students with extenuating circumstances; sporadic interest in online learning; and lack of vision and leadership (Barbour et al., 2011).

Some other studies have identified the ineffective use of technology, unfavourable organisational culture and the lack of managerial support as barriers to the adoption of computer-mediated online teaching and learning using ICTs. For example, Celikkan et al. (2013) found that getting familiar with new technologies and limited resources available for equipment are important factors needing effective management for successful integration of technology in the classrooms. Smyth (2005) described that with the technological sophistication, mobility and greater ease of use, the technical use issues have decreased. However, according to Anastasiades et al. (2008), technology alone is not sufficient to ensure collaborative and interactive learning; the way technology is used determines expected benefits of a technology.

A literature review by Simonson et al. (2011) found five main barriers during the development of technology-based distance education programmes. The barriers related to organisational culture, such as resistance to change, lack of shared vision, lack of strategic planning, slow pace of implementation and difficulty in keeping up with technological changes. Similarly, a literature review by Irvin et al. (2010) identified a lack of leadership support and understanding of DE by school staff members major barriers, hindering the development of DE in rural schools.

The lack of managerial support was another main challenge for the use of ICTs such as VC. The adoption of technology is adversely affected when organisational heads provide limited resources, such as expertise, time and budget (Celikkan et al., 2013). Similarly, Roberts (2009) argued that an online class is more open and transparent to the world; thus, the transparency puts extra pressure on the teachers. Therefore, they need extra managerial support, such as the provision of training, to ensure the provision of effective teaching (Roberts, 2009). Mupinga (2005) also reported the need 
for leadership support in terms of formulating workload policies and training for teachers as well as students for participating in the online environment. Roblyer (2008) considered governance of virtual schools an issue.

The challenge of gaining managerial support coupled with organisational issues and ineffective use of technology can undermine any ICT related initiative. Simonson et al. (2011) suggest the need for cultural change within organisations and greater managerial support with regard to the use of technology in organisations. Thus, if schools truly want to embrace the re-definition of education and make the most of the learner-centred, future focused, transformative pedagogies, then a different set of approaches and strategies are required that can promote adaptability and influence and be influenced by others in their community.

To review reported issues and challenges with respect to the Learning Exchange, it is over a decade since the formal initiation of the Learning Exchange around 2002. Since then, a few studies have addressed the Learning Exchange development, but are either limited due to their narrow focus, irrelevant after nearly a decade or so, or biased by being government chartered reports. The most relevant study was by Barbour, Davis and Wenmoth (2011), identifying three common barriers inhibiting the maturity of the Virtual Learning Network (read Learning Exchange) development: lack of collaboration and cooperation within and between clusters; lack of a coherent vision; and, difficulty in securing the necessary funding and, resources. To increase interactions, particularly between teachers of the same subject, Barbour, Davis, and Wenmoth (2011) recommend building a central repository of course content accessible for all school clusters in New Zealand. They suggest this could help in minimising inconsistencies in the course design and delivery phases as well as avoiding duplication of teachers' efforts.

However, the suggestion neither addresses licencing and copyright issues for course materials nor does it include differences of teaching styles and approaches. Most importantly, the suggestion has a micro-level focus and thus remains debatable because collaboration and cooperation are a subset of cluster theory. Hence, both have to be key parts of a cluster vision and should not be considered separate.

Similarly, suggesting funding from the MOE as a source for cluster maturity is also questionable. The rationale is explained below.

Like Barbour, Davis, and Wenmoth (2011), Browning (2005) also questioned the New Zealand MOE's funding and support formula as a possible threat to successful development of e-learning communities because the government support is only for the setting-up package and does not go beyond that. Stevens (2011) supports Browning (2005) and Barbour et al. (2011) by criticising the 
national funding policies for not contributing beyond the setup package. Consequently, school clusters find themselves in a difficult situation and thus struggle to sustain their development (Stevens, 2011). Barbour et al. (2011) believe that the government support is genuinely needed for such initiatives to thrive and grow. Besides the nationwide projects and short term initiatives, steps for expanding the MOE's role are also required for smaller projects at school or regional level (Barbour \& Wenmoth, 2013).

However, this study disagrees with the above studies given the 'existing nature' of the Learning Exchange programme. Obviously the availability of more funds means more resources and is most welcome. However, the above studies overlook the fact that the nature of the Learning Exchange is different from other projects in New Zealand, such as KAWM or TCS, and from government administered virtual schools around the world. The Learning Exchange programme has a bottom-up developmental approach, as opposed to the top-down bureaucratic developmental approach. Further, the original cluster prototype initiated and matured by OtagoNet included membership contributions as a key part of cluster financial self-reliability. That was an intentional move for sustainable development. In addition, the examples of privately run virtual school programmes in other countries provide further evidence regarding the existence of similar, independent initiatives. Nonetheless, the MOE has provided funding to support the development of clusters in major areas such as ICT infrastructure, teacher capability and e-principal capability building, ICTPD cluster funding, a VLN brokerage website and ASNet as a technical helpdesk. Therefore, within the existing context of the Learning Exchange, self-funding is a key part of the cluster development.

Another recent interesting development in the Learning Exchange was the merging of OtagoNet, CantaNet and some other clusters as a single large cluster called NetNZ. In their Statement of Intent, NetNZ (2013, p. 2) describes a number of limitations they experienced in the current cluster organisational structure, which include: "finite capacity, inefficient use of resourcing, an inflexibility to innovate and respond to emerging needs and demands, and a lack of resourcing". Those observations and experiences needed to be explored and recognised.

A lack of the required level of support for cluster coordinators was another key issue raised by Lai and Pratt (2004). Due to that, a lack of time and a lack of professional development impinged on the effectiveness of the coordinator's role in clusters and in member schools (Lai \& Pratt, 2004). More recently, Roberts (2013) has emphasised the provision of support not only for coordinators (or eprincipals) but also for teachers and students. The provision of support is more obvious due to the fact that teachers require extra effort for preparing lessons as well as training for engaging students and building teacher-student trust in the virtual environment (Davis et al., 2007). On the other hand, 
students also need extra support to cope with the changing class environments when in a single day students experience both virtual and face-to-face classes. In particular, interaction and engagement with unfamiliar students and teachers from different schools remain a challenge for students in the learning exchange.

In the presence of inflexible boundaries of the traditional school system, the theory of clusters, virtual schools and/or transformative pedagogies will not simply settle in easily. The integration of the new perspectives with the traditional face-to-face system or the transformation process from the old to a new system of teaching and learning requires restructuring of the school concept and adaptive leadership, strategies and approaches (Davis, Eickelmann, \& Zaka, 2013). Such integration via restructuring can allow evolution in the educational systems. Otherwise, those issues persistently restrict the development of school clusters as well as any other virtual programme.

\subsection{Cluster Self-Sustainability}

Given the self-reliant nature of the programme, self-sustainability has remained a challenge for the Learning Exchange school clusters in New Zealand and existed as a knowledge gap.

\subsubsection{A great challenge}

Although the opportunities from and benefits of the co-opetitive and collabetitive concepts in the cluster theory are enormous, self-sustainability on the other hand remains a great challenge for the clusters as well as the Learning Exchange community. As argued above, clusters in the Learning Exchange are self-driven initiatives from grass-roots level communities. Because of their selforganisation, 'self-sustainability' has been a key ingredient of the Learning Exchange cluster philosophy. Thus cluster members' financial contributions have a significant role in the model rather than being dependent upon external sources of funds. This means school leaders from the local communities are responsible for their cluster's development and growth.

However, based on the ground reality, clusters in the Learning Exchange have "experienced varying degrees of sustainability as they have evolved...[as a result] some clusters have found a degree of sustainability, others have, over time, diminished" (NetNZ, 2013, p. 2). That challenge provided an opportunity to study the cluster and the Learning Exchange's development and identify the supporting and inhibiting factors for making sustainable development.

From a general perspective, Kuah (2002, p. 221) considers that co-location of organisations is not sufficient to indicate clustering strategy when the clustering benefits, such as "innovation, productivity, growth or other superior competitiveness cannot be shown or described". In other words, members' commitments in terms of finance, time, human and other resources depends upon 
the values in terms of increased innovation, productivity, growth, student learning performance and other benefits that a cluster can generate for its members.

According to the NetNZ summary report (NetNZ, 2013), the merger was done to address increasingly apparent limitations by re-establishing the clusters as a multi-stakeholder cooperative, allowing the cluster to benefit from the economies of scale. This development reaffirms Porter's (1998) stance regarding clustering that allows each member to benefit as if it was bigger. In other words, the size of a cluster matters for its self-sustainability. What the minimum number of members for making a self-sustaining cluster in a Learning Exchange would be was one of the questions that remained unanswered. In addition, these are only a few of the possible challenges inhibiting the development of the self-sustainability of clusters. The supporting factors remained uncovered.

\subsubsection{A knowledge gap}

Because of its unique nature and rural context involving a number of small schools, the programme has gained very little attention. Some of the available studies were either from practitioners, such as e-teachers (VC class teachers), containing their personal reflections and discussing their observations (Pullar \& Brennan, 2008; Walsh-Pasco, 2004), or the studies were from management staff members (principals) reporting about their sabbaticals, describing management and leadership related topics with respect to schools in general (Douglas, 2007). In some cases, the studies were conducted for the Ministry, mainly reporting 'success stories'. In addition, the studies were limited and not comprehensive as they only covered some aspects. Therefore, a knowledge gap existed, particularly regarding the sustainable development of the clusters.

So far, studies such as Bolstad and Lin (2009) report about the Learning Exchange students' experiences, the Ministry of Education (2011) provides a guide for cluster schools and Barbour et al. (2011) discuss Virtual Learning Network (VLN) processes and report some barriers hindering clusters. Powell (2011) briefly mentions some clusters that have easily adjusted to the Learning Exchange while other clusters are struggling with the change; however, she does not state any reasons for the problem.

These are a few studies conducted about the 'VLN'. These studies neither specifically addressed the Learning Exchange programme nor the clustering strategy with the challenge of sustainability. Therefore, the previous studies are limited and the question still remained unanswered as to how some Learning Exchange clusters successfully developed, whereas some struggled to achieve sustainability.

The lack of evidence suggested the need for a methodological study of the Learning Exchange programme and clusters. For these reasons, a comprehensive study using two theoretical lenses and 
a number of methodological approaches was designed to investigate and uncover the facilitating and inhibiting factors for the development of self-sustainable clusters. Therefore, a comprehensive study was required not only to address the local or horizontal dimension of the programme for better learning outcomes and transforming performance but also to examine the vertical dimension linking the programme with a global context. Hence, the findings provide a view of sustainable cluster development and thus the study makes a great contribution to the development of Learning Exchange clusters. Further, the implications of the study are more likely to be beneficial to the international online learning community in general and self-organised groups of K-12 schools in particular.

In order to cover the gap and investigate the research problem, this research intended to address the following three research questions:

- RQ1: How was the Learning Exchange programme developed in New Zealand?

- RQ2: How was the programme utilised in some of the school clusters in New Zealand?

- RQ3: What were the factors that facilitated or inhibited the self-sustainable development of the Learning Exchange clusters in New Zealand?

The study selected four school clusters for data collection and used each of the clusters as a unit of analysis. Based on input from research participants, the Findings Chapter reports the initiation and growth of four clusters and subsequently the development of the Learning Exchange programme in New Zealand. Hence, the chapter answers the first and second research questions.

At the end of the Findings Chapter, Table 5.4 provides a detailed summary of the four clusters' findings. The Table lists the supporting and inhibiting factors identified with regard to each of the clusters, thereby addressing the third research question.

The Analysis Chapter interprets the outcome of the Findings Chapter to describe the development of a self-sustaining Learning Exchange cluster. The Discussion Chapter further builds upon the findings in order to conceptualise them, taking the findings to the next level.

\subsection{Chapter Summary}

This literature review chapter discussed a number of key areas. The literature review found that distance education has evolved through various generations and used a variety of technologies. Earlier generations adopted an industrial approach in order to reach a high number of individual learners. However, later generations with the mediation of telecommunication technologies and computers shifted their focus to improving the quality of teaching and learning processes and 
student engagement through group learning methods. The Learning Exchange programme was found to be one of the key emerging generations of distance education in New Zealand.

Regarding the adoption and uses of ICTs, a range of ICTs has been adopted and used in schools, some for synchronous and some for asynchronous educational and management activities. Initially, the key objectives of school leaders and governments included access to ICTs and development of technological infrastructure. The earlier users of ICTs in schools were staff members who explored the possibilities of using ICTs for school administration and curriculum development. In the context of this study, the adoption and application of ICTs for organisational uses are particularly relevant for enhancing collaboration and forming virtual clusters of small schools faced with geographical challenges. During later stages, ICTs were embedded in all aspects of schools for supplementing existing teaching and learning processes. More recently, with the learner-centred educational approaches, ICTs are being used to complement the educational processes. The Learning Exchange programme belongs to one of the transforming phase approaches.

The review described the Learning Exchange as computer-supported collaborative learning in which the learning happens through group interactions between participants during problem-solving tasks, thereby teachers and course material are not the only sources of learning. The review also found a strong connection with the Porter Project in New Zealand and the use of cluster theory as a collaborative approach for transformation of schools. In particular the ICTPD cluster programme of the MOE and the Learning Exchange cluster programme of the group of regional schools were identified as two main, but distinctive, examples of the application of the theory in New Zealand. The Learning Exchange was a programme self-organised by the regional school clusters. The programme allowed participating schools to combine emerging pedagogies from computermediated collaborative learning and the cluster theory.

To review states of virtual learning systems, the review found that most of the programmes in the developed countries started around the 1990s. However, due to their distinct characteristics and attributes, those programmes differ from each other even within a region or district. While some programmes are established and funded by the governments, some are private initiatives by independent schools. Similarly, some programmes are fully virtual schools, some combine face-toface classes with online instances and some, such as the Learning Exchange, provide online classes in schools where face-to-face education is the main approach. Therefore, identifying commonalities between various programmes would be very challenging. This was evident as not many studies have reviewed a broad international perspective involving more than a few countries. 
This chapter concluded by identifying a number of barriers to the development of computermediated online distance education in general. The issues were related to organisational culture, management support, integration and transformation processes, resourcing, government support and so on. With respect to the clusters in the Learning Exchange, a small number of previous studies were found but were limited. Those studies had overlooked the development of the Learning Exchange programme and the challenge of self-sustainability of school clusters. Therefore, this study was designed to address the research problem and the knowledge gap. 


\section{CHAPTER 3: THEORETICAL LENSES}

\subsection{Introduction}

After considering a number of theories, Actor Network Theory (ANT) was selected as an appropriate theoretical lens for reporting the research findings. This chapter discusses the ANT tenets that are relevant to and used in this study. The next section defines ANT and discusses its key principles of heterogeneity and symmetric approach. The sociology of Translation section explains the Translation process, including its four phases. The section discussing key ANT principles clarifies some of the basic concepts underpinning the theory. The criticism of ANT highlights some of the main issues raised in various studies and provides possible justifications offered by ANT advocates. That is followed by the section providing some justification for using ANT in this study. In particular, the section reinstates the limited use of ANT, adopting ANT as a lens instead of a method in this study. In addition to the use of ANT, this study utilises Complexity Theory to complement ANT. While ANT is used for the reporting of the research findings, Complexity Theory is used in the discussion and conceptualisation of the findings. Section 3.3 explains Complexity Theory with its key underlying concepts. Section 3.4 provides the rationale for combining both the theories.

\subsection{Actor Network Theory}

ANT or the sociology of translation can be defined as the study of heterogeneous networks made of both human and non-human elements. According to the theory, human society can be considered as a patterned network of heterogeneous elements where all the elements - humans and non-humans - have the agency attribute or ability to act or be acted upon (Callon, 1986; Latour, 1986; Law, 1992). The definition indicates a number of key principles underpinning the theory. First, actornetworks consist of both human and nonhuman elements. The range of non-human elements not only include technology or technical artefacts, such as computers, programming codes, databases, applications and so on but also other objects, organisations, policies, documents, concepts, symbols and so on.

Second, in addition to their inclusion, non-humans participate in the making and derailing of a social phenomenon or a network. In other words, non-humans have agency attributes which mean they can act or be acted upon (Law, 1992). Because of the agency attributes and the inclusion of nonhuman elements, the word 'actant' is preferably used instead of the word 'actor' to represent both the categories of the elements. According to Latour (1990, p. 67), "An actant can literally be anything provided it is granted to be the source of an action". The debate of 'actantiality' is discussed later by a comparison of the terms. 
Lastly, because of the variety of elements, such a network is described as heterogeneous. Although ANT originated in the field of social sciences, the heterogeneous approach of the theory negates either a purely socio- or techno-centric approach. Instead, the theory proposes a socio-technical approach (Cordella \& Shaikh, 2003). As recommended by Tatnall and Gilding (1999), a sociotechnical approach is much needed in situations where a mix of different elements is involved in a network. For example, a classroom is an association of students, teacher, books, whiteboard, markers and others. The elements jointly form their association (classroom) and produce agency and other effects, such as "ideas, identities, rules, routines, policies, instruments and reforms" (Fenwick \& Edwards, 2010, p. 3).

Therefore, ANT is a theory that is concerned with the examination of the association of human and non-human elements with the objective of understanding how these elements come together and manage to stay together (Law, 1992). The ANT process of Translation offers a 'programme of action' for studying the assemblage of the heterogeneous elements and identifying the relationships that comprise the network (Andrade \& Urquhart, 2010; Cordella \& Shaikh, 2003). The following sections discuss the above tenets including their associated principles further.

\subsubsection{Heterogeneity}

The concept of the network is fundamental in ANT. Murdoch (1998, p. 359) explains that in social sciences, the term network is commonly utilised to "describe technological relations, economic forms, political structures and social processes". However, ANT groups these networks together and refers to them as a heterogeneous network. A heterogeneous network means the assemblage of a host of dissimilar "elements that we tend to label technical, social, natural, political and so on" (Murdoch, 1998, p. 360). Thus, ANT proponents believe in societies, where all the materials - be they human or non-human - associate in networks, rejecting any claim that social relations can be independent of the material and natural world (Callon, 1986; Whittle \& Spicer, 2008). Therefore, societies do not merely consist of humans but also organisations, concepts and technological artefacts (Latour, 1994). As a result, the societies we live in are a mixture of these elements which are in continuous interaction and exist in the form of heterogeneous networks (Andrade \& Urquhart, 2010). For example, an overhead projector in a lecture room is an element, albeit silent, during the series of actions. It acts by supporting the teaching and learning processes. It is a matter of time until it stops working and its existence is realised. A moment before, the projector scarcely existed; however, later its individual parts became noticed. Therefore, ANT suggests these elements do not merely exist as a placeholder and thus should not be taken for granted (Latour, 1994). 
Since these elements perform their tasks routinely and appear to have disappeared from our networks, they are considered 'black-box'. The term black-box means a device or system that performs certain valuable functions, and for convenience anything that goes on inside such black boxes does not need to be understood (Winner, 1993). The process by which these actors are blackboxed and linked to other networks to create a larger actor-network is called Simplification and the effect is called Punctualisation (Cressman, 2009).

\subsubsection{Symmetric approach}

While heterogeneity emphasises the inclusion of a host of elements, the symmetric approach means they can have the same effect, thus requiring an approach that treats them on an equal basis. In other words, declaring both the human and nonhuman elements as 'actants' is a symmetric approach since the declaration views the power of both as equally (un)certain, (un)ambiguous and (in)disputable (Whittle \& Spicer, 2008). Similarly, the theory views all actants in a heterogeneous network as having equal roles in the (de)formation as well as (de)stabilisation of the networks (Latour, 1994). The approach is paramount and a significant contribution that brings the missing masses, the elements often taken for granted, into a single frame and assigns them the same degree of agency attributes (Whittle \& Spicer, 2008).

The Information Systems literature shows that two extreme approaches have been taken to researching implementation of information technology and technological innovations (Andrade \& Urquhart, 2010; Tatnall \& Gilding, 1999). The techno-centric approach considers IT as the enabler and primary focus, while users are treated as the secondary focus or the 'social context' (Carroll, Richardson, \& Whelan, 2012). Carroll et al. (2012, p. 52) assume that the techno-centric approach was based on the belief that "suggests that technology follows its own logic and patterns of usage" (p. 52) and thus considers IT the main factor behind a successful event - a philosophy of Technological Determinism. On the other hand, the socio-centric approach was supported by the social construction of technology (SCOT), a philosophy that suggests that society develops a technology and the role of technology is determined by society (Tatnall \& Gilding, 1999). Therefore, social constructionism sees users as the primary and IT as the secondary focus.

In contrast to these one-sided, singular approaches, ANT and others suggest the need for a middle ground - a socio-technical approach - in which both the technological and social can co-exist and augment each other. Tatnall and Gilding (1999) recognise that ANT's symmetric approach "deals with the social-technical divide by denying that purely technical or purely social relations are possible" (p. 957). 
To support its pluralistic socio-technical stance, ANT is based on three key tenets: agnosticism, generalised symmetry, and free association. Agnosticism refers to analytical impartiality towards both the human and non-human actants in a project (Tatnall \& Gilding, 1999). The principle of agnosticism clearly rejects any superiority assumption regarding any actant engaged in a network. However, ANT makes a distinction between micro- and macro-actants purely based on the actant's "performative effect" in the construction of their network (Law, 2009, p. 8). (Micro and macroactants are discussed later). By generalised symmetry, ANT recommends the use of neutral vocabulary for all the actants in describing their involvement and role in a networking development (Carroll et al., 2012). Generalised symmetry is important as it emphasises "the commitment to explain conflicting viewpoints in the same terms" (Callon, 1986, p. 196). The principle of free association suggests the abandonment of all a priori distinctions and dichotomies between actants, whether natural, social, political or technical (Callon, 1986).

Although the theory has been mainly used for reporting the findings of this study, the discussion here also indicates the methodological approaches that the theory offers to researchers. Specifically, the principles of heterogeneity clearly suggest dealing with organisations as heterogeneous networks of human and non-human elements. In addition, the socio-technical approach proposes agnosticism, general symmetry and free association tactics while dealing with the elements during data collection processes. The theoretical affordance is discussed in the Methodology Chapter in detail.

\subsubsection{Sociology of Translation}

The concept of Translation is a significant part of the theory and is of great interest to researchers as well as this study. In fact, ANT is also referred to as the Sociology of Translation. Networks continuously transform, and Translation affords observers the lens to view the transformation process. To explain the concept a number of explanations are quoted here. Latour (1994, p. 32) uses the word Translation "to mean displacement, drift, invention, mediation, the creation of a link that did not exist before and that to some degree modifies" elements or agents in a network. In other words, Translation "refers to the process of creating a temporary social order, or the movement from one order to another, through changes in the alignment of interests in a network" (Sarker, Sarker, \& Sidorova, 2006, p. 54). Callon (1986, p. 215) suggests that "Translation is the mechanism by which the social and natural worlds progressively take form". According to Law (1992, p. 386):

[Translation is concerned] with how actors and organizations mobilize, juxtapose, and hold together the bits and pieces out of which they are composed; how they are sometimes able to prevent those bits and pieces from following their own inclinations and making off; and how they manage, as a result, to conceal for a time the process of translation itself and so turn a network from a 
heterogeneous set of bits and pieces each with its own inclinations, into something that passes as a punctualized actor".

Translation is better understood by its four phases or moments which can in reality overlap (Callon, 1986). The four phases are required for stabilising the network (Andrade \& Urquhart, 2010). Figure 3.1 is commonly used to demonstrate the phases.

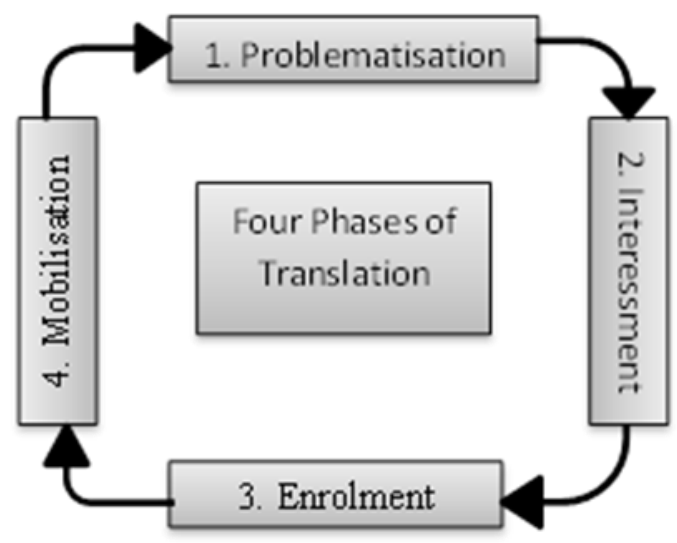

Figure 3.1 Four phases of Translation

Problematisation is the first phase in which problems, possible solutions, and key roles are defined by initial actants or initiators (Callon, 1986). According to Postma (2009), initial actants or actants initiating the process identify a problem and try to convince other actants that the problem is relevant and legitimate to all other actants. A problem can be anything that is designated an obstacle and hinders movement. If successful, some of the actants represent themselves as being essential or indispensable for solving the problem and thus "establish themselves as obligatory passage points" or OPP (Callon, 1986, p. 202). In other words, all other actants must accept and go through them in order to find a solution to their own problems (Postma, 2009). Otherwise, the goal of reaching a solution would be unreachable.

In the Interessement phase, initiators use strategies such as negotiation with other actants to convince them that "the interests defined by the initiator(s) are in fact well in line with their own interests (Mähring et al., 2004, p. 214). The attempt is aimed at validating the problem-solution definition and moving to lock allies and concerned entities (Callon, 1986). For convincing and binding actants to the description of the problem-solution definition and defined interests, Callon (1986) suggests they use and seek help from various devices - called the devices of Interessement. Wissink (2013, p. 5) suggests strategies ranging from "negotiations, plots, calculations, persuasions, briberies and violence" that can be used for Interessement.

After a successful Interessement, the Enrolment phase occurs which refers to the moment of organisation and alignment of actants in the newly created network (Sarker et al., 2006). During this 
phase, key roles are defined in an attempt to organise each actant and thus to establish a solid or irreversible network (Andrade \& Urquhart, 2010). However, in principle, a stable network still remains reversible (Callon, 1991), in the degree to which it can go back to an alternate option. In addition, since designated roles are assigned temporarily, an enrolled actant or ally may fail to act as promised or not abide by the agreed enrolment definitions, which is known as betrayal (Sarker et al., 2006). In addition to the irreversibility, inscription or recorded commitments and agreements is another strategy for restricting betrayal or protecting certain interests (Sarker et al., 2006). Some examples of inscriptions include Memoranda of Understanding and organisational hierarchies or shared memory such as software manuals, computer programs, and procedures.

Lastly, "Mobilisation refers to stabilisation of the network" (Postma, 2009, p. 139). In this phase, network initiators use a set of methods to ensure that all the actants act according to the agreements and safeguard the initiators' or network's interests (Mähring et al., 2004). According to Callon (1986), the process involves questioning and assessing the role of a few enrolled actants or spokespeople representing other actants not directly involved, to see whether they are truly safeguarding the interests of the initiators or network. If they truly represent the masses and abide by their agreed role and positions, the identities would become fixed and the network would be stable (Postma, 2009). Otherwise, the network would not become a reality and the Translation would be incomplete.

Callon $(1986,196)$ rightfully concluded that "translation is a process, never a completed accomplishment, and it may...fail". Further, the four phases are "more fluid and interrelated" and "the order of things is created and maintained through [actants'] strategic efforts to negotiate and manoeuvre one another into networks" rather than the above simplified descriptions (Mähring et al., 2004, p. 214).

However, Calas and Smircich (1999) and a large number of studies noticed and indicated a shift of focus among ANT scholars, particularly with respect to the description of Translation. Calas and Smircich (1999) noted that scholars of early actor-network studies were mainly interested in understanding the making of a centralised network through Translation. Alcadipani and Hassard (2010) also noted that early ANT ontology was criticised for not offering the approach to denaturalise a network (e.g. an organisation) and provide the flexibility of being reflexive.

However, ANT scholars are increasingly considering how heterogeneous networks can be decentralised as well. The change of focus is commonly known as the 'Actor-Network Theory and After' or 'after ANT' (Alcadipani \& Hassard, 2010). The change was due to the fact and the critique that actants are engaging in continuous interactions during which new actors join and the interests and 
relationships change. As a result, the required realignment of interests may reshape or even deconstruct the network. Due to these alterations, networks are therefore dynamic in nature rather than stable structures (Rieger, 2008). Based on the revised or 'after ANT' perspective, networks are processes or achievements, rather than stable relations or static structures (Calas \& Smircich, 1999). Therefore, according to Moser and Law (2006), much of the earlier ANT work was managerialist and optimistic in tone; however, works in the "after ANT" period have managed to raise doubt. The change of perspective reflects the flexibility of the theory regarding the study of the nature of networks. Therefore, the flexibility allows researchers to use ANT in an unorthodox manner.

\subsubsection{Key principles of ANT}

This section describes a number of key ANT principles that collectively shape the theory. The description here not only helps to understand the range of theoretical concepts but also demonstrates the depth that has been developed over the years.

Simplification and Punctualisation are two concepts that relate to stable networks. Networks stabilise if they have gone through the successful Translation process. All the actants and sub networks abide by the agreement and perform accordingly. For the sake of appearing as a single unit or stable network, the elements are simplified and they seem to have disappeared from the network. The process is known as Simplification and the effect of simplification is called punctualisation (Law, 1992). For example, a working multimedia projector in a lecture room often seems like an invisible element during the lecture because of its punctual performance. The working projector and other similar actants represent punctualised elements that have gone through the process of simplification. When enrolled into another network, 'punctual actants' reproduce the same performance.

Black-box is a term used for the parts of a network that are punctual or perform certain valuable functions but for convenience what goes on inside them does not need to be understood (Winner, 1993). For example what goes on inside a VC system may be interesting for technicians or designers in a different actor-network but not for participants in a classroom. Such black-boxes are no longer questioned or tested, and remain entirely opaque and invisible (Latour, 1994). All that users see is a box with input and output points and punctual performance. Although the feature makes a device irreversible, it is not in principle. In principle, a black-box can be re-opened when required - called reversible black-boxing (Callon, 1991).

Reversible Black-boxing means a process that deliberately authorises opening of a black-box for any reason (Latour, 1994). Indeed, a research study can be denoted as a reversible black-boxing that permits a researcher to uncover and identify concealed actor-networks (Andrade \& Urquhart, 2010). 
However, the question, critique, and challenge for researchers are knowing and deciding where and when to stop opening black-boxes. The Criticism of ANT section further discusses the debate.

Intermediary and mediator are two different but relevant terms used in ANT sociology. Intermediary refers to an element that "transports meaning or force without transformation: defining its inputs is enough to define its outputs" (Latour, 2005, p. 30). Therefore, they can be ignored. For example, a computer for an experienced user can be considered an intermediary which enables the user to achieve a purpose; the outcome of the use is predicable. On the other hand, mediator is used for entities that make a difference in the network by modifying meaning or relationships. They "transform, translate, distort, and modify the meaning or the elements they are supposed to carry" (Latour, 2005, p. 39). Therefore, mediators are active participants in a Translation and cannot be considered black-boxes. For example, the same computer for a new user works as a mediator as it changes the user's perceptions, meaning and performance. Further, due to the changes, the outcome of the use is unpredictable. Therefore, the nature of mediators and intermediaries can change with the changing perspective (Vos, 2014).

Inscription is a feature that is mainly related to technological artefacts that have their functions or instructions written into their internal memory at the time of manufacturing. For example, software written in a VC device or an application in a mobile phone have their use and instructions coded or dictated by their designers and programmers. Through inscriptions, the designers ensure the protection of their interests and perception about the use of the device in a network (González, 2012). However, from another perspective, Rhodes $(2009$, p. 5) regards inscription as "reports, documents, text, graphics, and videos, and they refer to the way technical artefacts embody patterns of use". The strength of the inscription defines the degree of irreversibility of such actants and the durability or stability of networks (Vos, 2014). Therefore, inscription can be used for technical and non-technical elements.

Actor and Actant are two associated but different terms debated in ANT studies. As discussed above, ANT is based on the concept of a heterogeneous network in which both human and non-human elements exist with agency attributes. ANT studies contend that actors do not embody agency attributes or actantiality (potential for action) but it is their relational dimension that generates instances of action (Cordella \& Shaikh, 2003; Law, 1992; Postma, 2009). For example, an instance of slow Internet speed can disrupt an online class. Similarly, as another example, the Internet and computers can be acted upon or be used for strengthening the relationship between students and teachers. In these examples, the Internet and computers produce agency attributes only in relation to other elements. Since the term 'actor' is usually associated with or reserved for humans, ANT suggests using actant for describing both the elements. In doing so, studies can overcome the 
human connotation of the word 'actor' and thereby abide by the 'general symmetric' approach while dealing with a variety of elements (Luoma-aho \& Paloviita, 2010). This study also adopts a similar approach with consistent use of the term actant from this point onwards.

The concept of micro- and macro-actants relates to the principle of agnosticism - rejecting any presupposed distinction or superiority assumptions between actants. However, a distinction exists between actants engaged in a network through the concepts of micro- and macro-actants, which is purely based on the actant's "performative effect" in the construction of their network (Law, 2009, p. 8). In other words, ANT rejects inferential distinction and dichotomies but accepts that the difference is only brought about by power relations and role of actants in the (de)construction of their network. For example, the ability to "assemble and keep together an association of micro actants" is what makes an actant remain a macro-actant (Vos, 2014, p. 55). Thereby, the difference is subject to empirical evidence rather than a priori determination.

\subsubsection{Criticism of ANT and possible answers}

Because of its ontology, ANT has received a number of criticisms. McLean and Hassard (2004) summarised five main criticisms that have been raised by scholars. The issues include:

- the inclusion and exclusion of actors;

- the treatment of humans and non-humans;

- the nature of privileging and status;

- the handling of agency and structure; and,

- the nature of politics and power in 'heterogeneous engineering' (McLean \& Hassard, 2004, p. 493).

The issue of inclusion and exclusion was raised in the reversible black-box section above. The criticism is because the theory sees everything as networks, the boundaries where one network starts and another ends and where they overlap are not discrete (McLean \& Hassard, 2004). Therefore, the challenge for an ANT researcher or a network observer is knowing and deciding what to include and what to exclude (McLean \& Hassard, 2004). In that scenario, an ANT researcher needs to make decisions about where to start and stop data collection. Bonner and Chiasson (2005) recommend that the level of reversible black-boxing deepens until no new controversies emerge. Cresswell, Worth and Sheikh (2010) and McLean and Hassard (2004) suggest that the primary focus should be on answering the research question and making rigorous and pragmatic decisions about data collection boundaries. Vos (2014) and other studies adopt strategies such as the point of 
saturation and the emergence of no new actants or no new controversies for deciding inclusion/excision of actant.

Therefore, answer to the question of where to stop basically remains at the discretion of the researcher. An explanation of the strategy used for establishing the boundaries for ANT in this study will be discussed in the Methodology Chapter.

The two criticisms - treatment of elements and the nature of privilege - are combined here. The two points raised here are symmetry between human and non-human and then privileging humans to represent non-humans. The symmetric treatment of humans and non-humans has received most of the criticism, particularly from sociologists. Amsterdamska (1990) in the review of Latour's book, Science in Action, argued:

Latour entreats us to consider science and technology as a heterogeneous network and to abandon all distinctions between humans and nonhumans; between nature, culture, and society; between science and technology; between what used to be called the knowing subject and the various objects of scientific inquiry; between science as a body of knowledge and science as the collective practice of a group; and, of course, between science and its context" (p. 499).

According to Whittle and Spicer (2008), such criticism is about being indifferent to the distinction between objects and subjects who are actually the designers of the objects and hold real power. On the other hand, McLean and Hassard (2004) describe the issue by explaining that, in order to include non-human elements, ANT proposes humans to represent the non-humans. For example, ANT suggests IT technicians represent IT artefacts. Therefore, the theory appears to heavily rely on the human subject being centred, with little room for non-humans. McLean and Hassard (2004) borrowed the phrase 'radical form of symmetry' to explain the criticism. However, Law (1992) explains that the theory's symmetrical approach is not about the centres of power or order between human and non-human; it is about the effects of power generated in a relational and distributed manner. Going back to the example of slow Internet, the case of working Internet and IT technicians would merely be a set of black-boxed, micro-actants. In the case of disconnected or slow Internet, the major effect is produced by disrupting the whole class and the micro-actants suddenly become the centre of attention. Therefore, as noted by Elbanna (2009, p. 408), the difference or "boundary is an issue of investigation rather than a starting point".

The fourth issue relates to the dualism or interplay between agency and structure or the effects of local elements on the structure of society and vice versa - a debate of Structuration Theory. According to McLean and Hassard (2004, p. 507) the argument about the local vs. global "relates to the claim that while ANT addresses the local, contingent and processual, it fails to attend to broader social structures that influence the local". In other words, the criticism is that ANT with its general symmetry ignores the influence of macro or social structures such as institutions, governments, 
states, language, culture and so on and thus primarily concentrates too heavily on the contribution of micro-level elements or local contingencies to the production of society. However, Law (1992) asserted that if sociologists want an answer to the question of how to solve the problem of reproduction, the answer lies not only in the inclusion of technology but also in granting them the agency attribute. That is because the difference between macro- and micro-social elements is due to their "interactional effects rather than primitive causes" (Law, 1992, p. 389). Similarly, Latour (1991, p. 116) responded to the debate of local vs. global by suggesting that "macro-structure of society is made of the same stuff as the micro-structure"; the change of scale from micro to macro and macro to micro is basically induced by the actants themselves; and thus that change should be the focus, not the a priori assumptions and influences. Therefore, the redistribution of 'actantial roles' should be a subject of empirical evidence rather than presupposed determination (Elbanna, 2009).

Lastly, the criticism is that ANT fails to deal with moral and political issues with the inclusion of technology in the network (McLean \& Hassard, 2004). Elbanna (2009) noted that the moral or ethical concern is in viewing humans as machines and machines as humans and not preserving some boundary between both. However, ANT proponents assert that the equivalence is for an analytical discourse only and thus should not be a moral concern (Latour, 1991).

Regarding the lack of a political dimension, Vos (2014) and other studies noted that more recently published ANT literature, particularly the articles in ANT and After have responded to this omission. The literature addresses the criticisms by establishing that ANT has offered an analytical lens to navigate the different layers of society without being concerned whether the actant is macro or micro, or local or social (Vos, 2014). Similarly, Alcadipani and Hassard (2010) summarised that with the new perceptive of de-naturalisation and the affordance of a reflexive approach, the ANT and After development has brought the politics of organising into ANT.

In particular, as discussed in the literature review chapter, the topic of clustering has entered into political discourse, leading to the design of policy interventions in the US, the UK and many other European countries (Lazzeretti et al., 2013). The examination of the cluster concept through ANT in this study restricts the criticism. The cluster concept has been used as a policy tool by the MOE in the socio-economic context and for gaining competitive advantage for the New Zealand Government. Studying the clustering strategy as the Government's policy tool and examining the advantage of the tool for the rural population of New Zealand provides a practical example showing that ANT can cover the political dimension of a phenomenon. 


\subsubsection{Justification for using ANT}

The selection of ANT aimed to provide this research with a lens in order to visualise the network of school clusters in the Learning Exchange and help the reporting of the findings based on the actants' accounts of the events. A number of rationales helped in the selection of the theory. First, technology, users, schools, $\mathrm{MOE}$, geographical location, policies and other elements have roles in the development of the school clusters and the Learning Exchange. ANT's principle of heterogeneity remains highly appropriate for that kind of situation. The use of ANT facilitated following those actants and observing how they interacted with each other and how those interactions were transforming their networks - the Learning Exchange clusters. In addition, as claimed by Hanseth et al. (2004), ANT helped the researcher to un-box underlying actants and their associations which had remained unnoticed and were taken for granted.

Second, the adoption was also because this study is not focusing on a particular element or aspect, such as users' experience or the role of IT in the development of the cluster. In other words, the study has no prior assumption regarding the role of any of the stakeholders or aspects in the transformation of groups of schools into a network of Learning Exchange clusters. Therefore, the tenets of agnostic, free association and general symmetry provided by a socio-technical middle ground guided how to approach various aspects of this study without any preference (The Methodology Chapter has discussed this point).

The third key rationale was the research questions. Law (2009) justifies that ANT is an approach, not a theory, because a theory usually 'explains why' something happens, whereas ANT 'describes how' things relate or do not relate. Precisely, this research utilised the process of Translation in the Findings Chapter to 'tell stories about how' some of the clusters managed to develop and become self-sustaining and how some of the clusters did not.

Fourth, the affordance of ANT allows researchers to adopt the theory as a research method with its own philosophical paradigm or to employ the theory as a theoretical lens in conjunction with other research paradigms, in particular the interpretive paradigm. Since this study was interested in sociomaterial constructivism within an interpretivist paradigm and qualitative methodology, using ANT as a theoretical lens was identified as a good fit, facilitating the research paradigm.

For example, the heterogeneous belief of ANT was appropriate for the role of social and material actants in the construction of the Learning Exchange network. Similarly, adopting ANT's method for data collection and an analytical lens and using that with an interpretivist epistemology is although debatable not a novel approach (Cordella \& Shaikh, 2003). This study admits the 'magnitude of the theoretical foundation of ANT' and does not intend to 'suppress ANT's own ontology' as emphasised 
by Cordella and Shaikh (2003). However, this study has taken the opportunity or the flexibility permitted by the depth of the ANT philosophy to use the theory in a limited way as a lens and not to use it in a holistic fashion and in its radical form.

In particular, the findings chapter uses the four phases of Translation from ANT to allow the 'actants to speak' for themselves and construct their network. The chapter reports in detail the input from the research actants only; the actants construct the four Learning Exchange clusters or networks without the researcher's interpretation or any evidence from the literature. Therefore the reality basically emerges from the actants' input. Later, in Chapter 6 the findings are interpreted by the researcher with barely any reference from ANT. Therefore, the use of ANT remains appropriate for the research methodology.

Fifth, none of the above criticisms had raised any significant issue or created any discrepancy with any part of this research. In fact, the inclusion of non-humans basically left the options open for identifying the supporting and inhibiting factors that might relate to human or non-human actants. Similarly, the concepts of macro- and micro-actants did not exist before the data collection. Indeed, they not only appeared during the Translation process but also helped to describe various roles and relations coming under an organisational hierarchy (which a reader might interpret as a topic of organisational politics). Similarly, the study is neither taking any political stance nor evaluating moral values.

Lastly, some other theories were also investigated as possible lenses for the study; however, they were not as appropriate. For example, Task Technology Fit (TTF), the Technology Acceptance Model (TAM) or Unified Theory of Acceptance and Use of Technology (UTAUT) are commonly applied to examining technological innovations, uses of technologies and individuals' performance. TTF is a model that provides individuals with a framework to achieve positive impacts on their performance by providing a better fit between tasks and the use of technology (Goodhue \& Thompson, 1995). TAM is concerned with the user's acceptance and use of a technology by identifying the influencing factors (Davis, 1989). Similarly, UTAUT is used for measuring factors that can influence individual users' intention and behaviour towards the acceptance and use of a technology (Venkatesh et al., 2003).

Structuration Theory was considered but it is mainly concerned with the examination of the interplay between agency (an individual's ability to act freely) and structure (the influence of social norms such as class, gender or religion) without agency attributed to technology (Jones \& Karsten, 2008). Adaptive Structuration Theory augmented Structuration Theory with the inclusion of technology. According to DeSanctis and Poole (1994), it is an approach for studying the role of IT in 
organisation change or the study of two structures: one brought in by IT and the other from human interactions in organisations. However, AST makes an a priori assumption that IT has a role in the change process and thus was not as appropriate as ANT given the objective of this study.

Therefore, criticisms of ANT were not considered a significant concern for this study. Further, this study used Complexity Theory as an additional theoretical lens complementing the use of ANT. The combined use is not only to provide an additional lens but also help to overcome or address some of the aspects/areas that might not be feasible with one theory. The next section describes Complexity Theory and discusses the fit between the theories.

\subsection{Complexity Theory}

This study uses Complexity Theory to complement the use of ANT. Specifically, ANT is used in the Findings Chapter for reporting the research findings, whereas Complexity Theory is used in the Conclusion Chapter for the discussion and generalisation of the findings. The rationale for using complementary theories and the fit between the theories are discussed in this chapter. This section is organised as follows. The next subsection gives some background information before defining the theory and complex adaptive systems. That is followed by the explanation of the key features and principles of complex adaptive systems. Further, some examples of the previous studies from Information Systems using Complexity Theory are provided to indicate that Complexity Theory is not an uncharted area for the IS scholars. A justification for the use of Complexity Theory is presented at the end of this chapter before the summary section.

\subsubsection{Background information}

The theory has roots in the work of Darwin's theory of evolution (Burke \& Shaw, 2007). Since the theory and its application are very broad, the description of Complexity Theory depends on the context in which the theory is being applied. The theory is interdisciplinary and has grown out of many theories including systems theory. Mitleton-Kelly (2003) regards the theory as interdisciplinary with key principles coming from biology, chemistry, artificial intelligence, robotics, and physics as well as sociology, economics and law. Therefore, it is mainly explained with respect to systems from technical and mathematical perspectives. The theory has been applied in organisational and social systems. Therefore, besides the association of the word 'systems' with complexity, other alternate words such as problems, situations, behaviour, structure, nature and organisations are also used to explain the theory.

However, according to Manson (2001, p. 405), "any definition of complexity [theory] is beholden on the perspective brought to bear upon it". Therefore, based on the research perspective and area, this study adopts the explanation of the theory from the 'aggregate' type. That is because the type 
of complexity closely relates both to this research as well as to the definition of the theory that is followed in this thesis. In addition, since the theory is very broad and interdisciplinary, the classification facilities the research with the provision of a narrow focus.

Manson (2001) classifies Complexity Theory on the basis of major disciplines in order to provide a coherent understanding of the theory; the listing includes three key types:

- Algorithm Complexity is regarded as the form of mathematical complexity theory.

- Deterministic Complexity deals with Chaos Theory and Catastrophe Theory that mainly suggest that two or three key components of a system can create large effects on the system. The concept is known as the butterfly effect.

- Aggregate Complexity focuses on the relationship between individual components of a system giving rise to the system with complex behaviour. In other words, the type or the category of the theory addresses "how individual elements work in concert to create a system with complex behaviour" (p. 405).

However, Reitsma (2003, p. 13) criticises the above classification by arguing that "[they] are different theories of the definition of complexity rather than different types of Complexity Theory". This is noted to indicate the existence of opposing views.

\subsubsection{Defining Complexity Theory}

The theory refers to a system as complex when the future behaviour of the system cannot be predicted, but rather emerges through the interactions between system units at the low level (Hasan, 2014; Kim \& Kaplan, 2006). In other words, a complex system's behaviour cannot be predicted but understood through the study of interactions between the system components. By focusing on the system components or units, one can only know about the units and not necessarily about the whole system and its behaviour (Burke \& Shaw, 2007). That is because of the continuous, dynamic and recursive interactions between the units of a complex system, which subsequently produces emergent behaviour.

From an organisational perspective, organisational management, politics or infrastructure are examples of complex systems, because they are multidimensional, consisting of multiple elements in inter-connected relationships. From a social perspective, communities and social groups are complex systems because of multiple memberships and inter-relationships. A biological body and our weather system are some other examples of complex systems. Complexity Theory views those complex systems as the outcome of dynamic and recursive interactions and links between the elements and the elements and the system. Thereby, to understand the nature, structure or 
behaviour of a complex system, the study of interactions should be the main focus. The definition or the suggested approach "stands in stark contrast to conventional science which is based upon Descartes's reductionism, where the aim is to analyse systems by reducing something to its component parts" (Cham \& Johnson, 2007, p. 1).

The literature makes a clear distinction between the terms complex and complication while introducing the theory. In contrast to the complex systems' definition, a Complicated System is one that "can be given a complete and accurate description in terms of its individual constituents, no matter how many, such as a computer" (Reitsma, 2003, p. 14).

Based on several characteristics of the system, alternate names are used for complex systems. Anderson (1999) and others prefer to use 'complex adaptive systems' or CAS, because of the adaptive nature of the systems. Mitleton-Kelly (2003) prefers using 'complex evolving system' (CES) because CES is more appropriate and better representative of the principles of complex systems. This study has chosen complex adaptive systems since the name is widely used in the complexity theory studies and the name fits better with the research.

\subsubsection{Key Features of Complex Adaptive Systems}

According to Hasan (2014), a complex adaptive system has a number of features that make its behaviour or nature adaptive as well as unpredictable. First, complex adaptive systems have a large number of units. The units in isolation are simple sub-systems; therefore, their nature or behaviour can be understood by studying them individually. Second, the units interact with each other in a dynamic, rich and non-linear manner. The non-linear interactions mean interdependencies (solving one aspect might disrupt/unbalance another aspect) and connectedness between components. Therefore, "Complex behaviour arises from the inter-relationship, interaction, and inter-connectivity of elements within a system and between a system and its environment" (Mitleton-Kelly, 2003, p. 4). Third, as a result of the asymmetric, multidimensional interactions, the system as well as the system units continually change and adapt to the changes. They never stabilise or fix at one position, as "fixity in the environment and its components does not exist" (Cohen, Manion, \& Morrison, 2006, p. 2).

Fourth, complex adaptive systems have open boundaries, making the system difficult or nearimpossible to be defined. The feature means the system is open to exchanging influences with the outside world. More precisely, complex adaptive systems exchange information and energy with the systems outside the system boundary. As a result, the system and the system components tend to self-organise and co-evolve themselves (Burke \& Shaw, 2007). Systems with closed boundaries face a 'radical decomposition' due to their inability to exchange information, exert and receive influence. 
Such systems remain fixed and without any adaptation feature, hence they decompose and disappear. Lastly, as a result of the above four, the system exists with an un-ordered, complex behaviour or a behaviour that sits between the 'ordered' and the 'chaotic' situations. For this reason, the term 'edge of chaos' is sometimes used to explain complex adaptive systems.

Figure 3.2 adapted from Cohen et al. (2006), provides a simplified illustration of system elements with a number of connections, giving rise to the emergence of a new structure. In turn, the new structure influences individuals. In addition, the dotted boundaries indicate the permeability of the system.

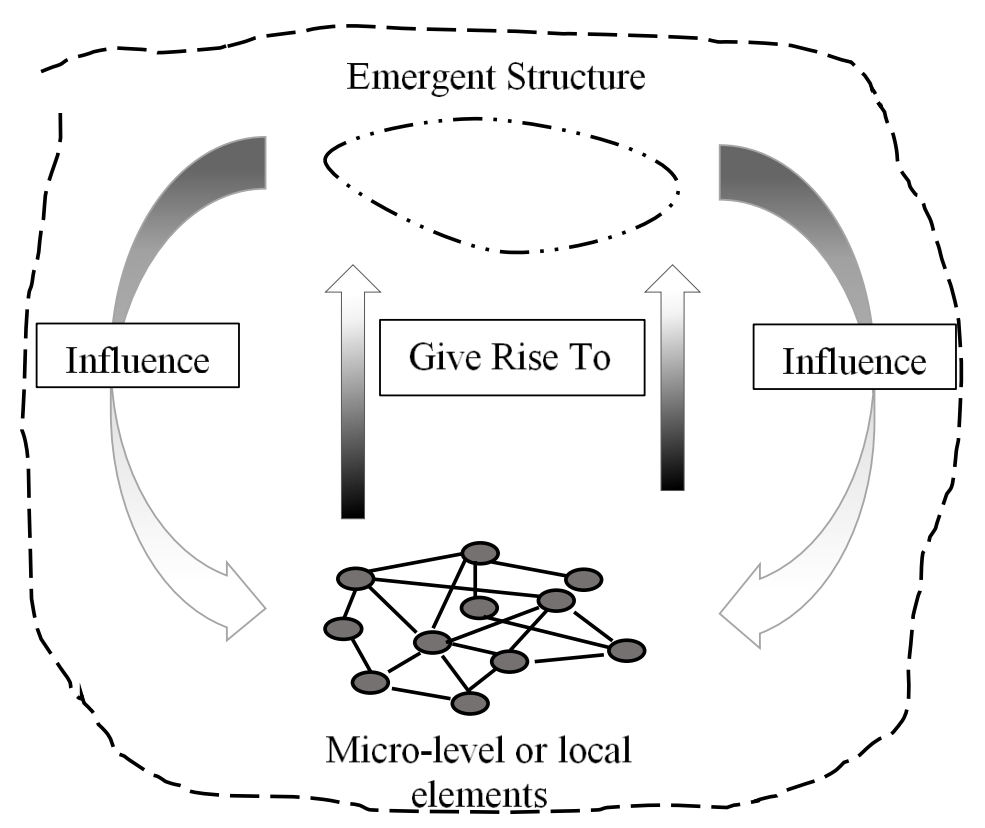

Figure 3.2 Emergence of a complex adaptive system

The following Figure 3.3, by Clemons $(2006)^{3}$, provides an elaborated view of complex systems with their key characteristics. Both the figures have been used to describe CAS in the following sections.

\footnotetext{
${ }^{3}$ Reprinted with permission from Marshall Clemens/New England Complex Systems Institute). Available at: www.necsi.org/projects/mclemens/cs char.gif
} 


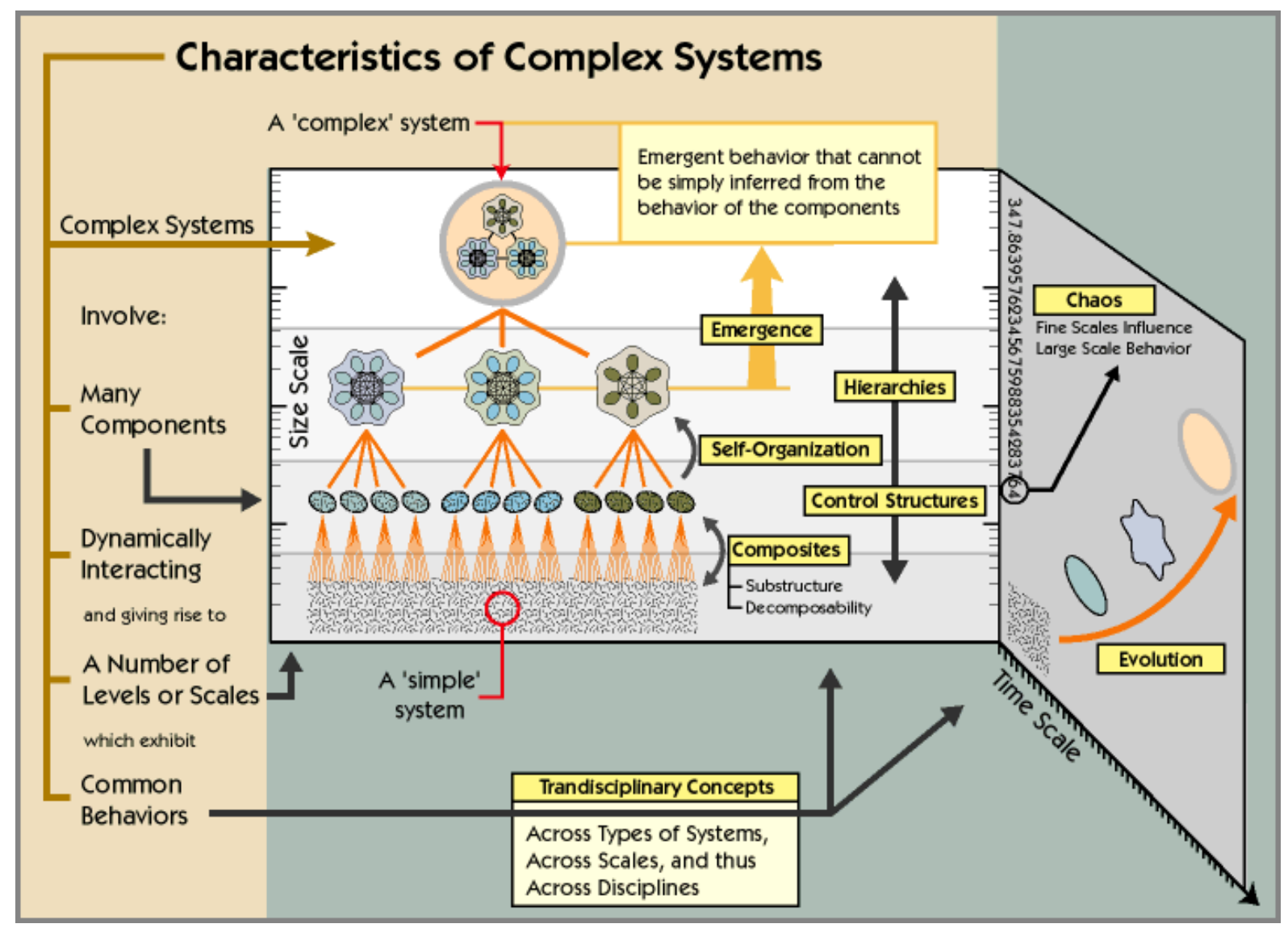

Figure 3.3 Characteristics of Complex Adaptive Systems

\subsubsection{Principles of Complex Adaptive Systems}

The principles of emergence, co-evolution, self-direction, self-organisation and interaction are paramount in Complexity Theory (Hasan, 2014). The following sub-sections briefly describe these concepts and some others related to this study. These concepts will be used in the Discussion Chapter for the conceptualisation and abstraction of the research findings.

\subsubsection{Interaction and connectedness}

Interaction and connectedness between individual units of a system are the keys to the rise of a system with complex behaviour. As mentioned above, system units interact with each other but in a non-linear manner. In fact, the interactions within a system and between a system and its environment are very asymmetric, non-linear and dynamic. That is because of the degree of connectivity and the interdependence. As a result, new systems and patterns emerge (Vessey \& Ward, 2013).

Connectedness in a complex adaptive system refers to the links, interconnectivity, and internal and external relationships. According to Mitleton-Kelly (2003), connectivity and interdependence in a human system mean that "a decision or action by any individual (group, organisation, institution, or human system) may affect related individuals and systems" (p. 5). Therefore, if one element in the 
connections is disturbed, either the element or system must adapt or die. Therefore, as described by Cohen et al. (2006), connectedness allows the whole system to survive by adapting and communicating. Mitleton-Kelly (2003) however argues that ever-increasing interconnectivity implies greater and wider ripples of disturbance and thus may not remain beneficial.

\subsubsection{Emergence}

As shown in the above figures, emergence is a bottom-up process that enables a higher-level hierarchy, structure or system to come into being and become important. According to Cohen et al. (2006), complex, global, diverse forms often derive from local elements with comparatively simple, local sets of rules and behaviours. The process of emergence means the "behaviours of complex systems clearly do not fall into our conventional top-down perception of management and production" (Cham \& Johnson, 2007, p. 2).

\subsubsection{Rules of interaction}

Interactions between system elements are based on their rules, also known as the rules of interactions or the principles of interactions. According to Mitleton-Kelly (2003), the rules of interaction are the underlying factors that set the dynamics of the relationship between local elements of a system. In other words, "Agents' actions are based on internalised rules" (Plsek \& Greenhalgh, 2001, p. 625). From the cluster perspective, those 'rules of interactions' are the underlying factors guiding the actions of cluster leaders.

Every system has their own internal rules and so do the school clusters. One of the research objectives is to identify those uncovered 'rules of interactions' for the development of school clusters and the Learning Exchange programme.

\subsubsection{Feedback and influence}

The terms feedback and influence are related. Feedback occurs in loops between interacting elements of a system (P. Anderson, 1999). Cohen et al. (2006) link the strength of an association with the recurrence of feedback. The greater is the recurrence of feedback, the stronger is the association as well as the influence. Influence can be regarded as a catalyst for the process of coevolution (Vessey \& Ward, 2013). As simplified in Figure 3.2, low level elements interact and give rise to new structures. In turn, the structures influence the elements and thus the whole system coevolves.

Complexity literature suggests two types of feedback: negative and positive. Negative feedback brings diminishing results or maintains stability in a system; therefore such feedback is regarded as balancing, moderating, or dampening (Byrne, 1998). For example, a pass or fail result can be 
regarded as negative feedback for a student, because the type of feedback only informs about overall success or failure and is least likely to lead to any amplification. On the other hand, positive feedback leads to reinforcement or amplification, which can drive change and bring increasing returns in terms of growth and development. For example, indicating the areas for further improvement provides rich feedback for a student to improve.

From the complexity perspective, complex adaptive systems have feedback between interacting elements, which are not only positive but also rich and in the loop (Mitleton-Kelly, 2003). The feedback allows the system to reinforce itself.

\subsubsection{Self-organisation and self-direction}

Emergence and self-organisation are partners in a complex adaptive system since new structures emerge due to self-organisation of system elements. Self-organisation can be regarded as the ability of the interconnected, interdependent and autonomous elements of an adaptive system to evolve into an organised form without the support of external forces (Hasan, 2014). The characteristic allows the system to respond to internal and external influences by re-organisation. For example, when a complex adaptive system receives energy or a piece of information from outside or from within the system, the system and its elements tend to re-organise and adapt to the changes (Burke \& Shaw, 2007).

The principle of self-organisation not only allows system components to form higher level hierarchies but also decompose into units. The decomposability is the complex adaptive system's ability to dismantle into levels and units without any loss of information (Wu \& David, 2002). The reason for decomposition is the loose vertical and horizontal coupling of the elements. It is a CAS feature because the process allows loosely coupled units and hierarchies to re-organise without any loss. However, a 'radical' or 'complete' decomposition is a concern as interactions do not exist between components.

From an organisational context, self-organisation can be a spontaneous grouping of people for a purpose. The group adapts and re-organises when some external factors influence it. Similarly, from the cluster perspective, since schools in New Zealand are autonomous bodies, they address their local needs and interests. More precisely, before the initiation of school clusters, various local schools from the Otago and Canterbury regions of New Zealand self-organised through self-initiative and formed their local school group. Later, the small group of schools from the local community level went through a further self-organisation process and eventually gave rise to the emergence of their local cluster - a structure that is more complex. 
On the other hand, clusters will disappear or go through 'complete decomposition' if there are no interactions or very weak interactions between their units.

A self-organised group is self-directed, departing from a command and control philosophy (Hasan, 2014). The feature of self-direction allows member schools of a cluster to choose the educational programme that suits their students and staff needs.

It should be noted that the characteristics of self-organisation and self-direction are more relevant to the Aggregate type of the Complexity Theory and less to other types. For example, a computer or machine might be automated but not self-organised and self-directed. That is another reason for choosing Aggregate complexity rather than Algorithm and Deterministic types of complexity.

\subsubsection{Co-creation and co-evolution}

The self-organisation and self-direction of system components allow the unleashing of the creative energy of the components (Hasan, 2014). A "co-evolution takes place within an ecosystem, and cannot happen in isolation" (Mitleton-Kelly, 2003, p. 7). Through interactions, components influence the system's behaviour and the system also influences the components. Similarly, the system interacts with other systems in their ecosystem. As a result, they influence and are influenced by others. Hence, the whole ecosystem adapts and co-evolves and thus the desired outcome is cocreated.

For example, through inter- and intra-cluster communication, member schools in a cluster not only influence each other and their cluster but also exert an impact on others in their Learning Exchange ecosystem. This means that the evolution of one cluster (partially) depends on the evolution of another cluster. In other words, the demise or the growth of one cluster affects the evolution of others and their whole ecosystem. Therefore, it is important to identify the factors leading to the self-sustainability and demise of clusters.

\subsubsection{Edge of chaos or self-organised criticality}

The term edge of chaos means that as a result of continuous self-organisation and co-evolution, a self-organised criticality or edge of chaos can be reached. Therefore, the movement towards evolution through adaptation for survival is a movement towards self-organised criticality. In a positive sense this means when a system moves closer to the edge of chaos, the prospect of a major breakthrough can revive a stalled or stagnant situation (Hasan, 2014). From an organisational knowledge sharing perspective, the closer an organisational system moves towards the edge of chaos, the more creative, open-ended, diverse and rich are the practices and ideas of the organisation and individuals, and the greater the connectivity, networking and information sharing between participants (L. Cohen et al., 2006). 
Apart from the above key principles, a number of other concepts exist in the complexity related literature. Cohen et al. (2006) outline a detailed list of components of Complexity Theory. Figure 3.4 gives a snapshot of the concepts that have been indicated but not described in detail in the above sections.

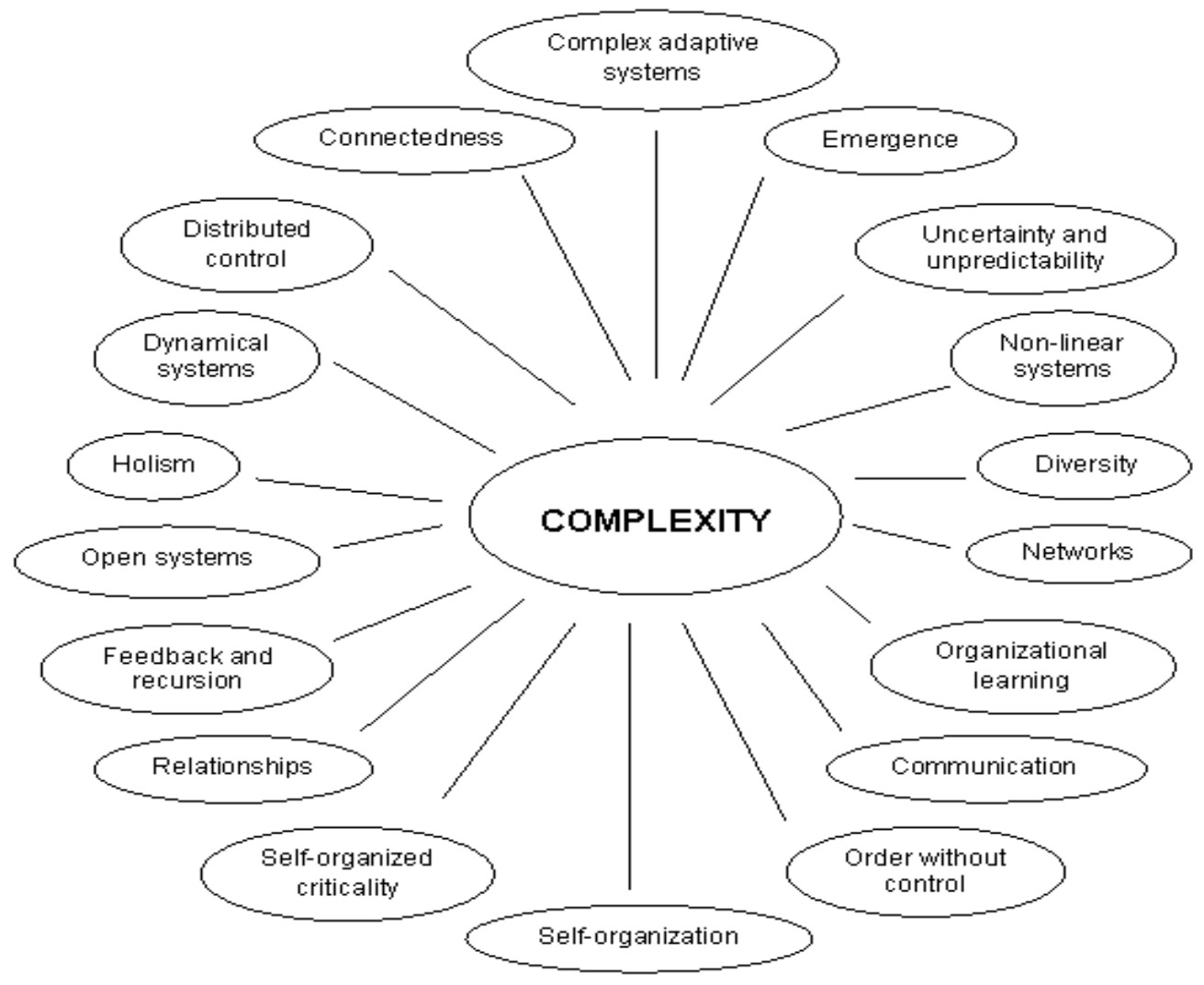

Figure 3.4 Components of Complexity Theory

\subsubsection{Use of Complexity Theory in Information Systems}

Two Information Systems' journals - the Journal of Information Technology, and Information Technology \& People -published special issues ( Jacucci, Hanseth, \& Lyytinen, 2006; Merali \& McKelvey, 2006) on the topic of complexity (Hassan, 2014). Kim and Kaplan (2006, p. 191) noted a tendency to disregard the contextual nature of systems and organisations during IS engagement, "thereby ignoring the co-evolutionary phenomena that drive both in new, and largely unanticipated, directions". Therefore, the authors recommend IS scholars apply CAS to enhance understanding of the co-evolutionary nature of IS engagement. Vessey and Ward (2013) believe that organisations and their Information Systems are CAS that co-evolve; therefore, they use the theory to address sustainable IS alignment in organisations. Burton (2013) believes that organisations co-evolve with their environment and Complexity Theory can be used to study the IT resources' alignment with business needs. Similalry, Nan (2011) draws a framework for the bottom-up IT use process by using complex adaptive systems theory. 
Moreover, both the theories have been combined in a number of studies. Hanseth, Jacucci, Grisot and Aanestad (2006) used ideas from ANT and Complexity Theory to study the socio-technical complexity of IS standards and standardisation efforts. Kim and Kaplan (2011, p. 5) analysed the commensurability of CAS theory and ANT to study co-evolutionary dynamics of IS emergence, because both the theories "share a common theory of existence and reality, i.e., ontology...[and] a common theory of knowledge, i.e., epistemology". By synthesising them, both the theories can provide a clear picture of a phenomenon (Kim \& Kaplan, 2011, p. 9):

ANT provides the apparatus to analyse how interaction dynamics unfold. It enables us to generate a narrative on the transformations and their mechanics - through enrolment, translation, punctualisation, and black-boxing. ANT reveals how complex phenomena are constructed, aligned, emerge, and are sustained as actor-networks. In doing so, ANT overcomes CAS's state-based analysis by highlighting how transition between states, or alternate landscapes, actually occurs. When the complementary insights of each theory are overlaid it is hoped that we will gain a clearer picture of the co-evolutionary dynamic of IS engagement.

Other studies, such as Fenwick (2010), Masys (2008), Masys (2010) and Stalder and Clement (1997) have also combined both the theories.

\subsection{Complexity Theory and Actor-Network Theory}

Using an additional theoretical lens to complement another theory is not uncommon. However, consideration is required before combing two theories in a single study. Studies are required to explicitly discuss the need for using two lenses, assess the fit between the potential theories and the research methods, and identify the possible contributions as well as challenges.

A number of reasons exist for using Complexity Theory to complement the use of ANT. The first reason is the high expectations from the level of studies. The expectation from Ph.D. studies is not only being highly conceptualised with an insightful research outcome but also making some theoretical contribution. The expectation can be addressed by employing more than one theory or analytical lens. The second reason is to overcome various limitations due to which both the theories might be criticised. For example, sometimes, one theory focuses more on one aspect of a problem than the other. Combining two theories allows the researcher to create a balanced and more inclusive view or lens for the study. For example, ANT takes into account minor details with a great level of focus on the elements or actants in the making of a network. On the other hand, complexity theory has less focus on the elements but more on the interactions between the elements and the outcome of those interactions. Therefore, both the theories complement each other by overcoming each other's shortcomings. The third reason is to allow the conceptualisation and generalisation of the findings. In this study, ANT has been used for data collection and reporting of the findings. 
Complexity Theory has been used to build upon those findings by taking the findings' outcome to a higher abstraction.

Regarding the fit between Complexity and ANT, no such criticism exists that would have been concerning for this study. Other doctoral studies such as Masys' (2010) have successfully combined Complexity Theory with ANT. The only point of concern is the slight difference of focus between both as mentioned above. That is a minor concern because both the theories are being used to cover different aspects of the research study. The socio-technical lens from ANT is used for the data collection and the reporting of the findings, whereas the principles of complex adaptive systems from the Complexity Theory are used for building upon the findings in the Discussion Chapter. The integration provides a 'complex socio-technical system' perspective. As a result, on one side, the combination generates insights and enhances the depth of conceptualisation while on the other side, integration remains a possible theoretical contribution of this study.

Regarding the level of fit between potential theories and the research methods, Complexity Theory suggests that complex adaptive systems have open boundaries and the growth or existence of a system basically depends on the openness or dissipativity of the systems. In other words, openness means system boundaries are fuzzy and fluid. In contrast, the case study method mainly involves the study of cases with (reasonably) distinguishable boundaries. For example, clusters can be viewed as educational systems with distinguishable boundaries. The standpoint from Complexity Theory also closely relates to ANT's stance on a network. That could be a possible challenge for this study. The challenge of establishing a research boundary is further discussed in the Methodology Chapter.

Another possible challenge is the different stance of both the theories on some aspects of a network or a system. For example, ANT is more concerned about network stability, compared to the uncertainty and unpredictable nature of systems in Complexity Theory. Network stability followed by irreversibility are the ultimate goals for actor-networks in ANT, whereas complex adaptive systems are defined as dynamic and not stable. That is because fixity of a system and its components is an indication of failure (Cohen et al., 2006). This study uses the term 'dynamic stability' to refer to self-sustainability and avoids the use of the term 'stability'. By doing, the gap between both the theories is minimised and thus the challenge is addressed.

\subsection{Chapter Summary}

The chapter explored and explained ANT which has been utilised for the reporting of the research findings. The chapter described the tenets of heterogeneity and symmetry along with the principles of agnosticism, generalised symmetry and free association. The translation process was explored and identified as a programme of actions for the development of a heterogeneous network. The 
discussion of those principles showed how ANT's analytical lens can be used for describing an event of transformation. The criticisms of ANT demonstrated the challenges that a researcher might encounter during an ANT-guided study. A justification of the use of ANT discussed the appropriateness of ANT for the reporting of the actants' accounts of the events regarding the development of the clusters and the Learning Exchange programme.

In order to provide a comprehensive view or address some of the aspects that might not be conceivable with one theory, Complexity Theory was selected to complement the use of ANT. Complexity Theory has been restricted to the discussion and conceptualisation of the research findings in the Discussion Chapter only. With that view, Complexity Theory was reviewed and the principles underpinning the theory were explained. Before this section, the need for a combined use of both the theories was considered by reviewing previous studies particularly from the IS discipline. The assessment included the identification of fit between both the theories while considering major aspects of the research, including the research objectives, questions, methods as well as possible contributions and challenges. 


\section{CHAPTER 4: THE RESEARCH METHODOLOGY}

\subsection{Introduction}

The research aim was to describe how the Learning Exchange was developed and describe the factors that supported and inhibited sustainable development. This chapter discusses the selected methodological stances and provides justifications for the research positioning. Further, the research design section describes the unit of analysis and the selection of the four cases (clusters) for data collection. The section also discusses the data gathering process and the data analysis strategy as well as related issues and challenges during the processes. Lastly, the chapter explains how the study addressed the challenge of quality and rigor during the research process.

\subsection{Research Paradigm}

A research paradigm is a set of assumptions or the world view that guides a researcher in how to understand and study the nature of a reality (Guba \& Lincoln, 1994). The following sub-sections describe the research paradigm - social constructivism. According to Guba and Lincoln (1994), studies with a constructivism paradigm aim to 'understand and reconstruct existing constructions'. Research paradigms are considered to have three key dimensions: ontology, epistemology, and methodology. In brief, these three dimensions represent the nature of the world, the researcher's place in that world and the range of possible relationships (Guba \& Lincoln, 1994). The following sections discuss these dimensions in relation to the constructivism paradigm.

\subsubsection{Ontological dimension}

A research ontology is concerned with the nature of a reality or the question and answer of what is real that can be known (Guba \& Lincoln, 1994; Walsham, 1995). In order to understand or view a reality, Fitzgerald and Howcroft (1998) outlined two main approaches - realism and relativism - that IS researchers commonly adopt. With a 'realist' ontological position, a reality is a set of tangible objects that can be studied independent of or without researchers by experiments in laboratories (Walsham, 1995). Fitzgerald and Howcroft (1998) regard realism as a 'hard' approach because it recognises the external world as pre-existing hard structures independent of an individual's cognition.

On the other hand, the relativist ontological position considers the external world to be subjective and dependent on its relative contexts (Field, 1982). With such an assumption, a reality remains intangible, soft in nature and with no fixed frame; therefore, a reality needs to be co-constructed by research participants and researchers (Fitzgerald \& Howcroft, 1998). 
This study considers the Learning Exchange or the phenomenon of interest a reality that consists of a host of sub-realities, interpreted differently by different actants based on their individual understanding. The individualistic view regarding the programme needed to be understood and reconstructed. Therefore, this research takes a relativistic ontological position.

\subsubsection{Epistemological dimension}

A research epistemology is concerned with the nature and justification of knowledge claims, representing the relationship between a researcher and a reality (Guba \& Lincoln, 1994). In other words, the dimension is about the stance that a researcher takes in the study of a phenomenon. To further clarify, Myers and Klein (2011) inform researchers regarding three epistemological positions - positivist, interpretivist and critical - for knowing about a reality. (The classification was previously proposed by Chua in 1986).

The positivist epistemology is a "Belief that [the] world conforms to fixed laws of causation"; therefore the approach is followed for verifying existing knowledge (Fitzgerald \& Howcroft, 1998, p. 9). The stance is usually taken for testing and validating existing knowledge about a reality (Myers, 1997). The critical epistemology is concerned with the critique of a reality by taking a moral stance (Myers \& Klein, 2011). According to Orlikowski and Baroudi (1991), the studies with a critical epistemology aim to expose "deep-seated, structural contradictions within social systems" for transforming the conflicting social conditions.

However, the interpretivist epistemology is concerned with the social construction and interpretation of meanings regarding phenomena (Myers \& Klein, 2011). In other words, people assign meaning to a reality based on their subjective perception. Therefore, realties are not fixed but change constantly. With that stance, the job of a researcher is to help participants with the coconstruction of a reality (Creswell, 2013).

This research is neither aimed at validating nor criticising any aspect of the Learning Exchange. Instead, the aim is to understand the participants' (or actants') understanding of the Learning Exchange and report and interpret those views, including contextual factors of the Learning Exchange phenomenon. Therefore, this research will follow an interpretive epistemology. By doing so, as exemplified by Klein and Myers (1999, p. 73), this "research seeks to understand a moving target".

It is important to clarify here that this study is using ANT as a lens within the interpretive paradigm. In other words, ANT is not used in this study as a method with its own ontology. Instead, the ANT lens is adopted to collect data and report the findings and then the interpretive paradigm is followed to interpret the reality by the researcher. By having this approach, this study hence avoids any 
possible clash between ANT and the interpretive paradigm, which has been discussed by Cordella and Shaikh (2003).

\subsubsection{Methodological dimension}

A research methodology identifies the techniques or procedures used by a researcher to best gain knowledge about a reality. According to Guba and Lincoln (1994, p. 108), the methodology involves the question of "How can the inquirer (would-be knower) go about finding out whatever he or she believes can be known?" Traditionally, three main research methods have been used in Information Systems studies: quantitative, qualitative and mixed methods. Quantitative research methods are designed to measure or validate hypotheses and correlate the strength of relationships between different variables (Straub, Boudreau, \& Gefen, 2004). Qualitative research methods focus on the exploration and reporting of rich information in order to develop a deep understanding of that phenomenon (Fitzgerald \& Howcroft, 1998). Mixed research methods combine both the qualitative and quantitative approaches for developing 'richer and deeper' insights regarding phenomena (Venkatesh, Brown, \& Bala, 2013).

Although the advantages of mixed methods are considerable, this study does not intend to validate or measure relationships between any variables. The study is mainly focused on providing a deep understanding and explanation of the development of the Learning Exchange as a complex social phenomenon. Therefore, the adoption of qualitative research methods remains a better fit for this study as well as the ontological and epistemological dimensions.

\subsection{Research Strategy}

Within qualitative research, a number of strategies are used in IS studies. According to Myers (1997), IS researchers use four main qualitative strategies: action research, case research, ethnography and grounded theory. The case research strategy has been adopted for this study, which is explained in the next section.

\subsubsection{Case research}

The case research is one of the strategies commonly used in IS for studying one or multiple cases (Myers, 1997). The strategy easily accommodates contextual and in-depth information through a variety of data collection procedures (Orlikowski \& Baroudi, 1991). According to Paré (2004), case research is useful: 
- "when a phenomenon is broad and complex

- where the existing body of knowledge is insufficient to permit the posing of causal questions

- when a holistic, in-depth investigation is needed

- when a phenomenon cannot be studied outside the context in which it occurs" (pp. 233-234).

According to Yin (2016), dealing directly with the phenomenon of interest within its actual context and getting as close to the case as possible are what make the case research strategy significant. In addition, with the strategy, the case and the context would be at the centre of interest and the main concern, not variables (Yin, 2016). Further, as Yin (2014, p. 16) stated, case research is used "especially when the boundaries between phenomenon and context are not clearly evident". This means that the scope of a case research would then go beyond the boundary of the phenomenon of interest in order to include the real-life context of the phenomenon.

This study selected multiple cases (four clusters) for data collection and eventual comparative analysis. The multiple cases were chosen to allow the findings to emerge from four varied cases and hence be robust. In addition, as described by Yin (2014), the multiple cases were compared to identify similarities and differences and hence allow the establishment of supporting and inhibiting factors. The case selection process is explained later.

\subsubsection{Selection of the case research}

With regard to this study, the Learning Exchange is a single case consisting of multiple sub-cases (clusters). Each of those cases was initiated in different locations in New Zealand and has unique priorities and needs. Each of those clusters operating within the case of the Learning Exchange had local socio-economic and community settings, based on which they had been initiated. This meant that the clusters needed to be studied within their contextual circumstances.

In addition, the cases consisted of contributions from both 'humans and technology'. In other words, the cases were co-developed in the form of the Learning Exchange by various elements. That meant various participants had individual perspectives regarding the case. Therefore, the phenomenon of interest was broad and complex.

Further, the development of the Learning Exchange had received very little attention from scholars and researchers. The existing attention had addressed some of the individual clusters or cases with successful development stories. The stories of less successful clusters and those that have disappeared were untold. As a result, an insufficient body of knowledge existed regarding the case of the Learning Exchange and a holistic and in-depth view was missing. Hence, the case research strategy was perceived as a good fit. 
With regard to the appropriateness of the strategy for the research question, Yin (2014) suggests case research as a more appropriate qualitative strategy for studies with 'how' and 'why' questions. Since this study aimed to answer how the clusters were developed and how the Learning Exchange was utilised, the method was found to be more appropriate for answering the questions.

Furthermore, the purpose of the case research can be descriptive, exploratory and explanatory (Yin, 2014). Descriptive case research studies intend to describe the phenomenon of interest in its realworld context, exploratory studies tend to assess research questions or propositions that would be used for further studies, and explanatory case research studies seek to address arguments regarding some sequence of events that might have or have not occurred (Yin, 2014).

This study aimed to provide an in-depth description of the case, including the identification and description of relationships between different elements in the Learning Exchange clusters.

Therefore, a descriptive case research strategy was perceived to be consistent with this study.

\subsubsection{Unit of analysis}

This study considered each cluster of schools as the unit of analysis. As discussed in the literature review chapter, a cluster in the Learning Exchange refers to a geographical group of schools from the same region taking part in online teaching and learning. A number of those school clusters have collectively formed the Learning Exchange. Therefore, the individual cluster was considered the logical unit of analysis.

To further clarify, two types of clusters existed in New Zealand schools in general. The ICTPD cluster as discussed in the literature review was primarily for teachers' training. In addition, the ICTPD clusters were not necessarily 'virtual' in nature. In contrast, clusters in the Learning Exchange were mainly for addressing the needs of students from small rural secondary schools and were solely of a 'virtual' nature. For virtual collaboration, they used VC, Adobe Connect, Google Hangout and other video-conferencing tools. Therefore, the differences were very evident between both the types of clusters. Hence, the unit of analysis in this study can easily be distinguished and used by any other study.

After defining the case, as suggested by Yin (2014), the research objective was revisited in order to re-identify the aspect of the unit of analysis to be investigated. The research objectives were to study the development of clusters and identify the supporting and inhibiting factors for selfsustainable development. The study proposition was focused at 'the development of self-sustaining clusters'. Therefore the study mainly focused on collecting data regarding the cluster development aspect rather than, for example, focusing on the design of the courses for online classes, the fit between teaching and learning styles or communities of practice for e-teachers. 


\subsubsection{The Cases in the Learning Exchange}

Since the inception of the reciprocal exchange model in the early 2000s, around 20 school clusters were formed in New Zealand. Table 4.1 provides a list of the clusters and a timeline of their initiation periods. These clusters possessed some common attributes that were perceived as possible case boundaries distinguishing them from other clusters. Therefore, those clusters were classified as the possible cases for selection for this study.

Specifically, the clusters in Table 4.1 were/are both receivers and providers of online courses. That was a significant feature, allowing reciprocity to take place. Similarly, most of the clusters in the table mainly consisted of small, rural schools. However, HarbourNet is an urban cluster and FarNet is a cluster consisting of both small and large city secondary schools.

Therefore, the list does not include the clusters of schools that only collaborated for professional development of teachers and school management or provided and did not receive any courses. For example, the Greater Christchurch School Network (GCSN) was also a cluster of schools. However, GCSN worked as a community of practice with principals and teachers and not students. Schools in the GCSN cluster mainly collaborated around PD (professional development) and technical support. As another example, although not very relevant, the 'Tertiary cluster' in the Learning Exchange was designed for a group of tertiary education providers, such as Telford, WinTec, and others. The members of the Tertiary cluster were course providers only, not receivers. They offered subjects such as Agriculture, Horticulture, and Equine Studies, which were not commonly taught at schools. 
Table 4.1 Learning Exchange School Clusters

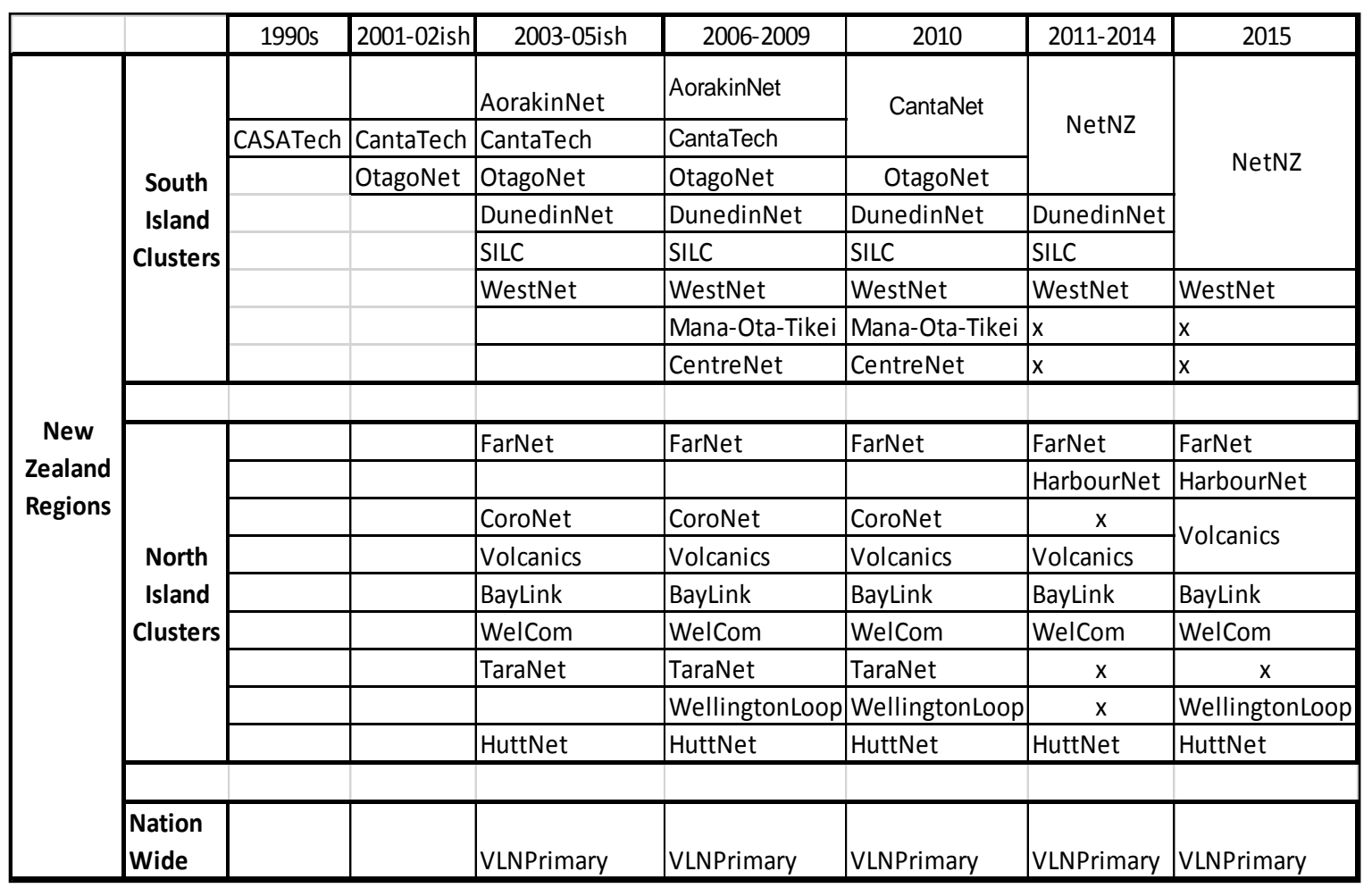

Further, the list includes school clusters that were mainly 'virtual' in nature. As discussed in the literature review, school clusters in the ICTPD programme were groups of schools that mainly operated in the face-to-face environment. They were formed by schools for a certain period of time for the provision of PD. They mostly disappeared when their cluster funding from the MOE ended.

Therefore, the list only contains the clusters that adopted the Learning Exchange model and used it for the virtual and reciprocal exchange of educational resources. In addition, they initiated the programme for serving students as well as staff members.

\subsubsection{Selection criteria}

Four was perceived as the possible number of cases or school clusters for data collection. For their selection, five criteria were set. They included the number of member schools, courses, and enrolled students, the nature of clusters and their operational level. These criteria were addressed by retrieving information from the Learning Exchange platform (http://pol.vln.school.nz/) and through personal correspondence. Table 4.2 provides information about each of those criteria. Based on the criteria, two cases were selected from each of the groups for including both developing and disappearing clusters. 
Table 4.2 Criteria for selecting cases

\begin{tabular}{|c|c|c|c|c|c|c|c|c|}
\hline \multirow[b]{2}{*}{ Clusters as in $2010^{4}$} & \multicolumn{2}{|c|}{ Number of Active Schools } & \multicolumn{2}{|c|}{$\begin{array}{l}\text { Number of Courses } \\
\text { Offered }\end{array}$} & \multicolumn{2}{|c|}{$\begin{array}{l}\text { Number of Students } \\
\text { Enrolled }\end{array}$} & \multirow[b]{2}{*}{$\begin{array}{l}\text { Nature of Cluster } \\
\text { (course } \\
\text { provider/receiver) }\end{array}$} & \multirow{2}{*}{$\begin{array}{l}\text { Nature of } \\
\text { Schools } \\
\text { (mainly small } \\
\text { rural /large } \\
\text { city) }\end{array}$} \\
\hline & $\begin{array}{l}\text { As in } \\
2014\end{array}$ & $\begin{array}{l}\text { Increase/decrease } \\
\text { in the number of } \\
\text { member schools } \\
\text { from } 2009 \text { to } 2014\end{array}$ & $\begin{array}{l}\text { As in } \\
2014\end{array}$ & $\begin{array}{l}\text { Change in } \\
\text { number of } \\
\text { courses from } \\
2011 \text { to } 2014 \\
\end{array}$ & $\begin{array}{l}\text { As in } \\
2014\end{array}$ & $\begin{array}{l}\text { Increase/decrease } \\
\text { in the number of } \\
\text { enrolled students } \\
\text { from } 2009 \text { to } 2014\end{array}$ & & \\
\hline CantaNet $^{6}$ & \multirow{2}{*}{39} & \multirow{2}{*}{+4} & \multirow{2}{*}{45} & \multirow{2}{*}{+10} & \multirow{2}{*}{498} & \multirow{2}{*}{+63} & \multirow{2}{*}{ Provider \& Receiver } & \multirow{2}{*}{ Small } \\
\hline OtagoNet & & & & & & & & \\
\hline DunedinNet & 8 & -4 & 1 & -5 & 64 & -27 & Provider \& Receiver & Large \\
\hline SILC & 10 & +5 & 3 & 0 & 31 & +3 & Provider \& Receiver & Both \\
\hline WestNet & 12 & +4 & 6 & -2 & 68 & -22 & Provider \& Receiver & Small \\
\hline FarNet & 18 & +6 & 15 & +13 & 282 & +196 & Provider \& Receiver & Both \\
\hline HarbourNet $^{7}$ & 13 & Not applicable & 15 & Not applicable & 187 & Not applicable & Provider \& Receiver & Large \\
\hline CoroNet & 3 & -5 & 3 & 0 & 28 & Not available & Provider \& Receiver & Both \\
\hline Volcanics & 15 & +5 & 20 & +8 & 190 & +115 & Provider \& Receiver & Both \\
\hline BayLink & 7 & 0 & 2 & 0 & 28 & Not available & Provider \& Receiver & Both \\
\hline WeLCom & 9 & Not available & 8 & +1 & 68 & Not available & Provider \& Receiver & Small \\
\hline TaraNet & 2 & -4 & 1 & -8 & 9 & -54 & Provider \& Receiver & Small \\
\hline Wellington Loop & 2 & +1 & 1 & -1 & 35 & 3 & Provider \& Receiver & Large \\
\hline HuttNet & 2 & -5 & 1 & - & 10 & Not available & Provider \& Receiver & Large \\
\hline VLN Primary & 44 & +41 & 32 & +30 & 320 & +308 & Provider \& Receiver & Small/national \\
\hline
\end{tabular}

\footnotetext{
${ }^{4}$ No information was found regarding CentreNet and Mana-Ota-Tikei clusters. Also, Tertiary and GCSN were excluded from selection due to their varied operational nature. ${ }^{5}$ Previously, clusters mainly consisted of rural, small secondary schools. However, more recently, they have been composed of all school sizes including small, medium and large. Therefore, the criterion provided some useful information but should not be considered very authoritative.

${ }^{6}$ AorakinNet merged with CantaTech in 2010. Therefore, AorakinNet was not listed separately.

${ }^{7}$ HarbourNet started operating in 2014. For that reason, some fields in the table are not applicable for HarbourNet.
} 
The first criterion, the Number of Active Schools, was to help identify the current size and growth of the cluster from 2009 to 2014. The compiled information indicated the clusters that had grown or shrunk. The second criterion, the Number of Courses Offered, was to indicate the participation of schools and the overall growth of the cluster in terms of offered courses. The rate of change indicated the perceived interest of students in the offered courses and trust of schools in the programme. Similarly, the third criterion, the Number of Enrolled Students, also showed students' interest and reliance on the Learning Exchange.

The fourth criterion, the nature of the cluster, ensured the separation of school clusters as the providers and receivers of courses from other clusters. That allowed the research to disregard the Tertiary, GCSN or other ICTPD clusters.

Finally, the criterion for the identification of school sizes was to indicate whether the cluster was composed of mainly urban, rural, semi-rural, both urban and rural or schools from throughout the country (national level cluster). This criterion was required because the research was particularly interested in gathering data from rural or semi-rural secondary school clusters. That was because the Learning Exchange was initiated by small rural secondary schools. Also, the initial review of the literature considered the programme more appropriate for meeting the requirements of small rural schools. Therefore, the criterion was included. However, according to Statistics New Zealand (2006), there are no internationally recognised definitions of urban and rural areas. Based on the guidance, the geographical classification of Learning Exchange clusters in this research was 'mainly' based on personal assumptions and should not be considered authoritative.

In addition to the above selection criteria, additional information from the literature was also used for assisting in the classification of clusters into two groups and the eventual selection of two clusters from each group. Hence, four clusters were selected as the cases and the research proceeded to the data gathering phase.

It should be noted that due to the human ethics agreement between the researcher and the research participants, the clusters and the participants are not referred to by their actual names. Therefore, the four clusters have been given pseudonyms: A-Net, B-Net, C-Net, and D-Net. The names were based on the sequence of the data collection process. For example, A-Net has been used for the cluster that was accessed first for the data collection and D-Net is the last cluster in the data collection sequence. 


\subsection{Data Collection Process}

This section first identifies the adopted data collection approach and then discusses multiple sources of evidence, including in-depth interviews, direction observation, and documentation, for data collection. Then, the involvement of ANT in the data collection is explained. Later, the section highlights the human ethics and guidelines regarding the data collection procedure and outlines the role of the researcher during the procedure.

\subsubsection{Data collection approach}

In qualitative research, a strategy is called inductive when research begins with broad research themes that are eventually refined through the data analysis processes (Carroll \& Swatman, 2000). According to Thomas (2006, p. 238), through an inductive approach, researchers use detailed interviews with participants "to derive concepts, themes, or a model through interpretations". Therefore, the inductive approach can be associated with an interpretive research paradigm and grounded theory research method, welcoming any theme.

In contrast, when a researcher enters a field with highly structured questions, the research strategy is called deductive (Carroll \& Swatman, 2000). Such an approach is suitable to identify whether gathered data are "consistent with prior assumptions, theories, or hypotheses identified or constructed by an investigator" (Thomas, 2006. p. 238). Therefore, the deductive approach can be related to studies with a positivist ontology for identifying falsification or validation of a theory or assumptions (Fitzgerald \& Howcroft, 1998). Therefore, this study avoided the deductive approach and an inductive approach was considered suitable for data collection.

\subsubsection{Using multiple sources of evidence}

This study used multiple sources for data collection. In general, Yin (2014) discuses six types of data collection procedures or possible sources of evidence: documentation, archival records, interviews, direct observations, participant observation and physical artefacts. Since each of these sources of data has their own strengths and weaknesses, Yin (2014) suggests case study researchers use multiple sources of evidence. In doing so, the selected sources complement each other and enhance the depth of collected evidence. Based on the justifications, this study followed the suggestion of using multiple sources of evidence.

\subsubsection{In-depth one-to-one interviews}

The one-to-one in-depth interview was used as the primary source for collecting data. That was because, according to Myers and Newman (2007), the interview is an important research procedure extensively used in IS for data gathering and particularly for gaining rich description of a reality. 
Similarly, Yin (2014) suggests that interviewing allows researchers to focus on individual participants' perspectives and meanings regarding a subject.

Specifically, in order to avoid an elite bias (an interview pitfall when only certain types of people are interviewed), this research accessed participants from all organisational levels in the selected cases. For example, e-students and e-teachers were accessed as the main users of the programme (The prefix ' $e$ ' is used by the Community for cluster participants). E-principals (cluster coordinators), edeans and school principals presented their personal views as well as representing schools' and clusters' perspectives. Other key individuals involved in the development of clusters and the Learning Exchange from outside schools were also interviewed, not only for gaining clarity, further insight and depth into the data but also for including various voices. The interviews with people from various organisational levels with different perspectives facilitated identifying relationships and interactions between different elements during the establishment of the clusters and the development of the Learning Exchange.

Thirty interviews were conducted, which ranged from 30 minutes (with students) to nearly 2 hours. All the interviews were audio-recorded digitally and then fully transcribed by the researcher. Each of those transcriptions was sent back to participants for corrections as well as clarifications with additional questions if necessary. The purpose of this member checking was not only part of the human ethics agreement but also as a key part of building confidence in the evidence gathered and maintaining research quality.

\subsubsection{Documentation}

Documentary information was used as another source of empirical data collection. The documents included cluster policy guidelines, memoranda of understanding between schools in a cluster, minutes of monthly intra-cluster meetings, progress reports, cluster self-review reports, reports of education review officers, newspaper reporting, documents from the MOE and user manuals regarding effective uses of technology such as VC.

According to Yin (2014, p. 107), the most important uses of documents are "to corroborate and augment evidence" collected through interviews. In this study, the benefits of including documents were threefold. First, some of the documents provided further information that was not discussed or could not be established during the interviews. For example, sometimes participants mentioned previous events but could not remember further details. In those instances, the documents provided clarification and a complete picture.

Second, documents were also used to confirm evidence. For example, some of the documents were very useful in the instances where participants had narrated a story differently, and the selection of 
the best accounts of the event was difficult for the researcher. Hence, the documents enhanced the trustworthiness of the evidence.

Lastly and most importantly, from the ANT perspective, the inclusion of some of the documents such as how-to-use-a-technology or user manuals was to ensure the 'voices' from non-human actants. The next section discusses the role of ANT during the data collection process in detail.

\subsubsection{Direct observations}

The technique of direct observations was utilised as the third source of data collection. The technique allowed the researcher to observe the role of some of the elements that were not covered during the interviews. In particular, the technique was very useful for considering the elements that were taken for granted by the research participants. For example, in one of the schools, a portion of the whiteboard in the student learning area was observed to have been effectively used for communication between e-students, e-teachers, and e-dean. That was observed as a critical part of the deep local support for e-students. In another instance, a damp, smelly VC room was observed 'speaking' on behalf of 'the things' by indicating the underutilisation of the resources.

In short, multiple sources of evidence were used for data collection, which included in-depth interviews, direct observations, and documentation. The sources were collectively analysed, reported and interpreted to reconstruct the reality of the development of the Learning Exchange.

\subsubsection{Participant selection and data saturation}

Two of the important decisions during the data collection process are the selection of participants and deciding when to stop collecting data. The decisions to establish boundaries become a challenge in a study using ANT because "actor-networks are theoretically boundless as each actor is also a network, and following of the network could continue ad infinitum" (Vos, 2014, p. 84). Therefore a decision to cease data collection was needed to define the extent to which actants can be followed and black-boxes be opened.

A number of strategies were adopted to address 'the problem of selection'. First, the study boundaries were divided into two - outer and inner boundaries. The outer boundaries separated the cases or school clusters from other clusters. On the other hand, inner restrictions focused on internal aspects of the cases that were relevant to the research objectives and questions. Second, clear selection criteria were outlined in order to set the boundaries around the Learning Exchange network. Section 4.3.5 discussed the factors while outlining the criteria in detail. Third, the case research method was selected as a strategy to define the outer boundaries of the study. 
Lastly, for setting internal boundaries, various approaches suggested by other ANT scholars were considered regarding how to know where and when to stop. This strategy was to assist in deciding on data saturation. Cresswell, Worth and Sheikh (2010) and McLean and Hassard (2004) suggest that a decision regarding the data saturation should be focused on answering the research question and making rigorous and pragmatic decisions. Vos (2014) and other studies adopted strategies such as the point of saturation and the emergence of no new actants or no new controversies for deciding inclusion/excision of actants. In other words, the answer to the question of where to stop basically remained at the discretion of the researcher, which was informed by previous studies.

Regarding the selection or recruitment of participants, the first participant or representative was found during the literature review process. The participant's name appeared a number of times on various documents. During the data collection, the actant was followed and interviewed first. Based on the actant's suggestion, other actor-networks were followed, which became, in a way similar to the snowball sampling method. In addition to the snowballing, interview data and other documents were used to identify potential research participants whose response could represent other actants.

A total of thirty interviews with human actants were conducted. Some of the actants contacted did not participate whereas some were contacted twice after their first interview and agreed to do so. In one case, one participant changed nearly half of the interview transcript and added more meaningful data. Regarding the length of the interviews, some interview sessions lasted for nearly two hours whereas sessions with students lasted an average of 30 minutes.

\subsubsection{Guidance from ANT}

The literature recognises ANT as a theory with its own methodological dimensions, helping researchers from diverse fields to translate a phenomenon. Studies such as Tatnall and Gilding (1999) advocate the addition of ANT as a research approach for qualitative studies in IS. Section 3.2.2 in Chapter 3 mentioned this topic. This section discusses some of ANT's suggested approaches and their adoption or abandonment during this research.

\subsubsection{The role of the researcher - following actants}

Looking back at the ontological dimension of ANT discussed in the theoretical chapter, ANT views a reality as a host of dissimilar, heterogeneous actants (de)constructing a reality (actor-network). With that stance, ANT encourages researchers to follow actants within their associations, although for a short period of time, during data collection. With the suggestion to 'follow actants', ANT proposes researchers become part of the network and listen to the stories narrated by participants during the data gathering process without preparing interview questions in advance. That is to let the 
participants (actants) construct the phenomena under investigation rather than imposing preconceived concepts (Vos, 2014).

For the reason of 'following actants' within their clusters, the researcher visited some of the schools. The researcher joined some of the live VC classes, observed students' interactions in the learning centres and visited VC rooms and facilities. In particular, the researcher travelled between schools to note the geographical and other contextual factors in which the networks were operating. Although during that period the researcher acted as an insider, his role remained as a silent actant.

Most importantly, visiting and joining the networks allowed the researcher to observe actants acting, being acted upon and reacting within their associations. As a result, the collected data were more relativist in nature. That again remained appropriate with the relativistic ontological position taken in this research. Whittle and Spicer (2008) also recognised that ANT is often positioned as an approach that embraces a relativistic stance.

With the suggestion of following actants, ANT guides researchers by stating three key guidelines: agnosticism of the observer; generalised symmetry requiring the researcher to use a single repertoire; and free association requiring the abandonment of all a priori distinctions between actants (Callon, 1986). The principles were adopted and found consistent with the paradigm selected for this study.

\subsubsection{Non-human actants as a source of evidence}

The concept of heterogeneity in ANT emphasises the roles of humans as well as non-humans in the construction and transformation of a reality (network). The emphasis brings the challenge of collecting evidence from non-human actants. Since the principles of heterogeneity and symmetry sit at the core of ANT, this study had to ensure the collection of evidence from non-human actants and their inclusion in the translation of the development of clusters.

For that purpose, this study adopted the strategy of approaching potential representatives or agents of non-human actants ( Luoma-aho \& Paloviita, 2010; Vidgen \& McMaster, 1996; Vos, 2014). In the strategy, the agents were followed to speak for the non-human actants. For example, during the interviews, e-principals and e-deans not only described their roles but also spoke about the nonhumans (for example, ICTs, currency, natural factors as geographical context and so on) in the (de)construction of their network. The agents also mentioned the influences of non-humans in relation to their individual successful role performance as well as the challenges brought by continuous changes in those elements. For example, clusters in the Learning Exchange were previously known as the VC-based course sharing programme. However, more recently, the role of VC has been minimised due to the influences of other artefacts such as Adobe Connect, Google 
Hangout, Skype and other desktop based group video-conferencing applications. As a result, the description of clusters has changed and the VC basis of the programme is no longer valid. Similarly, participants represented their organisations and spoke about their policies regarding funds and the role of funding in the sustainability and disappearance of clusters.

The inscriptions in ANT or the documentation as a source of evidence suggested by Yin (2014) and others was also included in data collection. In fact, some of the documentary inscriptions went beyond the augmentation and corroboration uses. In the absence of information, 'some of the documentary inscriptions' worked as inferences not merely for giving clues, but mainly for providing 'definitive findings'. That contrasted with Yin's (2014) suggestion of using documents for the provision of clues. Rather Yin (2014, p. 107) argues that "the inferences could turn out to be false leads". However, in this study, that was not the case for some of the documents. That was because the documents were found to have acted as 'macro-actants' (the elements with greater influence in the network). For example, some of the major decisions were made based on the clusters' selfreview documents. Further, those documents were not from a single author and had been reviewed previously. Moreover, the documents were analysed with the original reviewer's comments and the findings from the documents were corroborated by the research participants through the member check process further discussed later.

In summary, this study followed a set of methods that augmented each other. The study was not intended to focus on strictly and solely using either theoretical concepts of ANT or methodical philosophies only. Instead, the study perceived that theoretical maturity coupled with the established IS methodological frameworks would be an insightful exercise. In addition, since the study also used Complexity Theory, the sole adoption of ANT approaches as research methodologies would have opened another avenue for argument. Therefore, the study used a set of established IS methods and techniques coupled with the ANT approaches where appropriate.

\subsubsection{Managing ethics}

This study followed a number of guidelines and took practical steps towards managing ethics regarding interviews, documents, and observations. According to Myers and Newman (2007), although the qualitative interview is a strong research tool, it is often treated as unproblematic and as a straightforward means of data gathering, which is not true. One of the key guidelines Myers and Newman (2007) recommend for avoiding issues and pitfalls during a qualitative research process is for researchers to assure participants regarding the confidentiality of gathered data. That is suggested to be carried out by formal adoption of ethical guidelines, involving permissions and respecting and fulfilling commitments (ibid). 
In addition, since data gathering involved collecting perspectives of students under 16 years old, special attention was required in terms of human ethics for minimising the risk of any issues. As a result, rules for interviewing underage students were specified. Those rules were included in the human ethics application.

The human ethics application was prepared and presented to the Human Ethics Committee at the School of Information Management, Victoria University of Wellington. After gaining approval, data collection commenced. The following are some of the main guidelines adopted from the New Zealand Association for Educational Research (NZARE, 2010):

- An information sheet and consent form were provided for children's parent/guardian.

- The information sheet informed children and their parents about the research they were invited to participate in.

- Through the information sheet and consent form, this study reassured parents regarding data confidentiality by explicitly informing them that the names of their children would not be recorded or published in the research.

- Parents were clearly informed that gathered data would only be used for research purposes and the gathered data would be destroyed once the research is published.

- Parents were informed of their right to withdraw from the research two months after the interview date.

In addition to these guidelines, individual schools' own code of conduct for visitors was followed while visiting the schools for class observations and interviewing minors as well as adults.

The guidelines were outlined in the consent form and information sheet. Those documents were provided well before the data collection to give participants and guardians enough time to decide. Appendices $4 A, 4 B$ and $4 C$ are sample information sheets and consent forms providing more details. Similarly, through personal email exchange, participants were assured of the confidentiality of any documents that they perceived as confidential. Therefore, within the research, the documents, participants and their organisations have not been identified by their names.

\subsection{Data Analysis and Representation Plan}

After the data gathering process in qualitative studies, organising and making sense of the data remains a key challenge for researchers. A number of studies have addressed the challenge of the data management and analysis phase. Miles and Huberman (1994) propose three general steps to address the challenge, which consist of data 'reduction' or condensing, display and conclusion. 
Similarly, Creswell (2013) suggests a data analysis and representation plan that includes three main phases: preparing and organising the data; reducing the data into themes and condensing the themes into codes; and, finally interpreting and representing the results.

Before discussing the steps, Yin (2014) suggests researchers adopt a strategy for analysis. The suggestions include relying on theoretical propositions, working with data from the ground up, developing a case description and examining plausible rival explanations (Yin, 2014). This study 'worked with the data from the ground up' in order to let the key concepts emerge from the data rather than relying on or examining some pre-existing concepts. The analysis strategy remains consistent with the inductive data collection approach, which emphasises avoiding any constraints on the emergence of concepts.

Based on Miles and Huberman (1994), Creswell (2013) and Yin (2014), the data analysis in this study included the following three phases.

\subsubsection{Transcribing and organising data - phase 1}

After data collection for the A-Net school cluster, audio-recorded interviews were fully transcribed by the researcher. The transcription process gave the researcher a complete picture of the responses and time to make notes for seeking further clarification. Once the transcripts were verified by the participants, a number of notes were made regarding emerging concepts within the MS Office files.

After every transcription, a short summary of each interview was written in a separate MS Word document file. The purpose of the summary was to note key ideas and concepts from the interviews for future references and to easily manage the massive volume of the data being gathered from four clusters.

After the first round of interviews and transcriptions from A-Net participants, data were gathered from participants in B-Net, C-Net, and D-Net school clusters. The same procedure of complete transcription, member checking and summarising was exercised.

\subsubsection{Segmenting, coding and reducing data - phase 2}

The second phase was about working with the sheer volume of data. In this phase, NVivo software was used to help classify interview text into many segments. The purpose of the segmentation was to subdivide data into different manageable categories. As a result, a number of categories were formed, each containing text on a particular topic or idea aggregated from various individual interviews. The categories were labelled with a word or phrase, called codes. 
Initially, a large of number of codes was produced, which is a common outcome. Figure 4.1 from Creswell (2012) illustrates the process of code reduction from many pages of raw data into themes in qualitative research. A similar approach was followed in this study.

Before reducing the data, some of the codes and their segments of text were revisited to ensure that the data were not redundant. The overlapping and redundant codes were then reduced by a number of strategies. At first, codes with the least references or lowest frequency were dropped or converged with other codes. As suggested by Creswell (2013), no counting of the codes was done in this study. That was to remain consistent with the nature of the qualitative research approach as not depending on statistics. Second, through revisions, relevant codes were collapsed into similar categories. Third, key concepts from the four phases of Translation in ANT were used for the supporting the formation of categories. That was because the study was eventually going to use the four phases of Translation as a template for the reporting of the research findings.

The end result of this phase was a list of 35-40 tentative codes, classified into four main categories, each representing one phase of the Translation process. Creswell $(2013$, p. 186) regards the main categories of codes as the "broad units of information" in qualitative studies.

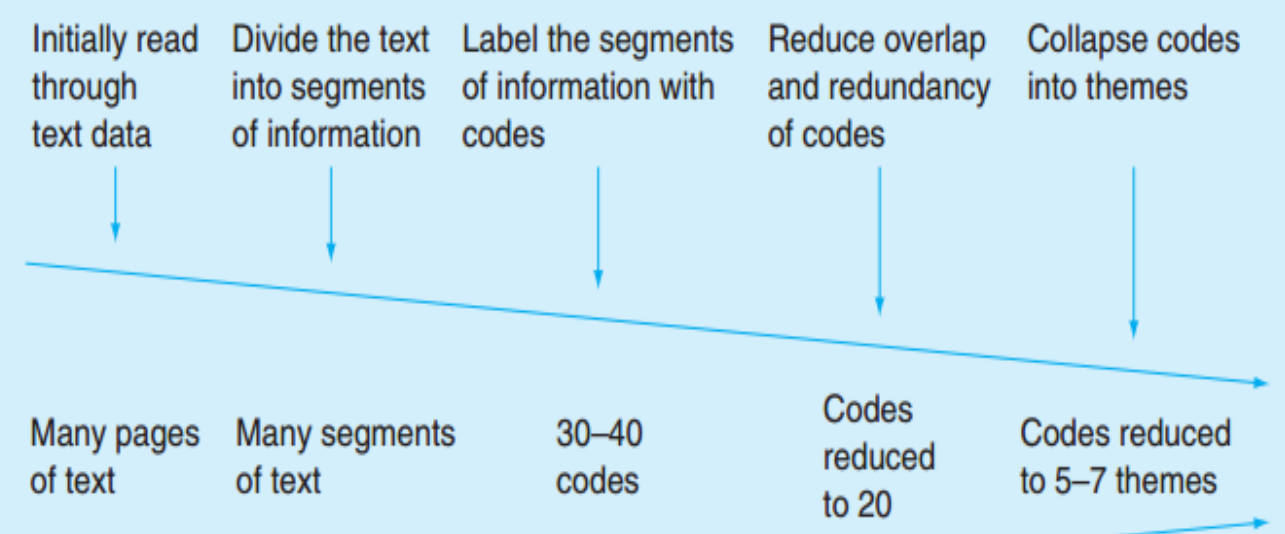

\section{Figure 4. 1 Organising data}

In this study, those codes are regarded as the factors, both supporting and inhibiting factors. Each of those codes is reported in the findings chapter and analysed in the cross-case analysis chapter.

\subsubsection{Representing and analysing data - phase 3}

The last main phase was the reporting and analysis of the data. Naturalistic language was used to report what was found, based on the accounts of the participants. At this step, no commentary was made by the researcher. The aim was to describe the cases based on the gathered data. Hence, 
analytical impartiality was observed towards all the views, rejecting any superiority claim from any actant in the cases. As a result, in-depth descriptions of each of the cases' development, since their initiation, were reported. For the reporting of the findings, the four phases of ANT were used, which worked as a framework. The reporting was mainly carried out by the descriptions of the cases. However, figures, tables, and graphs were used to visualise and support the descriptions.

Hence, with the reporting of the four case findings, the research addressed its first two research questions: How was the Learning Exchange developed and utilised by school clusters in New Zealand? The outcome of the findings chapter was a summary of key findings, including the factors that had supported or inhibited the development of self-sustaining Learning Exchange clusters. The summary thus answered the third research question.

Then, the four case findings were merged and examined to describe the development of a selfsustaining cluster. The intention was to allow the researcher to compare the findings from four cases and identify commonalities and differences. The interpretation started by revisiting and reflecting upon the research questions and objectives. The outcome of the case findings was interpreted by going through each of those identified factors. As a result, the interpretation provided a holistic view of how to develop a self-sustaining cluster - one of the major objectives of this research. The outcome of the analysis was a refined list of factors that led to the conclusion of this study.

\subsection{Research Trustworthiness}

Trustworthiness of qualitative research can be described as the validity and reliability of a research study (Seale, 1999). Due to the intangible nature of gathered data in qualitative studies, maintaining quality and trustworthiness remains a challenge for such studies (Gibbert \& Ruigrok, 2010). However, scholars such as Creswell and Miller (2000) recommend qualitative researchers follow a strategy to demonstrate the trustworthiness of their studies. For this purpose, Guba (1981) proposed four criteria for researchers to improve rigor and trustworthiness, which included credibility, transferability, dependability, and confirmability. According to the qualitative research literature (Creswell \& Miller, 2000; Guba, 1981; Shenton, 2004):

Credibility of research can be related to the extent to which the research findings are true or dependable.

Transferability means the degree to which a study's findings can be applicable to other groups and situations. Questions of the transferability of research findings may arise due to a limited number of research participants in qualitative studies. 
Dependability means the level to which similar findings would result if the work was repeated with the same method, context, and participants.

Confirmability relates to the objectivity or neutrality of research findings. The aspect may become an issue arising from researcher bias.

Shenton (2004) analysed those four criteria and endorsed them as significant aspects for demonstrating research trustworthiness. Table 4.3 adapted from Guba (1981) gives a brief description of the four criteria including their meaning and appropriate scientific terms.

Table 4.3 Four aspects of Trustworthiness

\begin{tabular}{|l|l|l|}
\hline \multicolumn{2}{|l|}{ Trustworthiness } & \multirow{2}{*}{ Scientific Term } \\
\hline Criteria & Aspect & \\
\hline Credibility & Truth Value & (Internal) Validity \\
\hline Transferability & Applicability & Generalizability \\
\hline Dependability & Consistency & Reliability \\
\hline Confirmability & Neutrality & Objectivity \\
\hline
\end{tabular}

To ensure quality and rigor in this research, the following approaches and guidelines were adopted. As recommended by Gibbert and Ruigrok (2010), these guidelines were to serve as a clear sequence of actions to ensure rigor.

To address the research credibility, two practical steps were followed. First, interview transcriptions were sent back to interviewees to check for accuracy of transcriptions as well as make clarifications if required. That promoted confidence in the gathered data. Later, individual case summaries of initial findings were posted to participants to get their feedback and comments on the findings. The step was intended to check if the emerging findings were valid. Participants mostly agreed with the findings and suggested some minor changes.

To ensure transferability of research findings, as recommended by Shenton (2004), detailed descriptions of the Learning Exchange clusters or cases and contextual evidence were collected. For that reason, interviews were in-depth, not semi-structured as in some studies. Similarly, physical visits were made and data were collected through observations. The steps are considered to have justified the applicability of findings in other situations.

Regarding dependability, the changing nature of each study makes dependability a challenging criterion for qualitative studies. To address the challenge, clear explanations of each of the research processes have been provided and consistency between all the dimensions of the methods has been discussed. In doing so, the study has enabled future researchers to repeat the work. 
To address the confirmability aspect, the research adopted the three ANT principles of agnosticism, free association, and generalised symmetry. In other words, the researcher's role remained limited during the data collection by mainly following and listening to the participants, without driving the directions of the interviews. Since the researcher had no prior relations with any of the cases, the aspect was not very relevant. These steps were perceived to have improved the research integrity and objectivity.

\subsection{Chapter Summary}

The chapter began with the discussion of the research paradigm and the selection of a constructivist paradigm. The relativistic ontological view was found as a better fit than a realist world view for this research. The interpretivist epistemology with an inductive approach for gaining knowledge from participants were found relevant for the study of the Learning Exchange clusters. The qualitative research methodology was proposed because that would enable the researcher to collect and report contextual information about the Learning Exchange clusters.

Regarding the research design and data collection strategy, the case research was justified as an appropriate strategy. With that selection, four Learning Exchange clusters were described as the cases for data collection and units of analysis. The criteria for the selection of the cases were also discussed.

Regarding the data collection, in-depth interviews, direct observations and documentation were described as the multiple sources for gathering evidence from individuals. In particular, the role and guidance of ANT was discussed with regard to the collection of data from human as well as nonhuman actants. The topic of human ethics was discussed for the collection and preservation of the interview data and gathered documents.

At the end, a four step strategy was proposed for addressing trustworthiness and ensuring the rigor and quality of the research. The next chapter reports the findings of the four cases. 


\section{CHAPTER 5: RESEARCH FINDINGS}

The chapter outlines the research findings regarding the development of the four cases - A-Net, BNet, C-Net and D-Net school cluster - by using the Actor Network Theory's (ANT) analytic lens. The findings have been compiled from in-depth interviews with individuals, various documents and direct observations discussed in the Methodology Chapter. Some of the interviewees have been directly involved while others have been indirectly part of the clusters but have had close relationships with the network actants. Some examples of inputs from non-humans included cluster self-review reports, memorandum of understanding (MOU) between the schools and the MOE, ICTPD cluster documents, and others. Those inscriptions were un-boxed, analysed and reported. In order to report those four major stories, the process of Translation from ANT has been used as a theoretical lens, providing a theoretical basis for the research findings. The four phases of Translation - Problematisation, Interessement, Enrolment and Mobilisation - describe the development of the four clusters and identify and present various actants along with their roles in the network construction. This chapter aims to address the following questions:

- How was the Learning Exchange programme developed in New Zealand?

- How was the programme utilised in some of the school clusters in New Zealand?

- What were the factors that facilitated or inhibited the development of the Learning Exchange in some school clusters in New Zealand?

This chapter is divided into five main sections. Each of the next four main sections reports the research findings regarding A-Net, B-Net, C-Net and D-Net respectively. In doing so, the study has addressed the first two research questions. At the end, Section 5.5 provides a summary of the chapter. The summary provides the key mediating and disruptive factors regarding the development of each of the four clusters separately. Hence, the third research questions is addressed.

Before reporting the findings, Figure 5.1 illustrates the four phases of Translation and the possible activities associated with the development of each of the four clusters. The phases have been described in detail in Chapter 3 (Theoretical Lenses). 


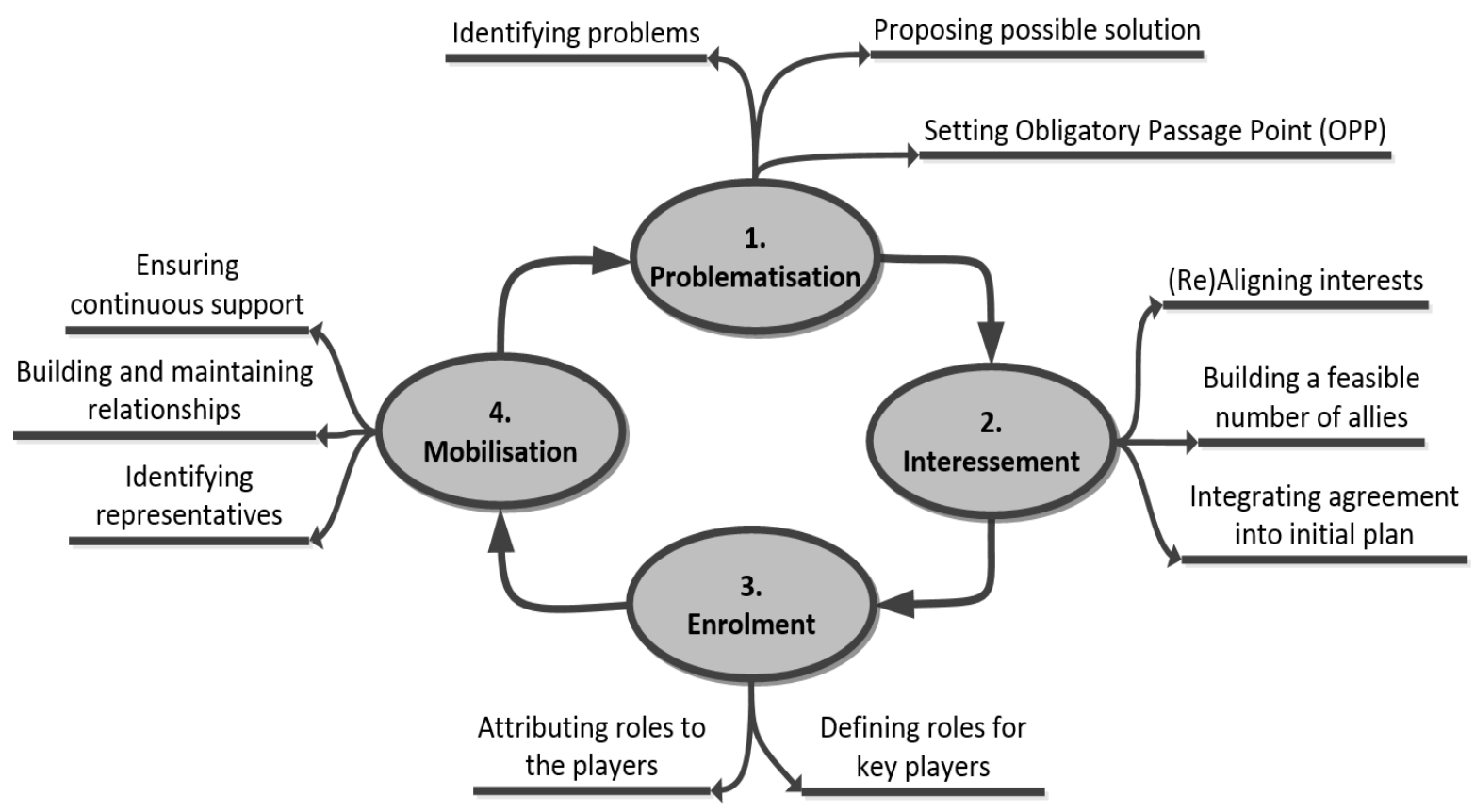

Figure 5.1 The Translation of Learning Exchange clusters in New Zealand

\subsection{A-Net Case Findings}

One of the disadvantages of studying in schools located in rural areas is having limited access to subject areas which are not part of a regular curriculum. The affected students and their school would then need to find alternative methods to access those resources. Around the late 1990s, a similar situation was faced by a number of small schools located in a rural region of New Zealand. Due to their limited resources, the schools struggled to meet the educational needs of their senior secondary students and teaching staff. The Correspondence School programme was considered an unsatisfactory solution by students and staff members. The situation led to the formal initiation of a video-conference-based virtual exchange of educational resources between seven or eight schools in the region. The group or cluster of schools utilised various ICTs for the reciprocal exchange of resources. The group of schools is called A-Net in this study.

To formally execute the proposed solution, A-Net initiators successfully persuaded some key players needed for the formal initiation of their cluster around 2001-02. Various roles were set up and responsibilities were assigned to the cluster participants. In particular, the roles of cluster coordinator and e-dean were established to oversee cluster activities and manage links and relationships between different participants inside and outside the cluster. The cluster leadership had strategies in place for supporting and maintaining good relationships between students and staff involved in the Learning Exchange activities. 
Since its inception, A-Net has developed and became a self-sustaining virtual cluster of 25 schools in 2013. Because of its success, the A-Net model has been adopted by a number of other school clusters across New Zealand. The model or the programme is known as the Learning Exchange, as discussed in the Literature Review chapter. The participating clusters offer online synchronous classes for their students needing to study the subjects that are not available at their own schools. Students from member schools are enrolled in those classes with a teacher from one of the schools. Classes are taught over the VC for an hour once a week for the whole school year.

The following sections describe the A-Net case findings through the four phases of Translation.

\subsubsection{A-Net Problematisation - becoming indispensable ${ }^{8}$}

The Problematisation phase identifies the problem or the main reason that had led the A-Net initiators to search for a solution and then form a network of schools in the region. The phase also helped to answer questions, such as: What made those schools interested in that solution? Did they have any other solution already in place before adopting the new solution? Who were the key initiators and focal actants actively involved in the formation of the network? How did the focal actants convince potential players in that Problematisation (the problem-solution definition and agreement)? This section provides answers to such questions.

\subsubsection{Defining the problem}

To identify the problem, I asked A-Net initiators to recall the time when they initiated A-Net and give some of the reasons why they needed this network of schools. Their stories revealed that in the early 1990s, small schools in rural New Zealand were unable to meet the growing educational demands of their secondary level students in Years 11-13. Those students wanted to have a variety of subject options but schools could not provide them due to the small number of students. Consequently, a growing number of students were moving to urban and boarding schools, resulting in some schools having to close their secondary level. In addition, because those schools could not offer a variety of subjects, their specialised subject teachers had to teach outside their specialised areas and were becoming gap-fillers. Therefore, a growing number of teachers were also leaving and the problem became a matter of survival for small rural schools. According to one of the initial actants $^{9}$ :

\footnotetext{
${ }^{8}$ The additional descriptions with the headings are intended to remind/indicate what the phase is about.

${ }^{9}$ In general, research participants have been referred as actors, and where necessary, actors have been described along with their roles, such as initial actors, e-teacher or e-student to indicate relevance of their comments.
} 
About back in 2000, our school was in a situation where we were losing a number of our senior students because we could not give them the courses they needed because of our small staffing number; and we saw a need to have to do something... for the survival of our Secondary School.

The research identified overall agreement on the existence of the problem, because all the actants involved during the project initiation described the same problem. Another A-Net initiator explained the same problem:

Given the small staffing and the roll numbers, especially for the senior part of our school, we couldn't actually offer a lot of those extra specialist subjects... like Economics and History and Languages.

[Therefore], a growing number of adolescent age students were leaving to study at urban and boarding schools.

Regarding the reasons for losing those students, it appeared that multiple factors had played roles in that problem. The actants' stories revealed three main causes affecting the 'Area Schools ${ }^{10 \prime}$ in the region - demographic changes of the 90s, the students' lack of satisfaction with The Correspondence School (TCS) and the limited financial resources appeared frequently during the data collection. According to initiators, demographic changes in the 90s had a significant impact on schools due to depopulation of smaller towns in rural regions of New Zealand. One of the actants revealed that:

Significant demographic changes were happening in rural New Zealand in the 90s [due to] the economic and political changes at the Western World... It was quite mercenary in term[s] of the effect on small communities. A lot of small businesses were closing down... and the rural communities were literally emptying out... That depopulation had a direct effect on schools.

Historically, TCS has remained the leading distance education programme for school-children in New Zealand and around the world as a solution to the situations where schools are unable to offer the subjects that their students want (Sumner, 2000). However, senior management actants said that students were not satisfied with the way TCS operated. The dissatisfaction with TCS was also indicated by Sumner (2000) and Thompson (1990), as discussed in the literature review. Therefore, TCS was unable to interest and enrol students in its network for studying specialised subjects.

According to an actant:

We were using the Correspondence School at the time to catch up on some of the other subjects but found...that wasn't ideal. That filled the gap but wasn't perfect and the kids... didn't really like Correspondence that much.

The lack of student satisfaction with TCS meant that students with specialised subject needs did not find their interests aligned with those of TCS. As a result, that misalignment of interests affected those schools by further lowering their number of secondary level students.

\footnotetext{
${ }^{10}$ The term 'Area School' in New Zealand is used for schools that are located in rural areas, and have both the primary and secondary parts working together. That is due to the small number of students and the higher cost of having two separate schools.
} 
The limited financial resources in small schools appeared as the third cause of the problem. The number of students in a school remains one of the underlying factors based on which the government allocates funds to schools. The findings revealed that due to the limited financial resources, the schools could not afford to assign a teacher to a specialised subject class with only a few students. Indeed, the limited financial resources in schools had left students with limited subject options. On the other hand, limited financial resources meant that the available teachers had to teach subjects outside of their specialised areas - becoming gap-fillers. As result, schools were unable to retain their specialised subject teachers. According to one of the actants:

The other thing which was happening was that the schools were getting smaller but they [schools] wanted to hold on [to] teachers... and make sure that schools had viable classes, classes big enough to staff and the staff to stay and continue teaching.

To give some context, while visiting some of the schools for data collection in June 2014, I travelled about 130 kilometres from the nearest airport to get to one of the schools. Schools in that area were at least $40-50 \mathrm{~km}$ apart from each other. Furthermore, the total population of the town visited was close to only 600 people at that time and the total number of students in that school was around 170, from Year 1 to Year 13. These facts further clarify the significance of the challenges faced by the schools in those regions where resources are already limited and the population is spread out as compared to the urban areas.

The demographic changes in the 90s, students' lack of satisfaction with TCS and limited resources were collectively affecting schools by making them unable to meet the educational requirements of their senior students. As a result, the number of senior students was falling and the problem became a matter of survival for schools. The schools saw the need to find some solution to the problem.

\subsubsection{Identifying the possible solution}

Because of overall agreement about the problem, the programme initiators tried to identify possible solutions. By persuading the actants, three possible solutions were identified: TCS, CASATech and ANet. The above Problematisation mentioned TCS as the existing, but unsatisfactory, solution during that time. According to the actants, because of the paper-based approach, TCS could not interest and enrol those students in its network. According to an e-student actant with recent experience of TCS:

[During my TCS course] I had no idea who my teacher was. There was no teaching and it was just a booklet and you had to fill out the booklet.

From the ANT's perspective, TCS is the Actor-Network responsible for addressing the needs of those students from remote areas. However, due to the weak connectivity between TCS and its studentactants they remained independent, not really relying upon each other. Therefore, student-actants 
were not satisfied with their representatives on the TCS actor-network, hence the actant left the network of TCS and joined A-Net.

The attempt at an alternate solution started in the early 90 s when schools from rural regions of New Zealand saw Internet-based telecommunication technologies as a potential actant necessary for resolving the problem. Those actants formed a network of neighbouring schools, called CASATech school cluster, to experiment with technologies. Telecommunication technologies were recruited into the CASATech network with the aim of enabling schools to offer specialised subject choices and subsequently stop 'betrayal' ${ }^{11}$ of their actants (senior students and specialised subject teachers). By doing so, schools expected to stabilise their individual networks (schools).

Based on the stories of the actants, the CASATech initiative underpins two facts: the introduction of the virtual clustering or networking strategy, and the first formal use of Internet-based telecommunication technologies in a cluster of schools for distance education in New Zealand. Regarding the clustering strategy, the research could not identify any informed theoretical basis for the usage of the clustering strategy. However, existing human relationships in those schools were identified as the foundation for the usage of this strategy. As one of the A-Net initial actants who participated in the CASATech recalled:

I guess, I don't think we consciously thought of clustering as a theoretical concept/strategy at the outset. There were existing relationships amongst the area schools and senior management... and those existing relationships were actually the foundations of the clusters.

Regarding the audio-graphic technological setting, an actant responsible for technological elements during the CASATech initiative described the setting as, "a limited, two-way, communication system where participants needed two separate telephone lines - one for audio and another for graphics from their computer screen". The setting was limited because participants could only see what was shared on the computer screen. They were unable to exchange learning materials, such as their class notes, exercises or assessment outcomes - called 'immutable mobiles'. According to Walsham and Sahay (1999), immutable mobiles are the elements of a network that are considered to be durable and mobile, capable of travelling through space and time. Additionally, participants using the audiographic setting could not have any visual contact or see a picture of a real person talking in those classes. One of the CASATech technical-actants noted:

It was about wanting to create a more personal sort of class, trying to replicate the in-person classroom where you can see other people... Therefore, you needed visual contact and the bandwidth up until the 90s, even right up to the year 2000 was not around to support that.

${ }^{11}$ Betrayal is an ANT term used for actants if they do not do what they have agreed to do. 
These technical limitations literally made CASATech less interactive - failing to bond their enrolled actants and mobilise further allies. Consequently, CASATech's initial actants were unable to develop the network they had created. However, the effort of finding a solution to the problem by creating a network of schools did have some effect on the school community in that region.

A third solution for the problem was described by the actants: in early 2000 a group of seven or eight schools from the A-Net region proposed a relatively new solution, built upon the CASATech experience. The latest effort indicated the continuous existence and severity of the problem, affecting the very existence of schools for nearly a decade. The findings revealed that the model proposed by the schools was different from CASATech on two fundamental grounds: using VC instead of audio-graphic technologies and following a reciprocal model as opposed to the subscription model. The proposed use of VC technologies was not only to connect two or more classes at the same time but also to enable participants to speak and listen as well as watch a real person talking at the same time, capabilities that were missing in the audio-graphic solution. The aspect of visual synchronicity during online classes aligned with the interests of the students and teachers because, according to one of the student actants:

It's good to know that you can see the other people in your class and you can hear their questions. That is really good to back yourself with that, because you know the people with the same questions and you know that he [the e-teacher] can answer them.

The second aspect of the new solution was the reciprocal or the Learning Exchange model. The model proposed by the A-Net group of schools was based upon the virtual exchange of existing human resources - teachers and students. In the exchange model, if a school had to receive a course, in return, they would simply offer a teacher to teach a VC class based on the school's capability and the availability of their teacher, whereas the subscription model was built on the financial commitment in which schools (which were already small and financially struggling) had to pay a certain amount of money for enrolling their students in the CASATech classes. The Learning Exchange model was described as a way of efficiently exchanging and maximising participating schools' existing educational resources. In other words, the clustering and exchange model reflects the idea of building up the numbers in schools that were facing a decreasing number of senior students at that time, because according to one of the A-Net initiators:

Scale was of everything. If you were too small you had to close them down and shift kids out... [Therefore] we set up this reciprocal model where who wanted to be there had to offer something and they could then sign up as many students they want.

The proposed solution of clustering of schools reflected the assumptions behind the Porter's project (Crocombe, Enright, \& Porter, 1991) discussed in the Literature Review chapter. 
The combination of the improved technology and new learning model appeared to be a promising solution; however, the overall credibility of any proposed solution during the Problematisation phase also matters. In other words, wider agreement over a problem-solution definition can indicate the credibility of a proposed solution. With that view, I asked the programme initiators to recall any disagreement over the VC-based learning exchange solution. This was to identify any 'sabotaging actant' and 'controversy' at that stage. When I asked, "Did everyone in the initial meeting agree with the proposed solution?", the individual stories uncovered that seven or eight area schools, their Community Trust and a local polytechnic were participating in the early meetings, and everyone in that meeting agreed with the problem-solution definition.

In the main meeting we got the green light; and we had the Community Trust saying that we all back you and buy the gears. So we were given a green light and we just ran with it.

Another individual initiator also responded positively regarding the agreement during the Problematisation phase:

No, I don't recall any antagonism in the early days because it was put out there and let's get this started... and we all saw the need.

However, by further 'following', the story slightly differed by indicating a 'controversy'. For some of the participating schools, the programme was also seen as a means of getting faster Internet and VC equipment in their schools.

...part of the meeting was not only about how you can use the VC but actually get in VC equipment into your school... as well as getting faster Internet. So that brought schools in just for that reason...

The difference meant that some actants did agree with the problem-solution definition and were interested in building a network partly because without building the network they were unable to get faster Internet and VC equipment. Therefore, the difference remained insignificant without affecting the Problematisation at that stage and the development process progressed. At this point, the study black-boxed the controversy until the reappearance of the link.

The above efforts show the persistence and support of all the actants from the local community for finding a solution, but at the same time the above events indicate the absence of active support from the natural actant in schools - the MOE. The individual accounts of the events noted that the MOE did not offer any support during the programme initiation and chose to step back and leave schools on their own. According to one of the programme initiators:

In the early days, I was a bit frustrated because all the efforts was coming from our group of schools and the Ministry, a kind of, stepped back and watched what is happening.

The Interessement Section elaborates regarding the MOE's role. 


\subsubsection{Obligatory Passage Point: aligning interests}

After the successful problem-solution definition, another key aspect of the Problematisation is the establishment of an Obligatory Passage Point (OPP) by focal actants. OPP is the situation through which every actant has to pass and that process of passing through that point aligns their interests. Based on Callon (1986), focal actants in any network establish an OPP that remains parallel with their own interests. Then they convince other actants of a possible detour, which is necessary for establishing a unified and central network. Figure5.2, adapted from Callon (1988) illustrates the realignment of interests by focal actants and the establishment of the situation through which every actant has to pass. To a great extent, the sustainability of a cluster depends how well the established OPP addresses the needs of actants in a network.

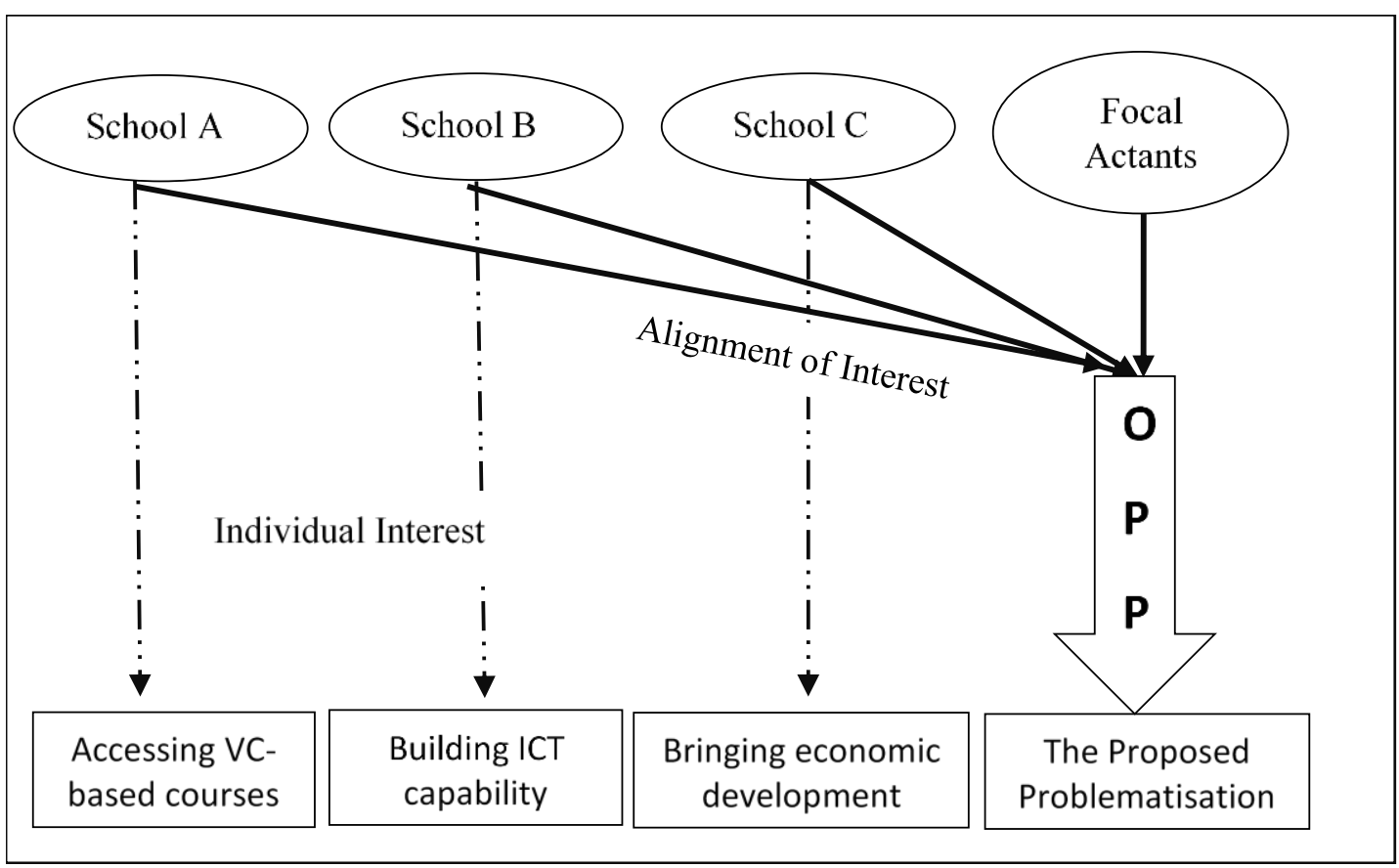

\section{Figure 5.2 An illustration of Obligatory Passage Point for school clusters}

During the A-Net Problematisation, some of the initial actants were recognised as representing the problem-solution definition and took the role of 'focal actants'. Based on the individual stories, the research identified that seven or eight deputy principals were involved in the initial meetings. Two of them were active and knowledgeable; therefore the two actants became focal actants - called cluster coordinators by the schools. The research found the role was central to the existence of the network, therefore the role is regarded as indispensable and able to establish an OPP for others. The Enrolment process further elaborates the role.

During the Problematisation the focal actants had established the reciprocal model and the VCbased class as the OPP through which every actant in the network had to pass. The reciprocal model remained essential for schools that wanted to participate in the network. In order to exchange 
resources, schools had to be a member of the group to get their students enrolled in a class. Without signing up and being a member, schools were unable to benefit from the solution and see their interest aligned with the network. In addition, the VC-based class remained the OPP for schools interested in the solution, since schools had to form virtual class in order to receive an online course. Without that new class structure, the formation of the virtual network would not have existed in the way the focal actants had planned. For these classes, VC equipment was selected by the focal actants as the obvious tool capable of connecting and providing visual contact between students and teachers from the member schools.

At the end of the Problematisation process, some questions arose, one of which was: Did the focal actants succeed in convincing and recruiting actants necessary for the formation of an alliance? The Interessement Section provides answers for such questions.

\subsubsection{A-Net Interessement - fettering together}

The Interessement phase is about focal actants trying to "convince other actants, whose interests are in line with the initiators' interests, to join the network" (Tsohou et al., 2013, p. 41). Based on the individual stories, the research found that the focal actants had identified interested actants necessary for building the network and persuaded them to play roles in the network development. The focal actants had determined that the Community Trust, the MOE, the polytechnic as well as neighbouring area schools were the important actants required for achieving their goal. Therefore these actants were persuaded by convincing them that the proposed problem-solution definition was aligned with their interests. With a successful Interessement these actants were recruited to gain their support for working and building the network together. Without their Interessement, the process of Translation - the programme of action for the development of the A-Net school network - would have been unsuccessful.

The focal actants had chosen to persuade the Community Trust because they knew the Trust was there for supporting local schools in the region. The Trust got interested in the Problematisation and saw its interests well aligned with the ones defined by the focal actants. By involving the Trust, the A-Net initiation gained some momentum, because the Trust agreed to fund member schools to buy VC equipment. One of the focal actants gratefully expressed:

We had local, quite big, players who were saying, "Hey look we know what you want to do; we want to get your communities alive and your schools alive"... The Community Trust helped us buying videoconferencing gears which were exceptionally very expensive at that time.

The focal actants had also anticipated that they would need broadband Internet for the VC equipment - non-human actants - to work effectively. By connecting VC equipment with a high speed Internet, initiators could easily interest further actants - students and teachers - and meet 
their expectations of a VC-based class. With the backing of the Community Trust, the programme initiators 'negotiated' with Telecom New Zealand to develop a special Internet package for the schools (that was before the Project Probe, a NZ Government initiative for broadband). Regarding the role and patronage of the Community Trust for the provision of broadband Internet in the participating schools, one of the focal actants recounted about the events:

They [the Trust] had the philanthropic vision to say, "Hey look, we will underwrite it"... and there was a very quick transition to broadband technology from the old dial up technology... Telecom offered our fast broadband at the time, and we managed to get our videoconference link up and working.

The focal actants had also foreseen that the support of the MOE would be crucial for building the network, therefore the initiators from the grass-roots level had decided to intensely lobby the Ministry. Though from the Problematisation we know that the MOE had initially stepped back, this time the initiators were endeavouring to engage the Ministry in the programme through personal channels. As a result, the MOE agreed to support the programme by covering the cost of building a video-conferencing bridge for connecting different classes. The bridge was greatly needed for connecting VC classes from different schools so students could see participants from different sites. Later, the Ministry also agreed to finance ASNet - a third party technical help desk whose services were hired by the MOE - for supporting schools to deal with technical issues related to VC equipment. All the actants interviewed regarded ASNet as unproblematic, therefore I decided to bundle-up and ignore - black-box - ASNet for the time being.

However, not all initiators were satisfied with the level of MOE support. Some considered instead of having an active role, the MOE had chosen a passive role, making the MOE a little controversial in the network. According to one of the initial actants:

I have always understood that they [the MOE] haven't tried to work a little bit more. They've been as a passive support rather than a strategic or active support to say "OK, how can we help these guys?".

On the other hand, some initiators had a different view regarding the MOE's role and its level of support for the programme. One initiator noted:

Innovation sometimes has to come from schools themselves and then the Ministry will come along later when they think that something looks really useful, then they will come and put their support in.

In addition to the Interessement of the Community Trust and the MOE, the polytechnic was recognised as another key actant which needed to be aligned in the Problematisation, as the Polytechnic was teaching agriculture related courses which schools could not offer to their students due to their limited resources. The Polytechnic saw their interests aligned in the network because their participation in the programme was perceived to increase their enrolments. Therefore they accepted the problem-solution definition and agreed to work together with the programme initiators. According to one of the initial actants: 
Right from the beginning we invited [the polytechnic] to be part of [A-Net]... they came on board almost as a de facto [A-Net] member and offered agriculture [courses].

Documentary actants - the things - gathered during the data collection revealed a relatively sizeable number of agriculture courses being offered through the polytechnic. In return, the polytechnic another actor-network itself - was not only able to increase their enrolments but also to interest potential actants (Years 11-13 students) in their own network; since those prospective students could then be enrolled in the polytechnic's network after they completed their secondary school's education:

By actually tapping into students from [A-Net, the polytechnic] have actually brought students to their campus after schooling. Their numbers [of students] have improved and I think that is a direct consequence of being that de facto member and maintaining that thing and coming in and working with us. This is a very direct sort of relationship.

This scenario indicates a direct effect of the A-Net school network on another actor-network. Due to that effect, a third party course provider for schools can be seen as an important factor stabilising the newly established network.

Last but not least, other area schools in the region were needed to engage in the network. That was necessary to have a sufficient number and a variety of courses available for member schools to exchange so that their interests can continuously be aligned in the network. Schools were convinced to dedicate teacher(s) to teach VC-based classes with students from their own as well as other schools. On the other hand, the engagement of schools was important for having a viable number of students for running VC-based classes. Therefore, other schools in the region were mobilised to join the network. More details regarding the roles of member schools as well as teachers and students in those schools are provided in the next section.

The above findings suggest a relatively unchallenged Interessement process during which the initial actants had successfully bound a number of actants greatly needed for building the network. Because the initiation was at a grass-roots level involving the local community, the MOE's level of support seems to be reasonable. By having an active role, the MOE would have most likely taken ownership of the programme and brought in a top-down bureaucratic approach in dealing with how the network should work; since that is the usual approach most government as well as business organisations use in their projects. In that case, from the theoretical point of view, the centre of power would have shifted and it would have been the Ministry creating network effects and maintaining relations in the network rather than the focal actants and the initiators - the seven or eight deputy principals and their schools. The nature of the network would then have been different to what the initiators wanted. The network would not have comprised a self-sustaining cluster; rather it would have been a dependent group of schools mainly relying on the MOE's support (such 
as the VLN Primary, a cluster of 'primary' schools, which is currently in a financial crisis). Therefore, the limited involvement of the MOE in the programme remains justifiable at this point.

The above findings also discovered that the Community Trust was involved and financed schools to buy VC equipment. Telecom New Zealand was approached to develop a special broadband Internet package for member schools. After some efforts, the MOE was convinced to financially support the development of a video-conferencing bridge for the school community. Third party organisations, such as the polytechnic and a local university were enrolled to offer agriculture and other courses that were not generally taught at schools. Importantly, other area schools which were not involved in the programme initiation were persuaded to become part of the network. These events indicate a successful Interessement, since without their recruitment the Translation could not have moved to its next phase - the Enrolment.

\subsubsection{A-Net Enrolment - defining roles}

The Enrolment is the third phase of the Translation which "involves a definition of roles of each of the actants in the newly created actor-network" (Mähring et al., 2004, p. 214). According to the individual accounts of the events, the initial actants formed a new association - the A-Net cluster of schools - in early 2002 with 11 classes. The new association remained different from the actants' original associations (schools). Students, teachers and other actants still remained part of their mother organisations, but at the same time, they became members of the A-Net association too. Based on the research findings, the following paragraphs outline different roles alongside their tasks in the network.

\subsubsection{Cluster coordinator}

The role of a cluster coordinator or e-principal was defined as having responsibility for overseeing ongoing cluster activities and remaining in continuous contact with different actants in the member schools. Overseeing activities meant that a cluster coordinator was responsible for working with deans from each member school to organise specialised subject teachers, enrolling students and managing the VC-based courses before the start of every school year. During the year, the coordinator was assigned the responsibility of managing the smooth running of those courses by being in continuous contact with member schools via online means as well as by having physical visits to each of the member schools. Therefore, the cluster coordinator role was found to be central in the network, linking and bonding every actant and relation in the network. That also rationalises coordinators as the focal actants representing the network. According to a cluster coordinator:

My key role and responsibilities have always been about relationships with e-teachers, with principals and schools... You're a bit of a human hub... to sort of connect people with the people they 
need to... It [my role] is ultimately about people and it is about relationships; that underpins

absolutely everything.

The above quote accurately sums up the basic task of a cluster coordinator as the actant responsible for building and mobilising allies for the network: an actant who has the role of continuously attempting to (re)build and maintain links between different actants.

Since the role of cluster coordinator was the node at a central position in the network, concerns were raised regarding the risk of network destabilisation due to the concentration of power at a single point. When I asked, "What if a cluster coordinator who manages all the contacts and links all the relationships decides to leave for another role outside this network"? The coordinator replied:

I think it [the cluster] will go through a bit of a rocky patch because that is one of the dangers. Due to the risk factor...we have deliberately tried to have a distributed team of leadership... [Where] we have got different responsibilities but we are acting as a collective team. We will bring new people on [as the cluster grows].

The response explained how the initial actants had defined the role of a coordinator and delegated tasks for the formation of the network, indicating a good Enrolment effort. The response also indicated the awareness and anticipation of the initiators regarding the risks associated with different roles.

\subsubsection{Member school}

Another role defined in the Enrolment was the role of member schools, which was created for schools - as organisational, non-human actant - participating in the network. A member school was delegated three tasks. First, each member was responsible for creating an e-dean ${ }^{12}$ role and dedicating one of their staff members to the role. E-dean was to provide support for students and be a contact person in their school. Second, each member school was assigned the responsibility of providing some funding for the cluster coordinator's salary. Finally, each member school was assigned the task of providing at least one e-teacher to teach a VC-based class based on the network's need and the school's capacity. However, schools deemed to have limited resources and joining the network for the first time were exempted from dedicating e-teachers. Such schools were allowed to earn placements for their e-students without dedicating an e-teacher initially. The exemption by the coordinators can be seen as a strategy used for interesting new actants, including schools and e-teachers as well as e-students. All the above three commitments were delegated to schools as they joined the network.

\footnotetext{
12 From this point onwards the study calls deans, students and teachers e-deans, e-students and e-teachers, because the roles have just started to appear in the network.
} 
These responsibilities were based on the foundations of the exchange model as the proposed solution in which member schools had to exchange their students and teacher. According to one focal actant:

We set up this reciprocal model where any school who wanted to be there had to offer something and they could then sign up as many students as they want.

\subsubsection{E-Dean}

Within the member school, the e-dean role was established and defined to support e-student and eteacher actants in the member school; in addition, the e-dean role was to act as the contact person for the cluster in member schools. Based on the actants' stories, actants with the e-dean role were recognised as the dedicated participants in the network for continuously supporting e-students and e-teachers within their schools. E-deans were also the primary point of contact for the cluster coordinators as well as other member schools' e-deans. From the theoretical lens, the e-dean was the actant representing the network in their school and holding together the links of e-students and e-teachers in the network by aligning their interests within the network. Additionally, the e-dean had the responsibility to 'enrol' new actants (e-students and e-teachers) every year by identifying their problems, and interesting them in VC classes. Therefore, the e-dean role was identified as being as important for schools as the role of cluster coordinator was for the whole network. In other words, the e-dean was another powerful role that involved continuously (re)creating links and relations in the A-Net school network. One of the e-deans reported her role as being a "conjure" assisting and preparing students for a different learning environment as self-paced learners. In her own words:

... [schools] have realised over the time that they [e-students] are not quite tertiary students yet. They haven't quite developed that responsibility for their own learning. So schools have realised that we [e-deans] are sort of that conjure between being told by a teacher "do this, do that, do this, do that" because that is what they have come from the primary end of the school to being independent self-managing learners when they leave school. We have realised you need this level of support. You need someone who encourages them along, making sure they are on task.

From the theoretical perspective, it is important to note that every school by itself is a network where not only e-actants but also face-to-face (F2F) actants come into play. In that network, F2F teachers were found as the hostile actants opposing VC classes, since they felt affected and annoyed, and sometimes threatened by the growing number of students joining VC classes. The opposition was one of the significant factors capable of sabotaging the role of member schools and consequently the network stability.

Because you are dealing with human and probably one of the biggest constraints are human attitude and some beliefs. When you are growing participation of online space within a school, often other teachers within that school feel quite threatened. That is perhaps one of the bigger barriers. 
Indeed, some member schools studied in this research were successful in countering the opposition by having some strategy to deal with the issues. Therefore, the positive role played by the senior management of member schools remained a significant factor for the network's development and stability. The hostile attitude of F2F teachers can disrupt any member school's contribution in the network if the school's senior management treat the problem as insignificant.

\subsubsection{E-Teacher}

The e-teacher was another 'interested' actant from the member schools with the task to deliver online VC courses. The e-teacher actant was responsible for preparing class activities and delivering a one-hour long video-conference-based class every week. In addition, every e-teacher was allotted a separate three indirect-contact hours per class every week - making altogether four hours for a VC class. Those three hours was for replying to student emails, i.e. helping students to comprehend their learning material. Most importantly, those three hours were for building relationships with estudents and maintaining their links in the network. Therefore, the focal actants had set four hours as a standard for teaching a VC class and member schools were obliged to follow that standard.

According to a cluster coordinator regarding the teaching hours:

... certainly in the early days that was one of the things which we had to fight. We had to say that a class is a class and because now you have got VC that doesn't actually mean that you are not teaching. Otherwise you are not going to get people [teachers] in there.

The obligation was very important for aligning interests of both e-teachers as well as e-students. However, despite the clear definition of the standard, some schools were not meeting their commitment, causing some e-teachers to leave the network making the school less active with fewer students and courses in the network. The schools had allocated e-teachers only two hours one direct and another indirect-contact hour - instead of four, since the schools perceived one indirect-contact hour per week as sufficient for e-teachers activities outside VC classes. Therefore, allocation of fewer hours was a problem, undermining the enrolment of new e-teacher actants. One e-teacher responded to the problem by saying:

... if they [e-teachers] will think that I have got to teach a whole hour, and then I have got to design, I have to mark, I have got to do a whole lot of emails and I have got to digitise resourcing and get that onto [the] website, then they won't do it because that takes more time not less time than the faceto-face teaching. Face-to-face teaching is easier for the same amount of time.

When I asked another e-teacher, "Is the fewer number of hours one of the reasons not many teachers want to teach a VC class?", she responded:

Absolutely, there is no way I would do it for two hours a week. It is just no way the workload and the marking-load can be completed... all that takes much longer and people [face-to-face teachers] say, "Oh, what do you do with your spare three hours a week?" 


\subsubsection{E-Student}

Within the member schools, e-students were the dedicated actants interested in receiving VC courses based on their personal needs, skills and interests. The enrolment of e-student actants started at the end of every year when member schools announced to offer online course(s) next year based on each school's own capacity and needs. The cluster coordinator along with e-deans enrolled those interested students in the offered courses. With the use of Internet-based videoconferencing technologies, e-teachers conducted those classes with students from different schools. According to an e-student:

I like it [VC class] because obviously being from a small school we don't really get that many opportunities to do a lot of different courses.

E-students were delegated the task of being responsible for their own learning and managing their study independently. For that task, e-students were required to attend a one-hour VC class every week. In addition, e-students were also required to manage their three self-study hours independently. During those hours, if e-students had encountered problems regarding the course content, they had to contact their e-teachers (mainly via emails) and seek their help. Therefore, the e-teacher was the first port of call for e-students regarding the course content related issues. For managing and resolving VC equipment issues, printing course notes and other administrationrelated activities, the e-dean was the actant responsible.

\subsubsection{Parents}

The study identified parents as another important, however black-boxed, actant closely associated with e-student actants. According to Vos (2014), parts of a network that are "considered no longer interesting, or where they are simply accepted as they stand, are thought to be reliable and unchanging" (p.61). Parents were found to have an influencing role on e-students not only during their Interessement and Enrolment but also during their 'Mobilisation' (next phase) in the network. However, member schools, e-deans and cluster coordinator were found to have overlooked formally enrolling parents in the network. Though parents are generally involved in schools' boards of trustees (BoT), A-Net remains a separate association. When I asked schools about the lack of parents' roles in the network, one of the e-dean actants admittedly responded:

[School's e-Learning review committee] have identified that we haven't [promoted parents' involvement] really, because it has become what I call bread and butter - what we do every day... we need to do more sort of promoting of what we actually do [in VC]... because I think that is important that parents see how the students are actually learning, because they would have learnt in the classroom ... completely different to how we are operating here now.

The lack of such promotion posed a challenge for e-students in maintaining their Enrolment in the network or meeting their obligations and responsibilities as self-managed and independent learners. 
This is because e-students require parental support to maintain their link in the network. Consequently, the absence of parental understanding and support posed a challenge to the Mobilisation of actants too. Regarding the parents' support, an e-dean responded:

You know, some of them [students] can't have Internet access as home. Well for the student who is doing e-learning that is actually not very good... So parents need to understand that we are teaching through a whole lot of different mediums now including the social media. So it is not so simple to say to your child that you can't have Facebook because that may be actually harming the children's learning and putting them in a disadvantage.

Therefore, the e-student role in member schools was a weak node in the network and the issue remained a factor that can destabilise the network, particularly when the whole network is assembled with a 'student-centred' approach and built for integrating geographically isolated students in schools. The Mobilisation Section further explains this challenge.

\subsubsection{Technological actants - the things}

Video-conferencing equipment including other non-human actants were brought into the network for the exchange of learning resources and facilitating communication between geographically isolated participants. Both A-Net as well as CASATech initiators had recognised telecommunication technologies as potential actants with problem solving capabilities if employed accordingly. Based on that understanding, the A-Net focal actants specified that the usage purpose of the VC equipment was a good match with the interest of the A-Net school network. As a result, VC was enrolled in the network as the actant responsible for providing a platform for conducting an online class. The VC equipment includes a set of TV screen, video camera, document camera and microphone, and is connected to the Internet. More recently, other non-human elements have been enrolled in the network which include computers, laptops, Internet-based applications (email, Skype, Facebook, Google Applications and so on) and mobile phones.

During the situations where VC had failed to perform its delegated tasks, e-students were calling their e-deans and ringing other technical helpdesks in order to make the technology work. Those situations of social ties - calling the e-dean, ringing ASNet and resetting the VC equipment - were the 'movements of modification ${ }^{13 \prime}$ caused by 'the things'. Therefore, this research considered every actant relevant for the network and assessed their effects on the A-Net school network.

To conclude the Enrolment, due to the successful Interessement, the process of Translation moved and the Enrolment took place. During the Enrolment, the focal actants defined various necessary roles with their relevant responsibilities. However, all the roles and their associated tasks relied on

\footnotetext{
${ }^{13}$ Modification is an ANT term that can be seen as one of the important aspects of a stable cluster. It is a shift that is necessary for the stabilisation of a cluster.
} 
the actants' own discretion, on a voluntary basis without the focal actants having much accountability. Perhaps that could be due to the nature of schools in New Zealand as independent bodies. According to a cluster coordinator:

We have some guidelines and also one page conditions of memberships as a receiver of courses. That is about supporting learners and so on; and as provider for [A-Net] we have got a one page of [obligations]. We also got various manuals which we work with e-deans and e-teachers.

These documents were not very effective for assuring all member schools including e-teachers, edeans, and e-students fulfil their obligations in an uncompromising manner. The next section explains the challenge in further detail.

\subsubsection{A-Net Mobilisation - supporting enrolled masses}

The Mobilisation is the final stage in the process of Translation, which involves ensuring that initial actants involved in the Problematisation are able to represent the problem-solution definition and enrolled collectivities (Postma, 2009). The initiators ensure that all the actants work together to maintain the problem-solution definition and keep other actants enrolled in the network (Vos, 2014). The findings revealed relationships and continuous support as the two important interrelated factors underpinning the network's stability.

\subsubsection{Organic relationship}

According to Tatnall and Gilding (1999), "a network becomes durable partly due to the durability of the bonds that hold it together, but also because it is itself composed of a number of durable and simplified networks" (p. 959). This means that a network can be durable if relations between and within different elements of that network are strong. For example, the durability or stability of A-Net would depend on how good relationships are between different actants at the cluster level, and how good those relationships between those cluster actants are within their corresponding schools. The role of the cluster coordinator discussed in the above section answers the question regarding relationships at the cluster level. The coordinator's previous quote is repeated at this point to demonstrate the significance of relationships between actants:

My key role and responsibilities have always been about relationships with e-teachers, with principals and schools... You're a bit of a human hub... to sort of connect people with the people they need to... It [my role] is ultimately about people and it is about relationships; that underpins absolutely everything.

However, maintaining that relationship was a different challenge that could undermine the network's stability, if neglected. The findings revealed that the cluster coordinator and some of the e-deans had not only built but also maintained that relationship at a 'personal' level and by developing a sense of community and ownership rather than a service-client type relationship. According to the cluster coordinator: 
Our programme is more about learning communities, about learning relationships between students and students, and students and teachers, and actually that is the core about our model...There is a lot of feeling of ownership by the schools and the students about what we are doing compared with fairly institutional service.

About the significance of the relationships between network elements, he further added:

It is something which again is almost a grass-roots and organic relationship, and it is really, really difficult to just try and do it and switch it on.

\subsubsection{Continuous support}

Providing continuous support was identified as another significant factor that had successfully mobilised actants from member schools. Arranging monthly meetings between member schools and e-teachers was important for providing continuous support from the focal actants. Specifically, 'eday' and 'e-hui' were the annual formal gathering that promote continuous support as well as developing relationships with newly enrolled actants, and (re)building and maintaining that relationship with the existing ones.

E-day was recognised as the e-students' and e-teachers' annual gathering, held once at the start of every year to provide an opportunity for the actants to meet each other face-to-face before the start of their VC classes. This was a major act of mobilisation - ensuring continuous support. According to one of the e-student actants:

I think it [e-day] is good, because it gives us a chance to actually meet our teacher F2F, and actually have a conversation with them and meet other students...It is really helpful. They [e-teachers] kind of go over what they expect [from us during the year] and how they are going to run the year and what sort of thing [communicating tools] they will use to keep in contact.

Most importantly, the e-day was an act of building trust and relationships. Regarding the outcome of e-days, one of the organisers believed:

We have found that those teachers who have actually met their students...at the start of a course, actually just build that relationship. They [students] just get to know that person [e-teacher], and the students will have much less trouble contacting someone that they have met than if it is, "Oh I don't know [the teacher]". It is trying to break down those barriers [between students and teachers].

Some e-teachers had taken the initiative to arrange additional physical visits during the year to meet their e-students for building a better teacher-student relationship and helping students to feel comfortable making the most of the available support. Those visits, e.g. during a sports event, aimed to break the barrier of students' "shyness during a VC class full of strangers and not engaging with eteachers and e-students whom they have never meet physically". According to an e-teacher:

I try to visit them [e-students in my class]. A lot of the students play Saturday sports... So I will go and watch them if they say my rugby team is playing here on a certain date. I will try to go and watch them... We have a ski trip in September...I am there for the four days and that is great because they get to know each other really well by staying together. 
However, the identified issue was that not all e-participants prioritise to attend annual e-days. Some participants had not attended because their schools were very far from the e-day location, but others had simply not attended the event even when they could do so. When I asked one of the estudents, "Have you been to an e-day?", she surprisingly responded:

E-day? No

When I further enquired, "So you have no idea what it is?", the e-student again said "no". In addition, when I asked one of the e-day organisers, "why some member schools were not sending their e-participants?", the organiser expressed her frustration regarding some schools' absence and responded:

... [their absence] frustrates us even more. The ones who are close should be here [on the e-day], and that has been a frustration for (cluster coordinator) and I. We said it was essential that they come but not all schools have prioritised it to make sure their students get here.

That indicated the conflict of interests or priorities between member schools and the focal actants. The focal actants considered e-day essential for the Mobilisation of the actants, because e-teachers and e-students always need continuous support to maintain their links and continue their relations in the network. However, senior management in member schools were not fulfilling their obligations. On the other side, e-deans were unable to convince or were failing to develop enough 'interest' in their senior management for supporting school participation in the Mobilisation activities.

\subsubsection{Top management support}

In the development of schools' priorities, schools' senior management, particularly principals, are responsible for setting their organisational priorities. How schools' leadership perceive VC activities or online teaching and learning influence their contribution to such activities. Therefore, the leadership perception was a driving force for some but a barrier for other schools to their virtual activities. That fact was more evident after a change of leadership in member schools. There was either a significant increase or decrease with a change of school leadership - particularly the principal. Regarding the schools' senior management support, one of the e-deans actively participating in the network said:

We have been very lucky. I don't think we would be anywhere near the stage with e-learning without that support because I have seen other schools and they say, "Oh the principals don't understand; its senior managers don't understand". If you don't have that senior management support, it would be a very hard battle to fight on your own. I am lucky because I straddled both the senior management and our department in here.

The e-hui was noted as the professional development (PD) workshop held once at the end of every year, in which experienced e-teachers shared their experiences with e-teachers newly enrolled in 
the network. The sharing of experience was a self-managed professional development workshop provided by the focal actants to support e-teachers. The PD programme was found corresponding to the MOE's 2002 ICT strategy indicated in Table 2.2 above in the Literature Review Chapter. One of the key components of the strategy was to "Support educators in integrating ICT into curriculum and management practices" (Powell, 2011, p. 5).

In addition, the event was as an opportunity for e-teachers to meet other e-teachers of similar subjects to exchange class resources. According to a member school principal:

[During the e-hui] we talk about development and how best to develop the teaching. So there are some good pedagogy...and some good support...There is also a growing amount of research around what makes an effective e-teacher. We have started using some of that at the same time.

Although the PD seemed to be an excellent effort, most of the e-students interviewed expressed concerns with their e-teachers' teaching styles in an online environment. Some of the e-teachers were reported to replicate their face-to-face class strategies during VC classes, and others even as not having any strategy at all. One of the e-students with four years of VC experience responded that over the years many things had changed except the learning and teaching. Another e-student described different teaching strategies in VC where one e-teacher was referred to as "just throwing information" while another e-teacher was regarded as "engaging students by asking questions". One e-student with three years of VC experience having taken eight VC-based subjects expressed frustration with one of her VC classes and regarded that class as a "train wreck" and the e-teacher as "very disorganised", and recommended a "lesson plan". She compared two of her VC classes and noted:

My Level 1 [VC course] was basically a train wreck. A lot of it [a VC course] depends on a teacher and how kind of organised the teacher is and able to do that. My Level 1 [VC class] teacher was very disorganised... I would definitely definitely recommend the lesson plan idea that my [other VC] teacher has. So when teachers teach a class I know from experience that they have sort of a layout.

Another e-student clearly suggested more professional development programmes for e-teachers so they could adapt their teaching strategy for teaching online:

I think there could be some improvements in the teachers, like how they teach, because they have to remember that they are not just in a [face-to-face] class. Well they are in a classroom but the kids aren't just right there. So they have to adapt their teaching to suit the needs of [students] being at different schools.

The e-students' above dissatisfaction towards e-teachers' delegated obligations not only indicated how critical the e-hui was for the Mobilisation of e-teachers but also questioned the number of PD opportunities particularly focused on e-teachers' needs. From the theoretical perspective, these dissatisfied actants could betray and leave the network after their failed Mobilisation experiences, and hinder the Interessement of prospective e-student actants. Therefore, the absence of a 
personalised PD programme for e-teachers was one of the factors that could affect the stability of the A-Net school network.

\subsubsection{Deep local support}

Deep local support meant how well member schools supported their e-students locally. During the Enrolment, member schools and e-deans were delegated the task of supporting their e-students at their own school level. E-teachers was responsible for the teaching and learning processes whereas deep local support from schools was basically intended to assist e-students to cope in the new environment and during the transitional process - from being teacher-led learners to self-managed independent learners. The support was significant for helping e-students to maintain their relationships with their e-teachers and e-fellows and remain enrolled in the network. To clarify the nature of the support, an initial actant responded:

The other thing which makes a difference to whether it [the programme] works or doesn't work for learners is how well the schools themselves get around and support the students, not in a teaching way but in a pastoral way.

One of the schools' senior management actants regarded the provision of such support as one of the factors for e-students' success in the online environment. This is because some of the e-students might be experiencing the environment for the first time or not have much experience of being independent learners. They need some mediating elements for that modification and indeed the deep local support is one of the main elements. According to the focal actant:

... looking at the students' learning experiences... one of the key success factors we identified is how well a student did in the online space, was the degree of school support around...all of their students - particularly for their weaker students.

Challenges were found regarding the provision of local support, a task promised to be undertaken by the member schools. Some schools within the A-Net had set up multiple layers of support around their e-students, whereas other schools had left their e-students on their own. In one school the estudents had four layers of support, both in teaching as well as pastoral ways: First, the schools had an active e-dean with many support roles such as administrator (student enrolment and photocopying and printing materials), technical assistant (resolving technical issues by herself as well as by ASNet), mediator (contacting and reminding e-teachers to respond to e-students' emails if not responded to within 48 hours), examiner and so on. Secondly, pair and peer learning strategies were placed around e-students in the schools by grouping e-students from the same or different levels. That was to provide collegial support in case e-students were social learners. The third layer of support was a mentoring scheme in which each e-student was provided with a mentor who was a teacher in that school from a similar subject area, if not from the same subject. For example, a calculus subject teacher was a mentor for 2-3 e-students taking mathematics classes over VC. This 
was so e-students could have access to a local teacher for any quick query. Finally, the school had a one week long e-learning module at the start of every year for their e-students. The short module aimed to train e-students to cope in an online environment which remained very different from their face-to-face class environment. In particular, that module was helpful in supporting the transition of e-students from being purely instructor-led learners to independent and self-managed learners.

Regarding the deep local support, one of the school's senior managers responded:

... to be successful in a VC class, you [have] got to have a lot of support network around your kids. You can't just dump them in a VC class... you can't just assume that you put a kid in a room and give them a teacher from somewhere else and a website, and they are going to be successful... They [schools] need to say, "Well, OK, what we are doing to help the student deal with the technology? How we are going to help the student to [get] the really best they can out of it?".

In addition, the findings revealed that such deep local support had helped in building and maintaining student-teacher relationships by keeping both the parties informed and in continuous contact. Without that support, student-teacher relationships were quite weak and students had experienced many issues, such as: lack of engagement or feeling bored during VC classes; lack of student-student interaction; difficulty in becoming independent learners; poor student-teacher relationship; lack of trust or feeling shy during VC class; getting late email responses from eteachers; uncovered course content; an uncomfortable or damp VC room; having frequent technological issues; and not feeling confident in using different technological tools available in the VC room. One of the focal actants agreed there were problems with e-students in a few A-Net cluster schools and nominated poor support as a barrier and the reason for most of the problems:

Because a student in a VC class has one hour direct contact and three indirect contact hours, depending on how well schools provide that support is probably the single biggest factor to whether the initial first experience of an online student is successful for them or not or highly successful. That poor support is a barrier. If it does not exist and they sign up a student and then forget about that student, then that student is really going to struggle.

To generalise, the absence of well-placed and well-managed support in some member schools significantly undermined the Mobilisation of e-students as well as the member school itself in the online space. In contrast, e-students from schools with a robust support strategy for their e-students were more confident and prepared in that space. Furthermore, the e-students seemed to be more organised and equipped for tertiary education because those are some of the key skills required at tertiary level. The production of skilled students can be regarded as a direct effect of the A-Net school network over the tertiary education providers. How well those prepared e-students from the A-Net perform at tertiary level remains a useful aspect to be explored by another study. 


\subsubsection{Summary of A-Net Case Findings}

ANT is a theory that attempts to identify controversies in a network and make connections between those controversies to explain 'how something happens' rather than attempting to solve and justify 'why that happened' (John Law, 1992). For that reason this study attempted to identify controversies and their links in A-Net. For that identification, the four phases of Translation were used to interpret the development of the school network. Those links were labelled as the factors that can (de)stabilise the school network.

During the Problematisation, the findings discovered the actual problem in schools and the possible solutions available at that time. According to the initiators, during the early 1990s area schools in the rural region were unable to meet the learning needs of their specialised subject staff and students in Years 11-13. That near-failure situation was described as the effect of demographic changes, causing area schools with small student rolls and consequently less government funding. Less financial resources meant that schools could not offer a variety of subjects to their secondary level students as per their needs. Specialised subject teachers had to unenthusiastically teach the subjects they were not good at. The initial actants regarded TCS as a solution, albeit unsatisfactory, at that time. Another initiative started at that time was described as the first Internet-based technological attempt, but the initiation remained limited due to insufficient Internet speed and other technological restrictions. Their finance-based subscription model also failed to compel schools that were financially strapped already. Therefore, the limitations did not allow CASATech to flourish further and create enough interest amongst actants for developing their network.

The second technology-based attempt for a solution was proposed in the year 2000 by a group of seven or eight schools in the region. In the new solution, the group proposed to enrol videoconferencing equipment as the technological actant and offered the reciprocal learning model as the strategy. VC as the non-human technical actant was aligned with the interactivity need or interest of e-students and e-teachers. Similarly, the reciprocal or the Learning Exchange model as the conceptual actant for the exchange of learning resources was seen aligned with the interests of the member schools. No major sabotaging actant was identified during the Problematisation. Therefore, all the seven or eight initial school deputy principals accepted the problem-solution definition and agreed to build the network - called the A-Net cluster of schools. Two of the initial deputy principals were established as the focal actants to represent the network and cluster coordinators. Because the role was central to the existence of the network, the role remained indispensable and able to establish the Obligatory Passage Point for other actants. Based on their understanding, the focal actants established the reciprocal or the Learning Exchange model and the VC-based class as the two OPPs through which every actant in the network had to pass. 
The Interessement process began when the focal actants started to convince other actants to accept the Problematisation. The Problematisation was seen as aligned with the interests of the Community Trust, the MOE, the polytechnic and other local area schools. In addition, these actants were deemed highly significant for building the network. Therefore the focal actants persuaded them to join the network. The findings uncovered these actants as a few of the factors necessary for the network's durability. The MOE was, however, reported as a passive actant instead of having an active role in the network. On the other hand, for some participants, self-sustainability was more relevant to the core of the network and an active MOE role could undermine such characteristics. The engagement of the polytechnic was one of the important aspects of the A-Net that was deemed to have been black-boxed due to its punctual behaviour. However, clusters attempting to stabilise cannot afford to black-box such actants. Therefore, they need to open such black-boxes in order to gain active support for stabilising their networks.

The process of Translation proceeded into the Enrolment phase during which the focal actants formed the A-Net cluster in 2002 with 11 classes. Different roles were defined and tasks were delegated to different actants. The role of cluster coordinator was defined to oversee cluster activities and manage links and relations between different actants inside and outside the cluster. Regarding the coordinator's role, a distributed team of leadership was a significant aspect for cluster stability. The role of member school was created with the responsibilities of dedicating one e-dean to enrol and mobilise other actants (students and teachers), contributing to the cluster coordinator's salary, and providing at least one e-teacher to take a VC class. The e-dean was the actant responsible for providing continuous support to e-students and e-teachers within their local school, continuously (re)creating links and relations between actants. The e-teacher role was defined and delegated to the actants enrolled to deliver online courses, during which he/she was in charge of building good relations with e-students and ensuring the maintenance of their links in the network. The e-student role was created for the actants interested in taking the subjects based on their personal needs, skills and interests. In addition to the member schools and the MOE as the organisational actants, other non-human elements, such as technical and symbolic actants were identified. Technical elements included VC equipment, the Internet, computer-based applications and mobile phones. Course curriculum and cluster guideline documents were recognised as the symbolic actants. The research identified parents as important potential actants; however the focal actants had failed to enrol these actants, as they could have played a mediating role during an e-student's Interessement as well as Enrolment and Mobilisation. However, member schools including the focal actants had not shown interest in enrolling parents in the network building process. Face-to-face teachers were identified as a factor that can hinder the development of the network at schools, because their own 
role was threatened by the VC classes. Overcoming such opposition within the schools was the responsibility of schools' senior management. The uneven number of direct and indirect teaching hours was seen as another issue that could affect network stability. Despite the clear guidelines, some of the member schools were not meeting their obligation of allocating four hours per class to their e-teachers. Uneven teaching hours was undermining the enrolment of e-teachers. Though attempts at successful Enrolment were made by the focal actants, all the roles and tasks were based on the actants' discretion - on a voluntary basis - without the focal actants having much accountability or power.

During the Mobilisation, the initial actants were building and maintaining good relations and providing continuous support to their enrolled actants. The research identified the cluster coordinator as the key actant for maintaining that relationship at a personal level by traveling and visiting member schools. E-deans were the actants ensuring continued support for the actants in their local schools. The 'e-day' and 'e-hui' were two formal attempts designed to develop relationships with newly enrolled actants, and (re)build and maintain relationships with their existing actants. Deep local support was a highly important effort, not only for ensuring continued support for e-students but also for the stability of the network as a whole. All these supporting events remain significant factors in the network's sustainability. Poor leadership perception about online learning activities was a factor that can sabotage the role of member schools in the network. The lack of personalised professional development programmes for e-teachers was found as another factor undermining the relationship between student and teachers and destabilising the network. To conclude, issues existed in some of the A-Net schools that could cause destabilisation in the network, however there were only a few such schools. They were outnumbered by the schools with a very proactive team of senior management and e-deans. Most importantly, they had their cluster coordinator holding together all the actants out of which they were composed. 


\subsection{B-Net Case Findings}

B-Net was the second cluster of schools that was studied in this research. As part of that, a number of B-Net schools were visited and interviews were conducted during and after the visit. Documents were gathered and studied to enrich the findings. Also, one of the cluster leadership team members was accompanied for a couple of days to observe how the network was managed and maintained.

B-Net was initiated in 2001 as a joint project of the MOE, local business and 10 schools in a region of New Zealand. In this study, the three-year long project is referred to as the Digital Project for Schools or DPS. Ten schools from the region were selected to participate in that pilot project. Most of the schools were small, located in the parts of the region that were thinly populated. Schools had a small number of students and staff who had to commute every day, travelling a long distance to get to their schools. Because of their challenges, the schools were found suitable for the project. The main goal of the project was to 'bridge the digital divide' in the region between the schools and improve student learning outcomes with the support of ICT. As part of that, the project financed the 10 schools ${ }^{14}$ that were mostly on the wrong side of the divide to equip them with the latest telecommunication devices and 'connect' them with other schools via Broadband Internet. Around the same time, the group of schools had successfully secured the ICTPD funding from the MOE. As a result, B-Net had become one of the 2001-03 ICTPD clusters of the MOE.

After the completion of both the DPS and ICTPD projects, 9 schools (mostly the existing B-Net schools) had decided to adopt the A-Net Learning Exchange model. The main reasons for the decision were to continue their digital progress and avail themselves of the benefits of the exchange model, particularly for the smaller schools struggling to offer a range of subjects to their students. Therefore, the nine schools had adopted the Learning Exchange model in 2004 and continued until 2007 without any significant change. In 2008, the two-year e-principal funding had started to make a significant impact on B-Net by allowing the schools to have a full time dedicated e-principal or cluster coordinator. With the support of school principals, the B-Net e-principal had further developed the cluster by increasing participation within and outside the cluster. As a result, after the end of the two-year funding, the cluster had grown from 9 to 15 schools and become financially selfsustaining. As of early 2016, 25 city and rural schools of all sizes from the region were part of the school community and were contributing to the Learning Exchange.

\footnotetext{
${ }^{14}$ Not all the 10 schools were small. A couple of city schools were included in the project to support the group, particularly for the development of digital learning resources in Te Reo Maori. That was another aspect of the project goal which is discussed later in the main findings.
} 
The following sections report the development of B-Net and its development from 2001 to 2015. The four phases of the Translation concept from ANT have been used for the reporting of the findings. The findings have been based both on the interviews with human actants and on the inputs from documentary actants that were gathered during and after the data collection process. The interviews lasted from 40 minutes to two hours. The interviews were fully transcribed and sent back to participants for them to confirm that the transcriptions were correct. Documentary actants included MOE reports on various B-Net initiatives, information from B-Net and VLN websites, cluster documents such as a responsibilities chart and annual calendar, and personal observation and correspondence. The data collection process was completed in early 2015 and the findings were finalised in early 2016.

\subsubsection{B-Net Problematisation}

This section identifies the problem and possible solution that led to the initiation and development of B-Net. The section also describes how some of the initiators represented the proposed problemsolution definition and their cluster.

\subsubsection{The problem and possible solution}

In February 2001, B-Net was announced as a joint project between the Government, local businesses and 10 schools, mostly from rural areas. The project, referred to as DPS in this study, was aimed to "bridge the digital divide" and overcome geographical barriers for some of the schools in the region. The goal behind that was to eventually improve the student learning outcomes, particularly in maths, science and technology. In other words, improving student learning achievements in the three subject areas was the early priority of the B-Net initiators - the New Zealand Government, local businesses and 10 schools in the region.

Specifically, the problem or need to improve student achievement was due to the geographical isolation and challenges faced by those schools. Some of the participating schools were from very remote areas and their student rolls were significantly low (see footnote 3 ). Although not all the schools were small or 'area' schools, most of the 10 schools were from decile $2^{15}$ at the time of the project initiation, i.e. having the greatest socio-economic disadvantage. Therefore, with the support of the ICT-based project, the initiators had expected to address the socio-economic gap by introducing opportunities through digital means in the schools on the wrong side of the divide. For some of the schools ${ }^{16}$, it was a significant challenge to arrange a teacher to teach general subjects,

\footnotetext{
${ }^{15}$ Decile is a measuring unit used by the NZ government to categorise different regions on a socio-economic basis. Decile 1 means the area with the worst position and decile 10 means the best position.

${ }^{16}$ One school was once the smallest high school in NZ. At the time of the research, the school was a composite school from a decile 1 region. It had a coeducation system and less than 90 students from year 1-13.
} 
such as, year seven maths, and maintain a good student roll. As a result, the students had to either take the bus for at least a couple of hours to and from the nearest school having the teachers to teach basic subjects. Thus, the students, in particular, were at a disadvantage and the schools remained isolated from other school communities.

To address the problem, the project initiators had identified the formation of a virtual learning community having access to the required digital equipment as a good solution. Through the formation of such a community, the initiators had expected to improve student participation and achievement. That was the high-level problem-solution definition that the research identified in the study of B-Net. The project initiators assumed that the goal of improving student achievement could be accomplished through the effective use of ICT. A documentary actant indicated the problem and the proposed possible strategy to deal with the problem:

..."from early background papers and communications, which note that some students are not achieving at the same rates as others, that it was felt that ICT had the potential to attract and engage students"

According to another documentary actant, the concept was to form a single "virtual school with 10 schools, 4500 students and 280 teachers". The advantage of that virtual school would be "economies of scale of a large organisation" and yet preserving their individual identities:

[B-Net] harnesses the resources of a school with a roll of 4,500 and a teaching complement of 280, yet preserves the autonomy and intimacy of each individual school.

Therefore, to improve their student achievements, the initiators had formed B-Net as a virtual community of schools in the region. That was foreseen as a solution to overcome their digital divide by enabling the schools to access digital technologies and connecting them as a community. Specifically, the DPS had four main objectives. The first objective was to build their technological infrastructure by equipping schools with the required digital hardware and software. To better connect schools as a community and with the outside world, increasing their Internet bandwidth was the second objective. The provision of quality teaching and learning resources via "resource development and sharing" was their third objective. Their last main objective was to offer professional development training for their staff members. These objectives were to achieve the initiators' goal of bridging the digital gap that existed between schools in the region and thus improving their students' achievements.

Since the project was aligned with the needs of all the 10 schools, they were all attracted by the problem-solution definition. They agreed to form a virtual community of secondary schools in the region, with a fulltime coordinator for the whole group, and include a "link teacher" and "literacy leader" from each of the schools. 
That was a big achievement for all the stakeholders in the region. Indeed, the B-Net programme was selected as one of the three finalists to represent New Zealand in the Stockholm Challenge. As one actant inscribed during that period revealed:

Three New Zealand web-based education programmes have been named as finalists in the Stockholm Challenge competition, which recognises innovative information technology solutions from around the world.

Around the same time, the cluster held various other contracts with the MOE, such as the B-Net ICTPD project in 2001-03 and the Literacy Leadership project in 2002. The 10 schools in B-Net had applied for the ICTPD cluster funding and were awarded a contract for three years (2001-03). As discussed in the previous chapters, the fund was for the provision of PD for their teachers to improve their ICT skills and to "support student learning in the ten...secondary and area schools". The project was intended to "share ideas and resources" and to provide "important educational, social and/or economic benefits to the students and families in the [region]".

Uniquely, the ICTPD project in B-Net had a cultural dimension as well. Since the region has a high population percentage from the Maori ethnic background, the schools in the region had teaching staff capable of producing bilingual educational resources, both in Te Reo Maori and in the English language. Therefore, the Government was interested in taking advantage of that benefit by promoting the development of bilingual educational resources to meet the educational needs of interested students and teachers from schools throughout New Zealand. As part of that, a Maori resource coordinator was appointed for the development of such resources. One participant reported the activity as being as big as the actual ICTPD project vision:

They did actually appoint someone to...go around [schools] and get community resources, particularly Maori community resources which could be sort of lodged with TKI [Te Kete Ipurangi or the MOE]. That was about as big as the vision was really...

In addition, the ICTPD project was focused on covering all subject areas and not just maths, science and technology, which was in contrast with the case of DPS. As one documentary actant ${ }^{17}$, an Education Gazette newsletter inscribed in July 2002, revealed:

Its [the DPS] key objective was to develop computer-based bilingual learning resources targeted at the maths, science and technology curriculums, however, the project has now been extended to include all curriculum areas and will incorporate the Ministry of Education's secondary literacy leadership professional development programme,

Although various projects were running in the cluster simultaneously, B-Net remained a common platform and a communication mechanism for all their projects. Similarly, although these were

${ }^{17}$ http://www.edgazette.govt.nz/Articles/Article.aspx?Articleld=6231 
separate projects, they were complementing each other and had become part of each other. As one documentary actant unveiled:

...by 2002 they [both the projects] had become so closely linked that both the evaluators and school personnel had difficulty in delineating them. It appears that [B-Net] was seen as an umbrella initiative that included both [DPS] and the ICTPD contract...

Although the above Problematisation was relevant to B-Net and provided the basis for the B-Net initiation, it was not very relevant to the main interest of this research study. What happened next in B-Net after 2003 was the main domain of this study. That is because B-Net adopted the Learning Exchange model in 2004 and further built the cluster upon their previous progress. Therefore, the modification or realignment of the B-Net network in the following section provides the Problematisation based on which the Translation of the B-Net development further proceeded.

\subsubsection{Re-Problematisation}

The research found that after the completion of DPS and the ICTPD project, most of the 10 schools in B-Net had decided to continue their digital progress. Their previous emphasis was on improving student learning achievements, particularly in maths, technology and science and on offering training for staff members. In the next phase, the B-Net school principals prioritised the learning needs of their senior students in all subject areas. Because of their geographical challenges and small size of most of the schools, their senior secondary students were unable to have access to a broader curriculum and specialist teachers in their local schools. The students were either accessing those courses through TCS or leaving those schools to study in bigger schools with specialised teachers. The situation was a matter of survival for the schools. As one participant reported:

For many of our [B-Net] schools, it was a matter of educational survival for them. [They looked for an alternative solution] so that students were not having to leave their schools in order to receive a quality education with a wide range of curriculum options. If they lost these students to other schools, then their school was at risk of having to close [their secondary part].

Therefore, the schools decided to find not only an alternate solution to TCS but a solution that could further extend their existing digital initiatives. Some of the B-Net initiators found the virtual exchange of classes via VC interesting and were convinced that this was a suitable solution for meeting their needs. With the exchange model, the schools could retain their senior students and thus stop their school being decapitated by the Government. As a result, they decided to adopt the Learning Exchange model from A-Net. One participant recounted the situation and exemplified the solution:

As far as I could picture it, they were small rural schools who didn't necessarily have all the specialist teachers, they needed to offer all the classes they would like to offer which meant that their students were either missing out or their students were going off to city schools where they could 
get the subjects they wanted. So I think they formed a small cluster like A-Net, [so] one would offer a senior physics and the other one might offer some senior chemistry and they would share them.

Another participant reported that the new solution was aligned with their previous project, and was going to complement that:

It was also a natural progression from the original [B-Net] project, to look for another opportunity for the schools to continue their digital journey.

Because of the geographical challenges, socio-economic disadvantage as well as diverse cultural background, the region and its schools, in particular, have remained a high priority of the NZ Government. For example, the group of schools was awarded the Collaborative Innovative Fund (CIF). The CIF project aimed to "provide funding and support to consortiums of schools which want to develop new styles of teaching and learning that will improve educational outcomes" of their students. Since the student learning outcomes were low in the region, their application was ideal. As a result, the external funding assisted the schools to initiate the Learning Exchange solution. As one participant informed:

[There were] 9 schools who had applied for an Innovative and Collaborative Funding project..., which provided the schools with video conferencing equipment with the idea of sharing teaching resources through the use of video conferencing.

The use of VC for the exchange of learning resources for meeting educational needs of their senior secondary students became the new problem-solution definition or "new vision of B-Net". Thus, the new B-Net cluster project was initiated in 2004, which has grown from 9 to 25 rural and urban schools in 2016. The nine schools formed the latest network of B-Net schools, known as the B-Net Online Learning Community. However, a documentary actant revealed that some of the nine schools were the original B-Net initiators while others were new members mainly from rural areas. As one actant inscribed at that time informed about the formation and the purpose of B-Net participation in the three-year long CIF project:

The nine schools in the [B-Net] project will receive $\$ 304,000$ in total over three years to establish their video conferencing facilities, develop video conferencing teaching skills, and enhance community partnerships.

For the management of the cluster, the research found that "a system of governance was developed for B-Net involving a B-Net Board of Principals with a Chair and an executive". In addition, a parttime facilitator was appointed to manage student enrolment in the VC programme. Therefore, the chair and the executive were the focal actants representing the network of schools at various forums. The Enrolment Section discusses these roles and others in detail.

Regarding the Obligatory Passage Point (OPP) suggested by ANT, with the redefinition of the Problematisation, the OPP evolved as well. Initially, participation in various DPS and ICTPD activities 
and meeting goals set for those projects were the OPP for the 10 member schools. However, with the change of focus in the newly defined Problematisation, the OPP was also re-defined and members' interests were realigned by the B-Net focal actants (who have mostly retired now). The exchange model from the A-Net joined all the participating schools to the point or goal of virtual exchange of learning resources. Since the need and the proposed solution matched their interests and their contribution to the previous projects, they agreed on the new goal. Therefore, participation in the Learning Exchange became the OPP for the network participants.

Although all the participating schools had agreed on the OPP, their priorities differed slightly. Since most of the participants were small rural schools, they needed the programme to access VC-based subjects for their students who could not have access to those subjects without the programme. On the other side, urban or larger schools wanted the programme for accessing VC courses to solve their timetable clashes. In other words, the urban schools were capable of offering all the subjects that their students wanted to study; however, due to timetable clashes, their students could not study all their selected subjects within their school timetable. Thus, those students from urban schools were offered VC-based courses. As one participant from an urban school reported:

We got to the programme because we were having clashes in subjects. There were some times boys could justify doing both subjects because it was the pathway with what they wanting to study in the future, they wanting to work. So with this [VC] they can do both. They can study their first and second both choices [for example] one in the classroom and one in VC.

Besides the needs of rural schools and interests of urban schools, one of the nine initiating schools was interested in the VC-based B-Net programme not only for their own students but also as a part of their school strategy to attract foreign fee paying international students. As one actant recounted:

[The school] was using it particularly, I think, to offer extra subjects to foreign fee paying students. That was because the programme involved e-learning and use of the latest ICT tools at that time, making it attractive for students to have access to such a new style of learning at the school level. Given the fact that their priorities differed, all the initiators had agreed to the formation of the cluster as the obligatory point in order to reach their individual goals. The word "diversity" was found to have been used to better indicate the 'difference of priorities or interests'. To conclude, initiators had agreed in principle to follow the OPP and contribute to the programme in order to continue their online community, aiming to support each other. With the successful CIF application, the schools started their network to offer subjects via VC from 2004.

\subsubsection{B-Net Interessement}

As described previously, Interessement is the phase of Translation during which potential participants are attracted towards the network by the use of the 'devices of Interessement'. The B- 
Net devices of Interessement during 2004 and onwards were their PD programme for staff and VC classes for students. The two 'devices' were their potential 'tools' for attracting prospective players, including neighbouring schools and other course provider organisations. The Interessement was found significantly important for making a self-funding cluster and subsequently building a selfsustaining model.

As mentioned above, nine schools participated in the latest B-Net initiative funded by the three year-long CIF project from 2004. The schools had continued in B-Net for the next couple of years without increasing the number of schools in the group. That was because the CIF project involved the nine schools only. Therefore, the B-Net initiators and focal actants had mainly focused on the participation of the nine schools. However, they had started to work with some tertiary and polytechnic institutes to receive some courses required for entrance into tertiary education. Since the group was small, the schools were not able to teach all the courses by themselves. Therefore, the intra-cluster mutual exchange of courses had started between all the Learning Exchange clusters around that time. Significantly, B-Net had the strength or advantage of being capable of teaching Te Reo Maori. One participant described that exchange and explained why that happened:

...we were able to offer the subjects we wanted by trading with some of the other clusters, because particularly the South Island schools were very short on Te Reo Maori teachers and schools like .... [a school] had very good Te Reo teachers who were able to trade their courses for some of the most traditional ones I suppose, more traditional academic ones [taught] in further South.

As a result of the intra-cluster communication, the Virtual Learning Network or the VLN had come into being. The VLN is currently the national level network of various regional Learning Exchange clusters. The Learning Exchange remains one of the key parts of the VLN. Indeed, most of the research participants were using the word VLN for describing the Learning Exchange. Since its formation, the VLN has grown and its website has become a virtual platform for various other virtual communities of interest with participants from all over New Zealand. Later in 2009, a national level governing body for the VLN - known as the VLN Community or VLN-C - was established to oversee the network, promote communication between its members and represent the network at the national level.

The B-Net Interessement had gained momentum with the announcement of the two-year long eprincipal funding project from the MOE. The external funding had allowed the cluster to appoint a fulltime cluster coordinator or e-principal. With the help of the funding, the B-Net initiators had seconded their existing part-time coordinator to a fulltime role as the B-Net e-principal. That development had made a significant positive impact on the cluster by supporting the role of e- 
principal and establishing B-Net leadership. With a fulltime focus, the role had brought momentum and more participants from the nine schools to contribute to the cluster.

As a part of the B-Net vision to develop a sustainable model, a number of city and small schools in the region were approached to join the community. With the agreement of the existing B-Net schools, the fulltime role had allowed the cluster to engage more players and thus become a selffunding and self-sustaining cluster. In particular, the role of e-principal was described as an important factor in the recruitment of other schools into B-Net. As one participant revealed there were several organisations of Northland school principals, and the B-Net e-principal was described as very active in approaching principals in those organisations:

And the e-principal...has been very good at getting to those meetings and saying, "these are some of the things you want to do, this is how [B-Net] could actually help you", and people then see that actually, "yeah we could do some of these things smarter, using facilities on [B-Net], and it's even managed to go outside of that...

In addition, the programme itself has been attractive and become the main impetus behind small rural schools joining the cluster. City schools had shown no interest initially, but later they had joined the cluster. Some city schools were not interested because of their competition with schools around them; some schools were not interested because they had the required resources and could afford to offer all the courses to their students by themselves. As one participant reported:

The city schools didn't really have anything to do with it as far as I can make out because they all prided themselves in offering a full programme, and so they had no interest in it at all, but later [some city schools] came in...

However, some city schools had joined the cluster later because there were some changes in the New Zealand school curriculum focus ${ }^{18}$. As the participant further added:

...I think they realised particularly with the [introduction of the] Trades Academy and stuff like that that there were opportunities there that they hadn't considered...

As a result of the B-Net strategy, leadership priorities and the changes in school curriculum focus, BNet member schools had increased from 9 to 12 in 2011.

With the introduction of the Trades Academy programme, the cluster had made a partnership with various polytechnics to provide tertiary secondary and tertiary related courses. B-Net was found to have enrolled some tertiary institutions to enable the cluster to offer tertiary level courses to their students. For example, in 2015, two courses were being offered by third party organisations: an

\footnotetext{
18 The Trades Academy programme aka secondary-tertiary programme (STP) was introduced in 2010 and initiated in 2011. The programme focuses on "delivering trades and technology programmes to secondary students based on partnerships between schools, tertiary institutions, industry training organisations and employers". http://www.youthguarantee.net.nz/secondary-tertiary-programmes/trades-academies/
} 
agriculture course was being taught through $\mathrm{VC}$ by the polytechnic and a tourism course was being received over VC by WINTEC (a polytechnic institute).

Another impressive B-Net Interessement strategy that the research found was the 'Associate Member' option. As a part of the strategy, the term Associate Member was created and offered to new schools to let them trial the programme. An associate member school could access any of the BNet VC courses without having to offer a course in their first year in B-Net. Similarly, an associate member was exempt from making any financial contribution to the management of the cluster for their first year. Then they were to decide whether to join the cluster or not. That was because for some of the small prospective schools it was a big investment to buy VC and other equipment for joining the cluster without knowing how critically their staff and students needed to access any of the B-Net opportunities. Therefore, the strategy was to remove any such fear that existed. As one participant informed, the strategy was very successful as it had increased the number of players in the network:

...associate member was something that [the e-principal] created which was interesting....Associate Members means they [associate member schools] didn't actually have to offer a course or pay anything for that first year while they actually experience how it was going. And nearly all of those ones then brought in at the end of that year. So it certainly brought in [new schools].

Another finding relevant to the Interessement phase was mentoring the initiation of a cluster of schools in a highly urban area. In 2011, a group of three schools had joined B-Net with clear intentions to form their own cluster after a couple of years. One participant informed that a big school from a large city had difficulty in finding teachers to teach Te Reo Maori. The schools had consulted with the B-Net coordinator and other leaders and discussed their problems. As the participant informed:

They [the schools] were experiencing some dissatisfaction with The Correspondence School and wanted to support the learning of Te Reo Maori and they did not have a specialist Te Reo Maori language teacher. It soon became evident that with the interest of other schools in the area, that they could also start their own cluster.

As a result, the B-Net e-principal had agreed to lead the development of a new cluster and to mentor their cluster coordinator for the next couple of years. Initially, the schools were made associate members of B-Net. In the next two years, the urban cluster of schools was successfully established and their coordinator took over the role of e-principal. As one actant revealed:

[B-Net e-principal] was instrumental in establishing the...Community of Schools, which is now a very successful and sustainable city cluster.

Since its establishment, the cluster has grown and continuously contributed to the Learning Exchange programme. Indeed, the successful establishment of the cluster can be regarded as one of the significant achievements of the B-Net cluster and their e-principal. Moreover, as a result of the 
mentoring, a very good working relationship was built with the newly established cluster. That made a positive impact on B-Net by catering to each other's needs.

Their annual Conference was found to be another device of Interessement. That was regarded as an important gathering with significant impact on member schools as well as non-member schools. The Conference is discussed in detail in the Mobilisation Section.

In short, the cluster leadership team had a successful Interessement phase that had made a significant impact on the growth and sustainability of B-Net as a learning community. As of early 2016, 24 member schools were contributing to B-Net, which was a significant increase from nine schools in 2004.

\subsubsection{B-Net Enrolment}

The B-Net initiators had established various roles, responsible for the management and setting strategic directions of the four main B-Net projects: the DPS, ICTPD and CIF leading to the current BNet Online Learning Community programme. Initially, with the launch of the DPS, all the stakeholders had their representatives in the B-Net structure. That is because it was a joint project of various stakeholders. Therefore, for example, the Government had appointed a manager to oversee the project and a coordinator for the development of educational resources in Te Reo Maori. Similarly, the schools had appointed a project director, who was one of the school's principals, responsible to the B-Net principals' forum. However, since the ICTPD contract was managed by the group of 10 schools only, they had formed a system of governance which included schools only. Therefore, the research found that a B-Net board of Principals was established with a chair and an executive out of the 10 schools' principals. Based on the ICTPD funding requirements, the board had set their strategic goals and required outcomes.

That management structure provided a structural basis later for the initiation of the B-Net Online Learning Community during the CIF project. In addition, since B-Net had adopted the Learning Exchange model from A-Net, the adoption further complemented their existing organisational structure with the introduction of other roles such as e-dean and e-teacher. The following sections explain some of the important B-Net roles in the development and management of the network of schools.

\subsubsection{B-Net leadership team}

The cluster initiators had established a group of B-Net principals during the B-Net initiation to oversee the cluster and set their future directions. The group still operated when the findings were being reported. All the B-Net school principals and their e-principal were members of the group. They met regularly once every school term via VC to be informed about the cluster activities by their 
e-principal and to make strategic decisions and policies based on that information. Regarding the principals' perception about various B-Net programmes, the research participants regarded them, particularly the original principals, as visionary and clear in what they were doing. For example, in 2004 , one of the lead principals had clarified the nature of B-Net by describing that B-Net was not an ICT project, instead:

It's about learning, sharing resources and building relationships. We see the use of ICT as a vehicle to achieve these things.

Therefore, with a clear understanding of the cluster, they were very supportive of B-Net. That was what some of the clusters which have disappeared had lacked.

Similarly, like some other sustainable Learning Exchange clusters, the role of the B-Net e-principal was found to be significant in the group, having valuable input into the decisions. A reflection of that finding was evident when one of the initial B-Net principals was asked to describe what made those 25 member schools stay together as a single network. The participant responded that it was the principals who drove the cluster during its early stages, and then their e-principal had come along and held them together as a community of learners. Their e-principal had accomplished that by demonstrating the value of the cluster to the cluster member schools:

Initially, I think it was the principals themselves that actually made it work and then it was the energy of the e-principal. You have to acknowledge what people like...have done to actually hold this thing together. But the principals had to see what it's worth.

Therefore, the personal skills of a cluster e-principal in communicating and implementing the vision remained one of the key factors in the development and sustainability of a cluster in the virtual environment.

By establishing the value of the cluster, the e-principal had ensured participation or commitment from every member school and subsequently led the cluster as one sustainable entity. Since member schools were committed to providing a financial contribution (equivalent to a 0.1 staffing unit) and one e-teacher to teach a VC subject, the members needed to realise the value of the cluster for their students and staff. Given the fact that a diverse range of schools was taking part in B-Net, it was a big challenge for the cluster e-principal and its leading members to meet their varied needs. As small schools were short of subjects, larger schools had timetable clashes. If some of the schools wanted to access the programme to personalise learning based on their student needs, others were having the VC programme as an 'innovative' mode of learning on their options list for attracting international fee paying students. Some wanted to continue their existing digital trajectory by exposing their teachers in that environment to development of digital content, and 
then allow their other teaching colleagues to re-use and further build on that knowledge. As one school principal informed:

...when we went in, we are supposed to provide one teacher and the allocation of .1 [staffing unit], we provided 3 teachers [instead of one] because we wanted multiple teachers working in the environment... we've had to get our teachers up-skilled in putting all the material online and structured the way that others can get it...

One of the lead principals expressed his concerns by recognising the challenge of remaining focused on the real essence of B-Net and keeping a balance between the needs of every member school:

...I think it [B-Net] is more focused around the needs of schools [in their region]. To me, it still is a concern that if we're not careful, some of the bigger...schools could predominate where we've been trying not to let that happen, because I' $m$ then very concerned that this started with...smaller area schools...to help them to offer a viable curriculum, and I still think that's an important focus of what we do.

Thus, keeping a balance was a significant challenge that the B-Net leadership, particularly their eprincipal, had addressed.

\subsubsection{B-Net executive group}

In addition to the group of principals responsible for setting policies, B-Net had an Executive Group of five members: four school principals and their e-principal. Principals (except e-principals) were selected as members of the executive group for a two to three year period. They had their regular monthly meetings via VC to supervise the management of various activities run under the banner of B-Net. As one executive group member informed regarding his responsibility in the group:

[Part of my role is] continually checking on where we are at, I have a monthly meeting with the Executive and I prepare a monthly report against our goals etc.

Another member of the group informed:

...we've our online [B-Net] executive group for discussion and over-sighting everything...my role is to make sure that it [the cluster] stays viable financially.

This was a significant development because some other clusters that have disappeared had a similar supervisory group but the group members were their e-deans or lead teachers, not their principals. Therefore, keeping principals engaged at various levels of the programme was crucial for the sustainability of a cluster. With their involvement, they personally realise the cluster's impact on their individual organisations. Therefore, they not only get informed about various programmes organised by the cluster but they also advocate for the continuation of the cluster during difficult situations.

\subsubsection{E-principal}

The role of e-principal was found to be two-dimensional: being part of the cluster leadership team and working as a coordinator. The leadership dimension of the role has been discussed regarding the 
above two groups of B-Net principals. Besides that, the B-Net e-principal had the responsibility of working as a coordinator between e-deans and e-teachers from 25 (that was the latest figure) member schools. That aspect of the role involved the management of student enrolments in various VC classes within and outside B-Net in other Learning Exchange clusters. That activity mainly began before the start of a school year.

Similarly, another responsibility was the creation of points of difference to be used while 'trading' VC classes and student enrolments with other school clusters. For example, 12 students were typically enrolled in a standard VC class. If B-Net had a Level 1 Te Reo Maori class with only six students from B-Net, then the cluster would allow six more students from any other school cluster to be enrolled in that class. In return, B-Net would receive a similar number of spaces for its students to be enrolled in any of the VC courses offered by that particular cluster. That was how the trading in intra-cluster enrolments worked.

The coordinator's role was also to arrange e-teachers for those classes and provide professional development for the e-teachers. That aspect of the role was addressed on a regular basis by monthly meetings/workshops and the annual conference. Further details regarding the annual B-Net conference and monthly meetings are provided in the Mobilisation Section.

An important and relevant point to note was the two-year funding from the MOE for supporting the role of cluster e-principals. As discussed in the previous chapters, the funding during 2008-09 aimed to strengthen clusters' leadership and allow e-principals to establish self-sustaining clusters. As described in the above sections, the role of the B-Net e-principal, then coordinator, was a part time position. The position mainly involved the management of student enrolments and VC classes. Since the funding was started, the Learning Exchange clusters further developed and the role became more significant. The role expanded from the managing to the leading of a cluster. That was evident in the case of B-Net as well, because the two-year funding had allowed the clusters to build their cluster leadership with the intention to become a self-sustaining cluser. In addition, the external funding successfully transformed the role by taking part in the ownership of leading the cluster with the backing of B-Net principals. Therefore, after the e-principal funding, through the Interessement process, the B-Net e-principal had increased the number of B-Net schools from 9 to 25 . As one participant informed, the funding allowed cluster coordinators to gain leadership skills:

During this time [2008-09] they [the MOE] supported the e-Principals with some professional development around their leadership roles, which was very helpful for those who had not been in a leadership or management role in their own schools. 


\subsubsection{B-Net teaching and support staff}

Since the learning model was adopted from A-Net, the roles and responsibilities of e-teachers and edeans were similar. The similarity was an important aspect because some of the unstable clusters had also adopted the model but they had altered the roles and responsibilities of their participating staff members. For example, most of their e-deans and e-teachers were the same staff member without compensation for their added responsibilities. In some cases, their e-deans were not from the deputy principal level. As a result, their principals were not fully aware of the cluster and the value that the cluster could have added to their student and staff learning. Thus, such schools and clusters had shrunk and disappeared from the VLN-C scene at the national level.

However, in B-Net, they had adopted similar roles for their staff members. In some instances, there were extra support staff members dedicated to administering the VC learning area and supporting estudents during and after their VC classes. That was feasible because some of the B-Net schools were large and could afford to have a dedicated support staff member. Consequently, that provided good support for e-teachers and e-deans to continue with their responsibilities. One of the schools visited during the data collection process was observed to have a dedicated staff member. The staff member explained the role and responsibilities with examples:

For some of the boys, you have to be like a mentor. But, most of them [the students] are pretty good... For some, it's just that language barrier ... [for others] when they start at the beginning of the year they are quite shy. They don't talk. It [VC] is new to them. But I just say to them it is just like Skype except that you got a teacher there [and] you got some students, so....

With that kind of support, there could be the risk of the e-dean not being in charge or not being informed completely about what has been happening. With that point in mind, the e-dean was found to be well informed about the e-dean's role and supportive of the B-Net programme for their school. Indeed, the e-dean was very supportive of the programme and knew the value that the programme had brought into their school. To find out the e-dean's perception of the B-Net programme, I asked about the success of the programme and student outcomes. The participant replied:

I think it is successful but I don't think that success is only measured in credits. I'm student centred. I think that is my job, whereas other people, like weigh NZQA and achievement...In my mind that [the B-Net programme] exists for all sorts of reasons not just for achievements of credits.

Regarding e-students and technology, no such concerns were raised or observed during the data collection process. E-students were satisfied with the support they were receiving both from their schools and e-principal. Similarly, technology was found working and being used accordingly. Since both the groups of actants were 'punctual', they were, therefore, regarded as black-box in this case. 


\subsubsection{B-Net Mobilisation}

Mobilisation means network actants supporting the enrolled masses in a network. The provision of support is intended to keep the actants enrolled and ensure that focal actants are representing the assemblage.

The B-Net leadership team was found to have various initiatives to support school principals, edeans, e-teachers and e-students enrolled in the programme. With regard to the support for school principals to understand various initiatives, the quarterly principals' meeting was found to be a good forum both for existing and new principals coming on board. The forum has already been discussed in the Enrolment section.

In addition, the cluster was found to have been holding an annual conference for teachers and principals since 2013. That was found necessary not only for their e-teachers and e-deans but also for all the B-Net school teachers and principals. The Conference provided e-teachers and e-deans with a chance to "showcase the digital learning" that was happening in B-Net. For other staff members, it was an interactive opportunity for learning new ideas from key speakers and guests, and for equipping them with the key digital competencies that they would need to work in the new and challenging educational environment. This was how one documentary actant had described the Conference:

The Conference offers you an opportunity to get inspired, push the boundaries and step out of your comfort zones to work together, learn together, be designers (shapers), to create, innovate with other educators.

Therefore, the Conference was a good support initiative from the network leaders for their existing e-teachers and e-deans as a part of their existing PD programme. In addition, it was also a good formal Interessement strategy for attracting new teachers interested in being a direct part of B-Net. In general, the Conference was a step forward towards the integration of B-Net into the main school system and establishing B-Net activities as an integral part of the main school activities.

The e-principal was found to have regular monthly meetings with B-Net e-teachers and e-deans (previously known as e-coordinators). Those meetings were held to provide feedback and get updates on their classes or discuss any technical issues they were facing. As one participant informed, their last meeting was to discuss how to make the best out of the VC equipment for engaging students:

The last meeting we had ASNet come up and take everyone through how to use the different features of videoconferencing gear...as it is designed to be used... A lot of the how to provide the learning is fine, it's how to put it in a form and share it with the kids which is actually probably the biggest factor I would see. 
When enquired about the non-technical aspect of training for e-teachers, the participant further added:

I don't see any of our teachers struggling [from the pedagogical angle]. They can all pull it back nicely to the way, they can all structure it in the way the kids can work through it, but it's how do they [eteachers] make that [VC class] interactive.

Apart from coordinating their regular monthly e-teachers' and e-deans' meetings, B-Net had an annual gathering of e-teachers. Since the schools had access to the new mode of learning, the eprincipal was responsible for improving learning, adding value to the learning process in particular and to the cluster in general. As one participant informed:

There is an e-teacher gathering that [our e-principal] organises...at the end of the year for sharing and some up-skilling work.

Participants were satisfied regarding overall support for e-students from their local schools. E-deans and e-teachers were the main support people helping the B-Net e-students to maintain their enrolment in the network. In addition, like A-Net, B-Net had a one week module particularly designed for e-students that ran before the official start date of their VC classes. The module or orientation sessions aimed to help e-students adjust to the new environment. That practice was regarded as necessary for making e-students prepare for and familiar with the new environment before the start of their actual VC classes. The following Table 5.1 is a snapshot of the B-Net calendar that contains the orientation session:

Table 5.1 B-Net calendar snapshot

\begin{tabular}{|l|}
\hline B-NET SCHOOLS | KEY DATES | 2016 \\
\hline FEBRUARY \\
\hline Week 2 \\
\hline E-Deans: Run orientation sessions with e-students \\
\hline
\end{tabular}

\subsubsection{Summary of B-Net Case Findings}

B-Net was a virtual community of schools formed as a solution for addressing a number of various challenges. They intended to bridge the digital divide and overcome schools' geographical challenges. The community utilised ICTs to take advantage of their specific cultural background for broader educational purposes. They also intended to use the community as a platform for exchanging educational skills and resources and hence expecting to improve learning outcomes and contribute to the socio-economic development of the region. Further, they utilised ICTs and the cluster concept as a set of solutions for connecting individuals and organisations to gain the benefits of economies of scale. Their continuous (re)alignments and (re)adjustments of their cluster's directions to encompass individual organisational priorities enabled the cluster leaders to strengthen inter-cluster commitments and relationships. 
B-Net leaders had identified their strengths and leveraged them for the formation of a committed community and addressing their agreed goals. In doing so, B-Net leaders enabled themselves to meet their student, staff, organisational as well as wider community needs. Further, B-Net had strategies such as having physical visits and associate membership schemes for forming and expanding their alliance with potential players. As a result, the community had made themselves a self-sustaining group of small and large schools.

Regarding various roles, their leadership team had led and maintained their cluster as a selfsustaining group. They had done so by communicating and maintaining a clear vision with their individual members. Actants with delegated roles were given the necessary level of authority to allocate tasks and implement decisions made at B-Net principals' board meetings. In return, members had committed to maintaining the required level of human input and other resources for the reciprocity to take place. Since the members were communicated with and made aware of the benefits/values of the programme, they were willing and ready for minor organisational restructuring. Some examples of the required reforms were the re-positioning of their existing human, management and financial resources. In addition, the principals on board had provided the required level of remuneration for sustainable development of the cluster.

Cluster leaders were found supportive of their enrolled participants. The provision of support was perceived necessary by the interviewees as a key part of catering for the needs of cluster participants. That was done again through regular interactions and continuous communication of their cluster vision. The top management support indicated not only interest in their programmes but also their willingness to assist in the development of a self-sustaining collaborative community. 


\subsection{C-Net Case Findings}

C-Net was another cluster of schools, which I selected for this research. The selection criteria have already been provided in the Methodology Chapter. Before outlining the C-Net findings, some background information is provided here. A consultation process for the instigation of the C-Net school cluster was reported to have taken place in 2002 between six rural and semi-rural secondary schools in a region of New Zealand. That consultation was inspired by the MOE's announcement of its fourth round of the ICTPD cluster funding ${ }^{19}$. The funding was aimed at promoting collaboration between schools at regional and national levels for professional development of school staff around ICT. To avail themselves of that funding opportunity, a group of six secondary schools and their local economic development advisory trust (from now on LEDA trust) agreed to form a virtual school cluster. They also agreed to adopt the Learning Exchange programme initiated by A-Net. After making a successful application, the group of schools became one of the 2003-2005 ICTPD clusters ${ }^{20}$ of the MOE. Within a couple of years the cluster grew from six to eight small and large schools. With the MOE's two year funding for strengthening cluster leadership in 2008 , the cluster reached the height of its activities.

However, in 2010, after seven to eight years of participation in the Learning Exchange, the cluster was discontinued as a collaborative group of regional schools. The cluster was gradually dismantled along with the cluster coordinator or the e-principal's position. Some of the schools (two out of the eight) were reported to have been desperate for the continuation of the programme since they were very reliant on it. However, for others that was not the case. As a result, the two schools had to continue as individual schools instead of being part of a collaborative group. As of 2015, they were found struggling to maintain good student enrolment in their online courses.

The research questions of this study were: how was the Learning Exchange developed and utilised in the school clusters, and what were the facilitating and inhibiting factors necessary for the sustainability of the school clusters? Following sections answer the first question by outlining the findings on C-Net that practised the Learning Exchange between 2003 and 2010. To answer the second question, this chapter identifies the factors that supported the cluster to reach the height of

\footnotetext{
${ }^{19}$ As discussed in the Literature Review, the ICTPD cluster programme differs from the Learning Exchange clusters. The ICTPD funding was a part of the MOE's ICT strategy, 'Interactive Education' announced in 1998, aimed to change whole schools to the most recent teaching and learning paradigms and pedagogy by teachers integrating ICT into their regular programmes and classroom.

${ }^{20}$ It is important to note that there have been two types of school clusters using the funding stream. This research focused on the communities of schools with structured online teaching and learning programmes. This type of cluster is regarded as a virtual community of schools in this research. The second type was the local community of schools which was not necessarily virtual and was not participating in the Learning Exchange. That remained outside the scope of this research.
} 
its activities, and then outlines the factors that led the C-Net member schools to wind down the cluster. The following section reports the C-Net story by using the four phases of the Translation process from ANT.

\subsubsection{C-Net Problematisation}

Following sections identifies how C-Net problem and solution were defined by the focal actants, which became the basis for the initiation of $\mathrm{C}-\mathrm{Net}$.

\subsubsection{The problem and solution}

The findings revealed that 26 schools from different parts of the North Island in New Zealand attended a meeting in 2002 where they were briefed regarding the availability of the ICTPD funding through the MOE. After that meeting, some rural as well as urban schools held their own regional meetings to discuss how they could tap into that funding which was aimed at the integration of ICT into school practices while collaborating in regional and national groups. Urban schools, however, did not seem to be interested in that collaborative programme as much as schools outside big cities. The outcome of those meetings was that only a group of six rural and semi-rural schools agreed to form a regional cluster - based on the same model as A-Net. When asked for the reason behind the city schools' decision, a participant replied that the funding was probably unique to the rural schools:

...this type of cluster collaboration based on the 'learning exchange' was more unique to rural schools. So the rural schools decided...to move ahead without the city schools...

At that point in time, the LEDA trust from the region was also attending their meetings and was very keen on that development. That was because the trust was interested in the regional development and making sure that the region remain 'connected'. In fact, the participants revealed the trust was one of the most interested actants in the initiation who actually signed the first contract with the MOE on behalf of the schools. Upon further un-boxing of the LEDA trust's role as one of the key initiators, one of the participants revealed:

In fact, they were actually held the contract with the Ministry for the first one or two years of that ICTPD contract, and the reason behind having them involved was that was just a legacy of how they had been working around [earlier projects]...

Another actant further clarified that, apart from the ICTPD funding, the trust had assisted the group of schools in accessing two other funding from various community sources. A documentary actant further revealed that the trust was actually one of the powerful actants in the inception of the cluster. The inscription in that actant read:

With the assistance of [the LEDA trust] a successful proposal for MOE ICTPD funding was made. [The trust] was a partner in this project and took on the role of fundholder \& administration. 
At the initial stage of the Problematisation, the six schools and the trust were found to have been the initial actants of the proposed group of schools. The establishment of network initiators role is an important step in the Problematisation, since network initiators are the actants who provide a problem-solution definition for the establishment of a network they intend to build. The point is further discussed in the following section.

In this case, however, the findings revealed that the decision to assign the trust such an important role proved to be an inappropriate decision. This contrasted with the case of A-Net where their local trust was a key supporting player rather than a leading one. (Later sections in this chapter explain the inappropriateness of that decision.) After a couple of years the trust left C-Net. When asked for the reason for that departure, one of the participants provided the following reasons:

The relationship with the outside organisation and then the external facilitator situation, you know, having a large amount of our funds going into another organisation and having them organise it.

To identify the nature of the problem at the schools, it can be reported that most of the initiators were not actually motivated to build a virtual cluster because of some ongoing problems that could have compromised the teaching, learning or the viability of their schools. In fact, the ICTPD funding was the main driver that drove the initiators for having PD for their staff in those schools. The initiators saw the ICTPD funding along with other local community funders (as mentioned above) as a good resourcing opportunity for organising PD for boosting the application of ICTs and bringing in the latest computer technology, video-conferencing equipment, ICT networking devices and faster Internet at the time. To check whether the key driver was accessing the fund for ICT infrastructure development, when asked, "Can we say that ICTPD funding was the key driver for schools in the region to get together?" the actant denied and responded:

The ICTPD funding cannot be used for infrastructure - other funding streams were accessed for this. The two priorities infrastructure and PD and the different funding streams were sort of interdependent and beneficial to each other.

Regarding the solution, at about the same time around 2002, information about the instigation of the A-Net school cluster was circulating in the school community in New Zealand. The A-Net model had just been up and running for a couple of years at that time. Therefore, the model was collectively selected by the initiators as a good solution to adopt for making a successful funding application. The initiators did not seem to have faced any challenges in finding a solution to their identified priority, as one of the participants described:

...application for ICTPD funding was very closely modelled on [A-Net], the whole model was straight out of the [A-Net] book, just rubbed out [A-Net], changed it to [C-Net], literally, that is how it worked I think for most of the clusters. 
After reporting the A-Net findings, the commonality between the A-Net model and the defined problem was the notion of ICT only. In the original model, the provision of wider curriculum choices for the retention of their senior students was their key motive, which is a long-term motive. However in this case, the motive was the need for professional development and collaboration between staff. It was revealed that this PD programme was meant to be for all the teaching staff, not only for e-teachers participating in the Learning Exchange or the VC-based virtual classes. When asked to describe about any collaboration between teachers and schools, once ICT infrastructure was in place, the answer was:

There wasn't much of it to start with. We tried to encourage our schools and our teachers to have staff meetings, curriculum meetings between them. Didn't happen in our cluster.

As mentioned above, student retention was not a major problem in most of the schools either apart from in one or two of the schools - as compared to the schools in A-Net. That meant that increasing the options for their students was found to have been ignored at the initial stage. The student need for accessing wider curriculum choices was only realised later after a couple of years. That was perhaps due to the fact that most of the schools had and have reasonable student enrolment. Only two of the eight schools were Area Schools ${ }^{21}$. When asked about the importance of the provision of courses for senior students, one of the participants replied:

[Once C-Net schools] realised, then there was all these other ones [benefits] that they could pretty much choose from anybody's courses, that was quite motivating for them as well too. Instantly their kids could access a broad curriculum.

One of the documentary actants revealed a fascinating inscription story compared to the narration by human actants. The document inscribed in 2002 by the initiators, portrayed member schools as having a very ambitious objective and forward-thinking approach. A snapshot of the evidence stated:

By the end of this three-year project we aim to have achieved whole school change, with teachers integrating information and communication technology (ICT) into their regular programmes and classroom experiences more effectively.

The inscription also stated that during that process schools wanted to cater for the PD needs of each school and develop an online community for the exchange of educational resources via virtual classes and staffrooms, nurturing "a shift towards the most recent teaching/ learning paradigms and pedagogy".

\footnotetext{
${ }^{21}$ As a reminder, the term 'Area School' in New Zealand is used for schools that are located in rural areas, and have both the primary and secondary parts working together. That is due to the small number of students and the higher cost of having two separate schools.
} 
Has an inscription been successful or unsuccessful? The answer depends on the performance of the actants in the execution of the script. So far the Translation has been unable to find a programme of action that might have been aligned with the execution of the script or actual priorities of C-Net member schools. Questions were asked regarding the emerging concepts of teaching and learning focused around $21^{\text {st }}$ century learning environment, and the shift in school paradigm from traditional to connected and then networked schools. When asked about the C-Net and member schools' vision regarding the use of technology for teaching and learning in the 21st century, one of the participants responded:

I don't even know what our vision was. I don't even know where our old documents are. It was probably just cross out [A-Net] and put [C-Net], though I can't really remember to tell the truth.

In response to the question about "principals' own vision, leadership or commitment about futurefocused learning", one of the participants answered:

Yeah, those ideas weren't really around back then. It was about using technology in the classroom. These answers differed from what was promised by the initiators in the inscription quoted above. To conclude, the Problematisation above indicated the initiation of a weak association between actants and their priorities, interests, problems and proposed solution. The ICTPD funding from MOE inspired the six schools and the LEDA trust to initiate a PD programme for their staff members. By adopting the Learning Exchange from A-Net, they formed a virtual network of schools. Their staff members had the opportunity of collaborating virtually with each other, 'if required'. Later, the schools had the opportunity to access a wider range of generalised and specialised curricula for their senior secondary students, 'if needed'.

\subsubsection{Obligatory passage point}

During the problem-solution definition, another development is the selection of the focal actants, leading to the establishment of the Obligatory Passage Point (OPP). As illustrated in Figure 5.2 in section 5.1.1.3, C-Net focal actants tried to convince members and other potential players that the proposed definition is relevant to them and coherent with their interests, and that interest can be achieved by accepting the proposed detour and formation of an alliance. Without the alliance actants cannot individually achieve what they want because of what Callon calls "a series of obstacles problems" (p. 8).

One of the documentary actants revealed that C-Net initiators had established a team of three people as the focal actants. Two of them were principals from the member schools. They were nominated as the "project directors". The third actant was a member of the LEDA trust, selected as the "project facilitator". The two principals were to engage other school principals, and the 
facilitator was to administer cluster operations as well as hold the fund. The team made itself indispensable for all other actants to achieve their objectives. Specifically, the team established the OPP for C-Net and the passage point remained in line with the team's route or interest.

Consequently, the team members did not need a detour to get through the passage point whereas others had to.

However, the establishment of the OPP in C-Net was controversial ${ }^{22}$, during the initial stage.

Although the C-Net team of focal actants seemed to be a good distribution of responsibilities, the project facilitator was an external contractor employed by the LEDA trust. That was an organisational body which was not a direct part of the school community. This point was mentioned in the above sections where the LEDA trust held the first C-Net contract with the Ministry. Because the role was very powerful in the network, the position cannot be downplayed. By further un-boxing through examining the available material from the Internet, the findings indicated that the facilitator had a good experience of managing and administering local council projects, but had not had any work experience of teaching and learning in schools. That was evident from one of the participants' comments:

...[the project facilitator] was employed by the trust. He was actually an employee of their partners and then he was a private contractor. He was never originally from any of the schools in [C-Net].

The point is that a local, organic and grass-roots level programme was adopted, but implemented, by having a top-down business approach instead of managing and running the programme by someone from the local community of schools. This debate might not have been seen as an issue at the beginning of C-Net, but it did count in the long run and became apparent when the culture of online teaching and learning developed in those schools was examined. Following sections elaborate on that point.

\subsubsection{Re-Problematisation}

In the final year of the three-year ICTPD contract, some of the issues were rectified with a reProblematisation. In 2005, the LEDA trust no longer had the contract and the schools revisited the network activities. That was when some of the schools prioritised professional development for their teachers and making the senior part of their school a viable area. As one of the participants who was not part of the initiation in 2002-03 reported:

In 2005, when the [C-Net] cluster was established, and all the secondary schools...11 or so of us, were invited to join the cluster, do some training, and teach our subjects in another way, and I

\footnotetext{
${ }^{22}$ The word controversial or controversy is an ANT vocabulary. The reader can use words such as debatable as a close synonym.
} 
thought that sounded kind of fun, stimulating, interesting... so I thought, OK, I can get some more senior students this way...

With the re-Problematisation another two schools decided to join the cluster, expanding the number of member schools from six to eight, as one documentary actant revealed. That was when one of the initiators had their first student enrolment two years after C-Net's inception and started some PD for their teaching staff:

....[the schools re-established] the cluster, the principals were supportive, we did training and we got our first students, all in about 2005.

Another significant rectification was the decision of selecting a cluster coordinator from the local school community. The first coordinator was a deputy principal at one of the schools and had an interest in technology and e-learning, as revealed by one of the participants. In 2006, an ICTPD cluster facilitator was selected to take the role of cluster coordinator and represent the network. Later sections discuss why that development was significant.

The new cluster coordinator had challenges to maintain the role indispensable due to the different student roll, the traditional school system and the leadership norm in the member schools. Schools in New Zealand are independent entities. They make decisions based on their own local values, needs and priorities. In 2005, the student roll at one of the schools from Years 1-13 was 148 while another schools from Years 9-15 had 835 students. Similarly, some of the member schools were rural and others were semi-rural or city schools. Also, two of the eight schools had realised that the adoption of the Learning Exchange programme was important for their viability. However, they were outnumbered by the rest of the schools where the programme was not a high priority. Given the differences, therefore, convincing those different schools to follow a common detour in order to get to a collective goal was found to be a difficult task for the new C-Net cluster coordinator.

Another challenge for the new cluster coordinator was influencing or convincing principals and deputy principals at member schools. The norm in schools is that principals are expected to be led by someone from a deputy principal's level at least, if not from a principal's level. Since the newly appointed facilitator was employed in a part-time (0.2) position and was not a deputy principal or from a similar hierarchical level, the role was challenged. For the eight school principals it seemed to be unrealistic to be led by a staff member from the teacher's level. As a result, the role of the coordinator was found to be somewhat superfluous and not indispensable for the member schools. In most of the school clusters in the Virtual Learning Network (VLN), their coordinators were deputy principal which is why sometimes the role was referred to as e-principal. Buchanan (2013) examined the cluster leadership structures in the Learning Exchange that affected the collaboration in those clusters. Figure 5.3 demonstrates such clusters where cluster coordinators or e-principals are from 
the same hierarchical level in the cluster leadership structure as a principal. Specifically, cluster coordinator would chair the group and would be leading the group of e-deans in schools for the cluster activities. A-Net can be related to this leadership structure.

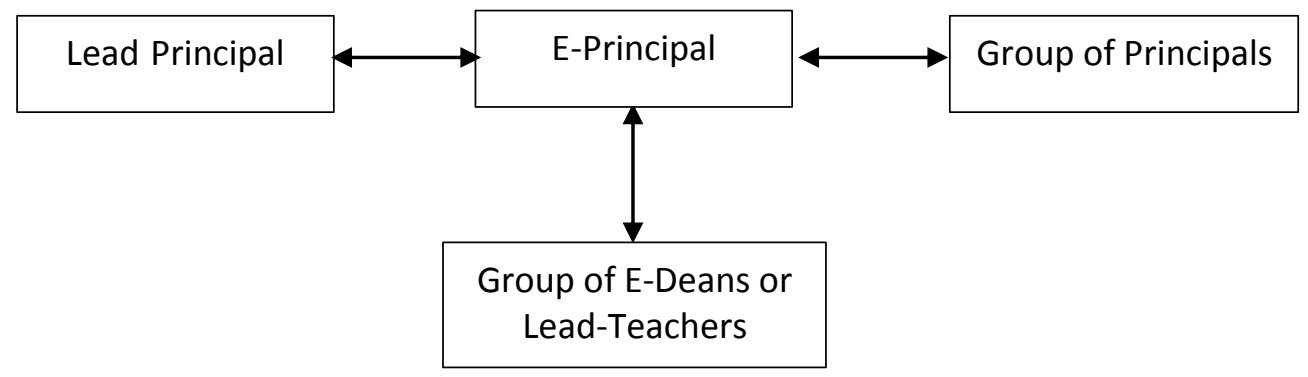

\section{Figure 5.3 A-Net Cluster leadership structure}

Figure 5.4 below shows the cluster leadership structure in which a lead principal would chair the group and the coordinator would be at the same level as principals when it comes to the cluster business. B-Net is one of the clusters that can be related to this cluster leadership structure. In this structure, an e-principal would join the cluster group of principals' meeting and work closely with the lead principal, in order to lead the group of lead teachers in schools for the cluster activities.

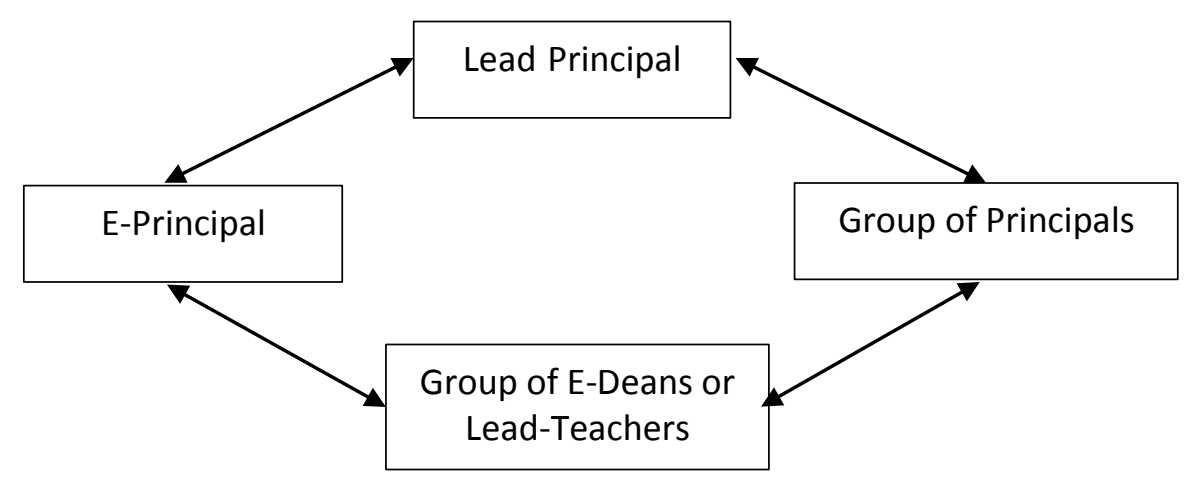

\section{Figure 5.4 B-Net cluster leadership structure}

However, in C-Net, the role of cluster coordinator was not influential in that group of principals' hierarchy when it came to the cluster business. Figure 5.5 illustrates the scenario that was close to the C-Net case. Since that structure determined the power of the coordinator in the network, their structural hierarchy had challenged the role in the group. As a result, C-Net coordinator was not a direct part of the strategic decision-making group - the group of C-Net principals. That meant the role was downplayed. According to one of the participants, the role of coordinator was not vital, and that only seemed important with the backing of the lead principal. 
... the lead principal was really supportive of the... [coordinator's role and] was the one who got on the case of other principals, you couldn't really direct schools to do other things because they were all autonomous organisations, but you could encourage...

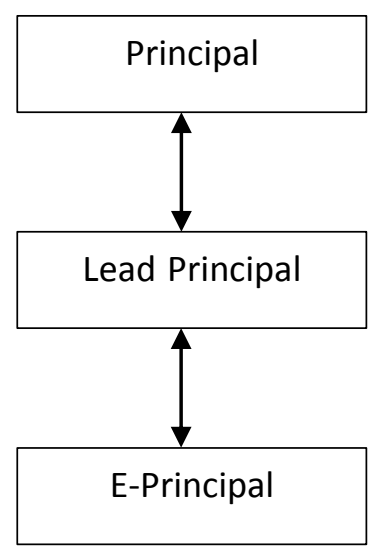

\section{Figure 5.5 C-Net cluster leadership structure}

That leadership culture or norm might be justifiable from another viewpoint, such as organisational; however, the findings revealed that managing and coordinating activities of a virtual group required a different set of skills from that of a school principal role. The cluster was a cross-organisational group whose members were virtually associated with each other. In addition, the role of a coordinator needed time and dedication, which a school principal, already having a full-time responsibility, might not be able to afford.

In short, the re-Problematisation attempt did succeed to some extent in rectifying the problemsolution definition. Students' and teachers' needs were prioritised. The role of coordinator was redefined and assigned to someone from the school's community. However, the role was re-defined only to follow and pass through the OPP established by the group of principals, instead of leading the shift or realignment. Therefore, the group of principals made themselves indispensable without including the necessary focal actant.

\subsubsection{C-Net Interessement}

During the Interessement phase focal actants use various strategies or approaches to convince and lock potential actants in the network. Potential actants are the ones whose interests are thought to match with the initiators' interests. The locking of actants is done to strengthen the new association. The findings revealed that before the second Problematisation attempt of C-Net in 2005, the earlier problem-solution definition of the initiators did not succeed in associating new actants in the network. That was because the weak Problematisation failed in developing successful devices of Interessement that would have helped to lock a body of allies into the network (Callon, 1986, p. 8). That setback or failure was found to be one of the underlying factors that had contributed to the 
slow dismantling of C-Net after 2009. Before outlining the reasons for the setback, the importance of associating potential actants are explained here.

Before the Interessement could start, associating other neighbouring schools was critical for the long-term financial self-sustainability of the cluster. The more schools in a cluster, the more financial contributions are received from member schools and that lowers the overheads for each individual school. That was the case in A-Net, B-Net and some other active virtual clusters where members were committed to making small financial contributions even if the clusters had some external funding. However, in this case, the number of interested schools only grew from six to eight in 2005, which was not enough to employ a full-time coordinator, leaving the cluster to completely rely on some external funding for the coordinator's position. For a cluster's self-sustainability, at least 10 committed member schools were found to be needed, each with a $10 \%$ (called .1 by the schools) financial contribution. Still, that contribution was only sufficient for the salary and did not cover any operational costs that might arise. Therefore, successfully attracting and recruiting new member schools was highly important for strengthening the newly-built association. As one of the participants responded:

...yet for us it was about developing an economy of scale where we could make it work for everybody.

Despite several attempts and the use of different strategies, the focal actants had failed to engage a feasible number of schools into the network. It was found that the network initiators had seen the importance from the beginning of engaging more schools in the cluster. Therefore, the initiators and focal actants had tried to involve four or five city schools from the region in the network. They had used different strategies and attempts to ally and lock the city schools into the network. Nonetheless, the initiators could not do so and were "strongly dissuaded" from including other schools. One of the participants reported having used a lobbying strategy:

...I worked really hard, almost lobbying...some principals, getting involved with things they were doing, visiting them personally, doing the bigger picture things with them to get them working with us and it just didn't seem to go anywhere, so I just gave up trying, really.

I tried to understand why the city schools were not interested and also why there have been small virtual and 'local clusters' of schools in the Island but not big enough clusters (except one). That enquiry was inspired by a recent development in the VLN community in New Zealand where some of the original and reasonable size clusters merged and formed a bigger Learning Exchange cluster with around 40-45 schools. Based on the individual stories, I found a mix of different reasons. First, one of the factors was accessing different MOE funding channels, including ICTPD, multiple times rather than one huge region trying to split a single fund. For example, some of the city schools which had refused to become part of the C-Net school network had their own successful ICTPD funding 
application that was put forward later on for their staff's professional development needs. As one of the actants informed:

Some of the...schools picked up ICTPD funding around 2010 - did PD with technology but did not do any online teaching and learning.

Second, local values and needs differed between schools and different regions. For example, city schools would like to have access to more specialised subjects as compared to rural schools where they need both generalised (such as level 1 maths) as well as specialised subjects (such as level 3 accounting). Also, as it is apparent from the above quote, some schools might only need PD for their staff and not VC-classes on regular basis. Third, geographically, schools in the region where C-Net was located are not very far from each other. The region is less dispersed as compared to some other regions where the population is more spread out. Lastly, the dynamics and relationships between school leaders were another factor that stopped city schools from being part of C-Net. As one of the actants described:

...I don't know if it's a [C-Net regional] thing that they're a little bit parochial in their attitudes about, you know, what's important to them and who they work with, but they just did not look out of the region.

Around 2009, as a part of the re-Interessement, a suggestion was made by cluster coordinator to engage primary schools as prospective actants for the network. However, the suggestion was turned down by the group of principals without giving it any serious consideration, indicating towards the weakness of the C-Net cluster leadership structure. When asked for the reason for that decision, one of the participants expressed disappointment with that decision:

From my perspective I was wanting them [the C-Net member schools] to work with the primary schools as well, and I was sort of pretty much strongly dissuaded from including primaries because they're different from us and I was a secondary principal. So the primaries didn't even get a look in, I was just really disappointed about that.

Those were the findings regarding attempts to convince and ally other actants into the network, and the reasons why they did not show any interest. Again, VC classes through the Learning Exchange or PD at C-Net had not flourished to work as the devices of Interessement in order to overcome these differences and attract potential players in the network.

Even within the initial actants - the six schools and the LEDA trust - their interests or priorities were found to be different and not completely aligned, at least for the first two years (Above Figure 5.2 regarding the OPP illustrates the difference). For a successful Interessement, alignment of interests is the basic requirement for locking allies into place. For most of the initiators, developing their ICT capability was seen as important in general. The priority worked as a device of Interessement for the first two years until the external funding was available. However, for some of the initiators, that 
access was just a step forward towards solving a bigger problem which was critical for the viability of the senior part of their schools. They had prioritised the provision of senior secondary courses from the very first instigation of the virtual clustering of C-Net schools in 2003. As one of the actants revealed about the risk faced by one of the schools before the C-Net initiation:

...there was a real risk that the senior school student enrolments would fall below critical point and the school would be re-capitated...

An emphasis on the provision of specialised subject VC classes for students or PD for staff through video-conferencing could have worked as 'the devices of Interessement' not only within the six schools but also for the city schools. However, most of the member schools had not prioritised specialised subjects for students or PD for their teachers. Most of the member schools had their own regular senior student enrolments and they did not need to depend upon enrolments in the Learning Exchange to maintain their school rolls. As discovered in the above paragraphs, some of the schools had their first group of students enrolled in the online courses in 2005. Therefore, those schools had no vested interest in the programme. As a result, the alignment of interests remained weak within the network, let alone convincing actants from outside the network. One of participants recounted:

I think there would've only been probably a couple of schools where if you took it [the Learning

Exchange programme] away it was going to be a big thing...

Due to the above 'series of obstacles problems', the Interessement phase partially succeeded in the second attempt in 2005, with the number of schools growing from six to eight and with an improved re-alignment of interests. Focal actants locked those eight schools as allies and stabilised their identities as C-Net member schools. However, the devices of Interessement still remained weak and the Interessement phase did not fetter the required actants together for a long-term sustainable network.

\subsubsection{C-Net Enrolment}

Because C-Net had adopted the A-Net model, most of the roles remained the same; therefore, the descriptions have not been repeated here. The following sections only report the differences.

\subsubsection{Coordinator}

As discussed in the previous chapter and in the above Problematisation, the role of a cluster coordinator or e-principal was identified as one of the most important actants with the capability to hold a cluster structure together. However, in C-Net that cannot be reported as true since the role was found to be unnecessarily strong during and after the instigation of the network for two years, and then it was weak during the re-Problematisation. In C-Net the coordinator role was initially known as "project facilitator" and the actant in that role was not from the school community, unlike in other clusters. The facilitator played the role for the first two years before abandoning the 
network. The role was then handed over to a deputy principal temporarily before entrusting that role to another actant from within the school community. That development of a successive spokesperson was a necessary displacement, because "the notion of translation emphasizes the continuity of the displacements and transformations" (Callon, 1986, p. 18). That displacement can be in terms of goals and interests, and/or displacements of human beings and inscriptions.

Based on the collected data, despite that re-definition, the role still remained unsettled and of low profile in C-Net. In 2006, a new C-Net coordinator was employed in a part-time (0.2) position. In 2007 , the role was increased to a 0.4 position, equivalent to two days' work per week. The role only became a full-time position in 2008-09 when the MOE announced two-year funding for the eprincipal position which was aimed at strengthening the cluster leadership. An inscription from one of the documentary actants read:

The government has approved the funding of e-Learning Cluster Leadership Grant by the Ministry to support schools/clusters to maintain cluster leadership roles and support cross-cluster relationship building with a key goal of e-learning cluster sustainability.

Based on C-Net leadership structure in Figure 5.5, the coordinator was to report and work closely with the lead principal and the lead teachers in the member schools. The responsibilities of the role revolved around operational activities only, unlike some other cluster coordinators (such as in Figure 5.3 and 5.4) who had greater strategic and fewer operational responsibilities. Specifically, the C-Net coordinator was supposed to lead the e-teachers and e-students whereas the lead principal was to lead the group of principals. One of the actants reported a memorandum of understanding (MOU) which was developed to outline responsibilities of the cluster coordinator. The MOU outlined inter and intra-cluster responsibilities of the coordinator. One participant recounted:

...we did have a memorandum of understanding that outlined how we worked together and the role of the e-principal and the role of the lead principal...[the role of] e-principal was around coordinating training, enrolments, and course delivery.

As a result, the role of coordinator was not valued as a strategic role in the network. That was also apparent when the e-principal funding from the MOE finished by the end of 2009. With the end of the two-year funding, the group of principals decided to roll back the role to the 2007 position by offering the 0.4 staffing time allowance. However, according to a participant that offer was "just a copout really". The offer was declined by the coordinator and the schools decided not to hire anyone else. A lead teacher from one of the schools that was highly reliant on the cluster was given the very basic operational responsibilities of the coordinator. The reason for the discontinuation of the coordinator's role was reported to be to avoid any further financial contribution and reclaim the small contributions that the member schools were making. As one participant answered: 
So for schools to not replace [e-principal], that was essentially a decision on their part which would release that proportion of staffing back to their own schools.

Table 5.2 and Table 5.3 were compiled based on the statistics collected from documents and databases. The number of students and courses in 2008 and 2009 suggested that the activities had gained good momentum with the cluster having a full-time coordinator. That also indicated the impact of the e-principal's funding on the C-Net activities. Figure 5.6 and 5.7 are two graphical illustrations based on the two tables. The curves in both the figures clearly illustrate that finding.

Table 5.2 C-Net student roll

\begin{tabular}{|c|c|c|c|}
\hline & Local C-Net Students & $\begin{array}{c}\text { Out of cluster students } \\
\text { on C-Net courses }\end{array}$ & $\begin{array}{c}\text { Total } \\
\text { students }\end{array}$ \\
\hline 2006 & 38 & 12 & 50 \\
\hline 2007 & 28 & 12 & 40 \\
\hline 2008 & 57 & 21 & 78 \\
\hline 2009 & 63 & 41 & 104 \\
\hline 2010 & 52 & 30 & 82 \\
\hline 2011 & 26 & 18 & 44 \\
\hline 2012 & 18 & 18 & 36 \\
\hline 2013 & 5 & 13 & 18 \\
\hline 2014 & 9 & 9 & 18 \\
\hline 2015 & 13 & 18 & 31 \\
\hline
\end{tabular}

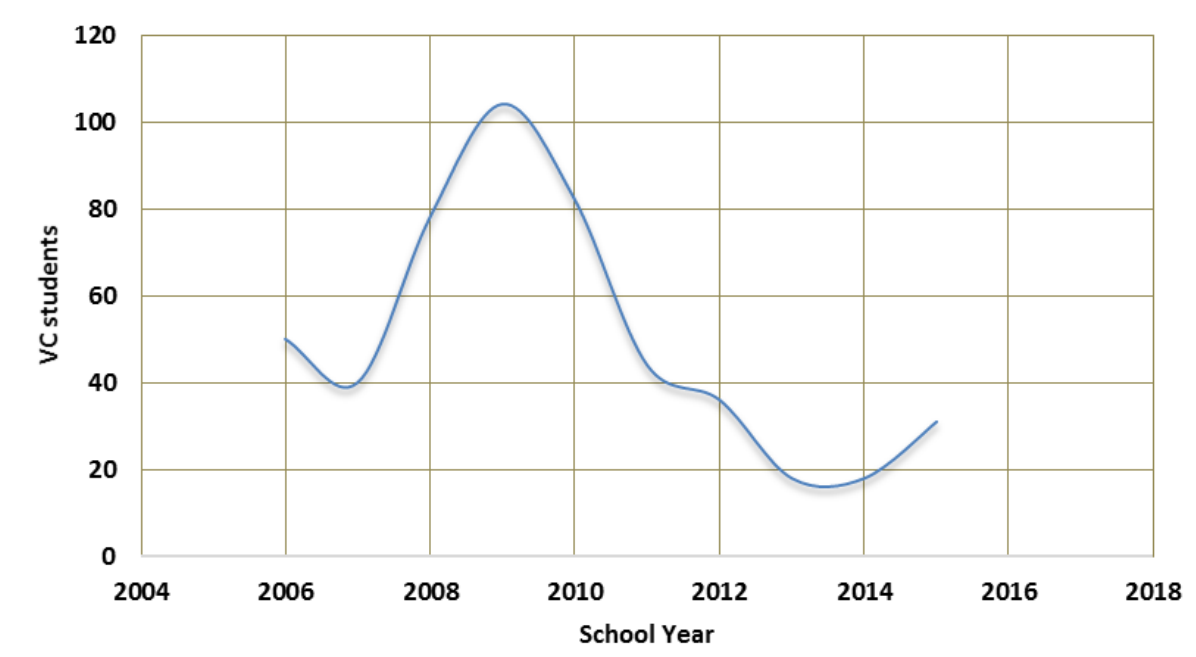

Figure 5.5 Number of C-Net students 
Table 5.3 C-Net Subject choices

\begin{tabular}{|c|c|c|c|}
\hline & $\begin{array}{c}\text { Number of Subjects } \\
\text { taught on VC }\end{array}$ & $\begin{array}{c}\text { No of subjects received } \\
\text { from other clusters }\end{array}$ & $\begin{array}{c}\text { Total } \\
\text { classes }\end{array}$ \\
\hline 2006 & 6 & 8 & 14 \\
\hline 2007 & 5 & 7 & 12 \\
\hline 2008 & 5 & 16 & 21 \\
\hline 2009 & 8 & 19 & 27 \\
\hline 2010 & 4 & 17 & 21 \\
\hline 2011 & 5 & 10 & 15 \\
\hline 2012 & 3 & 11 & 14 \\
\hline 2013 & 2 & 4 & 6 \\
\hline 2014 & 1 & 9 & 10 \\
\hline 2015 & 2 & 4 & 6 \\
\hline
\end{tabular}

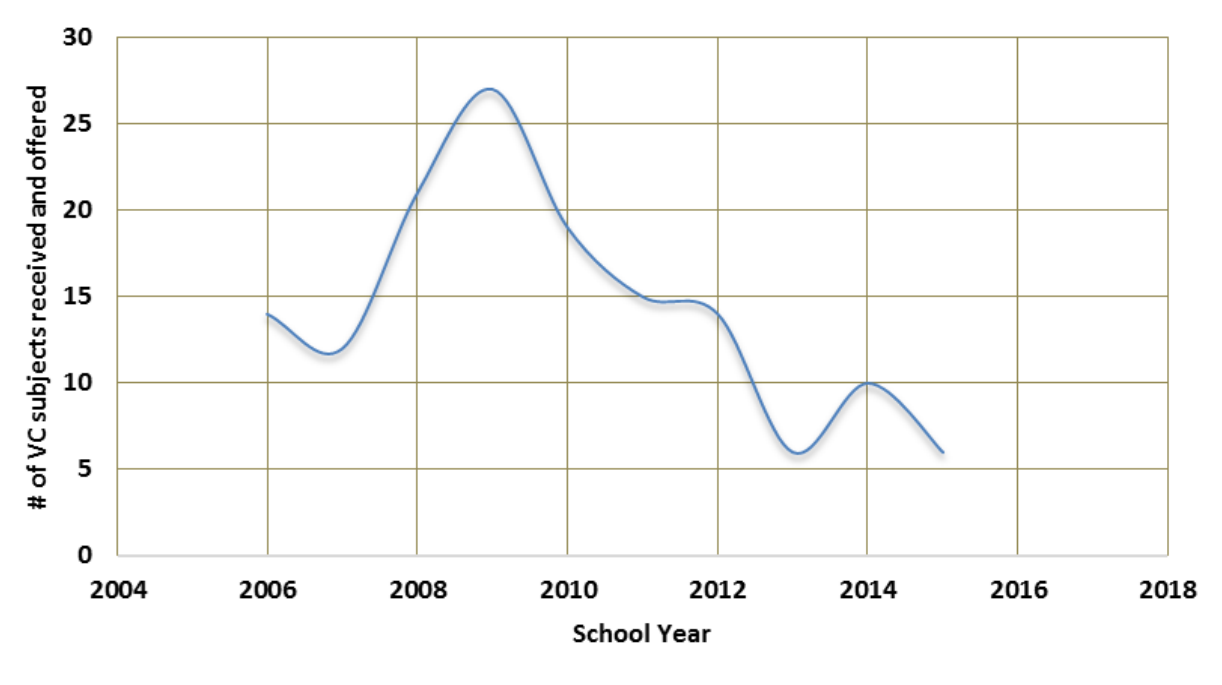

Figure 5.6 Number of C-Net courses received/offered

The decision to discontinue the role seemed to be one of the significant reasons for the disappearance of the cluster. As the C-Net activities have gradually decreased, such as, in 2014, CNet offered only one subject. In 2015, there was not a single student from C-Net in one of the two subjects offered by one of its member schools. One of the participants explained their current situation by correlating the small numbers with the absence of a cluster coordinator.

[C-Net] stopped functioning as an entity with an e-principal around the time the cluster funding stopped....Since then, we have had limited students, as we are very careful about only letting motivated, independent learners do the classes via VC.

Although the numbers in the above tables seem to have been small compared with the numbers of face-to-face classes and students, the nature of VC classes and the set of skills developed by estudents and e-teachers through those classes were reportedly of high quality. Pedagogy in those classes was based on the concept of personalised learning and students being the main focus. 
Similarly, teaching and learning strategies evolved around future-focused and networked learning environment. E-students in those classes were having the experience of being independent and selfmanaged learners while studying a wide range of subjects that sometimes even students from city schools might not have the opportunity to study ${ }^{23}$. That is what made those numbers valuable.

\subsubsection{Lead principal}

Unlike the cluster coordinator role, the lead principal was a powerful role in C-Net as compared to some of the stabilised school clusters. The role was to chair the group of C-Net principals for 2-3 years before it was handed over to a different member school principal. The cluster coordinator had to collaborate with the lead principal and not directly with the group of principals. One of the coordinators reported:

I led the lead teachers, and I wouldn't say on an equal footing, but I tried to lead the principals as well. But the lead principal led the principals and I worked closely with her, would probably be a better way of putting it.

That means C-Net was not a single network structure, but two. One structure was the group of principals, led by the lead principal. The second one was the group of teachers and students led by the e-principal or cluster coordinator. Both the structures were linked by the relationship between the coordinator and the lead principal. However, over the years, the original lead principals and the principals involved in the instigation of C-Net changed and many new members joined the group of C-Net principals, the group responsible for overseeing and setting the strategic directions of the cluster.

We had had a rollover of every single principal...That was huge, so where we had principals who'd been leading from the start, they were now gone, and there were other people in their place that hadn't had the same commitment, who didn't have the same priorities, who weren't as, I think, forward-thinking about, you know, what was going to be happening down the track.

With the gradual change, the nature of the relationship between the lead principal and coordinator had also changed.

We had a couple of really good lead principals...who were strong leaders in their own group and they were really good at getting people on board, and I guess when we also lost our original lead principal that changed things a little bit too. They don't have the same sort of influence, you know.

These findings indicated the gradual rise of the lack of commitment and unfavourable perception of the cluster and online teaching and learning due to poor leadership structure and decisions. As a

\footnotetext{
${ }^{23}$ Subjects included: Te Reo L1, L3; Art History, L2, L3; Ag/Hort L3; French L3; Stats L1; Spanish L3; Young Enterprise; Physics L2, L3; Accounting L1, L2, L3; Biology L2; Calculus L3; Chemistry L3; Classics L3; Computing Y9/10, L3; Economics L1, L2, L3; Graphics L2; History L2; Human Bio L1; Music L1.
} 
result, the programme further lost its value, which already had not been stable in its growth and development in the region.

\subsubsection{Member schools}

Member schools, represented by school principals, were the actant believed to have been locked into the network in order to meet the teaching and learning needs of their students and staff. In conjunction with their role, a MOU was outlined, agreed and signed between the member schools for a shared commitment and collaboration. The nature of the MOU was time-based and dependent on the member schools' own level of commitment. As one of the participants reported:

...we had a memorandum of understanding...for two/three years at a time, and there was no obligation from schools to maintain that the next time around.

In addition, the MOU was found to be inadequate, not covering the quality of teaching and learning. That meant the MOU was not being comprehensive. As one of participants expressed his dissatisfaction:

The MOU was specifically around delivery and assessment...it was not around the quality of the teaching at all. It was purely around, yes, this school provides the teaching to the other schools' students and provides the assessments and the results. That is the extent of the MOU.

That inadequacy was found to have caused poor performance by some of the member schools. The role of the member schools was to support and meet their students' learning needs and their staff's professional development needs. Instead some of the schools were reported as restrictive in their timetabling and conservative in exposing their students to the new environment necessary for their future learning. They were reported to actually be "gate-keeping their students" registrations for the online courses and being "highly selective" in responding to their students' application for online Learning Exchange courses. This was despite parents being very keen to have their children enrolled in the subjects their children wanted to study. Moreover, student applications were found to have been turned down by their schools in order to avoid providing any support for those students studying online. As one of the participants informed:

...two of the schools were gate-keeping a lot of students, you know, often they would only let the good students do the work, and then they'd be fine. I strongly campaigned for them to say, "Well this is about learning for everyone" and try and set some more support systems in place so that all your kids can have this opportunity.

When I asked the participant, "so what was the response from the schools?" The participant quoted what schools had said:

...“Oh, no, only good Year 12s and Year 13s do it"...

Similarly, in the early days, the perceptions of e-teacher and teaching via video-conference in the Learning Exchange was found to be very discouraging in some of the schools. One of the participants 
recounted that literally there was no show of interest among teachers in teaching an online subject, and when the question of who wanted to be an e-teacher was asked, "there was no show of hands" from the staff. No one wanted to be an e-teacher, perhaps due to negative perceptions. In the end, the programme was used as a "dumping ground" for their ineffective teaching staff. As one participant reported, one member school assigned an e-teacher who was later moved out of the school due to incompetence. In other cases, the teaching staff were assigned by some of the member schools to e-teach online in order to sort out their local timetable problems.

...to a point it was a little bit of a dumping ground about who can we get to e-teach? Well, that'll sort out our timetable problems.

That was the case of the cluster which was initiated for professional development of their staff. These findings showed how interested member schools were in the network, how aligned their interests were with rest of the actants and the network, and how strongly locked they were in their identified roles. The findings strongly indicated very low opinions about online teaching and learning in general and the Learning Exchange programme in particular. Based on the definition by Davis (2006), the group of principals was supposed to be the strategic leadership dissatisfied with their present situation, continually searching avenues for further improvement. However, the participants did not report any such actions taken to set directions of the member schools and translate their strategies, if any, into actions in order to "nurture a shift towards the most recent teaching/learning paradigms and pedagogy" - as promised in their 2003-2005 ICTPD application. That was perhaps due to the fact that the programme was not actually integrated with the main school activities. As one of the participants reported regarding the knowledge of other staff regarding the VC programme:

I don't think our teachers know. Some of them don't even know I do VC teaching...I think it's not well understood in our school.

The programme was not valued and integrated into the main school system. One of the participants answered to the question of the programme having any impact or effect on the main school activities:

...the only impact any other staff ever saw was occasionally a student might not be in [their] class.

Even that minimal impact was definitely not a positive effect. Apart from the issues identified in these findings, the reason for that lack of impact was reported to be the lack of support and interest from the C-Net principals.

...as I said before, you need to have principals who are actually passionate about it to keep it going, and there was none of that at [C-Net], it just gradually died of lack of interest.

That lack of support from the member schools' leadership was further supported with one of the coordinators admitting to have never reported to any board in member schools. 
Can't remember. I really can't think, I never presented to any boards except my own [school] when I first started.

That pointed to the lack of commitment and support from schools' leadership, and at the same time questioned the coordinator's own leadership skills. Indeed, some of the coordinators from growing clusters were reported to be famous for gate-crashing their group of principals' meetings.

\subsubsection{E-teacher}

In general the role and responsibilities of an e-teacher were found to be the same as defined in the original Learning Exchange model set by A-Net. However in some instances, a mixed narrative was found regarding the role. Despite the misguided perception about the role and lack of support from the senior management in the schools, some of the e-teachers and e-classes were reported to be very effective and successful. Indeed, one of the senior level e-teacher's classes had a better national record for scholarship results than any other e-teacher nationwide. Similarly, two senior language e-teachers' classes from other C-Net member schools were always oversubscribed as more students wanted to learn from them. These findings indicated some of the strengths that the eteacher role had contributed to the network, despite the series of problems and obstacles. On the other hand, some of the e-teachers were reported to be not as effective as the three e-teachers mentioned above. That was partly perhaps due to the above findings that indicated some of the member schools having negative perceptions about the role.

In fact, the role was found to have been overloaded with extra but important responsibilities. In the original model, an e-teacher was responsible for the preparation, delivery and assessment of an online course. In that model, each member school was to provide an e-dean (mostly from a deputy principal's level) who would be coordinating with the cluster e-principal and providing support to their local e-students. Most importantly, the e-dean was to ease the implementation of decisions made during the school management meetings. However, in the C-Net school network, in addition to their own responsibilities, e-teachers were expected to perform the role of e-deans as well, a decision that was made by the group of C-Net principals. To confirm that, when I asked, "Did every school have an e-dean to support the students?" the participant with e-teaching experience answered:

No. I mean, I was doing that as well, because I figured, oh, you're the person teaching, so you can be the e-dean of that. That was part of the job, just running around, tracking them [e-students] all down, and that pretty much became the job of the few teachers involved.

All that effort was without any remuneration or time allowance, despite already having a full teaching load to fulfil. When I enquired about any contract covering the responsibilities and time allowances, the answer was: 
No, there was no contract. The understanding was that if a teacher is delivering a course through the VLN then they need the same amount of time dedicated to that course as for any other class.

Right?... The reality was very different. The teaching time was done in one of my non-contact times... which is another reason why I'm not there.

From the theoretical perceptive, that indicated betrayal on the part of member schools, since they were required to treat an e-class as equal to a face-to-face class in terms of workload and time allowance.

\subsubsection{E-student}

This research could not find an e-student voice for this case, since the cluster was wound up around 2010 and the research was done in the middle of 2015. After 2010, the cluster was dismantled and the member schools continued individually. Other reasons for the absence of an e-student were because the e-student voice seemed to be so weak in the network, so the actant might have been less impressive and powerless in the network. That was because staff who were responsible for the confirmation of the student subject choices at the beginning of the year were not keen about the programme. When I asked, "Why there is not a single student from your school this year? Do they get all the subjects they want? The participant replied:

Not necessary...I don't think that the people who are students enrolled with at the beginning of the year when they come to confirm their subject choices, I don't think that often the VC option is encouraged as perhaps as much as it could be.

Therefore, e-students possibly interested in the Problematisation remained unenrolled, without having a significant presence in the network. In addition, participants did not report any controversies regarding the role of e-student. Therefore, black-boxing the role at this point was a suitable choice.

\subsubsection{The things}

Regarding the role of 'the things' (video-conferencing technology and the VC classes in the Learning Exchange programme). Thompson and Adams (2013) suggest answering the four questions posed by McLuhan and McLuhan in 1988. The research explored those four questions:

- What does [this technology or medium] enhance or intensify?

- What does it render obsolete or displace?

- What does it retrieve that was previously obsolesced?

- What does it produce or become when pressed to an extreme?

This research found that the VC-based Learning Exchange programme was meant to widen the subject choices for the learners, which would not only enhance the learning but also improve their time management and sense of being independent learners. The programme or the model was proposed by the initiators from A-Net to facilitate the displacement of the concept of face-to-face 
learning and learning behind the walls as well as displacing TCS. It had revived distance education and meant to invigorate the rural communities by helping to retain their students. If the programme was stopped it would send learners back to the TCS, isolation or the restricted subject choices. However, if it was over-used, school and student dependency on the VC would increase. As a result, a new set of VC units was purchased to accommodate more students. Over-use was not reported as a problem regarding any unit breakdowns.

Apart from the above four questions, this research found no issues regarding the enrolment of VC in the network. Participants responsible for technical problem-solving were very satisfied with the performance of VC and other related technologies. Therefore, the role of VC was black-boxed.

To conclude, although we saw attempts to re-define Problematisation and Interessement later in 2005, the Enrolment phase in C-Net remained the same with regard to most of the roles. The most significant change was the re-definitions of the cluster coordinator role: first, when the LEDA trust left and the schools offered a part-time position, then a significant boost in the role with the twoyear e-principal funding from the MOE, and at the end in 2010, roll-back of the role when the funding stopped and the member schools decided not to continue the role at a similar level. It would be appropriate to report that the re-Enrolment in 2005 was an improvement with increased PD and numbers of students and classes, due to the coordinator from the school community. However, the role deteriorated when the cluster coordinator position was not maintained in 2010 and handed over to an e-teacher without giving the teacher any extra time allowance or remuneration for the extra responsibilities. This was despite the fact that the e-learning cluster leadership funding aimed to strengthen the cluster leadership for supporting cluster sustainability, indicating the significance of the role. That decision was regarded as "just a copout really". The situation was found to have been inscribed in one of the documentary actants as unsustainable (original emphasis):

This current situation is not sustainable.

\subsubsection{C-Net Mobilisation}

For the C-Net findings, stories gathered from human and non-human actants were analysed to identify what strategies and actions the C-Net initiators had determined and taken to ensure that the enrolled actants would work together to maintain the Problematisation and also to confirm that they can represent the masses, establishing their legitimacy. To begin from the inception stage, the C-Net initiators representing the six member schools at the macro level had prioritised the provision of professional development for their staff as their prime interest. To achieve that objective, they built the C-Net school cluster. To that extent, it can be reported that the C-Net Translation was successful. The focal actants had only successfully represented the six schools by securing various 
external funding during the initial period. However the case was different when looked at on the micro level as well as after the first three years.

The research found that focal actants responsible for representing the whole network had ignored the enrolled masses, including e-students and e-staff, indicating poor Mobilisation. The research participants did not report any real effort for professional development for up-skilling ICT capabilities of e-teachers as well as face-to-face teachers in those schools, particularly during the first three years when the funding was for PD. That was partly because the LEDA trust was the project facilitator and there was no e-principal to cater for the professional development needs of their staff. In addition, no professional development programmes were reported by human actants and no document actant was found inscribed with such programmes. These findings showed no real representation of e-teachers by member schools, the group of principals or the cluster leadership. Similarly, neither productive efforts for enrolment of e-students for the VC classes were stated nor was any real interest discovered that would have broadened the options for those student actants. This was because there was no e-dean or e-principal that would have better represented e-students and e-staff. Such professional development programmes and VC classes could have worked as the "devices of Interessement" in order to maintain their interests aligned with the defined OPP. Therefore, these findings indicated that the focal actants - the two school principals and the LEDA trust - selected during the Problematisation in 2003 were macro-level actants and were unable to represent the actants at the micro level let alone ensuring they stay enrolled in order to stabilize the network. This was what one of the actants emphasised:

The cluster pretty much died and withered due to lack of any real support from the local principals...and if you don't have the support of the schools themselves, then it's just going to wither and die.

The actant kept emphasising:

You need to have principals who are actually passionate about it and motivated to support it, because if you don't have the support of the school administration, it's just not going to happen.

That was due to the fact that Problematisation was controversial and the actants' interests were not fully aligned. The group of principals representing member schools was keen on their building ICT capabilities which was only one part of the Problematisation. They did not prioritise the provision of senior curriculum courses needed by the staff and students. That finding has already been reported with the number of student registrations for the online courses during the early years when some of the initiators had their first e-students enrolled two years after the programme instigation.

After the re-Problematisation, the Enrolment phase was also found to have gone through a redefinition process, which had some positive impact on the Mobilisation of enrolled masses. Later in 
2005-06, an e-principal was appointed, albeit part-time, to collaborate with the lead principal and lead teachers in the eight (including two new schools) member schools. That can be seen as an act of organising the enrolled masses or collectivities as part of maintaining the Problematisation.

However, that was reported insufficient to ensure continued support and for the Enrolment of 50 estudents from different schools with 14 different courses and e-teachers (see Table 5.2). Since the environment was virtual for the actants, it needed support mechanisms for both the teaching and learning in order to gain a different set of skills as well as maintain their enrolment - the ultimate goal of the Mobilisation. This happened in the case of A-Net where some of the schools had four different layers of support around their e-students, known as deep local support. That kind of support was reported to be required particularly for e-students having their first experience of VC. Instead, in C-Net, e-students knew that they need to already have the required skills and competence in order to succeed in the new environment. One of the participants had asked an estudents to share her experience as a learner on VC. The participant reported the e-student's comments:

She said, you have to be committed and organised and all those things, and you...shouldn't go into a brand new subject, she thought you should go in with a high level of competence in that subject already and that was her experience on VC, it was an interesting comment.

This finding indicated that the programme was made available to the students with high competence only who would not require a great of level of support from their schools.

From Table 5.2 we can see that the numbers of students and classes doubled in 2009 as compared to 2006. This was when the MOE funding for the e-principal role was used for building strong leadership in the cluster. That allowed the e-principal to provide a good level of support to the enrolled masses and ensure that she/he was the legitimate person to represent them. Moreover, that allowed the spokesperson to make sure that all the actants would work together to maintain the problem-solution definition and keep them enrolled in the network. According to one of the participants, cluster activities had really picked up with that e-principal funding from the MOE, but after that everything just faded away. As one of the participants recounted:

Things were really driving along when you're working full-time and you're able to collaborate with the other e-principals [in other clusters]. But once the cluster funding had been taken away and the schools had to find their own money to fund the e-principal leadership position, it was like, you know, that man at the pub who's left his wallet behind [laugh].

That fund was meant to develop a self-sustaining cluster by the time it ended; however, the reality of the disappearance of C-Net indicated that schools in the cluster failed to make that happen. That not only would have helped them to ensure that they were truly spokespeople for their masses but also that they could maintain their enrolment. After the external funding ended, the schools were 
not willing to continue the cluster based upon the latest Problematisation anymore. When I asked for the reason, the actant replied:

And to me all I can think of is it just didn't stack up for them to prioritise against everything else they needed to do and to continue their full funding from their own schools, which was a kick in the guts really, because everything had built up so well and things were going so well.

As a result the Translation process rolled back from 2010 onwards and the network can be reported to have slowly disappeared with very minimal activity and a very small number of enrolled actants from individual schools.

\subsubsection{Summary of C-Net Case Findings}

Overall the findings suggested that C-Net was initiated for building ICT capability of their staff members and explore the possibilities of using ICTs in classroom. Based on Tilya's (2008) classification, C-Net efforts remained limited around the first two phases - the 'emerging' and 'applying' phases of ICTs in schools. The findings also suggested that the C-Net initiative did not enable schools to move into the next two phases - infusing and transforming phases - suggested by Tilya (2008). Therefore, C-Net became unviable or irrelevant for most of the member schools.

Based on the stories reported by the human actants and input from the non-human actants, several attempts were found to have been made by the C-Net initiators and focal actants to stabilise the network. However, the C-Net Translation process was challenged. If we look into those events, there have been multiple obstacles to a successful C-Net Translation.

First, C-Net was an opportunity-driven initiative rather than a problem-based one, since the cluster was based around the external funding. There was no single problem or interest that inspired the formation of the C-Net school cluster. The funding was available so the schools thought that the Learning Exchange model could be a good idea to adopt for the funding application. After making successful funding application, the network could have been developed and made self-sustainable, but that became less relevant for the initiators. Neither PD for staff nor VC-classes for students were reported during the first couple of years.

Second, the clustering was unnatural since the schools were of different sizes and their needs were different. Some of those schools were small and rural but others were relatively large and semirural. Therefore, student rolls were different and so were their financial and human resources. Similarly, geographically, these schools are not very far from each other, within half an hour's drive. Therefore, they might have not been desperate for some virtual communication due to geographical isolation. They have used the cluster for accessing specialised subjects if they did not need to access generalised subjects. They also could have prioritised PD for their teachers as that was the case for some of the city schools in the region when accessing the same funding for PD reasons. Moreover, 
demographically the population in the region is less dispersed compared to some other regions of New Zealand where the population are more spread out. Finally and most importantly, the actant playing the lead role and holding the funds was not from the school community. The actant was also a focal actant during the initial stages, which led to the inadequate setting of the obligatory passage point. Consequently, there was not an alignment of interests. These issues affected the Translation before the Interessement was started. Re-definition of the Problematisation did help the cluster to strengthen relationships and links between the actants. However, that proved to be for a short period of time while a funding channel was open and accessible.

Although the cluster was initiated for the provision of PD opportunities for staff members, no such evidence was found that would have informed about such activities in the cluster. The PD programmes for teachers and VC classes for students could have served as the devices of Interessement, the reason for being part of the network. In the absence of such long-term and personalised programmes not many other schools from the region showed real interest. Otherwise, more than 10 member schools could have helped the cluster to last longer. Other reasons included the mismatch of interest among the existing members, including the schools and the LEDA trust. Some feared the senior part of their school being re-capitated by the government due to their small secondary roll but others had sufficient enrolments. It can be reported that different channels of external funding have been the real devices of Interessement for the C-Net initiators; therefore, in future with a new and similar funding source, the members might get together again to access that funding for their schools. Without a realistic Problematisation the fate of that network would not be different from that of C-Net.

The Enrolment phase was first affected during the early Problematisation due to the selection of the trust being the driver of the programme. The role assigned to the actant was not appropriate since there was no real focus on teaching and learning in terms of professional development for teachers and the growth of VC classes. Although the role was redefined later by schools before the two-year MOE funding started, the role had a low profile which was only around operational responsibilities without having any strategic impact. As a result, the role was not valued by the group of principals responsible for the strategic directions of the cluster. The role could not help to create a clear elearning vision in those schools with a roadmap towards cluster sustainability. In particular, that was apparent with new principals replacing original and lead principals. The role was not valued as a fulltime position once the external source of funding stopped. Therefore, the coordinator decided to leave the network by the end of 2009 and the schools discontinued the role. Other problems with the Enrolment phase involved the member schools being restrictive and conservative in terms of not freely allowing students to choose the subjects of their choice, described as 'gate-keeping'. Similarly, 
there was no e-dean from member schools to coordinate the cluster activities and to support estudents and e-teachers. On the one hand, e-teachers were overloaded with the support and e-dean role, and on the other hand, member schools were gate-keeping students in order to avoid any workload need to support those prospective e-students.

A similar situation was found with regard to the Mobilisation phase of C-Net. No clear strategy was found to ensure support for the enrolled actants that could have helped to establish their legitimacy as C-Net representatives. During the initial stage, focal actants had successfully represented the schools securing external funding. However, the actants had ignored the enrolled e-students and estaff, indicating a poor Mobilisation. No evidence was reported by any human or non-human actants regarding any professional development programme for up-skilling ICT capabilities of teachers in those schools, particularly when the funding was for PD purposes. That indicated poor representation of e-teachers by member schools as well as the cluster leadership. Similarly, estudents were reported as actants without a support mechanism that could have helped them to remain enrolled in the network. In fact, schools were reported to have been gate-keeping their student applications in order to avoid any workload increase due to the provision of such support. In 2008-2009, during the MOE funding, the e-principal became a full-time role and was available to provide more support. That development did boost the number of student enrolments and eclasses. However, the cluster leadership failed to capitalise on that opportunity for the long-term sustainability of the cluster as well for maintaining the enrolment of students. When the external funding stopped, the whole re-Translation was rolled back from 2010 to the 2005-2006 position. Since that decision, the network can be reported to have slowly disappeared with a minimal enrolment of students and teachers teaching in the network. 


\subsection{D-Net Case Findings}

D-Net was initiated around 2002 by a group a staff from eight schools located in another rural region of New Zealand. The schools had prioritised a goal to integrate ICT into classrooms - facilitating a change of pedagogy. With that objective, the schools had initially focused on the formation of a virtual learning community of schools for collaboration and the provision of professional development opportunities for their staff around the uses of ICTs. As a part of that, the regional community first adopted the CASATech model using audio-graphic technologies ${ }^{24}$ before switching to follow the A-Net model. Therefore, the community redefined their PD programme and adopted the video-conference-based Learning Exchange model for their students. During their interaction with A-Net, the community of schools also learnt about the ICTPD funding from the MOE. Based on that information, the eight schools had made a successful funding application and become one of the 2003-05 ICTPD clusters of the MOE. With the assistance of the external funding and the adoption of the new Learning Exchange model, the schools formed their own cluster, known as D-Net. The cluster started catering for the PD needs of their staff around the uses of ICTs and providing students with the opportunity to use ICTs and have access to more curriculum options through VC. The cluster became one of the early contributing members of the Learning Exchange and continued its activities for the next seven to eight years before it was discontinued.

The research participants described D-Net as one of the active and organised clusters with a number of achievements. Being an early adopter of CASATech and then A-Net model indicated the D-Net initiators were proactive in their efforts to reach the goal of changing pedagogy in their schools. Also, the group got the New Zealand Prime Minister to officially open their cluster. A couple of years after its initiation, the cluster successfully organised a conference in the region with nearly $\mathbf{3 0 0}$ delegates from all over New Zealand and two international guest speakers. In addition, the cluster had three successful funding applications: ICTPD, Collaborative Innovations, and e-principal funding. Most importantly, under the banner of D-Net, the cluster organised its own individualised e-learning tools and programmes, e.g. KnowledgeNet, Gifted and Talented and Problem-Based Learning Programme (PBLP) ${ }^{25}$. These programmes aimed to expand ICT opportunities for all the teachers and students in their face-to-face classes, an indication of their pro-activeness and achievements.

However, after nearly eight years of contributions and numerous achievements, the D-Net leadership decided to dissolve the cluster in 2009. They discontinued the role of e-principal and the

\footnotetext{
${ }^{24}$ The CASATech model has already been discussed in the previous chapter. The model was used by a group of schools in the Canterbury region in NZ. They were using two separate telephone lines: one for audio and another for sharing a computer desktop screen as video. The group described the technological setting as audio-graphic. ${ }^{25}$ A pseudonym
} 
cluster as a collaborative group of schools in the region. As of early 2016, three of the eight schools have become members of a neighbouring cluster. However, one significant example of D-Net's accomplishments that still exists was the collaborative group of their principals who meet regularly to share management and leadership experiences.

The next sections outline the findings of that enquiry. At the end of this main section, the Summary Section concludes the findings.

\subsubsection{D-Net Problematisation}

The following sections describe the problem at D-Net schools and the possible solution, which lead to the initiation of D-Net. The sections also describe the reported challenges that required a redefinition of the D-Net Problematisation.

\subsubsection{The problem}

The research participants reported that, around 2002, a number of staff from a few schools wanted to develop their ICT skills and share their experiences. Geographically the region was and is thinly populated and schools are relatively small and are at a distance from each other. Due to these challenges, opportunities for professional development are rare for school staff in the region as compared to staff in cities and big schools. In addition, demands for learning how to use ICT had increased amongst teachers as well as students with the increased availability of computers and the Internet during the late 1990s. Therefore, the schools and staff had a great interest in developing their abilities to use ICT. This study found that interest or need was the main driver behind the formation of a collaborative group of staff from a few schools. Eventually the number of schools soon grew to eight and a greater number of staff followed a similar pattern. To confirm the main drive, when asked, "Was that staff collaboration because of student needs?" one participant replied:

No, no, the collaboration was for teachers' professional learning...of course supporting teachers... [like] I needed someone to moderate my work, I needed someone to give me information. So all the teachers would meet and a lot of our meetings were face-to-face...

Upon further enquiry, participants further explained that the staff were mainly IT teachers, enthusiastic about having that set of skills in order to utilise it in their classrooms. Extending the uses of ICTs to their students and classrooms was the other dimension of their ICTPD objective. From the schools' point of view, such objectives were addressing the needs and helping to overcome the geographical isolation of schools, including their staff and students. Since the overall agenda was shared by each of those eight schools, no agnosticism was reported. However, smaller schools in the group were more desperate to address the problems than others, since they were a significant factor in their low student and staff retention. Thus, the need to develop the ICT skills of their staff 
and then utilise those skills for the benefit of their students remained the common objective of the D-Net initiators.

Documentary actants revealed that the schools' leadership were aiming to align their pedagogies with the latest classroom practices and thus change their school paradigms. That was a broader perspective identified from documentary actants, but not indicated by the research participants. The following paragraphs explain this particular point in greater detail.

\subsubsection{Solution}

To achieve the objective of developing their ICT skills, the group of staff had searched for possible solutions. The group had first found the CASATech cluster of schools in the rural Canterbury region in New Zealand which was using an ICT setup to meet similar needs. CASATech was using the audiographic telecommunication setting for virtual collaboration and sharing of learning resources between its member schools. A meeting was held between the eight schools from the region to discuss the CASATech solution. Most of the meeting attendees were ICT teachers who conveyed the proposed solution and consulted with their schools' leadership teams. All the eight schools liked the idea and agreed to arrange a similar solution to the professional development needs of their staff. Each of the eight schools had set up two telephone lines: one for audio and another for sharing computer desktop screens as a visual aid. They intended to use that setting for online collaboration between their staff for learning the use of ICT hardware and software for their professional and classroom needs. They had made the required technological arrangements and started online communication and sharing of experiences with each other. As one of the participants recounted regarding the objective of their audio-graphic experiment:

Well, leading up to 2002, the first driver was the sharing, distance e-learning, and copying the audiographics associated with CantaTech. That was the only thing we focused on.

However, within the first three months, the group found that the audio-graphic setting was "not a sustainable solution". That was reported to be due to the slow Internet speed and the lack of interactivity as well as other technological limitations. That finding regarding the audio-graphic setting and CASATech was the same as the finding discussed in the previous chapter.

That dissatisfaction was found to be partly due to the above limitations and mainly due to the availability of the modernised version of the model via A-Net. Within a few months' time, they came across the A-Net solution and decided to seek further information regarding A-Net ${ }^{26}$. In 2002, one of

\footnotetext{
${ }^{26}$ After the initiation of the A-Net school cluster, a number of individual schools and communities of schools from various regions of New Zealand had approached the A-Net initiators and requested their help to initiate their cluster of schools. This research confirmed that the A-Net initiators had mentored many groups of schools, including B-Net, C-Net, and D-Net as well as other clusters adopting the A-Net model.
} 
the staff members had approached the A-Net cluster leadership to gather information for building a similar network of schools in their region. That consultation was reported to be successful because, first, D-Net became one of the early adopters of the solution initiated by the A-Net cluster of schools. Second, during that consultation, the group of schools also learnt about the ICTPD cluster funding offered by the MOE.

...the principals gave [someone] permission to research [A-Net]. They sent [the staff] down there and as a result of that we also learned about the ICTPD contracts that the government was beginning to run...

Based on the information gathered, the group of eight neighbouring schools held regional meetings during which they found the information very useful/relevant for their group. As a requirement of the ICTPD funding, schools had to form a regional group or learning community with a focus on professional development around ICT. The A-Net model provided the required template for the formation of a collaborative regional group. On the other hand, information about the possible source of funding was highly encouraging for covering some significant operational costs. As a result, the group of schools agreed to mutually apply for the next round of ICTPD funding and initiate a virtual cluster of neighbouring schools in that region. The eight schools made a successful funding application and became one of the 2003-05 ICTPD clusters of the MOE. With the assistance of the external funding, the schools initiated their regional cluster - the D-Net cluster of schools. The eight schools, which included three Area Schools and five high schools, became the D-Net initiators. According to one documentary actant, a team of four people was nominated by the group to make that funding application, and lead and represent the cluster from 2003 to 2005. (From the ANT's perspective, the team members were the focal actants for the new network.) One of the schools was nominated as the Lead School with its principal being given the role of Lead Principal, and one of its staff members was designated as the Project Director. The project director role would be equivalent to the role of a cluster coordinator or e-principal. A staff member from another school was nominated as e-dean for the whole D-Net, and later became assistant e-principal. The fourth member was designated as the KnowledgeNet coordinator. Since the KnowledgeNet programme is outside the scope of this research, the role has not been further discussed in this study. Therefore, the lead principal, the project director and the e-dean are referred to as the focal actants for the DNet school network for this study.

Once the research identified the problem-solution, the network initiators and the team of focal actants, the next activity in the Problematisation was the identification of the OPP. 


\subsubsection{Obligatory passage point (OPP)}

The OPP and the activity to establish one remain a significant part of the Problematisation of a network Translation. That is because, as illustrated in figure 5.2, OPP is the process that converges all the network actants on the proposed problem-solution definition. Thereby, passing through the point aligns actants' interests with the interests of the network defined by the focal actants.

In D-Net, the model of the virtual exchange of teaching experience and learning resources over VC remained as the OPP. Although the initiative initially aimed to meet staff needs mainly, the D-Net OPP was aligning the interests of all the cluster participants. The OPP was found to be acceptable for all the interested actants of the D-Net, since all the eight schools had similar goals of providing their staff with a collaborative opportunity to learn how to use ICTs as part of their professional development and classroom teaching and learning needs. That overwhelming agreement over the problem or the priority made the alignment process smooth. Therefore, the alignment of interest over the proposed solution as the OPP was an unchallenged process for the D-Net focal actants and other initiators.

\subsubsection{Re-Problematisation}

After the adoption of the new model from A-Net, the cluster had access to more opportunities. As a result, the D-Net initiators had redefined their Problematisation, due to having more than one priority. Based on the participants' accounts of the events and the evidence from documentary actants, the network initiators including the focal actants had prioritised three goals: 1) provision of ICTPD for their teaching and management staff members via VC, 2) integration of the gained ICT skills and capabilities into their classrooms to facilitate new approaches and pedagogies, and 3) expansion of subject choices for their senior secondary students via VC. As one of the documentary actants informed regarding their goals:

...provide quality professional development for teachers and leaders to extend their ICT capabilities. This will be achieved through the integration of ICT and a constructivist approach to learning..., establish the video conference (VC) school where each school shares a subject via VC...[and] to strengthen the whole school and their community as more seniors [students] are retained locally...

These goals inscribed in the documentary actants catered for the needs of every member of the school community and provided the basis for the initiation of a network of schools based on A-Net. These were broader than A-Net's initial objectives. However, the nature of the problem(s) identified by D-Net and their priorities remained different. In A-Net, schools were desperate to retain their students by providing broader subject options that their students needed to access. In D-Net, student retention was not the initiators' main priority or the problem; the priority was mainly about collaboration between schools' staff for their ICTPD needs. However, the priority had changed with 
the passage of time. After a few years, the D-Net Problematisation went through some further 'modification' and the provision of VC-based courses for students became a major priority instead of PD for their staff. As one the initiators revealed:

[D-Net] was more about the collaboration between schools and sharing between schools, that was a very, very big part of [D-Net] in the early days, and what's happening now, of course, is the video conferencing or the student learning as the major part. It's taken over...

Another documentary actant also confirmed that modification or shift which can be deemed necessary for the stability of the cluster. Indeed, the actant further informed that the shift has been around the integration of ICT into all classes in general and not just for the students in VC classes. The documentary actant, a review of D-Net by an independent commercial education consultant inscribed in 2008, informed that according to the D-Net principals:

...there was also a belief expressed that the [D-Net] initiative's ICT emphasis had moved from focusing on how to up skill teaching staff on the use of ICT hardware, to exploring uses of ICT as a tool to enhance pedagogical opportunities in the classroom.

In short, the problems or drivers behind the initiation have remained the same; however, their positions have differed on the member schools' priority list.

\subsubsection{Challenges}

Before reporting the Interessement phase, this section reports some challenges which are relevant to the Problematisation. Those challenges surrounded the cluster during and after the D-Net initiation. First, school teachers, not senior leaders, were mainly involved in the initiation and the Problematisation of the network. At the time when the Problematisation started, the people attending the first briefing were the teachers, not deputy principals or principals. In addition, the group of teachers were briefed by a senior teacher who was passionate about the cluster and remained one of the key initiators of the group in the region. One might argue that the briefing by a staff member at the teacher's level to the staff from a deputy principal level is realistic and not an unusual practice in a school community; however, that proved to be a turning point. One of the interviewees recounted that in the following meetings, some of the deputy principals chose not to attend. Instead, they or their schools opted to send their IT teachers who liked the idea or the problem-solution definition because of the element of IT. Subsequently, those IT teachers became the 'lead teachers' (e-dean) in those schools and representatives for the cluster activities. They were given the responsibility of initiating the cluster and managing its activities. According to one of the research participants:

Each school had to send a representative, and it wasn't always the DP [deputy principal], but it was in some cases... It was all sorts of teachers, whoever was interested, and they became the lead teacher in the school. So the lead teacher was the key contact person between the principal and the [D-Net] group. 
The point is that someone at a teacher's level in a school's management structure does not hold a significant position or power when it comes to delegating tasks to other staff from the same level. In addition, even to implement a decision made at management level again requires someone to have some authority, let alone making operational decisions or influencing senior management on cluster business. Therefore, that decision remains disputed. Although the teachers were repositioned as the 'lead teachers', they were mostly IT teachers and not VC or e-teachers. That debate was evident as the lead teachers were not referred to as 'deans' or 'e-deans', unlike A-Net. As another example, they were not allowed to use the term 'e-principal' for their coordinator until 2008 before the eprincipal's funding via MOE. Perhaps their coordinator was a teacher rather than a deputy principal. Therefore, for a school to remain as an active actant in the school's network, that 'lead teacher' role needed to be delegated to a person at a deputy principal level or above with some decision making and implementing power. As one of the interviewees noted, compared to A-Net, D-Net had a weakness of having no DPs. As a result:

...[D-Net] were not integrated into the management system of every school, because DPs do the integration more or less.

Besides, when they had DP(s) on board:

...the DP was actively opposing what the principal had agreed to, and the lead-teacher job was put in the hands of a part-time, bottom-of-the-rung teacher. You don't get far when that happens.

As a result, both the cluster and schools remained two separate structures with separate systems and boundaries, with no significant link joining them together. That gap was apparent in the later stage. As one participant reported:

But I think personally at the time [around 2009] I became convinced the lack of deputy principal involvement meant that we hadn't really built ourselves into the school systems. We were allowed on top of the systems, and that was easy to dispense with.

According to an interviewee from another cluster which can be regarded as a sustainable cluster, member schools need to re-structure their human as well as non-human resources for the growth of both the school and the cluster. As the participant shared:

We've really challenged the way schools structure the support and the facilities and the resourcing around these kids studying online. Because that's the only way you can grow it.

On the other hand, schools' senior management had the perception of developing the capabilities of individual schools by promoting their teachers as their representatives in the cluster. The D-Net principals "wanted to build the strengths of, and leadership, in each school. Therefore, they wanted the lead teacher in each school to be strengthened and to build their own leadership within each school". Obviously that was a constructive approach from the schools' point of view. However, the approach did not work, at least from the cluster's side, and could not support the long term 
sustainability of the cluster. Perhaps that was because the approach was focused on individual actants rather than the network itself. What the lead teachers brought into the individual schools once the cluster was dismantled as a collaborative group in 2009 remains an interesting area that could be investigated in the future.

Second, the findings also revealed that the D-Net schools had not adopted the shared funding model from A-Net. The financial model proposed by A-Net was to take a small financial contribution from each member school rather than being fully dependent on external funding sources. Interestingly, the eight schools had never contributed financially to the cost of running the cluster. Instead, D-Net member schools were influenced by and had relied upon external funding channels, including two rounds of the ICTPD funding and one e-principal funding during 2008-09. Specifically, their cluster coordinator or project director was partly coordinating activities for the whole cluster with eight schools and partly teaching at one of the member schools. Therefore, the position was partly financed through the ICTPD funding and partly paid by the school where the coordinator was employed originally and teaching face-to-face classes. That financial situation had continued until another funding - MOE's two year e-principal funding - opportunity was announced for all the virtual clusters for 2008-09. In other words, there was no shared responsibility for the financial ownership of the cluster, nor a joint effort to negotiate a financially self-sustaining cluster. As the study found:

....and of course it came to the crunch, because at the end of that year of 2009, we were running out of money and every contracts - and the government, the Ministry had always required that the schools promised to be sustainable at the end of the contract. Well, basically our schools reneged. They said they didn't want to.

The third challenge was the extended use of the model for achieving another interest. The actual model of virtual exchange of learning resources over VC was mainly and initially a solution for the retention of senior secondary students by widening curriculum choices. As discussed above, student retention was not a major problem in D-Net schools, since they had student rolls with more than 300 students compared to some schools in other regions with half of that number. D-Net were interested to use the model for the professional development of their staff and to adapt their classrooms and learning pedagogies with the $21^{\text {st }}$ century future focused learning as well as provision of wider curriculum choices. For that purpose, the cluster had organised multiple programmes at the same time. For example, besides the VC programme, the cluster was running the Gifted and Talented and PBLPs for their students. These programmes were regarded as "enriched specialist opportunities" which had extended the use of the cluster resources. Extending the application of the model to those areas was a very ambitious objective and thus required a different 
set of strategies and high level engagement and ownership from the cluster leadership. However, as one participant reported:

...in the early days the lead management team of lead teachers did most of the work, and then

slowly...we came up with shared policies that we all implemented more or less...

Leaving such ambitious programmes to be initiated and organised by the group of teachers proved to be a challenge, restricting the cluster's growth in the coming years. Although the group of D-Net principals was formed for overseeing the cluster and making strategic decisions, the operational management of the cluster remained one of the problems. As one participant reported:

Our lead teachers...helped manage the cluster [whereas in] A-Net, deputy principals managed the cluster and then they divested as deputy principals can do easily, they divested responsibilities to other people where it suited them, like to manage the actual students. So, they had more power to do things [than our lead teachers].

Therefore, the situation had challenged the management of the cluster within the member schools. Individual schools were reported to have struggled to implement the decisions made at the principals' group meetings. Thus, there was variation when what was decided in the meeting was not communicated to everyone involved.

To conclude, despite the challenges, the D-Net initiators had successfully identified and agreed on a problem-solution definition. They had secured the required funding from external sources for covering the cost of professional development and VC classes for students in the eight schools. In addition, they had adopted A-Net as their possible solution for facilitating their staff to learn the use of ICTs for the benefit of their students and schools. They had set up a team of focal actants to lead the programme and set the obligatory point for all their participants to be enrolled in the network.

\subsubsection{D-Net Interessement}

Related to the Interessement phase, three main aspects of the cluster were identified. First, D-Net initiators including focal actants had started various programmes including the provision of VC-based courses for their students and PD for their staff. Those programmes were identified as the possible devices of Interessement - tools to attract potential players - for the network. Second, the network initiators had identified and engaged some external players, for example polytechnics and a tertiary institution, in the network. However, that engagement was for a short period of time during the conception period of D-Net. Finally, some neighbouring schools were considered to be enrolled as the possible players in the network. They were persuaded; however, they were not seriously engaged to the extent of contributing financially to the cluster's self-sustainability.

Under the banner of D-Net, member schools had successfully organised multiple programmes that were running simultaneously. As mentioned above, the professional development programme for 
staff in the eight member schools was one of the key drivers behind the initiation of the cluster. The programme aimed to develop and promote a culture of collaboration and sharing, which could further support the desired change of paradigm in the schools. With the leadership of the initiators, the group of lead teachers had organised and managed a series of PD sessions not only for the teaching staff but also for the management staff from all the eight member schools. For example, staff members from the same subject area were collaborating or interacting in groups to share their experiences and exchange teaching resources. Notably, unlike other clusters, those collaborations were between all subject teachers and not just between VC teachers. That was because these collaborative programmes were regarded as a part of the wider ICTPD. That was why various Curriculum Faculty Groups (CFGs) were formed. According to one participant, the collaboration was among everyone from within and between the member schools:

...basically it was collaboration among schools and that collaboration not only included the students, it also was collaboration for teachers within the schools and our principals and DPs, so it was quite a big aim or goal that was set way back there in 2002.

Those were regular sessions conducted both over VC and in face-to-face meetings. The programme remained as one of the significant aspects of the D-Net cluster development during its early and middle stages. Thus, the PD programme was used as a device of Interessement for enrolling participants. The research found that, although the PD programme was successfully utilised to attract a good number of staff members to the network, the initiators had not tried to enrol participants from beyond the eight member schools. Perhaps this was because the cluster was reliant upon the external source of funding, which was for the eight schools only to subsidise the PD costs.

KnowledgeNet was another programme that the cluster was running in the eight schools for their staff. KnowledgeNet was regarded as a Learning Management System (LMS) that was bought for the eight schools to facilitate teachers' uploading and sharing their class material with their students and colleagues. The LMS was also intended to be used to create a pool of content where staff members could have access to a variety of teaching materials. The LMS was regarded as an earlier versions of Moodle ${ }^{27}$. As one documentary actant informed (original emphasis):

The potential benefit of Curriculum Faculty Groups across the eight schools to share subject knowledge, resources, experiences and encourage learning enthusiasm through the use of the Knowledge Net was defined as being very important.

Nonetheless, another documentary actant revealed that many of the staff members using the software were unsatisfied with the benefit compared to the cost of the package. That was because it

\footnotetext{
${ }^{27}$ An open source software package to replace learning management systems at universities.
} 
required more effort from the staff members and the output was below their expectations. The dissatisfaction meant that the 'device of Interessement' was unable to keep actants enrolled in the network. Since the LMS was not part of the study, it was not further investigated. However, that could be another potential avenue for further research to investigate the cost-benefit ratio of the system.

Similarly, the D-Net initiators had organised VC classes for their students who wished to study subjects that were otherwise not available at their schools. In fact, that was the actual objective behind the initiation and the concept of virtual clustering of schools in the Learning Exchange. That objective acted as a significant device of Interessement for attracting internal as well as external participants in the A-Net cluster. With regard to D-Net, the need for VC classes differed between DNet member schools, depending on their size and student needs. Therefore, as discussed in the Problematisation section, the provision of VC courses for their students was not their top priority during the inception stage of D-Net. However, that changed during the later stages. As a result, the VC courses had attracted a varying number of student participants from different schools. In particular, smaller schools had benefited more and highly relied upon the VC classes from the beginning. As one documentary actant inscribed by one of the D-Net principals informed, there was a common opinion amongst all D-Net principals (original emphasis):

The [D-Net] Area Schools particularly benefited from V.C. lessons in overcoming the barrier of isolation. Most [D-Net] schools saw benefit in accessing specialist, enriched niche learning. For Area schools however it was the lifeblood for their curriculum in addition to enriched specialist opportunities.

Besides the VC, the cluster was also running other "enriched specialist opportunities", such as the Gifted and Talented PBLP programmes for their students. These were individualised learning programmes available to all students to compete for from the [D-Net] cluster. For example, one participant described the PBLP and reported its achievement:

...[PBLP] involved the top three science students from year 10 in each school, and they were run as groups. It was basically a special programme for students...but probably not too relevant [to this study]. That was quite a model, and eventually...earning [a very prestigious national science award]...

The research found that those programmes had been successful in enrolling participants from within the eight member schools. Because the initiative had an internal focus, the cluster initiators had designed those programmes mainly for their own students.

Although those programmes had their own facilitators and were not relevant to this study, they were recognised as an aspect of D-Net. That was because all those programmes were running under the banner of D-Net, using the D-Net facilities such as VC and human resources for technical 
support. Thus the cluster was managing various programmes at the same time and its resources were stretched by those programmes. As one participant reported:

We ended up with a multi-pronged approach. There was video conferencing for student classes. There was ICTPD for teachers quite independent of video conferencing; there was special programmes for students like the gifted and talented programme that we ran.

The second aspect of D-Net was regarding the engagement of external players in the network. The research found that D-Net initiators had identified and eventually enrolled a few tertiary education providers and polytechnic institutes in the network, albeit only during the early stages. Different polytechnic institutes were engaged with to receive different subjects over the VC for their students. Similarly, some initiatives were trialled with a couple of universities in New Zealand. However, those contributions only happened during the early periods. Participants also revealed that D-Net had the opportunity to utilise tertiary providers such as their neighbouring university for any research activity at the cluster. That could have benefited the cluster and would have become a strength for D-Net. However, they had not taken up that opportunity. As one participant expressed:

...in my opinion, [during our early stages] we did as much or more with Polytech or tertiary institutions than [A-Net], except that they had a stronger research connection to ... [the] University and that became a strength for them too.

That was also experienced by the researcher while searching for material on research conducted on any aspect of D-Net. That was despite the fact that D-Net initiators had organised a regional educational conference during the early stages (which will be discussed in later sections). The absence of senior management teamwork was indicated as a reason for that lack of interaction with tertiary educators for any research activity. As one participant reported, one of the reasons behind the success of A-Net has been their senior management teamwork. Specifically, A-Net had a team of people coordinating the cluster at an early stage whereas D-Net had one coordinator for managing the cluster:

In A-Net, they had a fundraising expert...they had key deputy principals running the show...and then there was [a team member] doing the ICT technical development with Telecom. So they had a team of four people. It's one of their strengths, one of the reasons why they were leaders and still are.

Finally, D-Net had focused more on their existing member schools and their participants than expanding the cluster by including some neighbouring schools. With all the above programmes as the possible devices of Interessement, the initiators had the chance to attract more member schools and expand the cluster. However, according to participants, interest in expanding the cluster was very limited. That was because the cluster was reliant on the external source of funding. As a result, the schools had not contributed financially, an important aspect relevant to the financial selfsustainability of the model. The size of D-Net was never a problem; therefore the cluster leaders had limited interest in the inclusion of more members. Questions were asked about the possible relation 
between the size of a cluster and the cluster's financial self-sustainability. In response to the statement, "If we see other clusters that still operate, they are having more than 10 schools on board, particularly after the MOE's ICTPD funding", one participant replied:

...discussions never got that far. It never really got that far. No one proposed the model that might have worked because the only speakers were the ones who were saying we don't need it [i.e. the cluster] anymore.

A reported reason for the omission was that during the nine years of the cluster, D-Net had various sources of external funding. As discussed in the above sections, the eight schools had never made a formal financial contribution to the cluster out of their own operational funds. As one participant reported:

Well, we had nine years of funding. We had three rounds of funding that we applied for. So that, while the funding was there, the schools were, you know, together as [D-Net].

To conclude the Interessement phase, the schools had initiated the cluster with the aim to upskill their staff and integrate ICT into their classes to incorporate changing pedagogies. With that aim, the initiators had designed and organised several programmes intended for their own participants. With the assistance of different external financial sources, the cluster had continued its operations for a number of years, with limited success in engaging other neighbouring schools as potential players to make a self-reliant network.

\subsubsection{D-Net Enrolment}

Given the range of programmes offered, the D-Net initiators had established a variety of roles to maintain the network over the nine year period. Quite often those roles (particularly the key roles) and their responsibilities were found to be covering more than one D-Net programme. The situation was the same with regard to the role of the actants in the management of the Learning Exchange programme in D-Net. Actants involved in the Learning Exchange or the provision of VC programmes were part of the other D-Net programmes too, making the boundaries between their responsibilities indistinguishable for the purpose of this study. Nonetheless, this section discusses some of the main roles in an attempt to limit the focus to the scope of this study.

\subsubsection{Principals' Policy Committee (PPC)}

The committee was a collaborative group of eight school principals responsible for setting the policies and strategic directions of the cluster. The committee was regarded as a good forum for the principals to share experiences and discuss their problems about and beyond the cluster business. The study found that, before the establishment of D-Net, there was no such formal group of or forum for the principals in that region. After the initiation of D-Net, the committee was formed and named the PPC. Indeed, as of early 2016, the committee still exists and most of its members meet 
regularly despite the fact that D-Net has stopped operating. That was regarded as a learning forum for the principals and the achievement was reported as particularly beneficial for any new principal in the area. The committee members were reported to have regular face-to-face and VC meetings. Therefore, the participants viewed the existence of the committee as one of the greatest achievements or effects of the network. As one participant reported:

...as far as I know even today [mid-2015] there's still a small group of [D-Net] principals [who] meet regularly and just support each other. It's been wonderful for new principals coming into the area, that we've got a group of principals who are really established around them, that are in a network and I know there's been a lot of mentoring going on amongst the principals.

During the D-Net application for the ICTPD funding in 2002, a team of four people, each with different roles, was nominated to be responsible for leading the cluster. The team has already been described in the Problematisation in which it was referred to as the team of focal actants. The team included these roles: a project director which can be referred to as a cluster coordinator or eprincipal; an e-dean, which was later re-named as assistant e-principal; a KnowledgeNet facilitator; and a lead principal. The team was made responsible for representing and setting goals for the network that would be relevant and remain aligned with the interests of the D-Net schools. In addition, the team was responsible for supporting and maintaining relationships with the network actants as part of the network Mobilisation. In fact, according to one documentary actant, the cluster had handed the ownership of the management of the cluster to the cluster e-principal (then the project director) during the initiation period (original text):

Initially the e-Principal was vested with the responsibility to identify and develop an educationally based ICT strategy, present this strategy as a business case to secure funding, project lead any successful proposals and take an active role in facilitating the key outcomes of the [D-Net] cluster over the years.

The role of lead principal at the beginning of the cluster was to work with the team and support the cluster programmes. The lead principal role was continued with the establishment of the policy committee from which one of the principals was nominated for two to three years to chair and represent the principals' committee. Later, the team of focal actants was expanded with the inclusion of lead teachers from the eight schools and re-named as the 'Lead Management Committee' or LMC.

\subsubsection{Lead Management Committee (LMC)}

Although the PPC was established later, it was reported that the LMC was mainly organising and managing the cluster. During the earlier stages, the eight ICT or the lead teachers were the main initiators of the cluster with varied levels of interest from their principals. As discussed in the Problematisation, the ICT teachers, not even the school DPs, were mainly involved during the consultation meetings for the initiation of the cluster in the early days. However, school principals 
are the authority to be consulted and who approve the initiation of such programmes. Therefore, their principals were supportive of the development, but they were not directly involved. As one participant reported, the lead teachers from the eight schools initiated and drove the cluster without much involvement of the principals in the early days:

In a sense, the lead teacher group put together the initial strategies and programmes to do with video conferencing and ICTPD and stuff, and the lead principals just had to ratify it, and basically agree on the costs and the staffing. They weren't interested in the details, and maybe they should've been, but they weren't. So, the lead teachers drove it and eventually e-principal drove it.

When further asked about the role of the committee and the reason for the alleged variability of interest from their principals, one of the participants reported:

...they were like a board who set policy. They didn't want to run the detail. They didn't know much about ICT either. But they wanted the lead teacher group to do it...they [principals] wanted lead teachers to become the experts in the schools, not to buy in some big main person. They set the policy...

The above finding also re-established an earlier finding that the principals' strategy was to build internal capabilities of the individual schools, and the decision was an example of the strategy-intoaction.

Later, the team of focal actants was re-established with some changes. The role of project director was renamed e-principal, the e-dean role was re-named assistant e-principal, and two KnowledgeNet facilitators were included in the team instead of one. Since the study is focusing on the Learning Exchange programme, the role of KnowledgeNet facilitator is not discussed here. Within the team, the roles of e-principal and assistant e-principal were relevant to this study. Therefore, only these roles are examined in this study. Another change was that the eight lead teachers from the member schools were included in the original lead team. The team was renamed the LMC.

The objective of the LMC was to manage the cluster programmes and facilitate implementation of policy decisions made by the PPC. As we can see from Figure 5.9, the LMC had been working as a bridge between the PCC and the group of lead teachers or e-teachers in schools. The decision to give the lead teachers the role to manage the cluster within those individual schools without empowering them as e-deans in the management structure of the schools was reported to be a challenging task for the LMC members. Specifically, they had faced challenges with the implementation of policies and enacting the vision in the schools. The Problematisation Section has discussed the challenges in detail. 


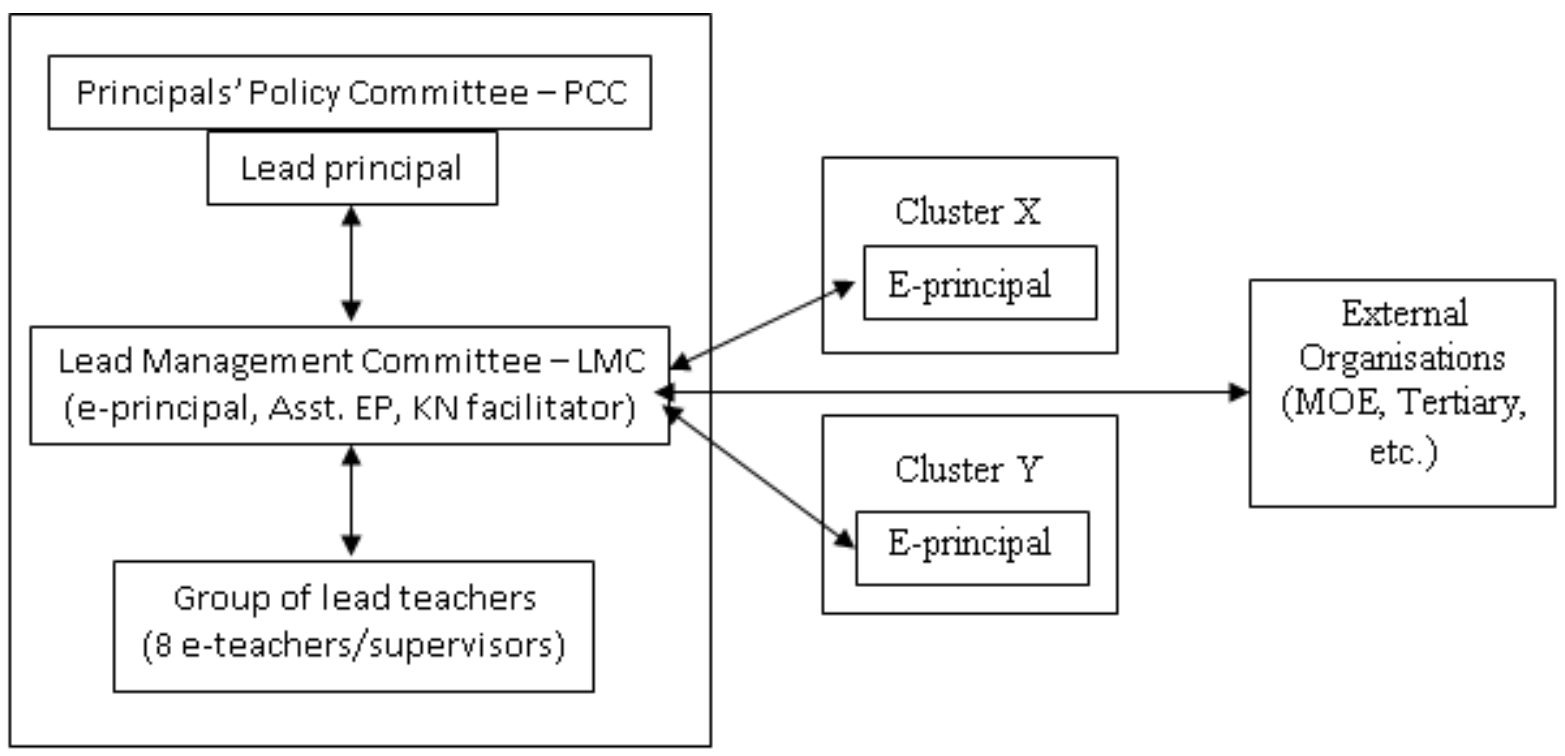

Figure 5.7 D-Net cluster leadership structure

\subsubsection{E-principal}

During the conceptual stage of D-Net, the role of project director was established with significant responsibilities. Based on the participants' responses and documentary evidence, the role entailed identifying, developing and presenting an ICT strategy, and then leading the management of different D-Net programmes. From an overarching perspective, the role aimed to facilitate the integration of ICT into classrooms and eventually proceed towards a pedagogical change in the DNet schools. The principals and schools had relied upon the e-principal's ownership of the cluster leadership and support for the cluster activities. Indeed, they had assigned the e-principal the responsibility of identifying and developing the cluster's ICT strategy. Equally they had entrusted the assistant e-principal with cluster leadership responsibilities and the provision of support to member schools.

The Problematisation Section has already discussed that the e-principal (then the project director) had successfully identified and presented the A-Net model as a possible ICT solution or strategy to the eight schools' representatives. The Section also discussed that the actant along with the team of focal actants had successfully secured ICTPD funding for D-Net from the MOE. Soon after D-Net's inception in 2003, the e-principal with his team had initiated different programmes, such as PD and KnowledgeNet for all their teachers and schools' management teams as well as VC classes for their e-students.

A documentary actant was found to have been formally inscribed with key tasks of the e-principal actant. Three key tasks were identified. The first task was regarding the internal development and management of the cluster. That included management of VC classes by organising e-teachers, arranging VC classes, enrolling e-students in those classes, coordinating with eight schools for VC 
class timetabling, providing training to e-teachers and so on. The second task included the development and management of D-Net's relationships with external organisations, such as tertiary institutions, vocational course providers and technical support providers. The last key task included the management of relationships with other clusters in the Learning Exchange or the virtual learning network community (VLN-C). The task was to collaborate with other e-principals from the VLN-C for the arrangement of inter-cluster VC classes. In particular, the collaboration was meant to support and ensure sustainability, quality, resourcing, staffing and communication of the programme at the national level.

The organising of a cluster-wide conference in 2004 was repeatedly reported as one of the examples of the team's significant contributions. As one participant recalled:

...it was quite an outstanding conference really. I mean, we had 300 people; we had 25 -ish presenters; we had 60 different break-out options; we had a few big-name key speakers, probably two international speakers. So, that went off with a bang, really....

A documentary actant summarised the conference debates and informed that the issues discussed included funding for schools, ICT infrastructure, future of schools, curriculum, professional development and e-learning. The conference was found to be one of the major achievements of the cluster and its e-principal actant as one of the key organisers. That was because the conference was the first of its type organised by any of the Learning Exchange clusters.

Although from the outset to the later stage in 2009 the role was found to be central in the formation and the ongoing management of the school network, the cluster was dissolved as a collaborative group and the role of e-principal was discontinued. The actant had been participating in the PPC meetings to update the PCC members regarding different aspects of the cluster. However, the policy was later changed and the actant was restricted from attending the PPC meetings and the lead principal was to brief the PPC regarding the cluster programmes. The research found that, since the actant was the main coordinator of the D-Net programmes, all their programmes were affected by that decision. As one participant reported:

[With that decision] suddenly e-principal was cut out of the C-Net development, and most of the activities stopped happening, and development discussions lacked leadership. And we had a range of programmes; we had about four or five different programmes running at different times and sometimes all at the same time.... After that, things stopped happening...

Participants were asked the reasons for that significant decision of the cluster's discontinuation. One of the reasons was the expectation that the cluster should have been self-sustaining after that many years. Specifically, from the beginning the principals had prioritised building their internal capabilities by allowing their teachers (mostly ICT teachers) to face the new challenge of leading the programme in those schools. As an example of that decision, the cluster had created the lead 
teachers' role played by their e-teachers instead of an e-dean role played by their DPs. As a part of that strategy, the group of lead teachers was made part of the LMC and paid for the management role. As one participant described:

...our lead teachers were very significant in our cluster...We were the only cluster (I think) that ever paid lead teachers a management unit, because the principals said they want to build up the leadership with their people in each school...So, we had cluster money, why don't we use it?

But why did the cluster disappear with their lead teachers in the absence of a cluster coordinator? That was the question asked to clarify the decisions and following events. One participant reported that there were changes of principals as well as lead teachers. Without a proper succession plan and with different perspectives, the cluster vision was lost in some of the schools. At the same time as the decision, the external funding had come to an end. As a result, some of the schools did not continue the programme in the same way as it was running before. As one participant reported:

... the proposal in the end was that the schools would take that [responsibility of funding] on, but they didn't want to give those lead teachers a management unit, and again, maybe they just lost the vision, or maybe they didn't have the right staff, or there' $d$ certainly been changes in lead teachers as well as changes in principals, and if they didn't have a vision for it, they certainly weren't going to fund it.

\subsubsection{Lead teachers' group}

The PCC members had decided that a teacher from each of the eight schools would manage cluster activities and support e-students in the individual schools. The teachers were assigned the title of 'lead teacher', a role similar to the e-dean role in A-Net. The eight initiators formed different groups of subject teachers so they could collaborate and moderate each other's work as well as share resources between them. The group consisted of lead teachers; however, they had more than one role. Lead teachers were found to be e-deans and e-teachers in the D-Net cluster. The responsibilities of e-deans and e-teachers remained similar to the tasks of e-deans and e-teachers discussed in the previous chapters. The difference was that in D-Net both roles were played by the same actant. However, as discussed above, the actants were paid accordingly. Another difference was that the lead teachers were given a role in the management of the clusters with a particular emphasis on building capabilities and leadership in the individual schools. That was reported to be a significant advantage of D-Net, as discussed in the above sections.

\subsubsection{Financial actant}

The above sections have discussed the funding in general. This section discusses the role of the funding in the discontinuation of the programme. During the nine years, the cluster had successfully secured two rounds of the ICTPD funding and one round of e-principal funding. The financial actant was temporary, since the actant was available for a limited period of time. However, reliance on such a temporary actant without an alternative plan, such as a small financial contribution by 
member schools, had made the cluster highly dependent on external funding. Financial dependency on some external actant has not been part of the actual prototype adopted from A-Net. When asked about the relation between self-sustainability of a cluster and financial contributions from its members, a participant replied:

Oh definitely. And it's the only way, and obviously the principals felt that after nine years, it should have stood on its own two feet, and it couldn't. It needed someone to drive it.

The quote also indicates that the cluster required a coordinator or e-principal to drive the collaboration. However, some of the school principals assumed otherwise. As the research found, some of the D-Net schools had assumed:

Now that distance learning had been established and associated hardware purchased, they would continue with the distance learning irrespective of funding sources.

From the theoretical point of view, external funding as the financial entity was instated in the network with a significant position and treated as a mediator instead of merely an intermediary. The reality should have been otherwise for the financial contribution from the D-Net members, because external funding channels were there for a limited period only. Such a member's contribution as mediator during as well as after any funding period could have supported the financial selfsustainability of the cluster. Most importantly, that mediator would have supported a significant change in the cluster by helping to create a culture of contribution. In reality, the earlier initiators of D-Net had adapted the A-Net model at this particular point. The precedent was then followed by the succeeding members of the D-Net leadership team.

In brief, the group of schools had a vision of building human resource capabilities in each of the schools and facilitating a paradigm shift in the school community. However, due to the changes of staff and leadership in the schools, enacting and preserving that vision in the new leaders had become a significant challenge for the schools. The new leaders had their own vision which was different from the Learning Exchange and the virtual clustering of schools. As a result, the programme had lost its value and importance. Because the financial actant had been allocated the central role in the network, the stoppage of the funding at the end of 2009 meant a decisive moment for the network. The actant could not further retain the bond and relation between the DNet actants. As one participant informed:

I think we had a good group of principals who appeared to give it a chance, and because there was funding, it wasn't costing the schools money, because the key person was funded...

In the absence of the financial actant, the schools were not ready to make an individual financial contribution for covering the management and operational costs of the cluster. A documentary 
actant informed regarding the frustration of schools having limited financial resources for organising such programmes (original emphasis):

Unanimous concern was expressed about resourcing. Cash-strapped Boards could not afford [necessary equipment]...All Principals reflected a degree of frustration with the government's expectation for schools to produce Knowledge Age thinkers on shoestring budgets...All Principals pointed out resourcing as a real barrier to progress.

However, after nearly nine years of funding the cluster probably had not made a valuable impact or place for itself among the schools and their staff members. Regarding the impact of the demise of the cluster, documentary evidence informed that some schools had considered it had "no impact to general teaching". As a result, the schools did not need the cluster anymore. In 2010, no more external funding was available, therefore the cluster was discontinued in 2011.

\subsubsection{D-Net Mobilisation}

The Mobilisation phase involves the support for network actants from network initiators that is necessary for retaining the Enrolment and maintaining the Problematisation. Overall the D-Net leadership, including the PPC and LMC members, was identified as supportive in terms of maintaining relations between the network actants. In other words, the cluster leadership was found to have ensured the Mobilisation of the D-Net participants.

The school management team, teaching staff and e-students were the three categories of participants contributing to the D-Net cluster. Each of these groups required support to maintain their ties and to be able to perform their responsibilities in the network. As discussed above, apart from setting policies, the PPC was considered a substantial support forum for the existing as well as new principals in the network. It was an emerging platform that had been assisting the school leaders since the inception of the network in the region. The forum had established a learning community for the school leaders which had been addressing their professional development needs. Moreover, that forum had been explicitly helpful for overcoming their geographical isolation. For the benefit of the schools, the principals' forum had facilitated exploring new opportunities for the future growth and improvement of the quality of teaching and learning in the schools. Irrespective of funding or the existence of D-Net, the group has been able to continue their collaboration.

In terms of support for teaching staff in the network, one of the key drivers of the cluster initiative was to meet professional development needs of the teachers around ICT. Because of the geographical barriers, learning opportunities for their staff were often limited to their local schools. With the formation of the cluster, the staff from eight schools were supported to exchange teaching resources and to be able to work with their peers from the same subject area in neighbouring schools. This was continuously supported by their local school leaders with a view to facilitating the 
change of school paradigm. The school leaders had enforced strategies to maintain the level of support for their staff. For example, Curriculum Faculty Groups (CFGs) of teachers were established for collaboration between all the D-Net teachers, whether face-to-face or VC teachers. As one participant added:

...we had collaborative faculty groups. There was about ten different groups in principle, but some were more active than others, and it kind of depended on the collaborative subject-leader who was nominated by their principal.

As discussed earlier, the provision of support for teachers' collaboration aimed to influence teaching and learning in classrooms as well as in the virtual environment. However, with the passage of time and the changes of principals and lead teachers involved in initiating the cluster, that vision had evolved. As one piece of evidence surprisingly suggested, some lead teachers held the view that "[DNet] was never intended to influence classroom teaching". Based on this particular finding, the leadership skill of a lead teacher can be reported as one of the factors playing a role in the demise of the cluster. That is because, from the conceptualisation stage, the PPC members had emphasised the goal of building internal capabilities of the schools by focusing on their lead teachers. Therefore, the lead teachers were made responsible for the provision of any professional development programmes for the teachers based on their identified needs. However, some of the lead teachers could not provide the level of support required to mobilise participants in the network and eventually the vision was lost. Beside the changes, regarding other factors for the loss of the vision, one of the participants acknowledged:

...one of them [reasons] would have to be potentially lack of skill in communicating a vision on my part....the other factor in relation to sustainability and the vision retention was the need. We had some bigger schools who weren't as desperate [to continue the cluster]. So they didn't perceive the need the same [as the smaller schools].

Students have been the central focus in the Learning Exchange and thus in many of the school clusters. A similar situation was found regarding the D-Net students. Both the policy committee of eight D-Net principals and the committee of lead teachers, assistant e-principal and e-principal had outlined support policies for their student participants. Again, from the theoretical perspective, those supporting steps were necessary for maintaining the connection of student actants in the network. Students were found to be satisfied with the support they had received from their lead teachers and other members of the LMC on subject related matters. Likewise, D-Net students were found to be satisfied with both the technological and physical infrastructure they had in their schools to assist them during their self-study periods. As one student participant recounted, their school effectively re-structured their physical facilities for their VC activities:

We had a really good set up and it was really cool because it was one, big, long room, so it was the area of desks and tables, then the partition wall, and then the VC, and then behind that was the 
office, so for any technical problems staff was right there as well, so I think it was running really smoothly....

Similarly, other evidence also indicated that students were satisfied with most of their VC classes, indicating organised and effective professional development programmes. When taking VC classes, e-students had not only accessed subjects of their choice but also enjoyed learning and being part of the D-Net school network. In particular, one student recalled one VC teacher teaching from a polytechnic:

...he was really well organised, he was brilliant, like he definitely, it definitely felt like I was in a classroom and he had his lesson plan... I really enjoyed the subject...it wasn't just me looking at the TV screen and him chatting away. So, I felt like he made the most of the VC, you know, the different parts of what the VC could do rather than just using it.

On the one hand that effective use of different tools and an appropriate style of teaching reflected the quality of training that the e-teachers received for teaching in that online environment. On the other hand, the findings revealed the suitable level of support that the schools had made available for their students.

The availability of good support for their students, teachers and leaders indicated the existence of a good mobilisation strategy for all the participants in the eight schools. Due to that, the cluster had a high level of participation from all the actants and contributions from all the eight schools. The overwhelming support and participation also reflected the main goal behind the initiation of the DNet cluster - changing the whole school paradigm by changing pedagogy.

However, due to the challenges identified, the network stopped as a collaborative group in 2011. As of early 2016, three of the schools have joined a neighbouring cluster and are contributing to the Learning Exchange community.

\subsubsection{Summary of D-Net Case Findings}

Based on the responses of the research participants and input from documentary evidence, this study found that in 2002 eight schools from a rural region of New Zealand had prioritised a vision to change their pedagogy by integrating ICT into their classrooms. By doing so the schools not only wanted to align their school paradigm with emerging teaching and learning practices but also to meet the professional and educational demands of their staff and students respectively. Based on Tilya's (2008) classification, the schools wanted to adopt ICTs not only for 'infusing' or embedding ICTs into their activities but also for 'transforming' their educational approaches.

The study found that the schools had adopted the A-Net school cluster model for organising PD programmes for their staff and providing VC classes for their students. Thus, a cluster of eight schools was initiated in the region and named the D-Net school cluster. In order to finance the 
cluster, a team of four people was initially nominated as their representatives to make a business case and apply for the ICTPD funding from the MOE. They successfully secured the funding and become one of the 2003-05 ICTPD clusters of the MOE. Three key challenges were identified with respect to the conception of D-Net. First, the schools had decided to rely upon the external funding. Second, their teachers, instead of DPs, were selected as e-deans to manage the cluster in individual schools. Third, ICTPD and other cluster resources were overstretched by organising multiple enriched specialised opportunities, such as KnowledgeNet, Gifted and Talented and PBLP. As a result, some of the programmes had consumed more resources than others with lesser benefits. Although the VC and PD programmes had remained significant aspects of D-Net, the cluster leaders had organised several other individualised opportunities for their teachers and students, mentioned above. All those programmes were found as the organised actions for achieving the goal of changing pedagogy in the schools. From the ANT's perspective, those programmes were the devices of Interessement for attracting participants to the network of schools. Although those programmes had attracted a high level of participation from member schools, the D-Net leaders were unable to include more schools in the network. That was found to be due to the fact that the funds were available for the eight member schools only. In the absence of a membership contribution aspect of the model and with no expansion to share the costs, the cluster ended up without having a workable financial model. The challenge was found to have played a decisive role in the dismantling of the network.

With regard to the Enrolment phase, the study found two leadership structures were established. The principals' policy committee or PPC was formed for setting policies and future directions of the cluster. A lead management committee or LMC was responsible for managing the day-to-day operations of the cluster. The LMC consisted of an e-principal, assistant e-principal and lead teachers from each of the D-Net member schools. Both the PCC and LMC had regular separate face-to-face and online meetings in every term. Within the two committees, two roles were found to be significant in connecting different parts of the network. The role of lead principal was to chair the PPC and communicate policy decisions with the LMC (see Figure 5.9). The role of e-principal or the project director had to coordinate the cluster programmes and brief PPC members. As a coordinator, the role involved leading the LMC members in the management of the cluster. Most importantly, both the committees as well the lead principal and e-principal were required to ensure support for the enrolled participants in the network. The challenges faced by the lead teachers in leading other teaching staff and managing the cluster in their individual schools were already identified in the Problematisation phase. Another significant challenge related to the Enrolment phase of the D-Net Translation was the assigning of a central position to the financial actant in the network. The ANT 
lens suggested that the temporary actant should have been assigned the role of intermediary instead of mediator in the network. However, without changing the financial policy of the cluster and the addition of more member schools, existing D-Net schools were unable to afford the continuation of the network. Thus, the end of the role of external funding led to the demise of the network.

Regarding the final phase of the D-Net Translation, the research found satisfaction amongst participants. The cluster leadership had provided physical and human support for maintaining the enrolment of the network actants. However, with the passage of time and changes of lead teachers and school principals, the need for the cluster had decreased and the vision had blurred in some of the schools. Specifically, some lead teachers were of the view that the "D-Net was never intended to influence classroom teaching". With such changes, the network perception had changed and similarly the need for supporting participant enrolment in the network was undermined.

To conclude, those challenges prohibited the development of D-Net as a self-sustaining school cluster. Therefore, the PPC members chose to stop the collaboration between the schools, except the collaboration between the principals. The role of e-principal was discontinued with a view that the lead teachers should be able to perform the different responsibilities of an e-principal, if a school needed to continue with the programme. However, that did not happen. When the cluster was dismantled, the lead teachers also did not show interest in the continuation of the VC programme. Eventually, from 2009 and onwards the cluster slowly disappeared. As of early 2016, three of the eight schools have joined a neighbouring cluster and the D-Net principals still meet regularly to share experiences and support each other.

\subsection{Chapter Summary}

With the above detailed descriptions of the four case findings, this chapter answered the first two research questions: how was the Learning Exchange developed and utilised in some of the school clusters in New Zealand?

Table 5.4 below summarises key findings and outlines the supporting and inhibiting factors with regard to each of the four clusters. Hence, answers the third research question. 
Table 5.4 A Summary of the key research findings

\begin{tabular}{|c|c|c|c|c|}
\hline Cluster & Phase 1. Problematisation & Phase 2. Interessement & Phase 3. Enrolment & Phase 4. Mobilisation \\
\hline A-Net & $\begin{array}{l}\text { Supporting factors: } \\
\text { - Identification of a common problem/need: } \\
\text { o student and staff retention } \\
\text { o limited financial and human resources } \\
\text { o the fear of schools being decapitated, } \\
\text { o changing pedagogies } \\
\text { - responding to identified problems/needs } \\
\text { - Adaptability } \\
\text { o Ability to build upon previous } \\
\text { experiences } \\
\text { o Pioneering an initiative } \\
\text { - Setting criteria for a self-reliant project } \\
\text { - Continually modifying accordingly } \\
\text { - Having a clear vision for the cluster as well } \\
\text { as a vision for long term self-sustainability } \\
\text { of the cluster }\end{array}$ & $\begin{array}{l}\text { Supporting factors: } \\
\text { - Successful identification of } \\
\text { potential players } \\
\text { - Engaging key internal and external } \\
\text { players } \\
\text { - Better utilisation of existing } \\
\text { resources/strengths/potential } \\
\text { - Knowing the need to expand } \\
\text { The need to have a sustainable } \\
\text { programme }\end{array}$ & $\begin{array}{l}\text { Supporting factors: } \\
\text { - Having a dedicated team of leaders } \\
\text { - Leader leading the change } \\
\text { - Building relationships } \\
\text { - Committed team members } \\
\text { o Member schools fulfilling their commitments } \\
\text { - Balanced distribution of responsibilities } \\
\text { - Better utilisation of organic relationships } \\
\text { - Ability to avoid antagonism } \\
\text { Having the desire to change and lead the change }\end{array}$ & $\begin{array}{l}\text { Supporting factors: } \\
\text { - Having a supportive team of } \\
\text { principals - macro level support } \\
\text { - Having supportive local DPs/Deans } \\
\text { and principals - micro level support } \\
\text { - Setting strategies for deep local } \\
\text { support } \\
\text { - Building relationships at macro and } \\
\text { micro level } \\
\text { - Organising programmes for } \\
\text { o maintaining relations } \\
\text { o communicating the vision } \\
\text { Satisfied participants }\end{array}$ \\
\hline B-Net & $\begin{array}{l}\text { Supporting factor: } \\
\text { - Utilising a specific cultural advantage for } \\
\text { broader educational purposes } \\
\text { o Expecting to improve learning outcomes } \\
\text { o Expecting to bring socio-economic } \\
\quad \text { development to a region } \\
\text { - Connecting individuals/organisations for } \\
\text { gaining the benefits of economies of scale } \\
\text { - Continually (re)aligning and (re)adjusting } \\
\text { needs/interests/priorities accordingly } \\
\text { o Responding to changing needs } \\
\text { o Also known as "Modification" } \\
\text { o Indicating clear vision }\end{array}$ & $\begin{array}{l}\text { Supporting factors: } \\
\text { - Knowing your strengths } \\
\text { o Such as ability to meet } \\
\text { student/staff/organisational } \\
\text { needs } \\
\text { - Leveraging your strengths to form } \\
\text { an alliance of possible players } \\
\text { - Having strategies for making allies. } \\
\text { e.g. } \\
\text { o Having physical visits or showing } \\
\text { presence } \\
\text { o Associate membership scheme } \\
\text { - Members' willingness to expand } \\
\text { and form alliances } \\
\text { - Having strategies for forming a self- } \\
\text { sustaining group }\end{array}$ & $\begin{array}{l}\text { Supporting factors: } \\
\text { - Having a vibrant/visionary team of leadership } \\
\text { - Ability to lead and maintain a self-sustaining } \\
\text { group } \\
\text { - Leadership ability to communicate and maintain } \\
\text { a vision } \\
\text { - Delegates having the level of authority to } \\
\text { dedicate tasks and implement decisions } \\
\text { - Maintaining the required level of human } \\
\text { input/resources } \\
\text { - Readiness of individual members for minor } \\
\text { organisational re-structuring } \\
\text { o re-positioning of their existing } \\
\text { - Principals on board with responsibilities } \\
\text { - Providing the required remuneration/ rewards } \\
\text { - Better utilisation of MOE's support for } \\
\text { developing leadership and a self-sustaining cluster }\end{array}$ & $\begin{array}{l}\text { Supporting factors } \\
\text { - Organising support programmes } \\
\text { - Leaders supporting enrolled } \\
\text { participants } \\
\text { o Knowing and catering for their } \\
\text { needs } \\
\text { - Addressing the need for regular } \\
\text { interactions for } \\
\text { o Continuous communication of a } \\
\text { vision } \\
\text { o showing support } \\
\text { o showing interest in a } \\
\text { programme }\end{array}$ \\
\hline
\end{tabular}




\begin{tabular}{|c|c|c|c|c|}
\hline C-Net & $\begin{array}{l}\text { Challenges or inhibiting factors: } \\
\text { - Opportunity-driven instead of a problem- } \\
\text { based initiative, } \\
\text { ○ External funds being the main factor for } \\
\text { the initiative, } \\
\text { - Failing to redefine the programme basis } \\
\text { - The challenge of aligning/converging } \\
\text { interests } \\
\circ \text { Variation of interests within initiators } \\
\circ \text { Weak convergence of interests } \\
\text { - Inappropriate selection of key players } \\
\text { - External players with a goal-setting role } \\
\text { - The network being dependent upon } \\
\text { external sources of funds } \\
\text { - Being small }\end{array}$ & $\begin{array}{l}\text { Challenges or inhibiting factors: } \\
\text { - Sustainability not being part of the } \\
\text { vision } \\
\text { - Failing to enrol a body of players in } \\
\text { the initiation of the group } \\
\text { - Lack of willingness and readiness } \\
\text { within the existing members for } \\
\text { further expansion } \\
\text { - Programme's weakness in } \\
\text { attracting other players } \\
\text { o Developing a small dependent } \\
\text { group }\end{array}$ & $\begin{array}{l}\text { Challenges or inhibiting factors: } \\
\text { - Inappropriate selection of players taking the } \\
\text { leadership role } \\
\text { - Ignoring/unaware of the importance of key roles } \\
\text { - Inappropriate delegation of tasks } \\
\text { o Coordinator having managerial role only } \\
\text { without having leadership responsibilities } \\
\text { - Unclear vision for the programme amongst } \\
\text { member organisations } \\
\text { o compromising various roles } \\
\text { - unable to respond to leadership changes } \\
\text { - Lack of interest from leadership team members }\end{array}$ & $\begin{array}{l}\text { Challenges or inhibiting factors: } \\
\text { - Conservative attitude of leaders } \\
\text { - Lack of support for participants } \\
\text { - Avoiding allocation of resources for } \\
\text { the provision of support } \\
\text { - Lack of communication } \\
\text { o affecting the mobilisation of } \\
\text { participants } \\
\circ \text { resulting in the loss of interest } \\
\text { o weak relationships }\end{array}$ \\
\hline D-Net & $\begin{array}{l}\text { Supporting factors: } \\
\text { - Having a bottom-up approach } \\
\text { o Staff members taking initiative to make } \\
\text { the change } \\
\text { o School principals backing the change } \\
\text { - Key drivers/reasons for the change } \\
\text { o Geographical challenge - being in a } \\
\text { rural area } \\
\text { o Small size of schools, PD needs of staff, } \\
\text { o Responding to changing pedagogies } \\
\text { - Adopting virtual grouping as a solution } \\
\text { - Selecting ICT as a vehicle for the solution } \\
\text { Challenges or inhibiting factors: } \\
\text { - Leaving the change dependent upon } \\
\text { external resources - MOE funds } \\
\text { - communicating/maintaining a vision while } \\
\text { having a bottom-up approach } \\
\text { - Integrating two systems (school and } \\
\text { cluster) complementing each other } \\
\text { - Having a multipronged approach }\end{array}$ & $\begin{array}{l}\text { Challenges or inhibiting factors: } \\
\text { - Ignoring/being unable to utilise } \\
\text { their potential to attract more } \\
\text { players from outside organisations } \\
\text { - Failing to form a sustainable } \\
\text { alliance by } \\
\text { o including external players } \\
\text { o better utilising various funds } \\
\text { o reliance upon some internal } \\
\text { financial resources } \\
\text { - Following a self-centred approach } \\
\text { o The challenge of remaining } \\
\text { small }\end{array}$ & $\begin{array}{l}\text { Challenges or inhibiting factors: } \\
\text { - Leadership } \\
\text { o Not maintaining a vision } \\
\text { o Not stopping the devaluation of a } \\
\text { programme/vision } \\
\text { o Not taking the responsibility of ownership } \\
\text { (getting involved) } \\
\text { - Failing to have a succession plan } \\
\text { o Overlooking impact of changes of leadership } \\
\text { team members } \\
\text { - Having a vertical organisational structure } \\
\text { o Not delegating the key ownership } \\
\text { responsibilities to key players } \\
\text { - The challenge of building internal capabilities } \\
\text { - Allocating central role to external sources of } \\
\text { funding }\end{array}$ & $\begin{array}{l}\text { Supporting factors: } \\
\text { - Meeting the need for providing } \\
\text { support to participants both at micro } \\
\text { and macro levels } \\
\text { Challenges or inhibiting factors: } \\
\text { - Failing to maintain the programme } \\
\text { vision } \\
\text { o Undermining the support and } \\
\text { the existence of the whole } \\
\text { network } \\
\text { - Weakening the relationships }\end{array}$ \\
\hline
\end{tabular}


Table 5.4 has been refined by removing common factors and consolidating the rest in the following table. Table 5.5 can be considered as a brief outcome of this chapter derived from the four cases.

\section{Table 5.5 Consolidated Findings}

\begin{tabular}{|c|c|c|c|}
\hline Phase 1. Problematisation & Phase 2. Interessement & Phase 3. Enrolment & Phase 4. Mobilisation \\
\hline $\begin{array}{l}\text { - Ability to merge and prioritise varying } \\
\text { interests/needs } \\
\text { - Adaptability or ability to respond to } \\
\text { changes } \\
\text { o Continuous realignment of } \\
\text { interests/needs with changes over } \\
\text { the period of time } \\
\text { o Continuous modification } \\
\text { - Formation of a virtual community of } \\
\text { learners/educators } \\
\text { o Grouping/clustering of } \\
\text { organisations with similar priorities } \\
\text { - Setting and maintaining a common } \\
\text { vision } \\
\text { - Changing organisational paradigm } \\
\text { - Ability to integrate two systems } \\
\text { (schools and clusters being part of each } \\
\text { other) }\end{array}$ & $\begin{array}{l}\text { - Sustainability being a key part of the } \\
\text { organisational vision } \\
\text { - Establishing a financially independent } \\
\text { body } \\
\text { - Having strategies for utilising } \\
\text { organisational strengths } \\
\text { - Engaging potential players and making } \\
\text { a self-sustaining alliance } \\
\text { - Forming economies of scale } \\
\text { - Efficient use of existing organisational } \\
\text { resources }\end{array}$ & $\begin{array}{l}\text { - Committed team of leadership } \\
\text { - Having a vertical organisational } \\
\text { structure } \\
\text { ○ Meeting the challenge of building } \\
\text { good relationships } \\
\text { o Ease of communicating vision } \\
\text { - Carrying out necessary organisational } \\
\text { restructuring } \\
\text { - Organisational power politics } \\
\text { - Managing change of leadership } \\
\text { - Not relying upon short-term players } \\
\text { - Commitment to making financial } \\
\text { contributions }\end{array}$ & $\begin{array}{l}\text { - Supportive team of leadership, } \\
\text { both at macro and micro levels } \\
\text { - Maintaining organic relationship } \\
\text { - Continuous support for } \\
\text { participants } \\
\text { - Top management support } \\
\text { - Maintaining the vision for the } \\
\text { existence of the cluster }\end{array}$ \\
\hline
\end{tabular}

Table 5.6 provides a list of the common factors that supported the development and self-sustainability of some of the clusters. The next chapter interprets the factors. 
Table 5.6 Supporting Factors

\begin{tabular}{|c|c|c|c|}
\hline Problematisation & Interessement & Enrolment & Mobilisation \\
\hline $\begin{array}{l}\text { - Being aware of emerging needs } \\
\text { - Showing responsiveness to continuing } \\
\text { changes } \\
\text { - Systems adoption } \\
\text { - Systems integration challenges } \\
\text { - Setting/maintaining/ } \\
\text { communicating a vision for building a } \\
\text { community }\end{array}$ & $\begin{array}{l}\text { - Organisational resource management } \\
\text { - Internal dependency or self-dependent } \\
\text { - The strategy of economies of scale } \\
\text { - Strength development and utilisation } \\
\text { - Capacity building } \\
\text { - Knowing the impact of external factors } \\
\text { (MOE e-principal funds for sustainable } \\
\text { cluster and leadership development) }\end{array}$ & $\begin{array}{l}\text { - Programme ownership } \\
\text { - Leadership support } \\
\text { - Distributed team of leaders } \\
\text { - Organisational restructuring of resources } \\
\text { - Responding to leadership changes } \\
\text { - Succession plan } \\
\text { - Maintaining a vision }\end{array}$ & $\begin{array}{l}\text { - Leadership support for all levels } \\
\text { - Programme ownership and } \\
\text { representation } \\
\text { - Having approachable leaders } \\
\text { - Continuous interactions and } \\
\text { communication for } \\
\text { ○ Maintaining relationships } \\
\text { ○ Enacting the organisational vision }\end{array}$ \\
\hline
\end{tabular}




\section{CHAPTER 6: DEVELOPING A SELF-SUSTAINING LEARNING EXCHANGE CLUSTER}

\subsection{Introduction}

This chapter gives a cross-sectional analysis of the four clusters in order to provide a holistic view for developing a self-sustaining Learning Exchange cluster. As described in the Methods Chapter, the cross-case analysis methodology allows the researcher to compare multiple cases by identifying commonalities and differences between the cases in order to provide a holistic view of a phenomenon. Based on that guideline, this chapter interprets the development of a self-sustaining cluster by combining, comparing or contrasting the findings with examples from individual cases. This interpretation aims to take the research to a higher, abstract level and provide a holistic view of a self-sustaining cluster.

The analysis revisits the research questions, in particular, by addressing the question of how some of the school clusters have become self-sustaining. As a result, a number of factors or combination of factors contributing to the self-sustainability of the school clusters are identified, which is the major objective of this research. Therefore, the analysis and identification of the supporting factors remain beneficial for all the Learning Exchange clusters. The existing sustainable clusters would ensure that they are on the right track. For the developing clusters, the analysis could be used as a guide for redirecting their strategies and becoming self-sustaining clusters.

Table 5.6 in the previous chapter listed some of the major findings that were considered as the supporting factors for the development of self-sustaining clusters. This chapter discusses those findings and provides a cross-sectional view of a self-sustaining Learning Exchange cluster. At the end, Summary and Conclusion sections review the chapter.

\subsection{Emerging Themes}

The following sections analyse the supporting factors identified from the findings in the previous chapter. In Figure 6.1, the factors have been classified into four main stages: anticipation and conceptualisation, resourcefulness, administration and programme management. The first stage is about developing a viable philosophy for the cluster. The second stage is to commit required resources. The administration of the programme requires a leadership team capable of leading the programme. The last stage is about making the programme work by providing support from all levels and reviewing activities and relations. 


\section{Supporting Factors}

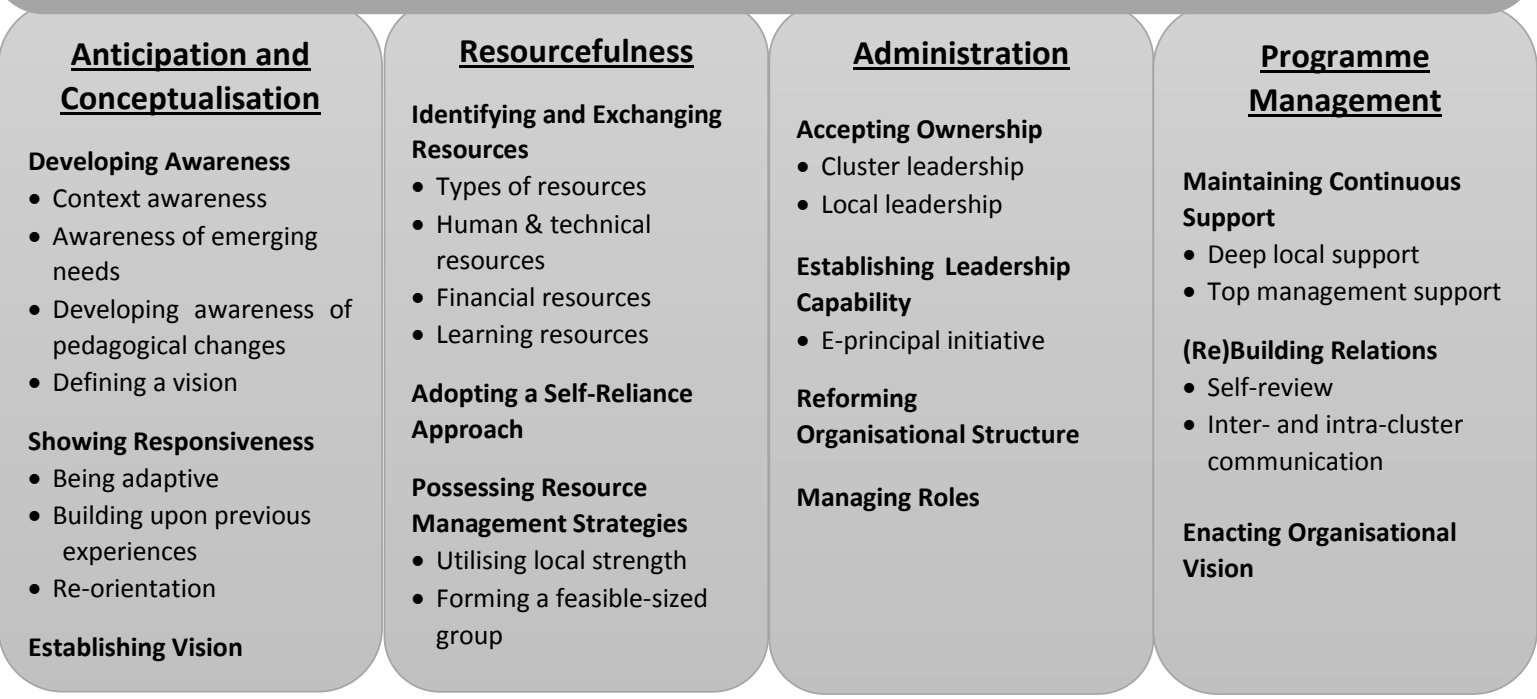

Figure 6.1 Developing a self-sustaining cluster

\subsubsection{Developing awareness}

Awareness of leaders regarding their operational context, emerging needs of their students and staff and the pedagogical changes was found significant in a self-sustainable cluster development.

\subsubsection{Context awareness}

Awareness of the school and cluster leaders regarding the context or situations in which they were operating was a significant factor for the initiation of a sustainable cluster. Such awareness enables the leaders to respond to local needs and set a vision for their future directions based on the ground realities rather than some short-term opportunities, such as a funding source. Without such an understanding, a group of schools might initiate a cluster or an online collaborative group but not be able to sustain it. Since the type of instigation is not rooted deeply in the grounds, after some time the reason or the need for the initiation will be lost. Some examples of awareness or understanding of the context could be their challenges, available resources, and weaknesses or strengths of the school community. The limited resources available at rural schools, their small size and geographical isolation were the key context-related elements that most of the cluster leaders were aware of. However, only cluster leaders from the existing self-sustaining groups had emphasised the need to establish their cluster based on those realities. For example, before establishing A-Net, school leaders from the region were aware of the precariousness of their local situation in which they were operating. Retention of students and staff without addressing their needs to a satisfactory level was almost impossible for the schools, particularly in remote areas. The context awareness had enabled them to keep the situation from challenging the very existence of their schools. Therefore, 
developing an understanding of the context is a key prerequisite for the conceptualisation and the instigation of a cluster.

Although the context in which the existing urban and semi-urban school clusters operate might be different from that of rural school clusters, the contextual challenges and opportunities still exist for all settings and require attention. For example, one of the B-Net leaders' challenges was the existence of a mix of different types of schools in their cluster. As some of the schools were rural and some were urban, their needs differed. Rural schools needed to respond to the basic requirements of their students and staff, whereas some urban schools were more interested in the continuation of their digital journey and some wanted to provide personalised learning to their students. With the knowledge of that contextual challenge, B-Net leaders had successfully responded to their needs and developed a vision that equally accommodated all their members' requirements. Therefore, the prospective school communities wanting to establish a Learning Exchange cluster need to base their group upon their local need or interest deeply rooted in their context.

\subsubsection{Awareness of emerging needs}

The need for a cluster changes and with the change awareness of emerging needs becomes a key factor in the realignment of the cluster. During the initiation phase, the basic aim could be to establish a cluster that could meet the requirements of students and staff, or the first aim could be to modernise the ICT infrastructure in schools and develop its effective uses for classrooms. However, after some time, the need tends to evolve and new expectations arise from the cluster participants. Identifying and keeping track of the emerging trends and expectations co-created by cluster participants becomes the key factor for the growth of the cluster. For example, as A-Net was developing after its initiation, the student and staff needs were changing and so were their expectations of the cluster.

Once A-Net was initiated and VC was employed, effective use of the tools was identified as an important factor for a positive outcome. Similarly, at a later stage accessing specialised teachers and subjects was no longer a serious issue because the access was established by then. The emergent expectation was the 'efficient use of resources' through better intra-cluster relationships, such as by reducing the duplication of VC classes. Therefore, the small organisations of participants from various schools allow them to co-create and co-evolve the need for their cluster. The responsibility of cluster leaders is to uncover the emergent needs or interests, an essential type of awareness for building a self-sustaining cluster.

Although the trends could be discovered and awareness could be achieved sometimes through surveys or other research studies, cluster leaders' own observations and experiences remain a 
reliable source for detecting emerging behaviour. Most of the clusters studied had some form of teacher evaluation and student feedback processes at the end of each year. However, not all the clusters had a final outcome from those inputs. Self-sustaining clusters learnt about the emerging trends through the regular steps based on the student and staff feedback as well as other studies. Therefore, the clusters are growing.

Regarding the role of cluster leaders' own observation and experience, such awareness can be developed through taking personal interest in the programme and having frequent interactions with the staff responsible for the management of the cluster in the local schools. Keeping the cluster at arm's length will definitely not help cluster leaders to develop such awareness and subsequently develop a self-sustaining cluster.

In contrast, leaders from developed clusters, such as A-Net, were not only involved in leading but also taking part in the day-to-day management of the cluster in local schools. Due to that strategy, leaders from one of the A-Net schools had observed on-going high demand for a particular subject from their e-students. Based on that observation, the school had started offering a face-to-face (F2F) class for that subject because of its popularity with their students. The situation had made the school leaders more interested in continuing their commitment to the VC programme.

Unlike A-Net, after a successful period of contribution and a number of achievements, D-Net was discontinued. That was because their staff's and students' needs based on which the cluster was initiated six or seven years previously were no longer valid. Specifically, ICT had arrived in D-Net schools by then and the staff were more computer literate. Therefore, training staff in how to use ICT was unnecessary by that time. On the other hand, D-Net leaders were mainly involved in the policy committee and nominated teachers from D-Net schools were primarily leading and managing the programme in schools. That leads to the point that for the sustainability of a cluster since the needs evolve over time, an awareness of emerging needs is critical for the cluster leaders. Therefore, knowing the emerging demands either through formal surveys or personal observations plays a vital role in the continuous growth and sustainability of a cluster.

\subsubsection{Developing awareness of pedagogical changes}

Another feature of a successful cluster is the development of awareness amongst the educators in the cluster about the continuous pedagogical changes. New pedagogies and approaches are continuously emerging in school practices, particularly due to the utilisation of ICTs in the educational processes. In particular, the ICT-driven change or the shift in school paradigms was anticipated during the 1990s when computers were first introduced into school practices in New Zealand. Since then, new theories have emerged. For example, according to social constructivist 
theory, learning should be a social rather than an individual process. Therefore, new concepts such as connected and networked schools are surfacing to replace the traditional brick and mortar definition of schools. For that type of learning to take place, learners and schools connect with other possible sources of learning, which are beyond the school boundaries. These pedagogies could be the reason for some of the schools taking part in the initiation of some of the clusters.

For example, D-Net leaders were also intrigued and inspired by their awareness of the shift in school paradigms. They adopted the Learning Exchange around 2003 to cater for the professional development needs of their staff and most importantly to integrate ICTs into their face-to-face classroom practices. They took practical steps by organising their own individualised e-learning programmes, the KnowledgeNet and PBLP, alongside the Learning Exchange. The response from the D-Net leaders was fundamentally based on their awareness and anticipation of the possible pedagogical changes in schools. Despite their awareness playing a key role in the fast development of the cluster during their earlier stages, D-Net disappeared later due to the absence of financial commitment from its member schools as well as neglecting to re-define their focus on the pedagogical changes. The reasons are discussed later in this chapter. The example of D-Net also indicates that one feature alone is not sufficient for building a self-sustaining cluster. In fact, a combination of features can help to develop a self-sustaining cluster. However, at this particular point, their failure to update themselves with the continually changing pedagogies became one of the reasons for their disappearance. Otherwise, since changing pedagogies were the key foundations of D-Net, any new pedagogical concept could have become a reason for their continuation.

\subsubsection{Defining a vision}

Leaders of sustainable clusters define a vision that addresses their collective needs and guides their decisions and future directions. The findings chapter regarded the vision definition as the problemsolution definition. In order to frame a collective vision, sustainable cluster initiators develop awareness about each member's requirements and engage in accommodating every member. While incorporating and adjusting to every member's interest, a balance is ensured that attracts every member school and supports them to integrate the cluster into their main school system. Otherwise, members lose the vision and the value of the programme. Ultimately the programme remains as a separate system, not integrated into the main school system. Unlike A-Net and B-Net, the C-Net vision was defined on the basis of external sources of funds rather than their local requirements. Once the funds stopped, so did the cluster itself. In other words, C-Net's vision did not involve building a self-sustaining collaborative group. Unlike C-Net and D-Net, A-Net from their conception and B-Net after 2009 made self-sustainability an integral part of their vision. 
Besides addressing their common needs, clear definition of a cluster vision is important for guiding their decisions and future directions. Although the setting of a future direction is not carried out very often, decision making happens quite frequently in managerial meetings. For instance, most of the clusters were found to have their groups of principals meeting at least once every three months to oversee the cluster activities. D-Net had a principals' policy committee, responsible for the managerial decision making based on their cluster vision. However, the nature of the decisions would depend on how realistic a vision is defined. Specifically, decisions based upon a vision that ignores self-sustainability will most likely lead to dependency and reliance upon external factors.

\subsubsection{Showing responsiveness}

Developing an awareness of one's context, emerging trends and changing pedagogies is the foundational step. Responding to the gained understanding is the next step. Therefore, developing awareness followed by some active response from cluster leaders are the two main factors required for the initiation and development of a self-sustaining Learning Exchange cluster.

\subsubsection{Being adaptive}

Adaptation is one of the reactive responses that a cluster can use for developing a self-sustaining cluster. Around 2002 and 2003 many groups of schools responded to their educational needs by adopting the Learning Exchange model from A-Net. However, not all of the groups were still operating after 2010. The clusters with adaptation as a key part of their strategic planning maintained themselves as self-sustaining groups. That is because initially all the clusters literally copied the A-Net model for their collaboration without any major modification. They adopted the model most likely to take advantage of the ICTPD funding opportunity. Later, since the inter- and intra-cluster interactions were dynamic, that allowed them to co-create new ideas based on their experiences. The emerging ideas were mostly based on the individual cluster's local needs and values, independent of the A-Net model. That was the opportunity for different clusters to adapt the model by modifying their cluster based on their own local needs. In other words, the transformation was the next goal for the clusters after 2009-10. The possible transformation required school leaders to react by adapting their directions accordingly. However, not all the clusters could and did so. Most of the clusters that exist today are the ones that adapted and successfully passed the transformation phase. Therefore, for a cluster to be self-sustaining, adaptation is a reactive response the cluster needs to be capable of.

The capability allows cluster leaders to change their cluster strategies and individual school priorities. They can do so by taking a personal interest in the cluster, examining and understanding the changes. That not only supports the self-sustainability of their cluster but also allows them to 
integrate the cluster with their main school system. For example, initially, B-Net was set up to respond to the need for bridging the digital gap for geographically isolated rural schools, providing them with educational resources and improving their educational outcomes. More recently, B-Net changed to respond to the needs of both the small geographically isolated schools as well as large city schools. In some other instances, B-Net was involved in helping some of the schools to continue their digital journey and support innovative ways of teaching and learning. Keeping a balance between both the small and large schools by catering to the needs of both without allowing one type of school to dominate the cluster was found to be an informed, adaptive response from the cluster leaders. That strategy allowed B-Net to become a collaborative group with a number of schools and gain the benefits of economies of scale, a strategy that led to their self-sustainability. As another example, the early achievements of D-Net indicated their adaptive response towards the changing teaching and learning styles in schools. D-Net adapted the Learning Exchange by initiating a multi-pronged approach to address the changing pedagogies. However, they miscalculated the resources available at that time and failed to continue their reactive response towards the changes in schools.

\subsubsection{Building upon experiences}

Another way of responding to changes and awareness is building upon previous experiences. In other words, a self-sustaining cluster is a learning organisation that is open to learning and embracing new approaches. The ability to adapt and build upon previous experiences placed A-Net in a self-sustaining position. A-Net leaders had responded to the needs of their staff and students by pioneering the Learning Exchange model, which was built upon their experience with CASATech. Since A-Net was aware of the financial requirements of operating a group, they made the model financially self-sustaining by networking with a number of schools. The cluster further responded to the need for the effective use of VC and other tools by organising professional development programmes for their staff members. Another relevant example of a proactive response and building upon their experience would be the situation wherein an A-Net school had learned about on-going high demand for a particular subject from their e-students.

More recently, A-Net leaders have made the cluster processes more efficient and resourceful by merging with another, neighbouring, sustainable cluster and forming a new bigger cluster. Why ANet has merged with another cluster remains an interesting area that needs exploring. Since the examination of the merger was beyond the scope of this research, it remained unknown whether the approach was a successful response. However, the positive response from the A-Net leaders by continuous learning from and building upon their previous experience is evident. This feature has 
guided them throughout their journey from the initiation, through growth and being self-sustaining to the emergence of a 'super-cluster' in New Zealand. Therefore, for developing clusters, building upon previous experiences is a strategy that can help them to develop their organisational learning and thus sustain their cluster.

\subsubsection{Re-orientation}

While adaptation and building upon experience are reactive responses, needing more synergy and innovation, re-orientation is a proactive response that can be employed for an incremental modification. This involves a continuous re-alignment of cluster directions towards the development of a self-sustaining cluster. Frequent revisits of the cluster directions followed by incremental changes can support a group of schools to embrace self-sustainability. Without such a response, a cluster is most likely to face a gradual disappearance.

For instance, a brief period of re-orientation helped C-Net to gain some momentum and reverse the passive response from the cluster initiators. C-Net's existence was challenged from the beginning wherein an external player was given a key role of fund holder. Indeed, that was a passive response of the cluster leaders. As a result, the player had failed to properly redirect the funds to meet the actual needs of the micro-level participants in C-Net. However, a re-orientation of C-Net by its leaders took place later to modify their cluster directions. The re-organisation helped them to focus on their real needs and thus increase their level of participation in the exchange of learning resources. As a result, the number of opportunities for their students and staff increased. However, the re-orientation for a short period of time was an insufficient response to put C-Net on the track of self-sustainability.

On the other hand, A-Net and B-Net had succession plans for leadership changes in schools. Their eprincipals briefed new school principals to refresh the school's commitment with their cluster and hence minimise any negative impact on the cluster due to changes of member school principals. With the briefings A-Net and B-Net e-principals informed new principals regarding various cluster activities and personally realised the cluster's impact on their individual organisations.

In addition to the re-orientation plan with new principals, A-Net and B-Net e-principals continually updated their member school principals to renew their commitment and support. In fact one of the sustainable cluster e-principals was famous for 'gate-crashing' their group of principals' meetings as a part of their re-alignment strategy.

\subsubsection{Establishing vision}

Self-sustainable clusters not only develop but also communicate their organisational vision regarding their online teaching and learning directions. A vision needs to be comprehensive as well as 
communicated across the board to every member of a group. That is more obvious when the group consists of multiple, separate organisations. It is the same for the self-sustaining Learning Exchange clusters. Since self-sustaining clusters have a large number of member schools (more than 10), their leaders need to give a great deal of consideration to communicating their cluster vision to their individual schools for the unification of the cluster.

Two separate approaches were found in the study. One of the approaches was followed by selfsustaining clusters wherein their e-deans had frequent interactions with their principals. In that case, both the principal and e-dean were aware of the directions and activities of the cluster. In contrast, the second approach was one wherein the decisions made at the principals' level never reached lower levels or they reached them but were distorted. That was because staff members leading the cluster within member schools were from lower ranks of the organisational structure and had fewer interactions with their principals. Therefore, to keep a cluster from disarray, communication of a cluster vision must be accurate, so that precise decisions are made upon that vision.

Another reason for emphasising the importance of communicating a vision to each member school is the fact that it makes the participants in member schools more aware of the value of the cluster. That allows the cluster system of learning to become an integral part of the schools. Unlike A-Net, DNet was led and managed as a separate system of teaching and learning, mainly by the lead teachers. Many school staff were unaware of the value and impact of the cluster on their F2F classes. That was because only lead teachers with an ICT background were involved in D-Net management at the school level. With that management structure, decisions were received and implemented as per requirements. As a result, D-Net was not integrated into the main school system. Both the cluster and schools were perceived as two separate systems rather than complementing each other.

Moreover, the inputs from the micro-level participants were not accurately received by the group of principals. In that situation, decisions made at the leadership level are most likely based on inaccurate information, indicating a poor communication channel. Therefore, proper communication of a vision plays a key role not only in enacting the vision but also in assisting to develop a selfsustaining cluster.

\subsubsection{Identifying and exchanging resources}

Once the proposal for initiating a cluster is agreed on in principle, the exploration of the existing resources available in the cluster becomes the subsequent focus area. 


\subsubsection{Types of resources}

The available resources in the Learning Exchange clusters comprised human, technical, physical facility, learning and financial aspects. The exploration is particularly important for the selfsustainability of a Learning Exchange cluster because of two factors:

First, the very basic tenet of the Learning Exchange is the 'exchange of resources'. Since most of the cluster schools are located in geographically isolated regions, the listed resources are limited. The identification of available resources enables the schools to exchange and thus maximise those limited resources for their members.

Second, the initiators need to know about the resources in their possession for any planning. The clusters are based on a bottom-up or a self-initiative developmental approach, which means that the clusters have been developed from a grass-roots level by their local school community members. On the one hand, the self-initiative approach gives the initiators a sense of ownership and independence as well as liberation from officialdom. On the other hand, the approach brings a greater level of responsibility for driving such an organic initiative. Therefore, the initiators need to know their existing resources.

The leaders of the four clusters had identified their available resources. However, they had to reorganise or re-allocate some of their resources for the exchange to take place. Most of the schools in the four clusters were reported to have re-structured their physical facilities for their VC classes and invested in their technological infrastructure development. Specifically, re-structuring of a learning facility, such as the library, to place VC equipment or bringing faster Internet speed for VC classes were the efforts that all the clusters had made. Similarly, all the clusters had re-allocated their teachers as VC teachers in order to facilitate the exchange process to take place.

\subsubsection{Human and technical resources}

The key difference that makes a cluster self-sustaining is the effective use of their human and technical resources - known as capacity building. All the clusters explored their available resources and in their memoranda of understanding agreed to make those resources available to the cluster. However, not all clusters utilised them effectively and made points of difference. More specifically, when it came to 'bargaining' courses between two clusters or earning placements for their students in other clusters' courses, A-Net and B-Net offered courses that could not only fulfil their own needs but also earn placements for their students. In contrast, some clusters ineffectively used their staff to offer courses that did not benefit the offering school or the cluster. One school cluster was found offering a VC course without a single student in that course from its own school or cluster. 
Moreover, the under-utilisation of human resources also means an unproductive use of technological infrastructure and physical facilities. That is because the facilities will be rarely used in the absence of an efficient strategy. Such as, one VC room was very damp and had an unpleasant smell because the room was probably opened once a week as the school had only one student enrolment in the VC courses.

\subsubsection{Financial resources}

Amongst the types of resources, financial resources have been the key factor in the (dis)continuation of a cluster. Since a 'school cluster' is a separate organisation, it requires 'continued' and 'reliable' financial support to maintain its operations. Depending on the cluster leadership structure and the size of a cluster, the budget of managing a cluster would include a salary for one or more coordinators, the cost of logistics and other operational costs. Therefore, a cluster requires a reliable, continuous source of funding to not only start but to develop and remain sustainable.

How to finance those costs is the very basic and obvious question that every cluster has to answer by coming up with the right strategy during their initiation phase. All the four clusters knew about the cost of managing a cluster, but their financial strategies differed. Some depended on external sources of funding to run their cluster while some relied on their own financial resources. The former disappeared with the end of the external funding and the latter continued to refresh, selfrenew and thus self-sustain. The difference between both the strategies and a clear answer to the above question are explained in the coming sections 6.2.5 and 6.2.6.

\subsubsection{Learning resources}

The learning resources not only refer to the course material but also the knowledge and experience held by teachers. Since the whole Learning Exchange phenomenon exists for the exchange of 'learning', this resource is therefore of high significance. Students in small rural schools can access TCS to receive course material, both in digital and printed forms, for any subject they need. Similarly, teachers can get course material from colleagues, the Internet and/or can design it by themselves. However, the knowledge and the experience of the specialised subject teachers are the potential learning resource that makes the Learning Exchange more subjective. This aspect also matters because one of the key objectives of the Learning Exchange initiative remains the efficient utilisation of experience and knowledge of specialist subject teachers in small rural schools. Therefore, for better cluster development and student as well as staff satisfaction, school leaders should not be using their specialised teachers as gap-fillers in their VC programme. The leaders should rather see them as enriched opportunities for their students to benefit from. 
The two self-sustaining clusters were found to be using their teaching staff not merely for the delivery of learning content. They were using their teaching experience and knowledge to gain a higher level of student retention in their VC classes. That is also because the virtual environment requires a set of skills and more effort for engaging students from a distance and creating an interactive class. Moreover, those self-sustaining clusters were utilising their e-teachers' experience and knowledge for the benefit of newly appointed VC teachers during their regular PD programmes and annual workshops. For example, during their annual conference, B-Net invites one of its VC teachers to address the conference delegates and share their VC experiences for training as well as encouraging new people to get on board.

Such efficient utilisation of the learning resources not only remains aligned with the core of the Learning Exchange philosophy, and increases the level of satisfaction amongst its participants, but also makes the cluster self-sufficient. Therefore, the cluster remained self-sustaining whereas C-Net and D-Net did not report any strategy that indicated their desire for efficient use of their learning resources.

\subsubsection{Adopting a self-reliance approach}

As mentioned above in section 6.2.4, the self-initiative approach remains at the very core of the Learning Exchange cluster development. Member schools in a cluster are responsible for guiding future directions of their cluster and setting policies for its development. Therefore, the local school communities in the Learning Exchange should possess self-organisation and self-management characteristics, which are necessary for the development of self-sustaining clusters.

Two different approaches were found regarding cluster development, particularly resourcing policies. For some of the clusters, all their policies and strategies remained around self-reliance since their inception stage, whereas some took a contrasting approach. Clusters adopting a self-reliance approach were aware of their limitations and strengths. The approach enabled them to absorb external factors, such as the interests of their local trust or the MOE's various funding opportunities, without deviating from their self-organisation policies. For example, A-Net had their local Community Trust on board and used various funding opportunities offered by the MOE.

However, the A-Net leaders embraced the opportunities without losing the very core of their selfreliance developmental approach. As a note, the cluster depended on other clusters only for the exchange of courses, since the trading of courses between clusters is the main factor in the formation of the Learning Exchange programme. Apart from that, the cluster mainly relied on its own resources. A similar situation was found with respect to B-Net. Regardless of the DPS or ICTPD programme's objectives, the B-Net cluster adopted the self-organised characteristics brought in by 
the Learning Exchange programme, and thus made the cluster self-sustaining. The adoption freed them from external influence or control.

It should be noted that the absorption of external factors and the mutual exchange of courses between clusters clearly and rightly indicate the rejection of a 'radical' self-efficiency or selfdependency approach. The research also suggests that no man is an island and a totally self-centred approach does not support self-sustainability. However, a self-reliant characteristic brings trust and control within an organisation, and is thus emphasised as one of the key features of a self-sustaining cluster.

On the other hand, the policies of C-Net and D-Net were based on dependency and reliance upon external factors. Indeed, the two clusters did not have a policy or vision that could have led to selfdependency. While both the clusters clearly knew that the various external funding opportunities were for a short period of time, they did not take the self-dependency approach being followed by some other clusters at the same time. In the absence of such an approach, both C-Net and D-Net were operating without any development strategy that would have led them to self-sustainability. Consequently, both the clusters dwindled and their virtual collaborative activities stopped.

Therefore, for the sake of maturity and self-sustainability, Learning Exchange clusters need to make the self-reliance approach an integral part of their resourcing strategy.

\subsubsection{Possessing resource management strategies}

While section 6.2.4 has analysed the identification and exchange of resources and section 6.2.5 emphasised the adoption of a self-reliance approach, this section highlights two strategies that have a substantial role in the formation of a self-sustaining cluster. The two strategies are significant because they can provide a clear roadmap heading towards self-dependency.

\subsubsection{Utilising local strength}

Section 6.2.4 has described the resources that are available to the Learning Exchange clusters. Some of the established resources, if used efficiently, could prove to be potential strengths, enhancing the development of a self-sustaining cluster. The better use of the cluster coordinator's role, a small financial contribution made by member schools, and effective exchange of local knowledge and experience are some of the examples of local resources that could be turned into strengths.

Specifically, a dedicated full-time cluster coordinator has been a key strength both for A-Net and BNet and a key value generating source. By having a full-time responsibility, their coordinators were able to make physical visits to each of their member schools and meet cluster e-deans, e-students and VC-teachers on a one-to-one basis. In particular, their coordinators could manage to meet and 
persuade their school principals more frequently, and listen to other senior leaders who were an indirect part of the VC programme.

Further, the coordinators were able to meet other face-to-face teachers and learn about their interests or concerns about the cluster programme. Those activities meant that key stakeholders in member schools could see the value of the programme that the schools were receiving. That was important for addressing any dissent that might have existed amongst other staff members. Therefore, the principals were satisfied and the school commitment to the cluster was further established.

Satisfied principals also meant a satisfied board of principals overseeing the cluster. Therefore, A-Net and B-Net coordinators were the key part of the board of principals. The strategy for a better utilisation of the coordinator's role meant that both A-Net and B-Net were enabled to integrate with the main school system. The strategy did not exist in either C-Net or D-Net.

The financial contribution by member schools remains a paramount example of turning local resources into strength for the cluster self-sustainability. As discussed previously, sharing small financial resources or membership contributions played a vital role in the self-sustainability of A-Net and B-Net. As another example, both A-Net and B-Net utilised various funding opportunities from MOE in a way that those opportunities allowed them to further build their local capacity and thus reinforce their development. Although the external funding opportunities were available, both the clusters continued to rely upon their membership contributions as a local strength and used the external funding to boost their existing activities.

However, C-Net and D-Net ignored the necessity for mutual bearing of the costs in running the cluster for a long time. Both the clusters spent the funding opportunities without having long-term objectives. They missed the potential to utilise the strengths that existed in the local schools. As a result, they disappeared. One might disagree and rightly argue that most of the schools in the Learning Exchange are small and from rural regions, they have limited financial resources available for managing other parts of the schools and therefore, expecting "to produce knowledge age thinkers on shoestring budgets" might be frustrating for the schools. Nonetheless, schools have access to other financing avenues from Government departments, which they could seek for supporting their programmes. However, some opportunities are for groups of schools and some are for individual schools to address their individual needs. The MOE's initiatives - such as the Secondary Tertiary Alignment Resource (STAR) initiative, the Youth Guarantee Funding programme and the Asian Language Learning in Schools (ALLiS) programme - are only a few of the opportunities that individual schools can benefit from. 
More recently, Investing in Education Success (IES) is another opportunity that both schools and clusters can access. As an example, A-Net was collaborating with their local tertiary education provider that was financially sponsoring a particular type of VC course. Therefore, if schools were unable to allocate funds from their individual budgets, the option of applying for other government initiatives existed for sharing the cost of running a cluster.

The better use of Maori language subject teachers at B-Net can be noted as another example of the better utilisation of local resources and turning them into one of their strengths. Indeed, that would be a classic example of the exchange of knowledge and experience from the locals to the wider community. As another example, some of the B-Net schools interpreted VC-classes as an innovative way of teaching and learning in an online environment. The interpretation allowed the schools to attract international fee paying students, and thus generate some revenue. In some schools, the interpretation intrigued more teachers to volunteer for teaching VC classes. In others, the depiction helped schools to continue their digital journey and digitise learning resources for their face-to-face classes.

\subsubsection{Forming a feasible-sized group}

Being small was a problem for schools before the Learning Exchange and will be a problem with the existence of the programme. Thereby, the maximisation of resources - opportunities as well as size - has been the basic founding concept behind the Learning Exchange initiative. Indeed, the concept of clustering means the grouping of organisations from a particular area to form a bigger organisation. In this case, the strategy of virtual clustering of neighbouring schools was to form 'economies of scale' in order to maximise the available educational benefits of the member schools and thus increase their organisational size.

All the clusters studied in this research as well as other Learning Exchange clusters followed the same strategy; however, some of the clusters disappeared and some still operate. In other words, the schools have formed their regional clusters to increase their size. However, they still faced the problem of sustainability. The reason for that, or the problem, partly lies in the size of a cluster or the interpretation of 'feasibility'. Through the formation of a cluster, the problem of being small might have been addressed but not accurately.

With the existing financial aspect of the Learning Exchange model, the smaller a cluster is, the greater the chances of its disappearance. In the existing model, the expected financial contribution from a member school is 0.1 or $10 \%$ of a teacher's salary. Based on the formula, at least 10 schools are required in a cluster in order to fund the salary of a full-time coordinator, regardless of any external funding. Both A-Net and B-Net had around 20 member schools each, whereas C-Net and D- 
Net each had eight schools. Therefore, A-Net and B-Net remained feasible-sized clusters, whereas CNet and D-Net were unfeasibly small. Thus, the formation of a cluster is a partial solution that can only delay the issue for some time. A comprehensive solution for the formation of a self-driven, selfreliant, self-sustaining cluster lies in the formation of a feasible-sized group of schools with at least 10 members.

This section argues that local strengths can be demonstrated as a strategic tool, not only for engaging participants within the cluster. In a similar way, the strategy can be subsequently presented as a tool for persuading other neighbouring schools to join the cluster and thus form a feasible group. To form a feasible-sized group, both A-Net and B-Net had strategized the use of their local strengths as well as available resources as the potential tools to attract other neighbouring schools. As a suggestion that did not exist in any of the four clusters, a cluster can use their VCclasses as an e-learning programme or a self-managed study initiative, particularly useful for senior secondary students. That is because the type of learning and skills can support students during their transition period, moving from a school or teacher-led learning system into university education, which involves more self-directed learning. Thus, the example is only a demonstration that could be helpful for inviting prospective school management teams.

Associate membership was another useful strategy that B-Net used for engaging new schools in their cluster. All the newcomers were allowed to trial the programme for one- to two years without making any financial commitment. The strategy was working well as it attracted many new members. Therefore, the example is suggested to all the clusters for increasing the number of members.

\subsubsection{Accepting ownership of leadership}

Because of its virtual nature and activities, a Learning Exchange cluster remains a different learning setup or system from a school learning system with face-to-face activities and physical presence. The difference means that a cluster requires a separate management team to own and lead the cluster.

\subsubsection{Cluster leadership}

Since every Learning Exchange cluster is a joint initiative of its member schools, it is understood that the groups of schools own their cluster's leadership responsibilities. In particular, their groups of principals are rightly assumed responsible for owning the cluster leadership. Indeed, cluster coordinators or e-principals were assumed as the cluster leader. That was apparent from the cluster management structures of the self-sustaining clusters.

However, in some cases that was not true, since there were no clear indications of who owns the cluster leadership responsibility. Hence, the ownership gap created complications in those clusters. 
For example, in the case of C-Net, the LEDA trust was made responsible for leading the community of schools, at least for a couple of years after their initiation. Later, for most of the time, their coordinator was given a minimal role in the cluster leadership. As a result, C-Net could not catch up with the pace of development as other clusters had. In the case of D-Net, their group of principals was not greatly involved in the cluster activities. Initially, their cluster coordinator had the responsibility of directing the community, and during that period the cluster grew. However, later, the role of coordinator was ended and a gap of ownership developed at the cluster level.

\subsubsection{Local leadership}

Similarly, cluster e-deans own the responsibility of leading the cluster at the local school level. In addition to the ownership gap at the higher level, the same gap existed in local schools, particularly in the case of D-Net. Their lead teachers could not lead the cluster in a way some of their senior management team members, such as deputy principals or deans, would have been able to accomplish. For example the A-Net and B-Net e-deans had the level of authority to dedicate tasks and implement decisions, as required to accomplish their ownership responsibility. Therefore, D-Net remained limited to the group of lead teachers only and separate from the main school system. As a result, when it came under pressure, the collaboration between the schools was easily reduced.

Therefore, it is suggested that like in some self-sustaining clusters, the role of cluster coordinators or e-principals should be given the responsibility of cluster ownership and leadership. That is because the school principals in the four clusters changed more frequently than their cluster coordinators. In addition, the cluster leadership requires a full-time commitment, which is impossible for a serving principal. Therefore, as in A-Net and B-Net, a distributed team of leadership consisting of cluster coordinator(s) and schools principals should be formed. From this, a cluster coordinator should be selected as a cluster leader to own the cluster business as well as being answerable to the board members. With a sustainable leadership role, the aim of a sustainable cluster can be achieved. At the local level, senior management team members should be given the responsibility of owning the cluster at the local level in the member schools. The suggestions are most likely to help overcome any ownership vacuum that might exist both at the cluster and local school levels.

\subsubsection{Establishing e-principal leadership capability}

Assuming that the coordinators are leading the clusters, they require support from their local school communities for developing their leadership capabilities. That is because, apart from one or two, most of the existing cluster coordinators had worked as school deputy principals before taking the role of cluster coordinators. They required support for leading their clusters through the challenges and developing sustainable school communities. With the support of the MOE and their local school 
principals, they managed to accomplish the objective of sustainability. With new people taking the role, they need the appropriate level of capability.

Given the fact that the clusters are self-driven local communities, the MOE supported the establishment of the leadership capabilities of the Learning Exchange coordinators. The two-year financial and mentoring e-principal support during 2008-09 from the MOE was aimed at the establishment of sustainable clusters with leaders capable of continuing the journey of sustainability. The project funded various full-time positions for the coordinators and supported mentoring of the coordinators in developing their leadership skills. The support did help many of the clusters and their coordinators by increasing their inter-cluster communication and learning from other clusters. As a result of the project, a national-level forum representing the Learning Exchange clusters was formed. (The forum was known as the Virtual Learning Network Community or VLN-C. In 2016, the forum was re-organised and renamed the NZ VLNC.) Most importantly, some of the clusters and their coordinators maximised the opportunity by continuing their development on a similar track once the funding came to an end in 2009. On the other hand, some clusters reverted to their pre-2008 position after the end of the funding and slowly disappeared. The disappearing clusters ignored the key objective of the MOE support - the development of sustainable clusters and the establishment of leadership capabilities.

In short, the leadership capability and personal attributes of a cluster coordinator is a big factor that plays a significant role in the self-sustainability of a cluster. Such attributes are not only required for leading the management of cluster activities and supporting participants but also for anticipating any future challenges and looking beyond the horizon.

\subsubsection{Reforming organisational structure/resources}

Section 6.2.7 has emphasised the acceptance of cluster ownership as one of the key requirements for the development of a sustainable cluster. This section recognises the importance of cluster ownership at the local school level and suggests a minor reform at the individual member school level. The suggested reform requires readiness of member schools to carry out some minor restructuring of their existing management hierarchy. Such a readiness is needed because strong local leaders can not only maintain the required level of human and non-human input to the cluster but also communicate the vision. In other words, strong local leaders lead the change and build relationships at the local level. The sustainable clusters had not only strong leaders at the cluster and national levels but also at the grass-roots level where the initiative started. Therefore, they had gained the level of maturity required for self-sustainability. 
Two reform options exist for member schools. First, the reform could be conducted by a redefinition of some existing roles. As mentioned above, schools identify a person from their existing senior management team for the representation of the cluster in the schools. That would delegate the person the ownership role of the cluster at the local level. The second option requires a greater level of reform, which would require the inclusion of one of their e-teachers or lead teachers in their management hierarchy and their being given the title of 'dean' or 'e-dean'. The proposed reform can give the prospective local leaders or e-deans the level of authority required to deal with other staff members and implement policy decisions. By opting for the second reform option, the existing D-Net development could have been retained if not intensified and the fate of the cluster might have been different. Therefore, a sustainable cluster needs strong local leaders who can support the change and establish the school's commitment to the cluster.

In addition to the two options, the members' readiness for a reform could inspire some changes with regard to their staff members and learning and financial resources. Specifically, while allocating staff members as e-teachers, schools should consider VC-classes' difference from face-to-face classes. That means member schools should provide the teachers who could build the teacher-student relationship in the online space. In addition, the schools should also adhere to the MOU between schools and their cluster by giving the suggested number of hours and remuneration needed for teaching online classes. The allocation of the required resources would satisfy the existing e-teachers and avoid discouraging, if not encouraging, other interested staff members. Another example of allocating resources was in one of the A-Net schools. The school had a mentoring scheme for their estudents in which some of their face-to-face teachers were made responsible for mentoring 4 or 5 estudents each. With that small reform/scheme, the school had not only brought their face-to-face teachers into the loop but also increased students' satisfaction with the programme and maintained the required human input.

\subsubsection{Managing roles}

A number of roles were identified by the research, which included lead principals, member school principals, e-principals, e-deans, and e-teachers as well as e-students. Although each of the roles required a clear definition of their responsibilities, some were strategic and thus had a direct impact on the cluster self-sustainability. Thereby, those roles require specific consideration. For example, with the changes of school principals, repercussions were high both for schools and clusters. Since the Learning Exchange clusters are relatively small local communities, any such change had considerable consequences. Hence, the clusters required some strategies to manage the role and minimise the effects. Similar effects were created by the changes of lead principals or e-principals. 
One way to manage the role and restrict the effect of personnel change would be the adoption of a distributed team of leaders' structure rather than a vertical management hierarchy. Some of the principals were more enthusiastic, well informed and had a more positive perception than the others. Therefore, they were nominated for the role of lead principal for their cluster. While they were serving, member schools had active participation in the cluster. With their retirement or move to another school, the cluster momentum gradually dropped. Therefore, it is suggested that rather than depending on one lead principal, a team of lead principals should be formed. For example, BNet had an executive group with four principals. That was besides their board of principals. In contrast, once the main D-Net lead principal went on study leave, their cluster started to face more hurdles and challenges than before.

In addition to the suggestion of a distributed team of leadership, the development of a succession plan would be beneficial for the management of leadership roles. Once a new principal starts serving, their cluster coordinators and board of principals should initiate various orientation sessions in order to maintain the school's participation. The findings revealed that leaving such a strategic briefing to lead teachers or even e-deans had a negative effect on the member school's contribution. Therefore, for sustainable development of a cluster, the impact of leadership changes should not be underestimated. The strategic roles should be managed with an appropriate approach.

\subsubsection{Maintaining continuous support}

On the one hand, all Learning Exchange participants require support for continuing their contribution. On the other hand, cluster leaders and schools have the responsibility of providing support and ensuring they maintain the required level of support. To do so, cluster and school leaders are required to allocate or realign some resources. A conservative approach from leaders towards supporting participants can otherwise compromise the members' participation and consequently the sustainable growth of the cluster in the member school.

\subsubsection{Deep local support}

Specifically, e-students and e-teachers need 'deep local support' to continue their participation in the environment which remains different from the face-to-face school system. E-students need facilities such as a learning environment for their self-study periods and pastoral support for developing their soft skills. For example, students in one of the A-Net schools had multiple layers of support. The support scheme ranged from teaching, pastoral care, peer-learning, and mentoring to the development of a specialised one-week long e-learning module for gaining the set of skills required for surviving in the online environment. Similarly, e-teachers required time and management allowances for teaching and managing VC classes to a satisfactory level. In addition, 
since the educational environment is different, the teachers require extra support for developing their professional and learning skills for online teaching and building student-teacher relationships.

Without such a level of deep, on-going, local, effective support in place, neither students nor teachers would have been able to perform their roles and maintain their contribution in their cluster at a successful level. Again, the discussion turns to the reform of management hierarchy and ownership of cluster leadership in local schools, as emphasised in the above sections. That is because a dedicated, authorised local leader can not only cater to the needs of its local participants and better manage the cluster in their schools but also illuminate the benefits that the programme is bringing for everyone in their school.

\subsubsection{Top management support}

A number of factors remain important for the provision of on-going local support. Top management's perception is one of the key factors defining their commitment. A school's top management team typically includes the school principal, deputy principals, heads of various departments and possibly their board of trustees. The findings revealed that top leaders' perception and information about the cluster or online teaching and learning is partly influenced by their school's needs and priorities and partly by their personal understanding. Therefore, both the parts are critical for the on-going development and sustainability of a cluster.

Some of the school clusters, such as A-Net and B-Net, were based on their member schools' needs and priorities, such as student needs, geographical challenges or pedagogical changes. Their school principals and other management team members were convinced to deliver the required continuous support for their participants. Their commitment was greatly influenced by their local requirements since their geographical challenges and local needs were considerable.

In contrast, the reason for the C-Net's adoption of the Learning Exchange was based on the available funding opportunity from the MOE. Neither their local needs nor their individual perceptions had a role in their cluster initiation. As a result, their top management had a conservative approach towards the delivery of any support programmes. Hence, the cluster dwindled easily without any major dissent. For example, some of the C-Net schools were enrolling only those students in the VC classes who required no support for continuing their online presence.

By having that conservative approach, the schools avoided the provision of such a level of support and thus saved some resources. As another example, for most of its duration, the cluster had only employed a part-time coordinator to support the member schools. On the other hand, D-Net was based on their students' and teachers' needs; therefore, their top leaders had a supportive attitude towards their local participants. However, due to changes of school and cluster leaders and their 
poor succession plan, their new management team members brought in a different perception about their cluster. Therefore, after a self-review, they decided not to support the continuation of the D-Net initiative.

\subsubsection{2 (Re)Building relations}

Since the cluster is a self-driven, joint project of its member schools, a coordinated effort is required for its management and development. For any joint or coordinated effort, the creation of a good working relationship is crucial both within and between its member schools. Clusters adopting the Learning Exchange programme are expected to inherit the organic features of the programme. More precisely, the existing relationship between the local communities of schools contributed to the initiation of the Learning Exchange clusters. However, further efforts are required for the renewal and rebuilding of relationships in order to grow and maintain a sustainable coordination.

\subsubsection{Self-review}

After the initiation phase, the dynamics of the relationships change over the passage of time. For the maturity and sustainability of the clusters, the organic, local relationships need to be continually refreshed and rebuilt. That is because member schools start depending on each other for the continuation of the programme and collaborative learning. Most importantly, their organisational survival depends on their shared resources and collaborative learning efforts. Therefore, the relations need to be built not only with new local participants joining the cluster but also with their existing members. That is where the cluster self-review process comes into play for incorporating changes and realigning their internal strategies.

Most importantly, that self-review process formalises the receipt of the varied feedback from cluster participants and allows the cluster leaders to further strengthen the collaborative learning and teaching processes. Further, by listening and incorporating participants' feedback, the cluster leaders can reinforce the support from top management and renew their relationships. As a result, the outcome would be a more mature and sustainable cluster.

Three of the four clusters studied had conducted self-reviews to examine and re-define their collaboration strategies and re-build their relationships. After their reviews, A-Net and B-Net had renewed their relations and terms, whereas D-Net principals decided to discontinue their cluster after a self-review process, due to their leadership, resourcing and some other challenges.

\subsubsection{Inter- and intra-cluster communication}

In addition to their organisational self-review for the realignment of their strategies, inter- and intracluster communication is another strategy for rebuilding existing relations and re-creating new links within and outside the cluster. The communication should support the growth of a local cluster as a 
sustainable organisation and increase the collaboration between various clusters for the development of a national virtual learning community or the New Zealand Virtual Learning Network Community (NZ-VLNC). While the clusters take care of their local participants, the NZ-VLNC advocates and lobbies for their community's advancement at the national level. The NZ-VLNZ can further build relations not only with various Government departments but also third party organisations such as tertiary education providers, polytechnics and other organisations outside the clusters.

\subsubsection{Enacting organisational vision}

The key purpose of any organisational vision is to lead the organisation to the future outlined in its strategic plan. The enactment of the vision would then mean the implementation of the vision's philosophy and strategic plan. The development of a self-sustaining, collaborative learning community of schools should be part of the vision and future of the Learning Exchange clusters.

The process of enacting a vision requires on-going communication of the vision with all participants for a shared, clear understanding of what the cluster and schools are aiming to achieve. A review process aims to ensure the right implementation and management of a programme, and identify any discrepancies. However, the process of enacting a vision is more than a review process. The enactment of an organisational vision is a long-term process starting from the very early stages, whereas a review is a process conducted at the end of a certain time period.

As discussed above, cluster and school leaders should take ownership of the programme and build their local and cluster leaders' capabilities. By doing so, the leaders will not only better communicate their organisational vision with their participants but also be able to anticipate challenges and reduce discrepancies that might undermine the enactment of their organisational vision. However, the findings revealed that the D-Net cluster vision was diluted, because their leaders had not clearly communicated their organisational vision. Their lead teachers were unaware of their future goals. On the other hand, A-Net and B-Net cluster leaders had a clear understating of their responsibility of communicating and ratifying their organisational vision with local leaders in schools.

\subsection{Summary}

The chapter discussed the development of a clear awareness and philosophy for the cluster formation. A comprehensive philosophy is expected to consider the local context, emerging needs and continuous pedagogical changes. Such awareness would provide the basic founding concept and commitment for the development of a self-sustaining cluster. Adaptation, building upon previous experiences and re-orientation were the three key types of responses that the cluster's philosophy could incorporate for their continuous growth and sustainable development. The possession of 
awareness and responsiveness were considered basic factors for the establishment of a collective, clear cluster vision.

In order to implement the vision and adopt the Learning Exchange programme, some key types of resources were identified. Since the Learning Exchange was initiated from the grass-roots level, the self-sustaining clusters had relied upon the financial and learning resources that were available at their member schools. Their members had rightly agreed to drive their cluster by sharing the cost of developing their cluster and efficiently using the knowledge and experience that existed in the local schools. Their self-reliance approach and the strategy of utilising the local strengths had not only allowed them to attract a high number of participants from within their local member schools but also helped them to form a feasible-sized group of schools by engaging with their neighbouring schools. Because of their self-driven endeavour, the MOE had agreed to support the Learning Exchange initiative.

Accepting the ownership of leading a cluster was recognised as another feature of a self-sustaining cluster. The leaders of self-sustaining clusters owned the role of leading their cluster and did not allow a leadership gap. They formed a principals' group and made themselves responsible for setting strategic directions of their cluster. In addition, self-sustaining clusters entrusted their e-principals with the responsibility of cluster leadership and were provided with the support required for establishing their capabilities. Similarly, the ownership of leading clusters at local schools was identified as crucial for the cluster development. Therefore, e-deans were selected as local leaders responsible for the cluster development. However, some member schools could not lead the cluster within their individual organisations without reforming their organisational structure. The suggested role-reform was to either make a staff member from the senior management team responsible for leading the cluster or promote their lead teacher to a senior position for the leadership role in the local school. The allocation of the required time and remuneration to e-teachers was another small change in the allocation of their resources that the individual schools were advised to implement.

Another feature of the self-sustaining cluster was the plan for managing roles, particularly their senior management roles. In order to deal with the changes of principals, a coordinated succession plan and a distributed team management structure were suggested to minimise the effect. At the end, the provision of continuous support was recognised as a basic need for building and maintaining relations as well as for enacting the vision in each member school.

\subsection{Conclusion}

This chapter analysed the key supporting factors emerging from the four cases and examined them for guidelines to the development of a self-sustaining cluster. Those supporting factors remain the 
key features leading to the development of self-sustaining. By possessing the right type of features, member schools can go beyond the mere augmentation of ICTs into schools. They can actually transform their educational practices into future focused, learner-centred approaches. 


\section{CHAPTER 7: DISCUSSION AND CONCLUSION}

\subsection{Introduction}

The previous chapter compared and analysed the findings from the four cases and compiled a list of common factors necessary for the development of a self-sustaining Learning Exchange cluster. The chapter concluded and recommended clusters adopt those features in order to become selfsustainable. To build upon that conclusion, this chapter proposes that those features basically define the dynamics of the relationship between the cluster participants and thus provide a foundation for the emergence of self-sustaining Learning Exchange clusters.

This chapter uses Complexity Theory to discuss and generalise the findings. Although ANT was used in this study, its use was limited to guiding the data collection process and providing a theoretical basis for reporting the findings. Complexity Theory has been used to complement ANT by building upon the outcome of the ANT-based findings. That is carried out by viewing the Learning Exchange clusters as complex adaptive systems and discussing the rise of the clusters as complex adaptive systems and related dynamics of the relationship between cluster participants.

\subsection{Viewing Clusters as a Complex Adaptive System}

This study views the self-sustaining Learning Exchange clusters as Complex Adaptive Systems. Adapted from Figure 3.3 in section 3.3.3, Figure 7.1 depicts the proposition and shows the Learning Exchange clusters as complex adaptive systems (following sub-sections will explain the diagram). The discussion is continued on the following four major foundations:

- First, local participants and member schools in a cluster are simple sub-systems at micro-level.

- Second, the clusters' local policies and features represent the dynamics of the relationship between the local elements from clusters.

- Third, local elements with the possession of the features give rise to the emergence of selfsustaining clusters or dissipative systems.

- Finally, the self-sustaining clusters exhibit the characteristics of Complex Adaptive Systems (CAS). 


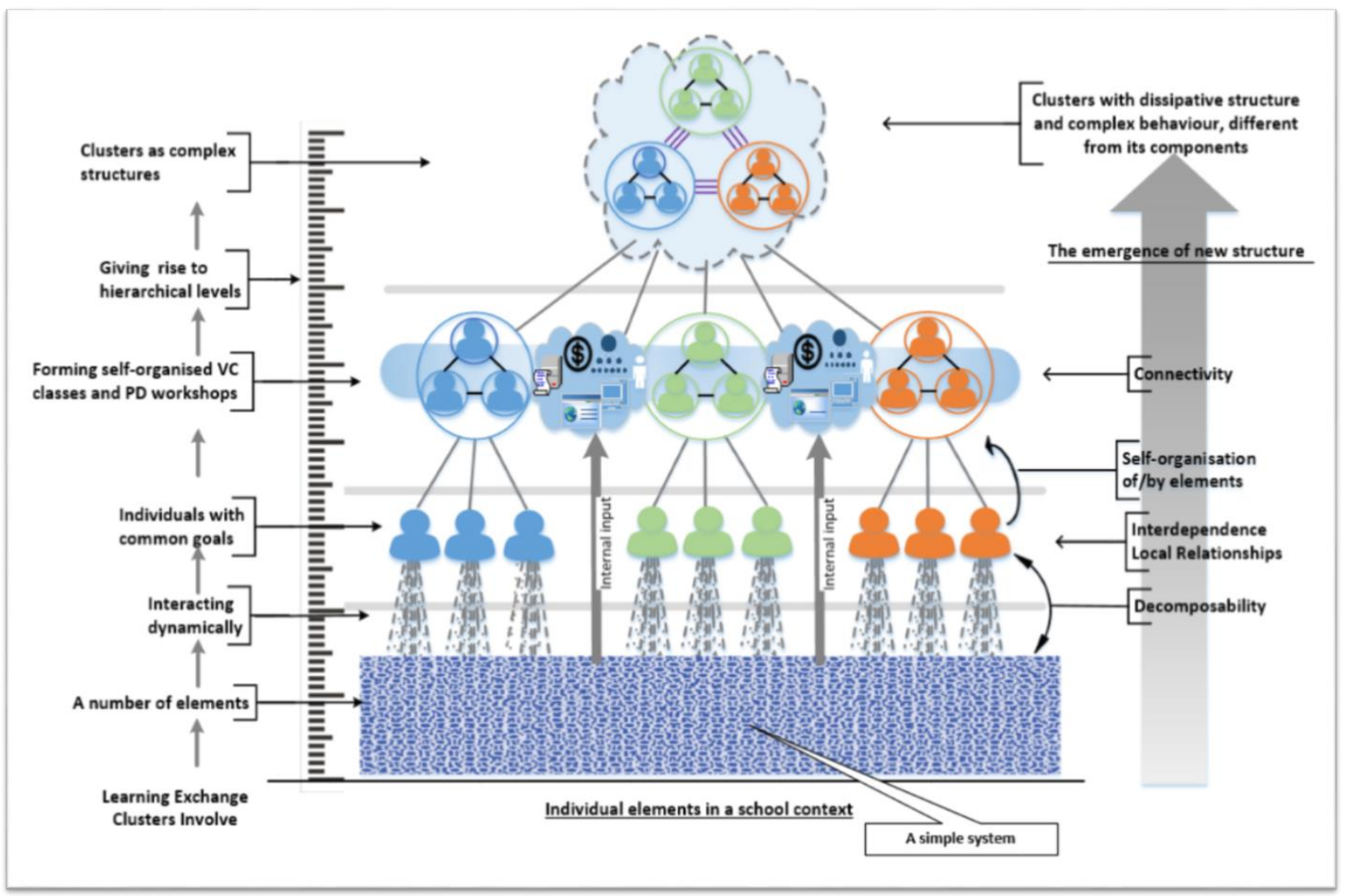

Figure 7.1 Self-Sustaining Clusters as Complex Adaptive Systems

\subsubsection{Local participants as simple sub-systems}

It is now known that each of the Learning Exchange clusters is formed with a number of local elements, including individual participants, member schools and ICTs as tools. From the Complexity Theory perspective, those local elements or units are simple sub-systems because they are from the local micro-level, and their behaviour and nature are predictable, making them simple systems. For example, e-teachers, e-students, e-deans, e-principals, member schools, and schools' management team members, as well as ICT elements, are individual units of clusters; they have their specific individual responsibilities in their cluster context. More specifically, an e-teacher has responsibilities that include preparing and delivering VC-based lessons, working towards building student-teacher relationships in the online space and supporting e-students offline. As another example, a VC-set, computer or other tools have their specific functionalities when it comes to a cluster context. A VC set in the cluster context is used for connecting students and delivering courses whereas in a business organisation context the set is used for communication. Similarly, schools as educational organisations in the small rural community and their principals as leaders have their specific individual roles within the cluster business.

By studying their individual responsibilities and job descriptions or uses and functionalities, their individual behaviour in that specific context can be described. Therefore, like any local units of a 
complex adaptive system, all individual elements of a cluster can be called simple sub-systems. In Figure 7.1, those elements have been represented by the blue texture at the bottom of the figure. Figure 7.2 shows them more precisely as individual units.

Although by studying individual elements their functionalities can be understood and their behaviours can be predicted, the functions and the behaviour of the whole system (cluster) is difficult, if not impossible, to understand and predict. One of the reasons is the interactions between the system elements and the self-organisation of the system. Another reason is the system's own characteristics, such as self-organisation, interdependence, self-direction, emergence and others. Sections 7.2.3 and 7.2.4 discuss those in further detail.

More precisely, the interactions between elements of a complex adaptive system are dynamic, recursive and non-linear, making the system's behaviour intractable and difficult to predict. For example, it might be easy to learn about rain, wind, temperature, snow, terrains and other individual elements of our weather ecosystem in isolation. Similarly, in Figure 7.2, we see individual elements with various colours representing their individual needs and nature. Similarly, elements representing resources, such as a computer, learning or financial resources, in isolation have their own distinct nature and functionality. Some units even have no specific characteristics (the user coloured grey). Once they interact with others, they form self-organised groups that are new structures with new behaviour or natures, shown in Figure 7.3. In that figure, participants with similar colours indicate a self-organised group of elements that have a similar interest. Their common interest indicates their local relationship with each other and their interdependence for achieving their common interest.

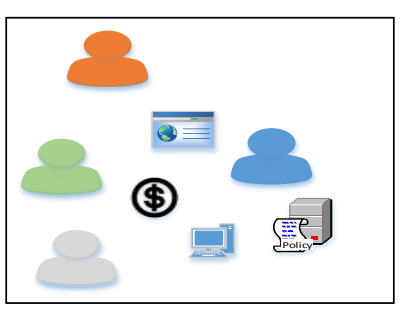

Figure 7.2 Separate parts

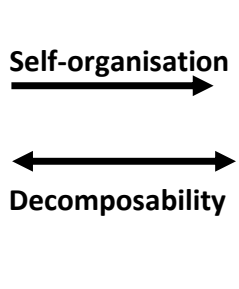

Figure 7.3 A VC class

A decomposition process occurs when there is no interaction among components. According to $\mathrm{Wu}$ et al. (2002), system decomposition is the process of separating system components according to their temporal and spatial scales. Based on that perspective, a VC class, a PD workshop or a member school gradually disappearing from a cluster happens because there has been no or insufficient interactions between its units. Therefore, the individual units of the cluster remained loose and eventually decoupled. For example, schools in C-Net ignored to support their participants by 
allocating the required resources and providing the support. As a result, their students and staff members lost interest in the cluster and thus their relationships become weak.

\subsubsection{Local rules and dynamics of relationships}

According to the Complexity Theory literature, the heart of the theory lies in the relationships between the system components (Manson, 2001). Moreover, the local or internal rules define the dynamics of interactions and relationships and thus feed into the emergence of new complex structures. Since interactions exist within and among sub-systems, local rules or principles define and set directions of those interactions. In other words, the internal rules provide the basis for the non-linear, recursive interactions between local elements, and offer foundations for the rise of new structures. Mitleton-Kelly (2003) agrees that local, ground or internal rules are the "principles of interaction between individual components" in a complex system (p. 6). The questions that need to be addressed here are what the local rules specifically mean and what they are in the cluster context. The answers are important not only for understanding the nature and directions of relationships but also for the emergence of the complex adaptive system.

For every system, their internal rules might be different, so they would be different for the Learning Exchange clusters. This research endorses that the identified factors or features summarised in the previous chapter are the local rules or principles of interactions between the elements of selfsustaining clusters. Those local rules feed various dimensions of cluster policies and strategies and thus set their future directions towards self-sustainable development. Therefore, those factors or features should be seen as the local principles of interactions within and among schools in a cluster. Figure 7.4 gives an exploded view of what dynamic interactions in Figure 7.1 would specifically mean for the self-sustaining clusters. (A similar visualising approach has been used by Chaffee and McNeill (2007) to visualise Nursing as Complex Adaptive System). 


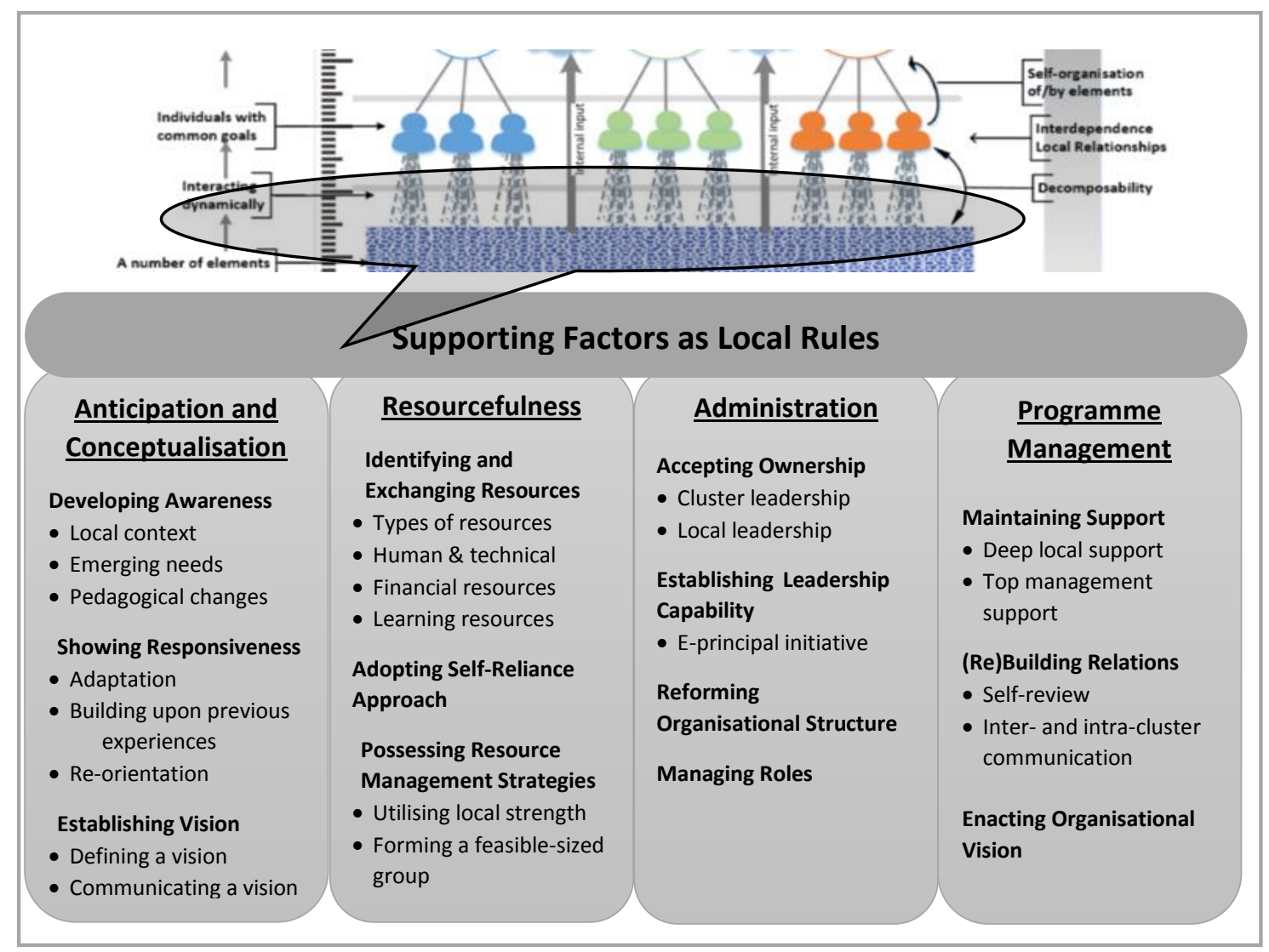

\section{Figure 7.4 Supporting Factors as Local Rules}

Mitleton-Kelly (2003) suggests the provision of "appropriate socio-cultural and technical conditions" to facilitate emergence (p. 21). The conditions are often represented by the organisational culture and procedures, informed by their local rules or principles. This research calls those conditions the procedures defined in the light of the identified factors in the previous chapter. Therefore, clusters with policies and organisational culture informed by the identified factors could emerge as adaptive structures. Otherwise, emergence could be "compromised, biased, fragile, sterile or maladaptive", which is the case for disappearing clusters (Mitleton-Kelly, 2003, p. 21).

The study found that those identified factors were the key characteristics of self-sustaining clusters, defining the dynamics of relationships between the cluster members and strategic directions of the cluster. Clusters containing most of the features were found to have developed themselves as more dynamic and networked systems of teaching and learning. In addition, those features also contain the principles that guided the interactions between the cluster elements and their external environment. During these interactions, self-sustaining clusters proved that they are "open systems" that can absorb external forces by adaptation. For example, during the interactions with their local community or the MOE, the self-sustaining clusters maintained their self-organisation and selfdirectedness, through their resourcefulness and self-reliance approaches. As a result, they maintain 
themselves as dissipative structures, by exchanging energy/information with the environment, when those external 'forces' could have easily diverted their directions from self-sustainable development. On the other hand, clusters stabilising at one position or clusters possessing a minimal level of the features were easily carried away by the external forces and eventually decomposed without maintaining their higher level formations. They made higher level formations such as VC classes and PD workshops; however, they were unable to adapt to the changes and make those structures selfsustaining. That was because the clusters lacked the supporting features in their policies. In other words, those formations were not able to absorb external elements or changes; nor could they readjust. For example, some clusters struggled to absorb MOE funding or struggled to adapt their educational practices according to changing pedagogies. In some, their local community groups from the external environment set their strategic directions. They lacked anticipation and they could not re-conceptualise according to changing needs. Therefore, they were instead absorbed by the external environment and thus could not self-sustain their structure.

Section 7.2.1 discussed the point of decomposability because of the lack of interactions between the local elements. The fewer the interactions between the elements, the greater are the chances of decomposability. From that perspective, the features in the fourth column of Figure 7.4 (programme management) were the identified factors supporting the relationships between cluster participants. For example, the deep local support and the extensive support from the top level school management team members were to back the building and re-building of links and relationships not only between individual students in VC classes and staff in the PD programmes but also between and within member schools. Similarly, the support for and the focus on the intra-cluster communication were done to enrich the interactions been various clusters for sustaining the structure of the whole Learning Exchange community as a complex adaptive system, a structure higher than the individual clusters.

Therefore, the study proposes that those identified features are the local rules, setting the dynamics of interactions and relationships between various units of self-sustaining clusters. Together with the characteristics of complex adaptive systems, those local rules set the required conditions for the emergence of self-sustaining clusters. That remains in line with Byrne (1998, p. 70), "Establishing local rules matters, but this is not a programme of always and everywhere". That means the identified factors are only to support the development process by providing the basis for interactions and emergence of a complex adaptive system. In addition, a complex adaptive system's own features can further add to the emergence of adaptive complex clusters. 


\subsubsection{The emergence of clusters}

Section 7.2.1 discussed the role of individual elements in the emergence of higher level structures through interactions and self-organisation. With regard to the Learning Exchange clusters, this study has suggested that member schools and cluster initiators from the micro-level work together to create structure; and with the support of the identified factors, the cluster can enrich the interactions between elements and thus survive and sustain its structure in the changing educational ecosystem.

The process of creating new higher level structures or orders is called Emergence (Mitleton-Kelly, 2003). As a result of the interaction, not only between the elements but also between the elements and external environment, new structures emerge that could not have been envisioned initially (L. Cohen et al., 2006). This section discusses the Emergence as a process and relates that to the emergence of self-sustainable clusters.

The process of Emergence can be explained from a system's point of view, in which a number of inputs are required, that interact and produce output. The right side of Figure 7.1 shows the emergence of clusters. In that figure, inputs are the individual elements or units of a system. The output is a complex adaptive structure. What goes between is the process of Emergence.

As the participants interact, they self-organise, connect and build relationships. For example, a number of science teachers in a school may form a group of science teachers. They become interdependent and generate higher levels of hierarchies, such as the group of science teachers selforganising and self-directing PD workshops with physics teachers from a few neighbouring schools and appropriating some ICTs for their virtual collaboration. For instance, in Figures 7.1 and 7.3, various resources or inputs have been organised and linked (represented by clouds in the diagram) by the participants to support the interactions and the self-organisation of the new structure. Similarly, the elements self-organise and form various VC classes for students. Those PD workshops and VC classes give rise to the emergence of a cluster.

The example, therefore, establishes that through connectedness, self-organisation and other characteristics, local elements form new, higher level networks that contain a greater level of complexity. The newly generated structures exhibit behaviour that is more complex and unpredictable than the behaviour of their units. Therefore, the behaviour of the whole system becomes greater than the sum of its parts. The stance opposes the traditional systems theory which has a reductionist approach. The reductionist approach in a systems context suggests distributing a system into parts and studying the parts in order to understand the system's functionalities. 
In addition, the process of emergence does not stop here. As the new structure is influenced by the local elements in the emergent process, in turn, the new structure also influences the behaviour of local elements through the feedback feature of the system. As a result, the whole system, including the elements, continuously adapts, re-shapes and thus co-evolves and never stabilises at one position. Indeed, the co-evolution and the rise of a complex adaptive system are not limited to interactions and feedback or influence between the system and its units. In fact, the rise of the complex behaviour of a system is due to the inter-connectivity and inter-relationships not only within a system but also between the system and its environment (Mitleton-Kelly, 2003). As a result, the system behaviour remains unpredictable and un-ordered, thus rapidly adapting and coevolving.

Based on the principles of emergence and interactions, Figure 7.5 illustrates the emergence of school clusters and the eventual rise of the Learning Exchange.

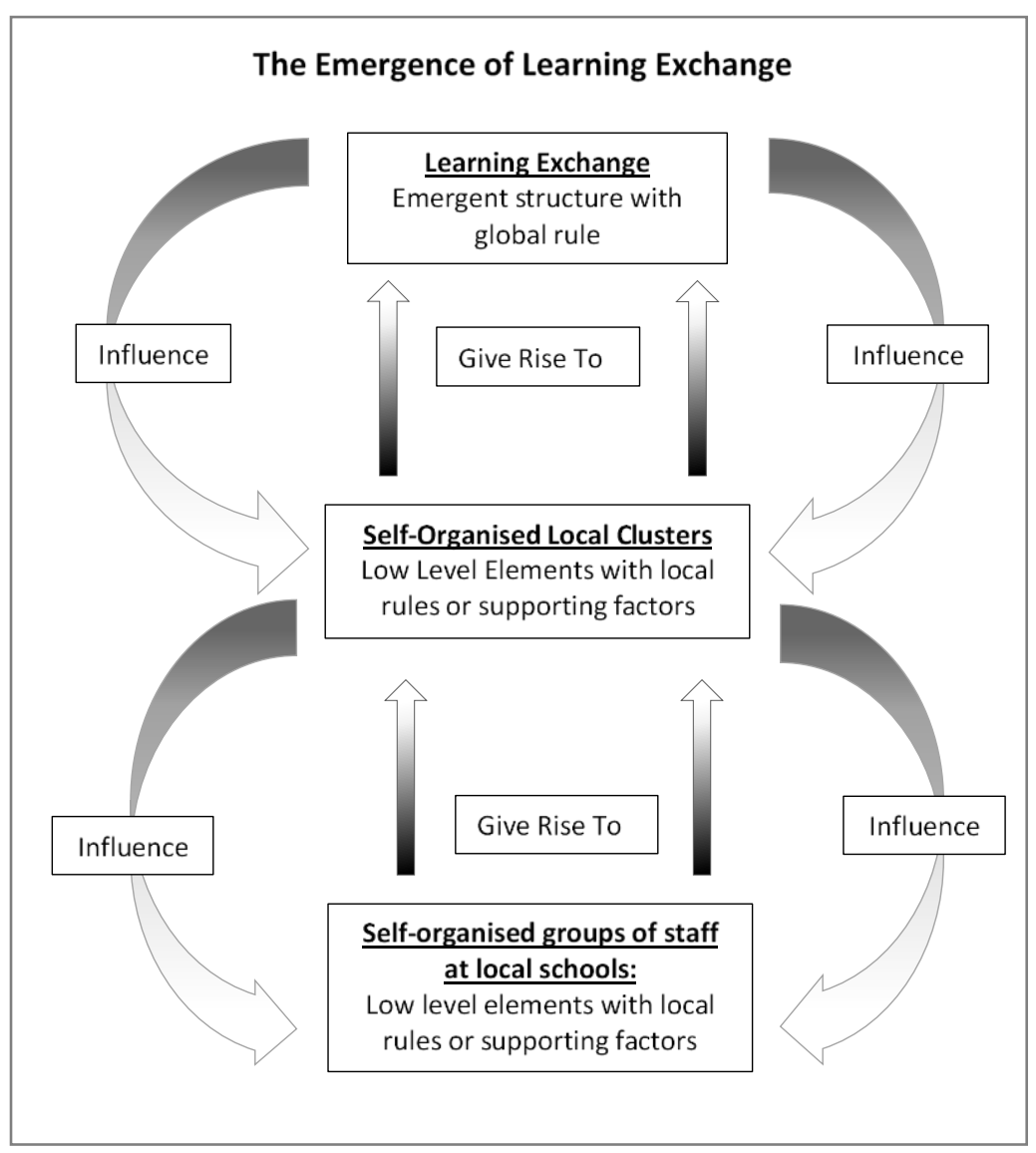

Figure 7.5 Emergence of clusters and the Learning Exchange

Since school clusters in the Learning Exchange consist of a number of inter-dependent participants, their teaching and learning perspectives and approaches co-evolve during their interactions and thus provide the condition for the emergence of new organisational forms. Based on that, the Learning 
Exchange can be regarded as an emergent structure which came into being due to interactions of participants from the local school level.

From the same perspective, the following Figure 7.6 shows an abstract level of the emergent process with respect to the emergence of self-sustaining clusters and the Learning Exchange community in the New Zealand school education ecosystem.

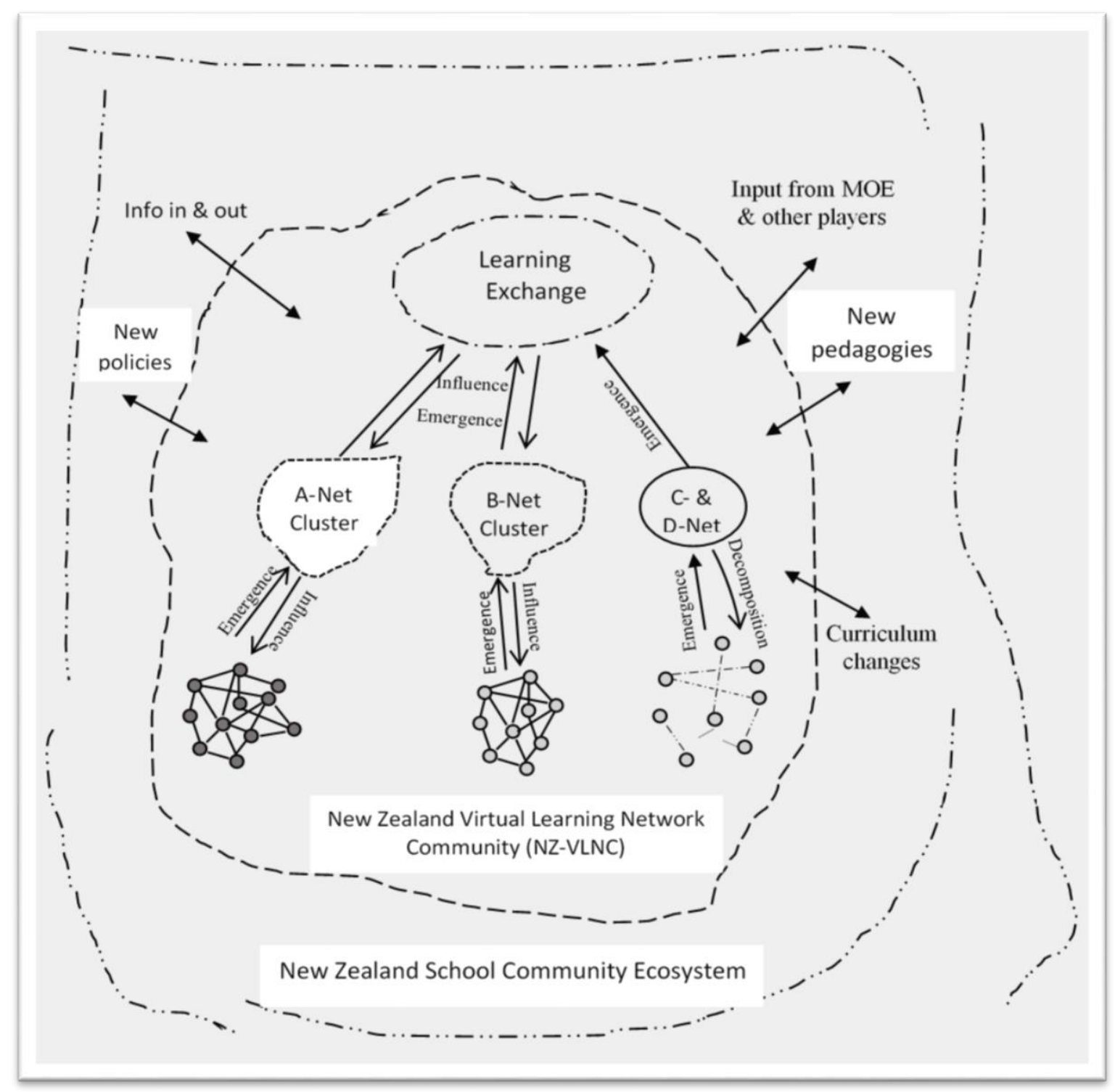

Figure 7.6 Co-evolution and the Emergence of self-sustainable clusters

In the illustration, a number of importation explanations are provided. First, the unit blocks of the ANet and B-Net clusters had strong interactions within their clusters, which are due to the local rules or appropriate 'socio-cultural and technical conditions'. Those enriched interactions lead to their self-organisation and emergence of their clusters with open boundaries or structure (illustrated by dotted boundaries). Due to the openness, they could adapt as well as influence others to adapt to 
their evolving ecosystem. As a result, a series of co-evolutions and co-creations took place.

Consequently, A-Net, B-Net and similar clusters successfully survived and sustained their development. In addition, the clusters played the role of system units and worked together for the emergence of a higher level structure, which is the Learning Exchange system of learning in the New Zealand Virtual Learning Network Community (NZ-VLNC).

With regard to the C-Net and D-Net school clusters in the above figure, the challenge started with the 'inappropriate local conditions' (the inhibiting factors). Eventually, their interactions remained weak within their units (illustrated as dots between the cluster elements) and between the system and the units (indicated by the absence of influence from the clusters on their units). Although new C-Net and D-Net structures did emerge, the structures had "closed boundaries" - unable to influence their units and/or be influenced by others in their ecosystem (represented by the solid circle). As a result, they continued their operations for some time as "ordered systems", having predictable and repetitive cycles of behaviour. Hence, they struggled to change, adapt and co-evolve accordingly, and eventually decomposed.

As discussed above, decomposability is the system's ability to be decoupled or dismantled into levels without a significant loss of information. Although the decomposability is an attribute of a complex adaptive system, a complete or radical decomposability can be disastrous for the system. That occurs when there is no interaction among the system components. From that perspective, C-Net, DNet and similar clusters can be described as having disintegrated because their local rules were weak, unable to establish interactions strong enough to interconnect cluster units. Therefore, the cluster units remained loose and decoupled, unable to self-organise and create a system that is open to learning. In contrast, the units of self-sustaining clusters exhibited rich and dynamic relations, allowing them to co-evolve their clusters as complex adaptive systems.

\subsubsection{Self-sustaining clusters as Complex Adaptive Systems}

In conjunction with the research findings, the sub-sections above have used a number of generic principles or characteristics of Complex Adaptive Systems. That was done with the intention to support the study's suggestion that the self-sustaining Learning Exchange clusters are complex adaptive systems. The sub-sections discussed the rise of self-sustaining clusters and the decomposition of disappearing clusters in light of complexity theory. Some of the complex adaptive systems principles used included: connectedness; non-linear, recursive, dynamic interactions and relationships; self-organisation; co-evolution and co-creation; open, dynamic, (un-) ordered systems; feedback or influence; organisational learning, emergence and so on. In addition, a number of figures were used from the complex adaptive systems' literature to further support the suggestion. 
From the lens of Complexity Theory, local staff members with their school leaders interacted and exchanged views and thus initiated a cluster of schools in a rural region of New Zealand. Later, various other regional school groups in their ecosystem (school community in NZ) were influenced by the new structure. As a result of the exchange of information, school leaders from other regions formed their own clusters, facilitating the co-creation of new regional clusters. Further, the mentoring and co-creation resulted in the form of intra-cluster exchange of learning resources and the co-creation and co-evolution of a higher-level structure - the Learning Exchange programme in New Zealand. The new structure boosted the desired outcome of having access to a wide range of curriculum choices at the local level and changed some of the macro-level associations. These developments can be viewed as the adaptation and co-evolution of an ecosystem - the Virtual Learning Network Community in New Zealand or VLNC-NZ.

Therefore, the self-sustaining Learning Exchange clusters can be viewed as complex adaptive systems, whose nature or behaviour cannot be predicted by the study of their units in isolation. In addition, their behaviour should remain unpredictable because of the clusters' continuous coevolution and adaptation. Moreover, because of dynamic interactions and influence, the cluster behaviour remains greater than the sum of its parts.

In addition, disappearing clusters did not exhibit the characteristics of complex adaptive systems. Instead, they were re-defined as closed, ordered systems. Therefore, they disappeared.

\subsection{Revisiting Literature}

Some of the key findings or approaches taken by this study aligned with previous studies. A number of significant studies such as Barbour et al. (2011), Davis et al. (2013), Powell (2011), Pullar and Brennan (2008), Stevens (2011), Wright (2010) and Zaka (2013) cover various aspects of the Learning Exchange. These studies provided a sound understanding and foundation for this study.

Two of the studies were very close to the findings of this study and those are discussed here. First, Davis et al. (2013) used some key concepts of complex adaptive systems to describe the changes in schools. They describe the relation between restructuring of school education and the evolution of both the education and the digital technologies applied within education. The authors use the ecological perspective as a rational approach to study the changes in schools and education. The authors' selection of an ecological perspective was based on the understanding that educational systems behave like complex adaptive systems, self-organising and evolving rapidly. On the other hand, digital technologies in education are described as continuously evolving. Therefore, based on the ecological perspective, both the digital technologies used within schools and the school education influence each other and hence co-evolve. 
Davis et al. (2013) also emphasised the role of visionary school leaders who can use their role or power to promote innovative uses of ICTs in their schools and subsequently facilitate the restructuring of schools and the education system. The authors also indicated that educational leaders have been slow to recognise the impact of ICTs in the restructuring of school education. These findings were also identified in this study.

However, Davis et al. (2013) put the e-teacher at centre stage because "in the ecosystems that we call education, the teacher has the most influence on the arrangements and behaviour of a class". Therefore the teacher was considered as the keystone that can stabilise or destabilise the ecosystem or classroom. That remained different from the concept of Networked School and centrality of estudents in the Learning Exchange.

Another study that is worth acknowledging at this point is Barbour, Davis and Wenmoth (2011) that identified three key issues inhibiting the maturity of the Learning Exchange. The issues included the lack of collaboration and cooperation within and between clusters, the lack of a coherent vision and difficulty in securing the necessary funding and, resources. The first two barriers can be interpreted through the concept of 'influence' the Learning Exchange can have on a cluster. The foundational of the Learning Exchange is based on the notion of collaboration. If there is a lack of collaboration and cooperation between clusters, then the clusters are either not being influenced by or receiving inaccurate influence from the Learning Exchange (see figure 7.6). Because of that inconsistency, their vision about the Learning Exchange and online teaching and learning is incoherent.

The third issue, difficulty in securing the necessary funding and resources, identified by Barbour, Davis and Wenmoth (2011), was disputed in the literature review section 2.5. The section described that within the existing context of the Learning Exchange, self-funding is a key to the cluster maturity. The research findings very clearly supported the research positioning. For example, identifying and exchanges resources, adopting a self-reliance approach and possessing resource management strategies were a few of the significant factors identified in this study, which had a major role in the cluster maturity and development.

\subsection{Chapter Summary}

In order to avoid or limit the challenge of unsustainable development, the school clusters participating in the Learning Exchange were recommended to embrace the identified features that were compiled in the previous chapter. Some of the clusters had policies and strategies containing most of the features, and thereby had become self-sustainable. On the other hand, clusters excluding or overlooking some of those features were not only faced with the challenge of becoming 
self-sustainable, but also struggled to achieve their local needs and objectives. This meant that their policies were weak and their strategies were unable to address their local needs. This study explored those vital characteristics and recommended clusters adopt them to become self-sustainable.

In order to assess the literature for recommendations or claims and establish further credibility of the research findings, this chapter utilised a number of key principles from Complexity Theory. Based on that, the study confirmed that the supporting factors identified in Chapter 5 are the key supporting factors, playing a founding role in the formation of A-Net and B-Net policies and strategies. Those supporting factors were the key features, setting the dynamics of enriched interactions between the A-Net and B-Net participants. Eventually, those features along with the generic features of complex adaptive systems had given rise to the emergence of adaptive, selforganised, self-directed, and self-sustaining school clusters. In addition, those features had shaped A-Net and B-Net as organisations that could both influence and be influenced by other systems in their ecosystem, and thus co-evolve.

On the other hand, C-Net and D-Net had disappeared because their policies and strategies largely failed to adopt the identified supporting factors or the local principles. As a result, both the clusters did not exhibit the behaviour or characteristics of a complex adaptive system. They lacked the sociocultural and technological conditions required for strong interactions and emergence as complex adaptive systems. Because of the challenges, the C-Net and D-Net formations faced radical decomposition, unable to co-evolve in the Learning Exchange ecosystem. Therefore, their structures disappeared.

\subsection{Research Contributions and Implications}

\subsubsection{Implications for the Learning Exchange}

Due to the contextual focus of the research, the knowledge gained from the research provides insights for the Learning Exchange community and could make a positive impact on overall community development. The use of two theoretical lenses allowed the research findings to be further refined to gain more impact. For example, the refined findings followed by the discussions can facilitate the community leaders to think and view their community from a different angle. Specifically, the findings from four clusters potentially provide a great deal of self-reflection and change to strategic thinking and policies, both for cluster and school leaders in the wider Learning Exchange community. Therefore, the identified features are not only beneficial for developing a shared understanding of individual cluster viability but also for revising their Learning Communities Online (LCO) handbook, guide or framework for existing and prospective clusters. 
At the individual cluster level, since the existing clusters have outlasted many others, the research objective was to identify the factors that can further support their continuation. Therefore, the research aimed to focus on the development of self-sustaining Learning Exchange clusters. As a result, the research outcome can provide cluster leaders with new as well as different dimensions, including from the very formation of their cluster philosophy through to the resourcing strategies and the management of the cluster. Therefore, the research outcome has implications for cluster leaders for their cluster growth as well as self-review and self-reflection.

In general, since the cluster is an organisation that is different from schools, the community leaders and potential players are urged to make decisions on a different basis. In particular, the virtual nature of the cluster makes it different but at the same time complementary to the day-to-day school education. The decision to integrate cluster style of education into the main school systems would allow all the students and teachers to experience one of the new modes of learning.

\subsubsection{Contribution to research}

Although the exchange model and the clustering of rural schools are interesting concepts, the model was unaddressed, both in New Zealand as well as abroad. In particular, the sharing and virtual reciprocal attributes studied in this research remain very relevant and interesting not only to the education field but also to the rising research trends of the 'Sharing Economy' and ICT4D.

The study highlights the potential of the Learning Exchange for changing the concepts of face-to-face and distance education. That is due to the fact that the programme is rich and providing a different unique and effective model. In particular, due to the changing nature of classroom education and school learning, the research focus remains relevant and contributes to the body of educational research.

The Shared Economy is often discussed with respect to meeting growing population demand in large cities and presented as a new business model. The collaborative consumption services (CCS) and Sharing Economy are often linked to the scarcity of resources due to the population density in large cities. Therefore, the perception of co-owning and sharing products or services, such as car-sharing, bike-sharing, accommodation-sharing and others has gained wide acceptance and popularity in the context of cities (Cohen \& Kietzmann, 2014).

Due to the strong presence of the notion of sharing staff skills and educational resources in the Learning Exchange, the study remained very relevant to the Shared Economy research trend. In the Learning Exchange, school clusters share their existing educational resources such as staff members' time and expertise, learning materials, facilities and students to enhance their impact. In other 
words, due to their collaborative and sharing strategy the school clusters co-created and co-evolved the Learning Exchange, and now they co-own the exchange programme.

Apart from the strong connection between the Learning Exchange and Shared, this study contends that the concepts of CSS and Sharing Economy are similarly relevant to the rural population or to the thinly populated areas. This study demonstrated that scarcity of resources also exists in remote areas. In urban areas the scarceness of resources is due to a high population whereas in rural areas that is due to remoteness and inaccessibility. Therefore, studies linking the notion of Shared Economy only to the high population and urban areas remain incomplete. That is evident from a recent trend showing Sharing Economy moving into rural areas and supporting rural revitalisation (Airbnb Citizen, 2017). However, research is lagging in this emerging area and more studies are needed to fill the gap.

Nonetheless, because of the scope of this study, the connection between the Learning Exchange and Sharing Economy was not specifically discussed in the thesis. However, the study considers that the scene is set as the case of the Learning Exchange is available for further investigation by Sharing Economy scholars. Therefore, the study contributes to the body of research.

Although the findings are highly contextual and relevant to New Zealand, the use of the Complexity Theory facilitated generalisation and applicability of the findings. The challenge of self-sustainability faced by the community-led, grass-roots level initiatives using various ICT settings is not specific to the New Zealand context only. The aspects highlight the impact of as well as the interplay between the Information Systems discipline, effective uses of ICTs and the wider society.

In particular, due to the developmental approach of the Learning Exchange, the programme remains highly practical for the ICT4D programmes worldwide. The Learning Exchange has remained exclusively beneficial for the development of the school community, particularly for schools in remote areas of New Zealand. The programme has a high level of participation from the beneficiaries and supplemented the existing social network of communities. These attributes clearly identify the Learning Exchange as one of the ICT4D programmes with the most impact.

In particular, one of the motivational factors of this study was the potential for application of some of the Learning Exchange attributes to a school setting in a developing country (e.g. Pakistan). The reciprocal exchange of resources, clustering strategy, the use of VC technology and other attributes of the Learning Exchange were identified as very applicable and feasible to be implemented with the assistance of the ICT4D project for schools. Therefore, the applicability of the phenomenon to other social developmental ventures with ICT and educational dimensions remains one of the key contributions of this study. 


\subsubsection{Contribution to theory}

As suggested by Whetten (1989), theoretical contributions of a research study depend on the study's demonstration of significant alterations to our existing understanding of a phenomenon. This research has contributed to both ANT and complexity theory in various ways. The first and basic theoretical contribution of this study is extending the use of ANT for making the Learning Exchange accessible to scientific investigation. Specifically, ANT as an analytical and a descriptive lens assisted the study in explaining what different components make a cluster and describing how those various components form and manage their network. By theorising the school clusters, the ANT ontology assisted the research to develop further insights and improved our existing understanding of the Learning Exchange clusters. In other words, our understanding of what the Learning Exchange is and how that has been developed has differed. Therefore, extended use of ANT for representing clusters as an abstract, theorised phenomenon was the first and the basic theoretical contribution of this research.

The second theoretical contribution is the act of combining both the theories for enhancing the research generalizability aspect. In other words, both the theories have their limitations. By combining both, the research not only addresses their limitations but also enhances the findings' generalizability. For example, ANT is regarded as a theory with a primary focus on micro-level sociotechnical entities and their relationships. On the other hand, Complexity Theory is regarded as limited in that the theory ignores the micro-level entities. This means that Complexity Theory is useful in explaining the dynamics of the interactions between the system entities and the emergence of higher level adaptive structures. By combining both the theories, a holistic view of the cluster phenomenon is established as a 'complex socio-technical system' of education. As a result, an in-depth level of analysis and conceptualisation is achieved and thus the limitations of both the theories are addressed.

Finally, ANT is more concerned with what and how and remains limited in predicting the future of any phenomenon. Complexity Theory was used to facilitate the outcome of ANT-based findings to address the shortcoming by predicting how a Learning Exchange cluster can become self-sustaining.

\subsection{Limitations and Avenues for Future Research}

One of the research limitations is the study's time constraint due to which other clusters could not be included. In particular, more data about other disappearing clusters and existing clusters could further the insights from the research. Specifically, some city-based clusters with larger schools also exist in the Learning Exchange. Their reasons for participating and how they have developed their clusters would have been interesting to explore. 
As in any other ANT guided study, one of the significant challenges was 'the difficulty of being an ANT' study and getting 'lost in Translation'. Similarly, the argument of what ANT is and what ANT is not was a great challenge. In particular, when most of leading ANT scholars argue and agree that ANT is not a method, nor is it a theory or a framework, the study becomes a challenge. It becomes even more frustrating when ANT specialists, such as Bruno Latour, use a very abstract and a mix of sociological and philosophical language while recommending (others) use simple terms and language. In addition, the challenge became even bigger when the study used ANT in a limited way by adopting the theory as a lens only. The approach required careful attention throughout the study. A number of avenues for future research arose from this study. One of the key areas would be the question of how well e-students with the experience of cluster-based learning perform in their tertiary education. Since the type of learning in the VC-based cluster classes is different, students gain a different set of soft skills while participating in online distance learning and taking the responsibility of their learning. How well those students are equipped and whether they perform better than other students without the experience of such a learning process would be interesting to discover.

Another important area for future research would be the study of the merger of a number of clusters into NetNZ. Since the examination of the merger was beyond the scope of this research, it remained unknown whether the approach was a successful response. Why some of the clusters in the South Island of New Zealand have merged with other clusters would be an interesting area that needs exploring.

\subsection{Research Conclusion}

This study started with the aim to explore the development of the Learning Exchange programme and school clusters in New Zealand. Based on the research gap, the study proceeded with three research questions: how was the Learning Exchange developed and utilised in school clusters? And, what were the factors that supported the development of self-sustaining clusters? The research addressed those questions by adopting a qualitative research methodology and selecting four Learning Exchange clusters as cases for the data collection. Actor-Network Theory (ANT) was used as a theoretical lens, primarily to provide a theoretical basis for describing the findings of the four cases. In particular, the process of Translation from ANT was used to assist the reporting of the four case findings. Based on the data collection sequence, the cases were named A-Net, B-Net, C-Net and D-Net. With the support of the theoretical lens, the research identified how the four school clusters and the Learning Exchange developed, thereby answering the first two research questions. 
At the end of the Findings Chapter, a list of inhibiting and supporting factors was compiled from the four cases' findings. Those factors were used to examine and analyse the development of the four cases in the Cross-Case Analysis Chapter. The intention was to provide a cross-sectional view for developing a self-sustaining Learning Exchange cluster. The factors were interpreted and compared between cases to identify commonalities and differences between the four cases. The crosssectional analysis assisted the study to identify the features needed for cluster self-sustainability. By doing so, the research not only addressed the third research question but also took the findings to a higher abstraction and provided a holistic view of a self-sustaining cluster.

The distilled outcome of the analysis chapter was a list of common features that were claimed to support the clusters to become self-sustaining. Those features were referred to as local features, rules, principles or conditions required for clusters' self-sustainability. The outcome was therefore recommended to all the school clusters for adoption, including A-Net, B-Net and similar clusters. That was because not all of those features existed in each of the Learning Exchange clusters. Some possessed more or less than the others. Therefore, the recommendations were seen as providing potential improvement for each of the existing clusters through adoption and adaptation. In addition, by adopting those features and incorporating them into their policies and strategies, they could deal with any significant future challenges jeopardising their self-sustaining development.

Complexity Theory was used in the Discussion Chapter for a number of reasons: complementing the ANT-based research findings; establishing credibility for the analysis outcome and the subsequent research claim; and, taking the research to an abstract level for generalisation. The chapter discussed the research outcome or claim in four key aspects. The chapter viewed and discussed the role of cluster participants as the units or sub-systems in the clusters, providing the basis for the emergence of clusters as adaptive structures. Secondly, it was confirmed that the compiled list of common features from the previous chapter were the key local principles, strengthening interactions and relationships between the cluster participants and between the systems, and thus providing the required conditions for the emergence of self-sustaining clusters. Thirdly, the supporting factors along with the generic principles of complexity theory were discussed as the basis for the emergence of self-sustaining clusters. Lastly, A-Net and B-Net were reviewed and redefined as Complex Adaptive Systems, structures that influence and are influenced in their ecosystem and thus co-evolve. In contrast, C-Net and D-Net had set policies and strategies that did not support them to be adaptive, open, unordered and learning organisations in their Learning Exchange ecosystem. Therefore, they could not evolve, let alone co-evolve in the Learning Exchange system. Thus, both the clusters faced the challenge of radical decomposition and eventually disappeared. 


\section{REFERENCES}

Al-busaidi, K. A. (2012). Learners' Perspective on Critical Factors to LMS Success in Blended Learning: An Empirical Investigation. Communications of the Association for Information Systems, 30(January 2012), 11-34.

Alcadipani, R., \& Hassard, J. (2010). Actor-Network Theory, organizations and critique: towards a politics of organizing. Organization, 17(4), 419-435. https://doi.org/10.1177/1350508410364441

Alexander-Bennett, C. (2016). Keynote: FarNet Ten Years on--The Past, Present, and Future for Distance Learners. Journal of Open, Flexible and Distance Learning, 20(2), 24-31. Retrieved from http://search.ebscohost.com/login.aspx?direct=true\%7B\&\%7Ddb=a9h\%7B\&\%7DAN=11981427 0\%7B\&\%7Dsite=ehost-live

Airbnb Citizen. (2017. How Airbnb Supports Rural Revitalization. Retrieved July 21, 2017 from, https://medium.com/future-of-sharing/how-airbnb-supports-rural-revitalization-c766c90d80d

Amsterdamska, O. (1990). Surely you are joking, Monsieur Latour! Science, Technology, \&Human Values, 15(4), 495-504. Retrieved from http://www.jstor.org/stable/10.2307/689826

Anastasiades, P. S., Vitalaki, E., \& Gertzakis, N. (2008). Collaborative learning activities at a distance via interactive videoconferencing in elementary schools: Parents' attitudes. Computers \& Education, 50(4), 1527-1539. https://doi.org/10.1016/j.compedu.2007.02.003

Anderson, B., \& Simpson, M. (2012). History and heritage in distance education. Journal of Open, Flexible and Distance Learning, 16(2), 1-10.

Anderson, P. (1999). Perspective : Complexity Theory and Organization Science Complexity Theory and Organization Science. Organization Science, 10(3), 216-232.

Anderson, T. (2009). Rose by Any Other Name: Still Distance Education-A Response to DR Garrison Implications of Online and Blended Learning for the Conceptual Development. Journal of Distance Education, 23(3), 111-116. Retrieved from http://www.jofde.ca/index.php/jde/article/viewArticle/653/981

Anderson, T., \& Dron, J. (2011). Three generations of distance education pedagogy. Internation Review of Research in Open and Distance Learning, 12(3), 1-18. Retrieved from http://www.irrodl.org/index.php/irrodl/article/view/890

Andrade, A. D., \& Urquhart, C. (2010). The affordances of actor network theory in ICT for development research. Information Technology \& People, 23(4), 352-374. https://doi.org/10.1108/09593841011087806

Annand, D. (1999). The Problem of Computer Conferencing for Distance-based Universities. Open Learning: The Journal of Open and Distance E-Learning, (September 2013), 37-41. Retrieved from http://www.tandfonline.com/doi/pdf/10.1080/0268051990140307

Annua, A., Watson, J., Gemin, B., Ryan, J., Wicks, M., Bullock, S., ... Young, J. (2009). John Watson, Butch Gemin, Jennifer Ryan and Matthew Wicks Evergreen Education Group. Learning.

Bahlmann, M. D., \& Huysman, M. H. (2008). The Emergence of a Knowledge-Based View of Clusters and Its Implications for Cluster Governance. The Information Society, 24(July 2014), 304-318. https://doi.org/10.1080/01972240802356075

Barbour, M., Brown, R., Waters, L., \& Hoey, R. (2011). Online and Blended Learning: A Survey of Policy and Practice from K-12 Schools around the World. ... for K-12 Online Learning. Vienna. 
Retrieved from http://www.eric.ed.gov/ERICWebPortal/recordDetail?accno=ED537334

Barbour, M., Davis, N., \& Wenmoth, D. (2011). Primary and secondary e-learning: Examining the process of achieving maturity. Unpublished report for the Ministry of Education New Zealand. Christchurch, New Zealand. Retrieved from http://www.vln.school.nz/file/download/114023

Barbour, M. K., \& Reeves, T. C. (2009). The reality of virtual schools: A review of the literature. Computers \& Education, 52(2), 402-416. https://doi.org/10.1016/j.compedu.2008.09.009

Barbour, M., \& Wenmoth, D. (2013). Virtual Learning as an Impetus for Educational Change: Charting a Way Forward for Learning in New Zealand. Christchurch, New Zealand. Retrieved from http://www.core-ed.org/thought-leadership/research/virtual-learning-impetuseducational-change-charting-way-forward

Bathelt, H., Malmberg, A., \& Maskell, P. (2004). Clusters and knowledge: local buzz, global pipelines and the process of knowledge creation. Progress in Human Geography, 28(1), 31-56. https://doi.org/10.1191/0309132504ph469oa

Bewley, D. (1996). Distance education in New Zealand: An historical sketch. Journal of Distance Learning, 2(1), 14-25. Retrieved from http://journals.akoaotearoa.ac.nz/index.php/JOFDL/article/view/169

Billowes, N., \& Alexander, R. (2013). ICT Professional Development (ICTPD) Programme - Bridging the Gap. In V. Ham \& D. Wenmoth (Eds.), eLearnings: Implementing a national strategy for ICT in education, 1998 - 2010 (pp. 48-57). Christchurch, New Zealand: Core Education.

Bolstad, R., \& Lin, M. (2009). Students' experiences of learning in virtual classrooms. Wellington, New Zealand: NZCER. Wellington, NZ. Retrieved from http://www.nzcer.org.nz/system/files/students-experiences-learning-virtual-classrooms.pdf

Bonner, W., \& Chiasson, M. (2005). If fair information principles are the answer, what was the question? An actor-network theory investigation of the modern constitution of privacy. Information and Organization, 15(4), 267-293. https://doi.org/10.1016/j.infoandorg.2005.03.001

Branon, R. F., \& Essex, C. (2001). Synchronous and Asynchronous Communication Tools in Distance Education: A Survey of Instructors. Trends Tech, 45(1), 36-37.

Browning, R. (2005). V.E.N. Report on eLearning communities. Dunedin, NZ. Retrieved from https://sites.google.com/a/virtualeducation.net.nz/ven/home/video-conferencing

Burke, J. C., \& Shaw, M. (2007). The implication of complexity theory on real option analysis in IT portfolio management. Association for Information Systems - 13th Americas Conference on Information Systems, AMCIS 2007: Reaching New Heights, 7, 4794-4797. Retrieved from http://www.scopus.com/inward/record.url?eid=2-s2.0-84870184627\&partnerlD=tZOtx3y1

Burton, J. (2013). Toward a Theoretically Consistent Explanation of IT Alignment. Thirty Fourth International Conference on Information Systems, Milan 2013, 1-10.

Byrne, D. S. (1998). Complexity Theory and the Social Sciences. London: Routledge.

Calas, M., \& Smircich, L. (1999). Past postmodernism? Reflections and tentative directions. Academy of Management Review, 24(4), 649-671. Retrieved from http://amr.aom.org/content/24/4/649.short

Callon, M. (1986). Some Elements of a Sociology of Translation: Domestication of the Scallops and the Fishermen of St-Brieuc Bay. In J. Law (Ed.), Power, Action and Belief: a New Sociology of knowledge (pp. 196-223). London: Routledge. Retrieved from https://bscw.uniwuppertal.de/pub/nj_bscw.cgi/d8022008/Callon_SociologyTranslation.pdf 
Callon, M. (1991). Techno-economic networks and irreversibility. In J. Law (Ed.), A sociology of monsters: Essays on power, technology ... (pp. 132-161). London: Routledge. Retrieved from http://www.unc.edu/ jbecks/comps/pdf/callon.pdf

Campbell, N. (2004). The vintage years of elearning in New Zealand schools. Journal of Distance Education, 8(1), 17-24. Retrieved from http://journals.akoaotearoa.ac.nz/index.php/JOFDL/article/view/130

Carroll, J. M., \& Swatman, P. A. (2000). Structured-case: a methodological framework for building theory in information systems research. European Journal of Information Systems, 9(4), 235242. https://doi.org/10.1057/palgrave/ejis/3000374

Carroll, N., Richardson, I., \& Whelan, E. (2012). Service Science: An Actor-Network Theory Approach. International Journal of Actor-Network Theory and Technological Innovation, 4(3), 51-69. https://doi.org/10.4018/jantti.2012070105

Carswell, A., \& Venkatesh, V. (2002). Learner outcomes in an asynchronous distance education environment. International Journal of Human-Computer Studies, 1997(56), 475-494. https://doi.org/10.1006/ijhc.1004

Celikkan, U., Senuzun, F., Sari, D., \& Sahin, Y. (2013). Interactive Videoconference Supported Teaching in Undergraduate Nursing: A Case Study for ECG. Education Technology \& Society, 16(1), 286-294. Retrieved from http://www.ifets.info/journals/16_1/25.pdf

Chaffee, M. W., \& McNeill, M. M. (2007). A model of nursing as a complex adaptive system. Nursing Outlook, 55(5). https://doi.org/10.1016/j.outlook.2007.04.003

Cham, K., \& Johnson, J. H. (2007). Complexity Theory: A Science of Cultural Systems? M/C Journal, 10(3). Retrieved from http://journal.media-culture.org.au/0706/08-cham-johnson.php

Chen, Y., \& Willits, F. K. (1999). Dimensions of educational transactions in a videoconferencing learning environment. American Journal of Distance Education, 13(1), 45-59. https://doi.org/10.1080/08923649909527013

Clark, T. (2001). Virtual Schools. Trends and Issues - A Study of Virtual Schools in the United States. San Francisco, CA: Retrieved from http://www.wested.org/online_pubs/virtualschools.pdf

Clemons, M. (2006). Characteristics of complex systems. Retrieved April 14, 2017, from http://www.necsi.edu/visual/systems.html

Codd, J. (2005). Teachers as "managed professionals" in the global education industry: the New Zealand experience. Educational Review, 57(2), 193-206. https://doi.org/10.1080/0013191042000308369

Cohen, B., \& Kietzmann, J. (2014). Ride On! Mobility Business Models for the Sharing Economy. Organization \& Environment, 27(3), 279-296. https://doi.org/10.1177/1086026614546199

Cohen, L., Manion, L., \& Morrison, K. (2006). Chapter One: Additional Resources - What is complexity theory? In Research Methods in Education (6th ed., pp. 1-7). Londong and New York: Taylor \& Francis. Retrieved from http://cw.routledge.com/textbooks/9780415368780/A/ch1doc.asp

Compton, L. K. L., Davis, N., \& Mackey, J. (2009). Field Experience in Virtual Schools - To Be There Virtually. Journal of Technology and Teacher Education, 17(4), 459-477.

Condie, R., \& Munro, B. (2007). The impact of ICT in schools - a landscape review. Becta, (January), 92. Retrieved from http://strathprints.strath.ac.uk/8685/

Cordella, A., \& Shaikh, M. (2003). Actor Network Theory and After: What's New for IS Resarch? ECIS 2003 Proceedings, 40, 1-12. Retrieved from http://60.88.dyn.Ise.ac.uk/asp/aspecis/20030037.pdf 
Cressman, D. (2009). A Brief Overview of Actor-Network Theory: Punctualization, Heterogeneous Engineering \& Translation. Paper for Simon Frasier University ACT Lab/Centre for Policy Research on Science \& Technology (CPROST), 1-17. Retrieved from http://blogs.sfu.ca/departments/cprost/wp-content/uploads/2012/08/0901.pdf

Cresswell, K. M., Worth, A., \& Sheikh, A. (2010). Actor-Network Theory and its role in understanding the implementation of information technology developments in healthcare. BMC Medical Informatics and Decision Making, 10(1), 67. https://doi.org/10.1186/1472-6947-10-67

Creswell, J. (2013). Qualitataive Inquiry and Research Design: choosing Among Five Appraoches (3rd ed.). SAGE publications, Inc.

Creswell, J., \& Miller, D. (2000). Determining validity in qualitative inquiry. Theory into Practice, 39(3), 124-130. https://doi.org/10.1207/s15430421tip3903

Creswell, J. W. (2012). Educational research: Planning, conducting, and evaluating quantitative and qualitative research. Educational Research (4th ed., Vol. 4). Pearson Education. https://doi.org/10.1017/CBO9781107415324.004

Crocombe, G., Enright, M., \& Porter, M. (1991). Upgrading New Zealand's competitive advantage. Auckland: Oxford University Press.

Davis, F. (1989). Perceived usefulness, perceived ease of use, and user acceptance of information technology. MIS Quarterly, 13(3), 319-340. Retrieved from http://www.jstor.org/stable/10.2307/249008

Davis, N., Eickelmann, B., \& Zaka, P. (2013). Restructuring of educational systems in the digital age from a co-evolutionary perspective. Journal of Computer Assisted Learning, 29(5), 438-450. https://doi.org/10.1111/jcal.12032

Davis, N., Roblyer, M. D. (Peggy), Charania, A., Ferdig, R., Harms, C., Compton, L. K. L., \& Cho, M. O. (2007). Illustrating the "virtual" in virtual schooling: Challenges and strategies for creating real tools to prepare virtual teachers. The Internet and Higher Education, 10(1), 27-39. https://doi.org/10.1016/j.iheduc.2006.11.001

Day, P. (2010). A brief introduction to the history of community informatics. Al \& Society, 25(3), 259263. https://doi.org/10.1007/s00146-010-0286-2

Dennis, A. R., Fuller, R. M., \& Valacich, J. S. (2008). Media, Tasks, And Communication Processes : A Theory Of Media Synchronicity. MIS Quarterly, 32(3), 575-600.

DeSanctis, G., \& Poole, M. (1994). Capturing the complexity in advanced technology use: Adaptive structuration theory. Organization Science, 5(2), 121-147. Retrieved from http://www.jstor.org/stable/2635011

Dillenbourg, P. (1999). What do you mean by "collaborative learning"? Collaborative Learning Cognitive and Computational Approaches, 1(6), 1-15. https://doi.org/10.1.1.167.4896

Douglas, D. (2007). Focus: Report To Coronet Principals And The Ministry Of Education On Selected Aspects Of Information Computer Technology In Coronet Schools. Te Aroha.

Elbanna, A. (2009). Actor network theory and IS research. Handbook of Research on Contemporary Theoretical Models in Information Systems, 403-419. https://doi.org/10.4018/978-1-60566659-4.ch023

Fenwick, T., \& Edwards, R. (2010). Actor-network theory in education. Routledge.

Fenwick, T. (2010). Re-thinking the "thing." Journal of Workplace Learning, 22(1/2), 104-116. https://doi.org/10.1108/13665621011012898

Field, H. (1982). Realism and relativism. The Journal of Philosophy, 79(10), 553-567. 
https://doi.org/10.1111/1468-0068.36.s1-1.1

Fitzgerald, B., \& Howcroft, D. (1998). Towards Dissolution of the IS Research Debate: From Polarisation to Polarity. Journal of Information Technology, 13(4), 313-326.

Garrison, D. (1997). Computer conferencing: the post-industrial age of distance education. Open Learning: The Journal of Open, Distance and E-Learning, 12(2), 3-11. Retrieved from http://www.tandfonline.com/doi/pdf/10.1080/0268051970120202

Garrison, D. R. (1985). Three generations of technological innovations in distance education. Distance Education, 6(2), 235-241. https://doi.org/10.1080/0158791850060208

Gibbert, M., \& Ruigrok, W. (2010). The What" and How" of Case Study Rigor: Three Strategies Based on Published Work. Organizational Research Methods, 13(4), 710-737. https://doi.org/10.1177/1094428109351319

González, G. R. (2012). A human resources project implementation An actor-network theory perspective. Contaduría Y Administración, 57(3), 9-39. Retrieved from http://132.247.146.34/index.php/rca/article/view/32179

Goodhue, D., \& Thompson, R. (1995). Task-technology fit and individual performance. MIS Quarterly, 19(2), 213-236. Retrieved from http://www.jstor.org/stable/10.2307/249689

Guba, E. (1981). Criteria for assessing the trustworthiness of naturalistic inquiries. ECTJ, 29(2), 7591. Retrieved from http://link.springer.com/article/10.1007/BF02766777

Guba, E. G., \& Lincoln, Y. S. (1994). Competing Paradigms in Qualitative Research. Handbook of Qualitative Research, 105-117. https://doi.org/http://www.uncg.edu/hdf/facultystaff/Tudge/Guba\%20\&\%20Lincoln\%201994. pdf

Guba, E., \& Lincoln, Y. (1994). Competing paradigms in qualitative research. In N. K. Denzin \& Y. S. Lincoln (Eds.), Handbook of qualitative research (pp. 105-117). CA: Sage Publications, Thousand Oaks. Retrieved from https://noppa.aalto.fi/noppa/kurssi/23e88001/luennot/23E88001_competing_paradigms_in_q ualitative_research.pdf

Guri-Rosenblit, S. (2009). Distance education in the digital age: Common misconceptions and challenging tasks. Journal of Distance Education, 23(2), 105-122. Retrieved from http://www.jofde.ca/index.php/jde/article/viewArticle/627

Ham, V. (2008). National Trends in the ICT PD School Cluster Programme. Wellington, NZ.

Hanseth, O., Aanestad, M., \& Berg, M. (2004). Guest editors' introduction:Actor-network theory and information systems. What's so special? Information Technology \& People, 17(2), 116-123. https://doi.org/10.1108/09593840410542466

Hanseth, O., Jacucci, E., Grisot, M., \& Aanestad, M. (2006). Reflexive Standardization: Side Effects and Complexity in Standard Making. MIS Quarterly, 30(Special Issue), 563-581.

Hasan, H. (2014). Complexity theory. In H. Hasan (Ed.), Being Practical with Theory: A Window into Business Research (pp. 49-54). Wollongong, Australia: THEORI. Retrieved from http://ro.uow.edu.au/buspapers/410/

Hassan, N. R. (2014). Systemic Complexity and Sociomateriality - A Research Agenda. 20th AMCIS, Savannah, (1999), 1-9.

Heeks, R. (2012). Deriving an ICT4D research agenda: a commentary on "Information and communication technologies for development (ICT4D): solutions seeking problems?" Journal of Information Technology, 27(4), 339-341. https://doi.org/10.1057/jit.2012.31 
Hopkins, N., Sylvester, A., \& Tate, M. (2013). Motivations For BYOD: An Investigation Of The Contents Of A 21st Century School Bag. ECIS 2013 Proceedings, 1-12. Retrieved from http://aisel.aisnet.org/ecis2013_cr/183/

Hoque, K., Samad, R., Siraj, S., \& Ziyadh, A. (2012). The Role of ICT in School Management of Maldives. In The New Educatioanl Review (pp. 270-282). Warsaw: Wydawnictwo Adam Marszałek.

Irvin, M., Hannum, W., Varre, C., \& Farmer, T. (2010). Barriers to Distance Education in Rural Schools. The Quarterly Review of Distance Education, 11(919), 73-90. Retrieved from http://www.eric.ed.gov/ERICWebPortal/recordDetail?accno=EJ914160

Jacucci, E., Hanseth, O., \& Lyytinen, K. (2006). Introduction: Taking complexity seriously in IS research. Information Technology \& People, 19(1), 5-11. https://doi.org/10.1108/09593840610649943

Johanson, G. (2010). Delineating the meaning and value of Development Informatics. In J. Steyn \& G. Johanson (Eds.), ICTs and Sustainable Solutions for the Digital ... (pp. 1-18). NY: IGI Global. https://doi.org/10.4018/978-1-61520-799-2.ch001

Jonassen, D., Davidson, M., Collins, M., Campbell, J., \& Haag, B. B. (1995). Constructivism and computer-mediated communication in distance education. American Journal of Distance Education, 9(2), 7-26. https://doi.org/10.1080/08923649509526885

Jones, M., \& Karsten, H. (2008). Giddens's structuration theory and information systems research. Mis Quarterly, 32(1), 127-157. Retrieved from http://dl.acm.org/citation.cfm?id=2017385

Keegan, D. (1995). Distance education technology for the new millennium: Compressed video teaching. ZIFF Papiere. Hagen, Germany: Institute for Research into Distance Education. Retrieved from http://deposit.fernuni-hagen.de/1901/

Kim, R. M. ., \& Kaplan, S. M. . (2011). Toward a synthesis of complex adaptive systems and actornetwork theory. ACIS 2011 Proceedings - 22nd Australasian Conference on Information Systems. Retrieved from http://www.scopus.com/inward/record.url?eid=2-s2.084869109441\&partner|D=40\&md5=6f2b7d3127403b9d60b83f864ff9f9of

Kim, R. M., \& Kaplan, S. M. (2006). Interpreting socio-technical co-evolution: Applying complex adaptive systems to IS engagement. Information Technology \& People, 19(1), 35-54. https://doi.org/10.1108/09593840610700800

Klein, H. K., \& Myers, M. D. (1999). A Set of Principles for Conducting and Evaluating Interpretivie Field Studies in Infomration Systems. MIS Quarterly, 23(1), 67-94.

Kuah, A. T. H. (2002). Cluster Theory and Practice: Advantages for the Small Business Locating in a Vibrant Cluster. Journal of Research in Marketing and Entrepreneurship, 4(3), 206-228. https://doi.org/10.1108/14715200280001472

Lai, K., \& Pratt, K. (2004). Information and communication technology (ICT) in secondary schools: the role of the computer coordinator. British Journal of Educational Technology, 35(4).

Latour, B. (1986). The powers of association. In J. Law (Ed.), Power, Action and Belief: a New Sociology of Knowledge? (pp. 265-280). London: Routledge. Retrieved from http://scholar.google.com/scholar?hl=en\&btnG=Search\&q=intitle:The+poweres+of+associatio $\mathrm{n} \# \mathbf{0}$

Latour, B. (1990). On actor-network theory. A few clarifications plus more than a few complications. Philosophia, 25(3), 47-64.

Latour, B. (1991). Technology is Society Made Durable. (J. Law, Ed.), A Sociology of Monsters: Essays on Power, Technology and Domination (Vol. 38). Routledge. https://doi.org/citeulike-article- 
id:3331003

Latour, B. (1994). On Technical Mediation - Philosophy, Sociology, Genealogy. Common Knowledge, 3(2), 29-64. https://doi.org/10.1111/j.1365-294X.2010.04747.x

Latour, B. (2005). Reassembling the Social: An Introduction to Actor-Network-Theory. Oxford University Press. https://doi.org/10.1163/156913308X336453

Law, J. (1992). Notes on the theory of the actor-network: Ordering, strategy, and heterogeneity. Systems Practice, 5(4), 379-393. https://doi.org/10.1007/BF01059830

Law, J. (2009). Actor Network Theory and Material Semiotics1. The New Blackwell Companion to Social Theory, (April), 141-158. Retrieved from http://www.heterogeneities.net/publications/Law-ANTandMaterialSemiotics.pdf

Lazzeretti, L., Sedita, S. R., \& Caloffi, a. (2013). Founders and disseminators of cluster research. Journal of Economic Geography, 14(1), 21-43. https://doi.org/10.1093/jeg/lbs053

Lee, F. (2009). Learning in nowhere: individualism in correspondence education in 1938 and 1950. History of Education Review, 38(1), 29-39. Retrieved from http://www.emeraldinsight.com/journals.htm?articleid=1925904\&show=abstract

Luoma-aho, V., \& Paloviita, A. (2010). Actor-networking stakeholder theory for today's corporate communications. Corporate Communications: An International Journal, 15(1), 49-67. https://doi.org/10.1108/13563281011016831

Mähring, M., Holmström, J., Keil, M., \& Montealegre, R. (2004). Trojan actor-networks and swift translation: Bringing actor-network theory to IT project escalation studies. Information Technology \& People, 17(2), 210-238. https://doi.org/10.1108/09593840410542510

Manson, S. M. (2001). Simplifying complexity: A review of complexity theory. Geoforum, 32(3), 405414. https://doi.org/10.1016/S0016-7185(00)00035-X

Masys, A. J. (2008). Pilot error: Dispelling the hegemony of blamism - a case of de-centered causality and hardwired politics. Disaster Prevention and Management, 17(2), 221-231. https://doi.org/10.1108/09653560810872523

Masys, A. J. (2010). Fratricide in Air Operations Opening the Black-Box: Revealing the 'Social. University of Leicester.

McLean, C., \& Hassard, J. (2004). Symmetrical absence/symmetrical absurdity: Critical notes on the production of actor-network accounts. Journal of Management Studies. https://doi.org/10.1111/j.1467-6486.2004.00442.x

Merali, Y., \& McKelvey, B. (2006). Using complexity science to effect a paradigm shift in information systems for the 21st century. Journal of Information Technology, 21(4), 211-215. https://doi.org/10.1057/palgrave.jit.2000082

Miles, M. B., \& Huberman, A. M. (1994). Qualitative data analysis: An expanded sourcebook: Lon: SAGE publications, Inc.

Minister of Education. (1991). Education Policy: Investing in People, Our Greatest Asset. Wellington: Government Printer.

Ministry of Education. (2003). Digital Horizons: Learning through ICT. Wellington, NZ.

Ministry of Education. (2011). Learning Communities Online: A Support Handbook for Cluster Schools. Wellington, NZ.

Ministry of Education. (2016). Virtual Learning Network. Retrieved August 16, 2016, from http://www.vln.school.nz/ 
Mitleton-Kelly, E. (2003). Complex Systems and Evolutionary Perspectives on Organizations: The Application of Complexity Theory to Organisations. Ten principles of complexity and enabling infrastructures. Retrieved from http://psych.Ise.ac.uk/complexity/Papers/Ch2final.pdf

Moffatt, C. (1996). Context-aware user-driven news recommendation. In \& S. M. J. G. Hedberg, J. Steele (Ed.), Learning technologies: Prospects and pathways (pp. 102-106). https://doi.org/10.1017/CBO9781107415324.004

Molina, M., \& Yoong, P. (2003). Knowledge Sharing in a Co-Opetitive Environment: The Case of Business Clusters. Journal of Information \& Knowledge Management, 2(4), 321-341. https://doi.org/10.1142/S0219649203000528

Moonen, J. (2008). Evolution of IT and related educational policies in international organizations. In J. Voogt \& G. Knezek (Eds.), International handbook of information technology in primary and secondary education. (pp. 1-16). Springer Science + Business Media. Retrieved from http://link.springer.com/chapter/10.1007/978-0-387-73315-9_67

Moore, M., \& Kearsley, G. (2011). Basic Concept. In Distance education: A systems view of online learning (3rd ed., pp. 1-25). Belmont: Wadsworth, Cengage Learning. Retrieved from http://books.google.com/books?hl=en\&lr=\&id=wXtsKAMiuAAC\&oi=fnd\&pg=PR4\&dq=Distance +Education:+A+systems+view+of+online+learning\&ots=4808Fm-VM\&sig=aTtPkLZ_7dxDzHvo1XJLIXHjivk

Moser, I., \& Law, J. (2006). Fluids or flows? Information and qualculation in medical practice. Information Technology \& People, 19(1), 55-73. https://doi.org/10.1108/09593840610649961

Mupinga, D. M. (2005). Distance Education in High Schools: Benefits, Challenges, and Suggestions. Clearing House, 78(3), 105. https://doi.org/10.2307/30190031

Murdoch, J. (1998). The Spaces of Actor-Network Theory. Geoforum, 29(4), 357-374. https://doi.org/10.1016/S0016-7185(98)00011-6

Murphy, E., Rodríguez-Manzanares, M. a., \& Barbour, M. (2011). Asynchronous and synchronous online teaching: Perspectives of Canadian high school distance education teachers. British Journal of Educational Technology, 42(4), 583-591. https://doi.org/10.1111/j.14678535.2010.01112.x

Myers, M. (1997). Qualitative research in information systems. MISQ Discovery, (June). Retrieved from http://www.inclentrust.org/uploadedbyfck/file/compile resourse/Qualitative Research/Presentations/Qualitative Research in Information Systems.pdf

Myers, M. D., \& Newman, M. (2007). The qualitative interview in IS research: Examining the craft. Information and Organization, 17(1), 2-26. https://doi.org/10.1016/j.infoandorg.2006.11.001

Myers, M., \& Klein, H. (2011). A set of principles for conducting critical research in information systems. MIS Quarterly, 35(1), 17-36. Retrieved from http://dl.acm.org/citation.cfm?id=2017486

Nalebuff, B. J., \& Brandenburger, A. M. (1996). Co-opetition: New York: Currency/Doubleday. https://doi.org/10.1108/eb054655

Nan, N. (2011). Capturing bottom-up information technology use processes: a complex adaptive systems model. MIS Quarterly, 35(2), 505-532. https://doi.org/Article

NetNZ. (2013). NetNZ Statement of Intent, 1-12. Retrieved from https://docs.google.com/document/d/1YQPGWGTGLgJdUlyzXNGZHSsF5RKq6nXvwisS1pvQzY8/ edit?usp=sharing \&pli $=1$

Nilsen, H., \& Purao, S. (2005). Balancing Objectivist and Constructivist Pedagogies for Teaching Emerging Technologies: Evidence from a Scandinavian Case Study. Journal of Information 
Systems Education, 16(May), 281-292. https://doi.org/Article

Nipper, S. (1989). Third generation distance learning and computer conferencing. In R. Mason \& A. Kaye (Eds.), Communication, computers and distance education (pp. 63-73). Oxford: Permagon Press.

NZARE. (2010). NZARE Ethical Guidlines 2010. Retrieved September 15, 2016, from http://www.nzare.org.nz/portals/306/images/Files/NZARE EthicalGuidelines2010.pdf

Orlikowski, W. J., \& Baroudi, J. J. (1991). Studying Information Technology in Organizations: Research Approaches and Assumptions. Information Systems Research, 2(1), 1-28. https://doi.org/10.1287/isre.2.1.1

Paré, G. (2004). Investigating information systems with positivist case research. ... of the Association for Information Systems, 13, 233-264. Retrieved from http://aisel.aisnet.org/cais/vol13/iss1/18/

Passey, D. (2002). ICT and school management: A review of selected literature. Lancaster University: Department of Educational Research., (JANUARY 2002).

Pegrum, M., Oakley, G., \& Faulkner, R. (2013). Schools going mobile: A study of the adoption of mobile handheld technologies in western australian independent schools. Australasian Journal of Educational Technology, 29(1), 66-81. https://doi.org/10.1234/ajet.v29i1.64

Plsek, P. E., \& Greenhalgh, T. (2001). Complexity science: The challenge of complexity in health care. BMJ (Clinical Research Ed.), 323(7313), 625-8. https://doi.org/10.1136/bmj.323.7313.625

Porter, M. E. (1990). The Competitive Advantage of Nations. Harvard business review. New York: The Free Press. Retrieved from http://cspug2s.units.it/sid/docenti/brusati/didattica/11 Porter The Competitive Advantage of Nations.pdf

Porter, M. E. (1998). Clusters and the new economics of competition. Harvard Business Review, 76(6), 77-90. Retrieved from http://www.rimisp.org/wpcontent/uploads/2012/07/31_rimisp_Cardumen.pdf

Porter, M. E. (2000). Location, Competition, and Economic Development: Local Clusters in a Global Economy. Economic Development Quarterly, 14(1), 15-34. https://doi.org/10.1177/089124240001400105

Postma, D. J. R. (2009). Deepening and broadening the critique of technology: An analysis of an ANT approach. University of Pretoria. Retrieved from http://repository.up.ac.za/handle/2263/25479

Powell, A. (2011). A case study of E-Learning initiatives in New Zealand's secondary schools. ProQuest Dissertations and Theses, 281. Retrieved from http://www.eric.ed.gov/ERICWebPortal/recordDetail?accno=ED526325

Pratt, K., \& Pullar, K. (2013). OtagoNet: One region's model for virtual schooling. Journal of Open, Flexible and ..., 17(1), 1-11. Retrieved from http://journals.akoaotearoa.ac.nz/index.php/JOFDL/article/view/192

Pullar, K., \& Brennan, C. (2008). Personalising learning for secondary students working in a blended (distance/face to face/vocational) learning environment. Computers in New Zealand Schools. Retrieved from http://scholar.google.com/scholar?hl=en\&btnG=Search\&q=intitle:?+Personalising+learningt' $+f$ or+secondary+students+working+in+a $+^{\prime}+$ blended+(+distance $+/{ }^{\prime}+\mathrm{f} 2 \mathrm{f}+{ }^{\prime} /+$ vocational+)+learning+ environment+'\#0

Reeves, S., Albert, M., Kuper, A., \& Hodges, B. (2008). Qualitative Research: Why Use Theories in Qualitative Research? BMJ: British Medical Journal, 337(7670), 631-634. 
https://doi.org/10.1136/bmj.a949

Reiach, S., Averbeck, C., \& Cassidy, V. (2012). The Evolution of Distance Education in Australia: Past, Present, Future. Quarterly Review of Distance Education, 13(4), 247-252. Retrieved from http://www.eric.ed.gov/ERICWebPortal/recordDetail?accno=EJ1005855

Reitsma, F. (2003). A Response to Simplifying Complexity. Geoforum, 34, 13-16. https://doi.org/10.1016/S0016-7185(02)00014-3

Resta, P., \& Laferrière, T. (2007). Technology in Support of Collaborative Learning. Educational Psychology Review, 19(1), 65-83. https://doi.org/10.1007/s10648-007-9042-7

Rhodes, J. (2009). Using Actor-Network Theory to Trace an ICT (Telecenter) Implementation Trajectory in an African Women's Micro-Enterprise Development Organization. Information Technologies \& International Development, 5(3), 1-20. Retrieved from http://itidjournal.org/itid/article/viewArticle/378

Rieger, O. (2008). Opening up institutional repositories: social construction of innovation in scholarly communication. Journal of Electronic Publishing, 11(3), 1-17. Retrieved from http://quod.lib.umich.edu/cgi/t/text/idx/j/jep/3336451.0011.301?rgn=main;view=fulltext

Roberts, R. (2009). Video conferencing in distance learning: A New Zealand schools' perspective. Journal of Distance Learning, 13(1), 91-107. Retrieved from http://journals.akoaotearoa.ac.nz/index.php/JOFDL/article/view/40

Roberts, R. (2013). Increasing Access for Learners - The Virtual Learning Network. In V. Ham \& D. Wenmoth (Eds.), elearnings: Implementing a national strategy for ICT in education, 1998 2010 (pp. 40-44). Christchurch, New Zealand: Core Education.

Roblyer, M. (2008). Virtual schools: Redefining "A place called school." In J. Voogt \& G. Knezek (Eds.), International handbook of information technology in ... (pp. 695-711). Springer Science + Business Media. Retrieved from http://link.springer.com/chapter/10.1007/978-0-387-733159_40

Roy, I., Cranefield, J., \& Toland, J. (2015). Collaborative Consumption : A New Zealand Case study. In SIGGreen Pre-ICIS 2015 Workshop.

Russell, G. (2004). Virtual schools: A critical view. In C. Cavanaugh (Ed.), Development and management of virtual schools: Issues and trends (pp. 1-25). Hershey, PA: Idea Group. Retrieved from http://labweb.education.wisc.edu/steinkuehler/curric606/readings/Russell2004.pdf

Sarker, S., Sarker, S., \& Sidorova, A. (2006). Understanding Business Process Change Failure: An Actor-Network Perspective. Journal of Management Information Systems (Vol. 23). https://doi.org/10.2753/MIS0742-1222230102

Schlosser, L. A., \& Simonson, M. (2009). Distance education: Definition and glossary of terms (3rd ed.). Charlotte, NC: Information Age.

Seale, C. (1999). Quality in Qualitative Research. Qualitative Inquiry, 5(4), 465-478. https://doi.org/10.1177/107780049900500402

Shenton, A. (2004). Strategies for ensuring trustworthiness in qualitative research projects. Education for Information, 22, 63-75. Retrieved from http://iospress.metapress.com/index/3ccttm2g59cklapx.pdf

Simonson, M., Smaldino, S., Albright, M., \& Zvacek, S. (2009). Teaching and learning at a distance: Foundations of Distance Education. (Simonson et al., Ed.) (4th ed.). Pearson Education. Retrieved from http://learning.fon.edu.mk/knigi/teachinganlearningatadistance-4.pdf 
Smyth, R. (2005). Broadband videoconferencing as a tool for learner-centred distance learning in higher education. British Journal of Educational Technology, 36(5), 805-820. Retrieved from http://www.jofde.ca/index.php/jde/article/viewArticle/585/901

Stahl, G., Koschmann, T., \& Suthers, D. (2006). Computer-supported collaborative learning. Cambridge Handbook of the Learning Sciences, 1-19.

Stalder, F., \& Clement, A. (1997). Actor-Network Theory and Communication Networks: Toward Convergence, 24. Retrieved from http://felix.openflows.com/

Statistics New Zealand. (2006). Defining urban and rural New Zealand. Wellington: Statistics New Zealand, 1-4. Retrieved from http://scholar.google.com/scholar?hl=en\&btnG=Search\&q=intitle:Defining+Urban+and+Rural+ New+Zealand\#0

Stevens, K. (2011). The distribution of instructional leadership in elearning clusters: an ecological perspective. University of Canterbury. Retrieved from http://www.ir.canterbury.ac.nz/handle/10092/5446

Steyn, J., \& Johanson, G. (2010). ICTs and Sustainable Solutions for the Digital Divide: Theory and Perspectives. (J. Steyn \& G. Johanson, Eds.). NY: IGI Global. Retrieved from http://www.ethnosproject.org/wp-content/uploads/digital-divide-theoryperspectives. pdf\#page $=150$

Straub, D., Boudreau, M., \& Gefen, D. (2004). Validation guidelines for IS positivist research. Communications of the Association Ofr Information Systems, 13(1), 380-427. Retrieved from http://www.cis.gsu.edu/dstraub/papers/Straub et al. 2004 working paper version.pdf

Strudler, N., \& Hearrington, D. (2008). Quality support for ICT in schools. In J. Voogt \& G. Knezek (Eds.), International handbook of Information Technology in primary and secondary education (pp. 579-596). Springer Science + Business Media.

Sumner, J. (2000). Serving the system: A critical history of distance education. Open Learning: The Journal of Open and Distance Learning, 15(3), 267-285. Retrieved from http://www.tandfonline.com/doi/abs/10.1080/713688409

Tatnall, A., \& Gilding, A. (1999). Actor-network theory and information systems research. In Australasian Conference on Information Systems (pp. 955-966). Retrieved from http://www.igiglobal.com/chapter/actor-network-theory-information-systems/14208

Taylor, J. (2001). Fifth generation distance education. Journal of Instructional Science and Technology, 4(1). Retrieved from http://www.ascilite.org.au/ajet/ejist/docs/vol4no1/Taylor.pdf

ten Brummelhuis, A., \& Kuiper, E. (2008). Driving Forces for ICT in learning. In J. Voogt \& G. Knezek (Eds.), International Handbook of Information Technology in Primary and Secondary Education (pp. 97-111). Springer Science + Business Media. https://doi.org/10.1007/978-0-387-733159_6

Thatcher, A., \& Ndabeni, M. (2010). A psychological model to understand e-adoption in the context of the digital divide. In J. Steyn \& G. Johanson (Eds.), ICTs and Sustainable Solutions for the Digital Divide: Theory and Perspectives (pp. 127-149). NY: IGI Global. https://doi.org/10.4018/978-1-61520-799-2.ch007

Thomas, D. R. (2006). A General Inductive Approach for Analyzing Qualitative Evaluation Data. American Journal of Evaluation, 27(2), 237-246. https://doi.org/10.1177/1098214005283748

Thomas, L. G., \& Knezek, D. G. (2008). Educational Technology Standards for Students, Teachers , and School Leaders. In J. Voogt \& G. Knezek (Eds.), International handbook of information 
technology in primary and secondary education (pp. 333-348). Springer Science + Business Media.

Thompson, G. (1990). How Can Correspondence-Based Distance Education be Improved?: A Survey of Attitudes of Students Who Are Not Well Disposed toward Correspondence Study. Journal of Distance Education, 5(1), 53-65. Retrieved from http://www.jofde.ca/index.php/jde/article/viewArticle/371

Tilya, F. (2008). IT AND EDUCATIONAL POLICY IN THE SUB-SAHARAN AFRICAN REGION. In J. Voogt \& G. Knezek (Eds.), International Handbook of Information Technology in Primary and Secondary Education (pp. 1161-1169). Springer Science + Business Media.

Tsohou, A., Karyda, M., Kokalakis, S., \& Kiontouzis, E. (2013). Managing the Introduction of Information Security Awareness Programmes in Organisations. European Journal of Information Systems, 24(1), 1-21. https://doi.org/10.1057/ejis.2013.27

Underwood, J., Baguley, T., Banyard, P., Dillon, G., Farrington-flint, L., \& Hayes, M. (2009). Personalising Learning. Retrieved from http://oro.open.ac.uk/34532/1/personalised_learning.pdf

Venkatesh, V., Brown, S. A., \& Bala, H. (2013). Bridging the qualitative-quantitative divide: Guidelines for conducting mixed methods research in information systems. MIS Quarterly, 37(1), 21-54. Retrieved from http://misq.org/bridging-the-qualitative-quantitative-divide-guidelines-forconducting-mixed-methods-research-in-informationsystems.html?SID=hoiroittfvokfvihphk189ndu2

Vessey, I., \& Ward, K. (2013). The Dynamics of Sustainable IS Alignment: The Case for IS Adaptivity. Journal of the Association for Information Systems, 14(6), 283-311. Retrieved from http://dml.regis.edu/login?url=http://search.ebscohost.com/login.aspx?direct=true\&db=bth\& AN=89619967\&site=ehost-live \&scope=site

Vidgen, R., \& McMaster, T. (1996). Black boxes, non-human stakeholders and the translation of it through mediation. In W. J. Orlikowski, G. Walsham, M. R. Jones, \& J. I. DeGross (Eds.), Information Technology and Changes in Organizational Work: Proceedings of the IFIP WG8.2 Working Conference on Information Technology and Changes in Organizational Work, December 1995 (pp. 250-271). London.

Voogt, J., \& Knezek, G. (2008). International handbook of information technology in primary and secondary education. (J. Voogt \& G. Knezek, Eds.) (20th ed.). Springer Science+Business Media. Retrieved from http://books.google.com/books?hl=en\&lr=\&id=X2dIYc5PpTkC\&oi=fnd\&pg=PR1\&dq=Internatio nal+Handbook+of+Information+Technology+in+Primary+and+Secondary+Education\&ots=jxzbE 0sDXo\&sig=g_0Fuu6PyFm--tkdrDXW8iC931E

Vos, M. E. (2014). RFID on the boundary between the public and the private sectors: An ANT/Institutional theory investigation. Victoria University of Wellington.

Walsh-Pasco, L. (2004). From teletubbies to teleteachers: Effective practice in video conference teaching. A paper submitted to the Ministry of Education e-Learning Unit, e-Fellowship Initiative. Wellington, NZ.

Walsham, G. (1995). Interpretive case studies in IS research: nature and method. European Journal of Information Systems, 4(2), 74-81. https://doi.org/10.1057/ejis.1995.9

Walsham, G., \& Sahay, S. (1999). GIS for district-level administration in India: Problems and opportunities. MIS Quarterly, 23(1), 39-66. https://doi.org/10.2307/249409

Watson, J., Pape, L., Murin, A., Gemin, B., \& Vashaw, L. (2014). Keeping Pace with K-12 Digital Learning: An Annual Review of Policy and Practice (2014). Retrieved from 
http://www.kpk12.com/wp-content/uploads/EEG_KP2014-fnl-Ir.pdf

Wenmoth, D. (2010). The Future - Trends, Challenges and Opportunities. In H. Vince \& D. Wenmoth (Eds.), eLearnings: Implementing a National Strategy for ICT in Education, 1998-2010 (pp. 196203). Christchurch, New Zealand: Core Education.

Whetten, D. A. (1989). What Constitutes a Theoretical Contribution? Academy of Management Review, 14(4), 490-495. https://doi.org/10.5465/AMR.1989.4308371

Whittle, a., \& Spicer, a. (2008). Is Actor Network Theory Critique? Organization Studies, 29(4), 611629. https://doi.org/10.1177/0170840607082223

Winner, L. (1993). Upon Opening the Black Box and Finding it Empty: Social Constructivism and the Philosophy of Technology. Science, Technology \& Human Values, Vol. 18, n(Summer), 362-378. https://doi.org/10.1177/016224399301800306

Wissink, B. (2013). Enclave urbanism in Mumbai: An Actor-Network-Theory analysis of urban (dis)connection. Geoforum, 47, 1-11. https://doi.org/10.1016/j.geoforum.2013.02.009

Wu, J., \& David, J. L. (2002). A spatially explicit hierarchical approach to modeling complex ecological systems: Theory and applications. Ecological Modelling, 153(1-2), 7-26.

https://doi.org/10.1016/S0304-3800(01)00499-9

Yin, R. K. (2014). Case study research: design and methods, 5th ed. (5th ed.). SAGE publications, Inc. Retrieved from http://capitadiscovery.co.uk/winchester-ac/items/332419

Yin, R. K. (2016). Qualitative research from start to finish. Guildford Press. London: Guildford Press. https://doi.org/10.1017/CBO9781107415324.004

Zaka, P. (2013). A case study of blended teaching and learning in a New Zealand secondary school, using an ecological framework. Journal of Open, Flexible and Distance Learning, 17(1), 24-40. Retrieved from http://journals.akoaotearoa.ac.nz/index.php/JOFDL/article/view/193 


\section{APPENDICES}

\section{Appendix 4A:}

\section{Participant Information Sheet}

Research Project Title: The Development of the Learning Exchange in New Zealand: An Actor Network Theory Analysis

Researcher: Arif Ali, School of Information Management, Victoria University of Wellington

As part of the completion of my PhD degree, this study is designed to examine the development of the virtual school clusters in New Zealand. The cluster use Learning Exchange programme, which is a videoconference-based resource sharing programme which was initiated by some schools around 2001. This study interviews individuals from the school clusters to identify - inhibiting and facilitating - factors during the development of school clusters in New Zealand.

CoroNet has been on the clusters that have contributed to the development of the Learning Exchange community. Therefore, this research study has selected CoroNet as one of the participating clusters for this research.

The research findings will contribute to a better understanding of the conditions required to assure sustainability of the clusters and consequently the programme. Therefore this study remains particularly beneficial to the schools' community in New Zealand.

I am inviting students and staff from cluster schools taking part in the Learning Exchange to participate in this study. Participants will be asked to take part in an interview for up to an hour. Permission will be asked to record the interview, and a transcript of the interview will be sent back to participants for checking. Victoria University requires, and has granted, approval from my departmental Human Ethics Committee to conduct this study.

Participation is voluntary, and you and your organisation will not be identified or named in any written report produced as a result of this research, including possible publication in academic conferences and journals. All material collected will be kept confidential, and will be viewed only by myself and my supervisors, Professor Pak Yoong and Dr. Allan Sylvester. The thesis will be submitted to the School of Information Management for academic verification by a selected group of examiners, and subsequently deposited in the University Library. All data collected from participants will be destroyed five years after the completion of the project.

Should any participant wish to withdraw from the project, they may do so within three months of the interview by e-mailing the researcher at Arif.Ali@vuw.ac.nz without having to give reasons; and, all data collected from the participant will be destroyed.

If you have any questions or would like to receive further information about the project, please contact me or my supervisors at 
- Professor Pak Yoong Pak.Yoong@vuw.ac.nz or 044635878

- Dr. Allan Sylvester Allan.Sylvester@vuw.ac.nz or 044636813

Thank you.

Arif Ali

PhD candidate,

School of Information Management,

Victoria University of Wellington

Email: Arif.Ali@vuw.ac.nz

Skype: arif.vuw

Phone: 04-46356868 Mobile: 0211165475 


\section{Appendix 4B:}

\section{Participant Consent Form}

Research Project Title: The Development of the Learning Exchange in New Zealand: An Actor Network Theory Analysis

Researcher: Arif Ali, School of Information Management, Victoria University of Wellington

I have been given and have understood an explanation of this research project. I have had an opportunity to ask questions and have them answered to my satisfaction.

I understand that I may withdraw myself (or any information I have provided) from this project, without having to give reasons, by e-mailing Arif.Ali@vuw.ac.nz within three months after the interview date.

I understand that any information I provide will be kept confidential to the researcher and their supervisor. The published results will not use my name, and that no opinions will be attributed to me in any way that will identify me or my organisation.

I understand that the data I provide will not be used for any other purpose or released to others.

I understand that the audio recording and transcripts of the interviews will be erased within five years after the conclusion of the project. Furthermore, I will have an opportunity to check the transcripts of the interview.

Please indicate (by ticking the boxes below) which of the following apply:

$\square \quad$ I would like to receive a summary of the results of this research when it is completed.

$\square \quad$ I agree to this interview being audio recorded.

Also, please indicate one of the following options that applies to you.

$\square$ I am 16-years old or over

$\square$ I am under 16-years old (Please ask your Parent/Guardian as well to sign the Parent/Guardian Consent Form before you take part in this project) ${ }^{28}$

Signed:

Name of participant:

Date:

\footnotetext{
${ }^{28}$ If you are under 16-years old, it is an ethical obligation of this study to make sure that your Parent/Guardian is aware of the whole data collection, storage and presentation processes and agrees with your participation in this study.
} 


\section{Appendix 4C}

\section{Parent/Guardian Consent Form}

Research Project Title: The Development of the Learning Exchange in New Zealand: An Actor Network Theory Analysis

Researcher: Arif Ali, School of Information Management, Victoria University of Wellington

I have read and understood the Participant Information Sheet which gives an explanation of the research project. I have an opportunity to ask questions and have them answered to my satisfaction before my child takes part in this study.

I understand that I may withdraw my child (or any information he/she provides) from this project, without having to give reasons, by e-mailing Arif.Ali@vuw.ac.nz within three months after the interview date.

I understand that any information my child provides will be kept confidential to the researcher and their supervisors. The published results will not use my child's name and that no opinions will be attributed to him/her in any way that will identify his/her name or the name of his/her organisation.

I understand that the data my child provides will not be used for any other purpose or released to others.

I understand that the audio recording and transcripts of the interviews will be erased within five years after the conclusion of the project. Furthermore, I will have an opportunity to check the transcripts of the interview.

Please indicate (by ticking the boxes below) which of the following apply:

$\square \quad$ I would like to receive a summary of the results of this research when it is completed.

$\square \quad$ I agree to the interview being audio recorded.

Signed:

Name of parent/guardian:

Parent/Guardian email address:

Name of child:

Date: 